Marcel Ayres de Araújo

Estudo de Metodologia para Modelagem e Simulação de Tensões Induzidas de Origem Atmosférica em Linhas de Distribuição Protegidas por Para-raios de $\mathrm{ZnO}$ 



\section{Estudo de Metodologia para Modelagem e Simulação de Tensões Induzidas de Origem Atmosférica em Linhas de Distribuição Protegidas por Para-raios de $\mathrm{ZnO}$}

Dissertação apresentada a Escola de Engenharia de São Carlos, Universidade de São Paulo, como parte dos requisitos para obtenção do Título de Mestre em Ciências, Programa de Engenharia Elétrica, área de concentração em Sistemas Dinâmicos.

Orientador: Prof. Dr. Rogério Andrade Flauzino

\section{São Carlos}

2013 
AUTORIZO A REPRODUÇÃO E DIVULGAÇÃO TOTAL OU PARCIAL DESTE TRABALHO, POR QUALQUER MEIO CONVENCIONAL OU ELETRÔNICO, PARA FINS DE ESTUDO E PESQUISA, DESDE QUE CITADA A FONTE.

Ficha catalográfica preparada pela Seção de Tratamento da Informação do Serviço de Biblioteca - EESC/USP

A $663 e$

Araújo, Marcel Ayres de

Estudo de metodologia para modelagem e simulação de tensões induzidas de origem atmosférica em linhas de distribuição protegidas por para-raios de zno / Marcel Ayres de Araújo; orientador Rogério Andrade Flauzino. São Carlos, 2013.

Dissertação (Mestrado - Programa de Pós-Graduação em Engenharia Elétrica e Área de Concentração em Sistemas dinâmicos) -- Escola de Engenharia de Săo Carlos da Universidade de São Paulo.

1. Descargas atmosféricas indiretas. 2. Linhas de distribuição. 3. Para-raios de óxido de zinco. 4. Tensões induzidas. I. Título. 


\section{FOLHA DE JULGAMENTO}

\section{Candidato: Engenheiro MARCEL AYRES DE ARAUJO}

Título da dissertação: "Estudo de metodologia para modelagem e simulação de tensões induzidas de origem atmosférica em linhas de distribuição protegidas por para-raios de $\mathrm{ZnO}^{\prime}$.

Data da defesa: $18 / 07 / 2013$

\section{Comissão Julgadora:}

Prof. Dr. Rogério Andrade Flauzino (Orientador)

(Escola de Engenharia de São Carlos/EESC)

Prof. Dr. Paulo Roberto de Aguiar

(Universidade Estadual Paulista "Júlio de Mesquita Filho"/UNESP- Bauru)

Prof. Associado Diógenes Pereira Gonzaga

(Escola de Engenharia de São Carlos/EESC)
Resultado:

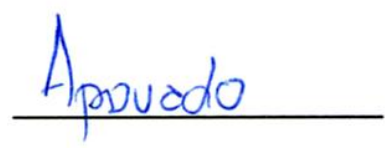

Coordenador do Programa de Pós-Graduação em Engenharia Elétrica e Presidente da Comissão de Pós-Graduação:

Prof. Titular Denis Vinicius Coury 



\section{DEDICATÓRIA}

Aos meus pais, ao meu irmão,

a minha namorada e aos meus

amigos. 



\section{AGRADECIMENTOS}

Gostaria de fazer um agradecimento especial ao meu orientador Rogério Andrade Flauzino pela oportunidade concedida, incentivo, orientação e confiança depositada para realização deste projeto de pesquisa. Agradeço também pelo apoio e compreensão nos momentos difíceis em que passei.

Ao professor José Carlos de Melo Vieira Júnior, primeiro orientador em minha vida acadêmica, pelas orientações, incentivo, amizade e atenção sempre prestada a mim.

Aos professores Diógenes Pereira Gonzaga e Danilo Hernane Spatti por suas valiosas contribuições em minha banca de qualificação.

A todos os professores da Escola de Engenharia de São Carlos que de alguma forma contribuíram para minha graduação e pós-graduação em Engenharia Elétrica pela Universidade de São Paulo.

A todos os funcionários do Departamento de Engenharia Elétrica e de Computação EESC-USP que colaboraram com o desenvolvimento desta pesquisa, sobretudo a Marisa, a Jussara e ao Leonardo do setor de pós-graduação.

Aos amigos de pós-graduação Oureste E. Batista e Lucas A. de Moraes, pelas contribuições e trabalhos em conjunto. Também gostaria de agradecer ao Oureste pelas valiosíssimas contribuições feitas às implementações computacionais desta pesquisa.

Aos meus amigos e irmãos Gustavo M. C. Joaquim, Rubens D. S. do Prado, e Vinicius C. Moro, pela imensurável amizade e companheirismo.

A Jessica A. T., minha namorada, pelo apoio, compreensão, dedicação, incentivo e companheirismo em muitos momentos difíceis.

Finalmente, agradeço a todos da minha família que sempre estiveram ao meu lado, me apoiaram e me incentivaram, em especial à minha mãe, Maria Agnola A. A. A., que sempre foi um modelo de determinação e perseverança para mim, e a maior incentivadora e exemplo para todas as minhas realizações. 



\section{RESUMO}

Araújo, M. A. (2013). Estudo de Metodologia para Modelagem e Simulação de Tensões Induzidas de Origem Atmosférica em Linhas de Distribuição Protegidas por Para-raios de ZnO. Dissertação de Mestrado apresentada a Escola de Engenharia de São Carlos, Universidade de São Paulo, 2013.

As tensões induzidas e sobretensões geradas por descarga atmosféricas diretas e indiretas são um dos principais causadores de desligamentos não programados em redes de transmissão e distribuição. Estes desligamentos comprometem o fornecimento de energia a milhares de consumidores, sobretudo em regiões com constantes variações climáticas e com características orográficas bastante diversificadas, como apresentado no território brasileiro. Desse modo, cada vez mais esses fenômenos são estudados a fim de desenvolverem-se procedimentos para proteção contra distúrbios causados por descargas atmosféricas. Neste contexto, esta pesquisa contempla o estudo do estabelecimento das descargas atmosféricas indiretas e das tensões por elas induzidas em linhas de distribuição, assim como o assentamento das mesmas nestas redes de energia. Não obstante, utilizando-se um software capaz de representar transitórios eletromagnéticos são modelados e implementados um alimentador teste de distribuição e um sistema para estimação de tensões induzidas no domínio do tempo baseado no modelo de Sune Rusck. Também são modelados e implementados para-raios de óxido de zinco, de forma a representar suas características dinâmicas, para proteger a linha sob apreciação dos distúrbios provocados pelas tensões induzidas. A partir de uma análise comparativa entre a operação do sistema de distribuição em regime permanente e frente aos desdobramentos promovidos pelas tensões induzidas, é determinada a melhor configuração, localização e quantificação dos para-raios a serem instalados para proteção do sistema teste. Por meio da avaliação dos resultados das simulações computacionais observa-se a robustez da subestação e quais os ramos e cargas mais suscetíveis a perturbações frente às tensões induzidas, bem como a maior proteção oferecida pelos para-raios aos elementos conectados próximos aos seus nós de alocação.

Palavras-chave: Descargas atmosféricas indiretas, Linhas de distribuição, Para-raios de óxido de zinco, Tensões induzidas. 



\section{ABSTRACT}

Araújo, M. A. (2013). Study of Methodology for Modeling and Simulation of Induced Voltages of Atmospheric Origin in Distribution Lines Protected by ZnO Surge Arresters. Dissertation Master's Degree presented the School of Engineering of São Carlos, University of São Paulo, 2013.

The induced voltages and overvoltages generated by direct and indirect lightning are a major cause of not programmed shutdowns in transmission and distribution networks. These shutdowns compromise the power supply of thousands of consumers, especially in regions with frequent climatic variations and quite diverse orographic characteristics, as occurred on Brazilian soil. Thus, these phenomena are more and more studied in order to develop procedures for protection against disturbances caused by lightning. In this context, this research focuses on the study of the establishment of indirect lightning and the voltage induced by them on distribution lines, as well as their settlement on energy networks. However, using a software able to represent electromagnetic transients, a distribution test feeder and a system for estimating induced voltages in the time domain based on the Sune Rusck model are modeled and implemented. In addition, metal oxide surge arresters are modeled and implemented to represent its dynamic characteristics, in order to protect the line under consideration of disturbances caused by induced voltages. From a comparative analysis between the operation of the distribution system in steady state and facing the developments promoted by induced voltages, it is determined the best configuration, as well as the location and quantification of the surge arrester to be installed to protect the test system. Through evaluation of the results of computer simulations, it is observed the robustness of the substation and which branches and loads are more susceptible to the disturbances facing the induced voltages, and the greater protection offered by the surge arresters elements connected near to its nodes allocation.

Keywords: Indirect lightning, Distribution lines, Metal oxide surge arresters, Induced voltages. 



\section{LISTA DE SIGLAS, SÍMBOLOS E ABREVIATURAS}

* ATP - Alternative Transients Program

* BrasilDAT- Rede Brasileira de Detecção de Descargas Atmosféricas

* CEA - Canadian Electricity Association

* CIGRÉ - International Council on Large Electric Systems

* CIRED - Congrès International des Réseaux Electriques de Distribution

* DNUTL - Dynamic Non-Uniform Transmission Line Model

* ELAT - Grupo de Eletricidade Atmosférica

* EMTP - Electromagnetic Transients Program

* $\quad$ EPRI - Electric Power Research Institute

* $\quad$ ERM - Extended Rusck Model

* HEM - Hybrid Electromagnetic Model

* IEEE - Institute of Electrical and Electronic Engineers

* INPE- Instituto Nacional de Pesquisas Espaciais

* LD - Linha de Distribuição

* LIOV - Lightning Induced Over-Voltage

* LIS - Lightning Imaging Sensor

* $\quad$ LT - Linha de Transmissão

* NBI - Nível básico de isolamento

- NEC - Numerical Electromagnetics Code

* RINDAT - Rede Nacional de Localização de Descargas Atmosféricas

* TEM - Transverse Electromagnetic

* ZnO - Óxido de zinco 



\section{LISTA DE FIGURAS}

Figura 2.1: Distribuição das cargas nas nuvens e no solo [adaptada de (UMAN, 1984)]....... 11 Figura 2.2: Probabilidade da amplitude máxima de corrente em virtude da polaridade da

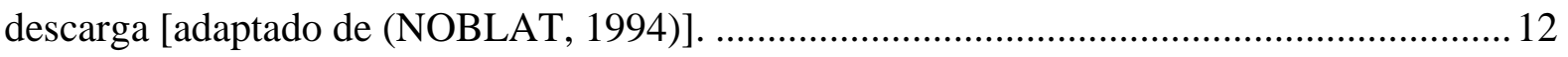
Figura 2.3: Representação da conexão entre os canais ascendentes e descendentes [adaptada de (VISACRO, 2005)]. .14

Figura 2.4: Representação da formação das descargas subsequentes [adaptada de (UMAN, 1984)].

Figura 2.5: Forma de onda típica da corrente de descarga com seus principais parâmetros associados para uma descarga nuvem-solo negativa [adaptada de (CIGRÉ, 1991; IEEE, 2004)]. 16

Figura 2.6: Distribuição acumulada de corrente baseada na equação de Anderson (ANDERSON, 1982). 18

Figura 2.7: Mapa de curvas isoceraúnicas do Brasil (NBR 5419, 2005). .19

Figura 2.8: Mapa de curvas isoceraúnicas da região Sudeste para o período de 1971 a 1995 (NBR 5419, 2005). 20

Figura 2.9: Taxa de relâmpagos nuvem-solo com dados obtidos pelo sensor de imagem de descarga nos últimos 13 anos $(1998-2010)$ e corrigidos com resolução de $0.1^{\circ}$ (NACCARATO, 2011).

Figura 2.10: Linha de transmissão sem para-raios atingida por uma descarga atmosférica direta em um de seus condutores energizados [adaptada de (VISACRO, 2005)]. 24

Figura 2.11: Linha de transmissão atingida em seus condutores de blindagem por uma descarga atmosférica direta [adaptada de (VISACRO, 2005)]. .25

Figura 2.12: Representação da reflexão da onda de tensão e determinação da onda resultante no topo da torre [adaptada de (VISACRO, 2005)] .26

Figura 2.13: Descarga direta em um condutor de blindagem a meio vão entre duas torres de transmissão de energia [adaptada de (VISACRO, 2005)]. .27

Figura 2.14: Representação de uma linha de distribuição afeta pelo campo eletromagnético gerado por uma descarga atmosférica indireta [adaptada de (VISACRO, 2005)].

Figura 3.1: Onda de corrente da descarga de retorno e da tensão induzida medidas em uma linha de distribuição experimental (BARKER et al., 1996 apud VISACRO, 2005). 39 
Figura 3.2: Passos iniciais da dinâmica de estabelecimento da corrente de retorno no canal de descarga [adaptada de (VISACRO, 2005)]

Figura 3.3: Condição inicial para a representação do estabelecimento do acoplamento eletromagnético entre linha e canal de descarga [adaptada de (VISACRO, 2005)]

Figura 3.4: Representação do estabelecimento dos quatro tipos de acoplamento eletromagnético entre linha e canal de descarga [adaptada de (VISACRO, 2005)]. 47

Figura 3.5: Disposição da linha e do canal de descarga em relação ao solo para a metodologia de cálculo de tensões induzidas pelo Modelo de Rusck com suas respectivas simplificações [adaptada de (MOTA, 2011)]

Figura 3.6: Disposição espacial dos condutores empregada para o desenvolvimento do Modelo de Rusck [adaptada de (SILVEIRA, 2006)].

Figura 4.1: Evolução dos dispositivos de proteção contra sobretensões (D’AJUZ et al., 1985).

Figura 4.2: Curvas de tensão e corrente de para-raios de $\mathrm{ZnO}$, de $\mathrm{SiC}$ e ideal [adaptada de (MAMEDE, 2005)].

Figura 4.3: Característica de tensão e corrente para o carboneto de silício e o óxido de zinco (D’AJUZ et al., 1985). 76

Figura 4.4: Curva característica de V versus I para um resistor não linear de ZnO [adaptada de (OLIVEIRA, 2004)].

Figura 4.5: Dependência do coeficiente não linear $(\alpha)$ em relação à densidade de corrente elétrica [adaptada de (FURTADO, 2005)]

Figura 4.6: Constituição de um para-raios de distribuição com invólucro de porcelana [adaptada de (HINRICHSEN, 2001)].

Figura 4.7: Constituição de um para-raios de distribuição com invólucro polimérico [adaptada de (HINRICHSEN, 2001)]. 83

Figura 4.8: Característica potência consumida versus tempo para resistores de $\mathrm{ZnO}$ de primeira, segunda e terceira geração (SANTOS, 2007). 85

Figura 4.9: Fator de correlação da corrente de fuga com o número de descargas para um resistor a óxido de zinco típico para um surto de $8 \times 20 \mu \mathrm{s}-400 \mathrm{~A} / \mathrm{cm}^{2}$ (SANTOS, 2007)..... 86 Figura 4.10: Fator de correlação da corrente de fuga com o número de descargas para um resistor a óxido de zinco típico para um surto de 500x1500 $\mu \mathrm{s}-35 \mathrm{~A} / \mathrm{cm}^{2}$ (SANTOS, 2007).86 Figura 4.11: Curva característica típica de um varistor de ZnO (FRANCO, 2008).............. 89

Figura 5.1: Disposição espacial do alimentador IEEE 13 Node Test Feeder. 95 
Figura 5.2: Amplitude de pico das tensões por fase para as cargas e os transformadores com o sistema do alimentador teste operando em regime permanente. 98

Figura 5.3: Tensões induzidas em uma linha trifásica (ERIKSSON, et al., 1982). 100 Figura 5.4: Tensão induzida medida no centro de um trecho de linha, cuja altura é de $10 \mathrm{~m}$, para uma descarga atmosférica de $10 \mathrm{kA}$ incidindo a $100 \mathrm{~m}$ de distância do centro da mesma. 102

Figura 5.5: Tensões induzidas medidas em diferentes pontos de uma linha com 10m de altura, para uma descarga atmosférica de 10 kA incidindo a 100m de distância do centro da mesma. 102

Figura 5.6: Tensões induzidas para quatro distâncias diferentes entre o ponto de incidência de uma descarga de $10 \mathrm{kA}$ e um trecho de linha, e mensuradas no ponto central deste segmento. 103

Figura 5.7: Tensões induzidas para três diferentes alturas das estruturas de uma linha, para uma descarga atmosférica de $10 \mathrm{kA}$ incidindo a 100m de distância do centro da mesma, e aferidas em um ponto localizado no centro da linha. 104 Figura 5.8: Tensões induzidas para três diferentes amplitudes da corrente de descarga, incidindo a 100m de distância do centro de uma linha de altura $10 \mathrm{~m}$, e estimadas em um ponto localizado no centro da mesma. 104

Figura 5.9: Características VxI do elemento Surge Arrester do Simulink (The MathWorks, Inc., 2013).

Figura 5.10: Atuação do modelo de para-raios selecionado frente a uma descarga de $10 \mathrm{kA}$. 112

Figura 6.1: Pontos de alocação dos para-raios (PRs), dos subsistemas para estimação das tensões induzidas (SETIs), e das cargas (Cs) no alimentador teste. 115

Figura 6.2: Tensões induzidas para os quatro casos a serem simulados. 117

Figura 6.3: Correlação entre os pontos de localização dos subsistemas para estimação das tensões induzidas (SETIs) e os pontos de incidência das descargas atmosféricas (DA) em relação ao alimentador teste para $\mathrm{y}=50 \mathrm{~m}$.

Figura 6.4: Tensão sobre o transformador da subestação para as 128 simulações do Grupo 1 $(\mathrm{y}=50 \mathrm{~m})$.

Figura 6.5: Tensão sobre o transformador da linha para as 128 simulações do Grupo 1 (y=50 $\mathrm{m})$.

Figura 6.6: Tensão sobre a carga 632/671 para as 128 simulações do Grupo 1 (y=50 m)... 122 Figura 6.7: Tensão sobre a carga 646 para as 128 simulações do Grupo 1 (y=50 m). 123 
Figura 6.8: Tensão sobre a carga 645 para as 128 simulações do Grupo 1 ( $\mathrm{y}=50 \mathrm{~m})$......... 123

Figura 6.9: Tensão sobre a carga 634 para as 128 simulações do Grupo 1 (y=50 m)......... 124

Figura 6.10: Tensão sobre a carga 671 para as 128 simulações do Grupo 1 (y=50 m)....... 124

Figura 6.11: Tensão sobre a carga 611 para as 128 simulações do Grupo 1 (y=50 m)....... 125

Figura 6.12: Tensão sobre a carga 652 para as 128 simulações do Grupo 1 (y=50 m)....... 125

Figura 6.13: Tensão sobre a carga 692 para as 128 simulações do Grupo 1 (y=50 m)....... 125

Figura 6.14: Tensão sobre a carga 675 para as 128 simulações do Grupo 1 (y=50 m)....... 126

Figura 6.15: Contabilização do número de atuações dos para-raios nas 128 simulações do Grupo $1(\mathrm{y}=50 \mathrm{~m})$.

126

Figura 6.16: Indicação dos para-raios em atuação para cada uma das 128 simulações do Grupo $1(\mathrm{y}=50 \mathrm{~m})$.

Figura 6.17: Tensão sobre o transformador da subestação para as 128 simulações do Grupo 2 $(\mathrm{y}=150 \mathrm{~m})$ 128

Figura 6.18: Correlação entre os pontos de localização dos subsistemas para estimação das tensões induzidas (SETIs) e os pontos de incidência das descargas atmosféricas (DA) em relação ao alimentador teste para $\mathrm{y}=150 \mathrm{~m}$.

Figura 6.19: Tensão sobre o transformador da linha para as 128 simulações do Grupo 2 $(\mathrm{y}=150 \mathrm{~m})$.

Figura 6.20: Tensão sobre a carga 632/671 para as 128 simulações do Grupo 2 (y=150 m).

Figura 6.21: Tensão sobre a carga 646 para as 128 simulações do Grupo 2 (y=150 m)..... 131

Figura 6.22: Tensão sobre a carga 645 para as 128 simulações do Grupo 2 (y=150 m). ..... 132

Figura 6.23: Tensão sobre a carga 634 para as 128 simulações do Grupo 2 (y=150 m)...... 132

Figura 6.24: Tensão sobre a carga 671 para as 128 simulações do Grupo 2 (y=150 m)...... 132

Figura 6.25: Tensão sobre a carga 611 para as 128 simulações do Grupo 2 (y=150 m)..... 133

Figura 6.26: Tensão sobre a carga 652 para as 128 simulações do Grupo 2 (y=150 m)..... 133

Figura 6.27: Tensão sobre a carga 692 para as 128 simulações do Grupo 2 (y=150 m)...... 133

Figura 6.28: Tensão sobre a carga 675 para as 128 simulações do Grupo 2 (y=150 m)..... 134

Figura 6.29: Quantificação do número de vezes em que os para-raios atuam nas 128 simulações do Grupo 2 ( $\mathrm{y}=150 \mathrm{~m})$

Figura 6.30: Indicação dos para-raios em atuação para cada uma das 128 simulações do Grupo $2(\mathrm{y}=150 \mathrm{~m})$. 135 
Figura 6.31: Correlação entre os pontos de localização dos subsistemas para estimação das tensões induzidas (SETIs) e os pontos de incidência das descargas atmosféricas (DA) em relação ao alimentador teste para $\mathrm{y}=250 \mathrm{~m}$. 137

Figura 6.32: Correlação entre os pontos de localização dos subsistemas para estimação das tensões induzidas (SETIs) e os pontos de incidência das descargas atmosféricas (DA) em relação ao alimentador teste para $\mathrm{y}=350 \mathrm{~m}$. 138

Figura 6.33: Tensão sobre o transformador da subestação para as 128 simulações do Grupo 3 $(\mathrm{y}=250 \mathrm{~m})$

Figura 6.34: Tensão sobre o transformador da linha para as 128 simulações do Grupo 3 $(\mathrm{y}=250 \mathrm{~m})$. 139

Figura 6.35: Tensão sobre a carga 632/671 para as 128 simulações do Grupo 3 (y=250 m). 140

Figura 6.36: Tensão sobre a carga 646 para as 128 simulações do Grupo 3 (y=250 m)...... 141

Figura 6.37: Tensão sobre a carga 645 para as 128 simulações do Grupo 3 (y=250 m)....... 141 Figura 6.38: Tensão sobre a carga 634 para as 128 simulações do Grupo 3 (y=250 m)...... 141 Figura 6.39: Tensão sobre a carga 671 para as 128 simulações do Grupo 3 (y=250 m)...... 142 Figura 6.40: Tensão sobre a carga 611 para as 128 simulações do Grupo 3 (y=250 m)....... 142 Figura 6.41: Tensão sobre a carga 652 para as 128 simulações do Grupo 3 (y=250 m)...... 142 Figura 6.42: Tensão sobre a carga 692 para as 128 simulações do Grupo 3 (y=250 m)...... 143 Figura 6.43: Tensão sobre a carga 675 para as 128 simulações do Grupo 3 (y=250 m)...... 143 Figura 6.44: Quantificação do número de vezes em que os para-raios atuam nas 128 simulações do Grupo 3 ( $\mathrm{y}=250 \mathrm{~m})$. 144

Figura 6.45: Quantificação do número de vezes em que os para-raios atuam nas 128 simulações do Grupo 4 (y=350 m) 144

Figura 6.46: Indicação dos para-raios em atuação para cada uma das 128 simulações do Grupo $3(\mathrm{y}=250 \mathrm{~m})$ 145

Figura 6.47: Indicação dos para-raios em atuação para cada uma das 128 simulações do Grupo $4(\mathrm{y}=350 \mathrm{~m})$ 146 



\section{LISTA DE TABELAS}

Tabela 2.1: Compilação dos parâmetros estatísticos por distribuição log-normal para descargas descendentes negativas levantados pelo CIGRÉ [adaptada de (CIGRÉ, 1991)] .... 17 Tabela 4.1: Composição química clássica dos varistores de ZnO (OLIVEIRA, 2004)..........77 Tabela 4.2: Características dos óxidos mais utilizados na fabricação de varistores de $\mathrm{ZnO}$

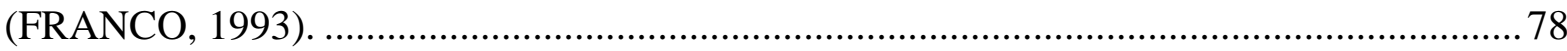

Tabela 5.1: Parâmetros dos transformadores (IEEE, 2013)................................................ 93

Tabela 5.2: Parâmetros dos capacitores de derivação (IEEE, 2013) ......................................93

Tabela 5.3: Características da carga distribuída (IEEE, 2013) .............................................. 93

Tabela 5.4: Características das cargas concentradas (IEEE, 2013).......................................93

Tabela 5.5: Distância entre os nós dos diferentes segmentos de linha, adaptada de (IEEE, 2013)

Tabela 5.6: Pico de tensão por fase para as cargas e os transformadores sob regime permanente. .98

Tabela 5.7: Corrente nominal de descarga de acordo com a norma IEC 60099-4, adaptado de (HINRICHSEN, 2012).

Tabela 5.8: Classe de descarga da linha de acordo com a norma IEC 60099-5, adaptado de (HINRICHSEN, 2012). 108

Tabela 5.9: Atribuição típica para o diâmetros dos resistores de óxido de zinco para classe de descarga da linha, adaptado de (HINRICHSEN, 2012). 108

Tabela 5.10: Modelos e características elétricas dos para-raios do tipo 3EK4, adaptado de (SIEMENS, 2013). 110

Tabela 5.11: Dados técnicos gerais relativos aos para-raios do tipo 3EK4, adaptado de (SIEMENS, 2013). 110

Tabela 6.1: Relação entre número da simulação e número do Subsistema de Estimação de Tensão Induzida (SETI) ativo.... 116 



\section{SUMÁRIO}

DEDICATÓRIA ..................................................................................................................... vii

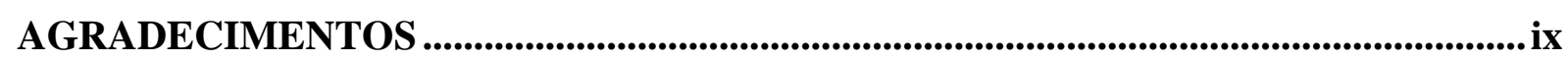

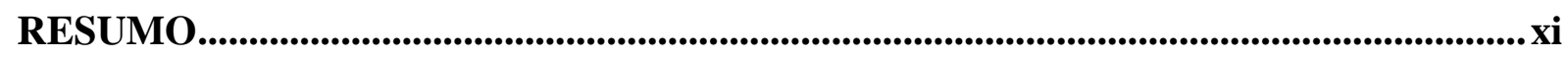

ABSTRACT ................................................................................................................................... xiii

LISTA DE SIGLAS, SÍMBOLOS E ABREVIATURAS ................................................... xv

LISTA DE FIGURAS.......................................................................................................................

LISTA DE TABELAS ....................................................................................................iii

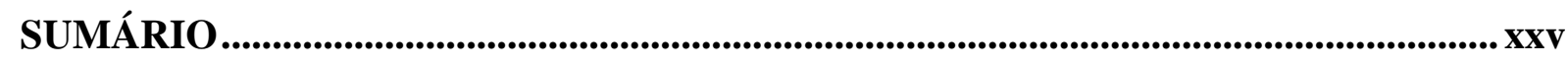

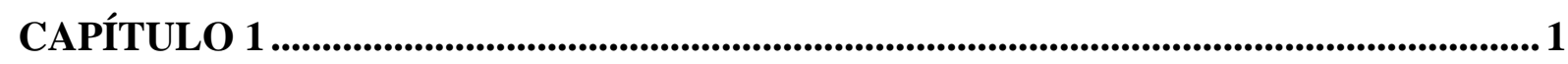

INTRODUÇÃO À DISSERTAÇÃO DE MESTRADO.........................................................1

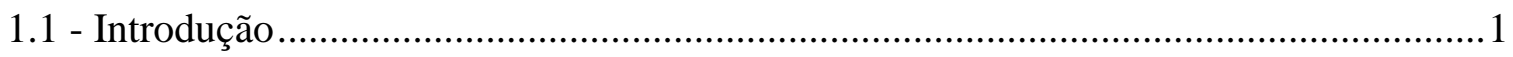

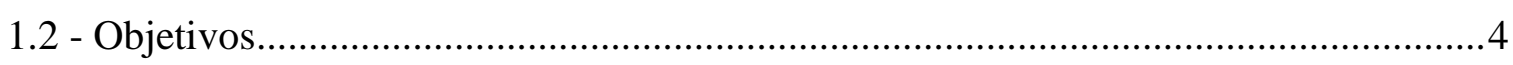

1.3 - Organização da Dissertação .....................................................................................

1.4 - Publicações e Atividades Acadêmicas Desenvolvidas ....................................................6

CAPÍTULO 2 .............................................................................................................

ASPECTOS RELACIONADOS ÀS DESCARGAS ATMOSFÉRICAS .............................9

2.1 - Definições e Conceitos Básicos...........................................................................10

2.2 - Processo de Formação das Cargas nas Nuvens ……………………………………....10

2.3 - Processo de Formação das Descargas Atmosféricas ......................................................11

2.4 - Características e Parâmetros da Onda de Corrente de Descarga ...................................15

2.5 - Incidências de Descargas Atmosféricas .................................................................18

2.6 - Tipos de Incidência de Descargas Atmosféricas e Respectivas Consequências ........22

2.6.1 - Características Pertinentes a Incidência Direta de Descargas Atmosféricas .....23

2.6.1.1 - Incidência Direta em Condutor Energizado ...............................................23

2.6.1.2 - Incidência Direta em Condutor de Blindagem.............................................25

2.6.1.3 - Incidência Direta em Condutor de Blindagem a Meio Vão.........................27

2.6.2 - Características Pertinentes a Incidência Indireta de Descargas Atmosféricas...28

2.7 - Considerações Parciais a Respeito das Descargas Atmosféricas ................................30

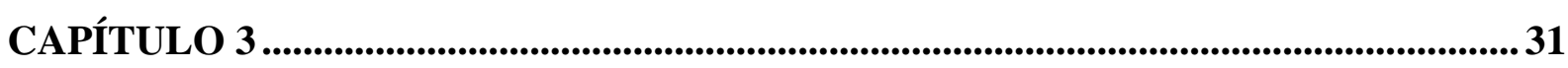

FUNDAMENTOS E MODELOS CORRELATOS ÀS TENSÕES INDUZIDAS POR

DESCARGAS ATMOSFÉRICAS .............................................................................31 
3.1 - Revisão Bibliográfica e Histórica 31

3.2 - Formação das Tensões Induzidas por Descargas Indiretas ...................................... 38

3.3 - Corrente de Retorno no Canal de Descarga ....................................................... 41

3.3.1 - Dinâmica de Estabelecimento da Corrente de Retorno..................................... 41

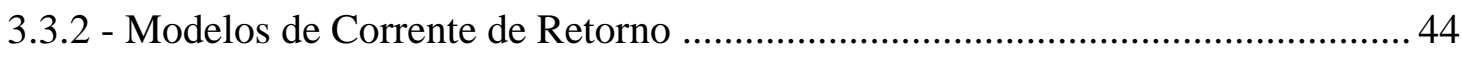

3.4 - Acoplamento Eletromagnético entre Linha e Canal de Descarga............................. 45

3.4.1 - Tipos de Mecanismos de Acoplamento Eletromagnético .................................. 46

3.4.2 - Modelos de Acoplamento Eletromagnético entre Linha e Canal de Descarga . 48

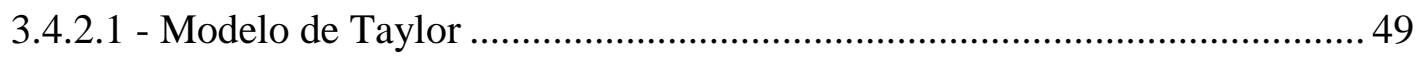

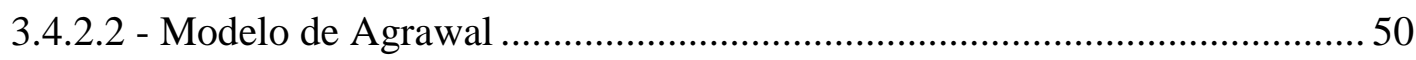

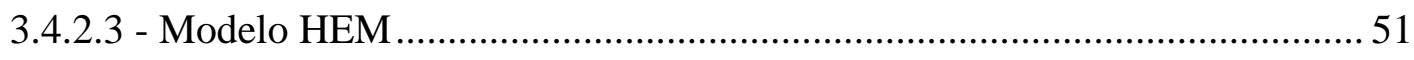

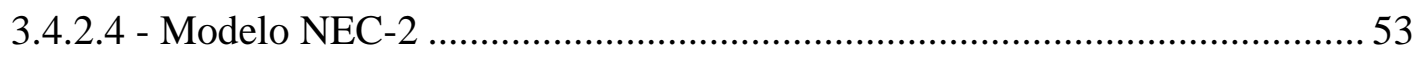

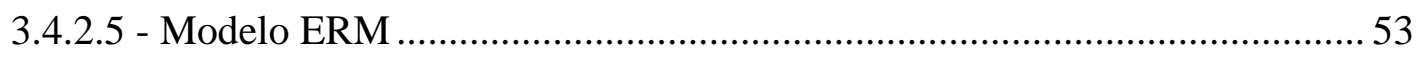

3.4.2.6 - Modelo de Rusck ...................................................................................... 55

3.5 - Variáveis que Influenciam na Amplitude e Forma das Tensões Induzidas ............... 62

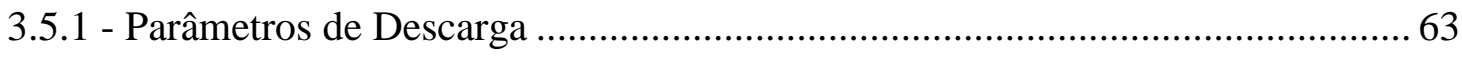

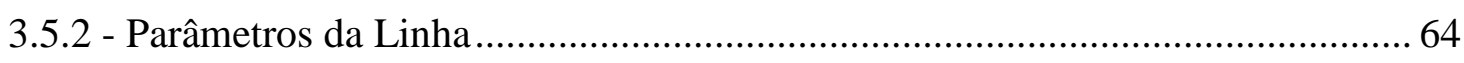

3.5.3 - Parâmetros de Configuração entre Linha e Canal de Descarga ......................... 64

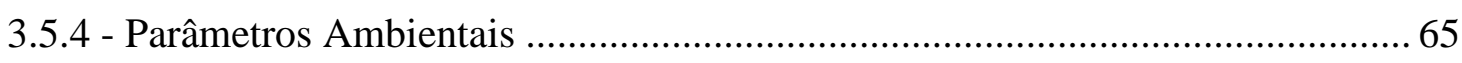

3.6 - Considerações Parciais sobre a Modelagem de Tensões Induzidas.......................... 65

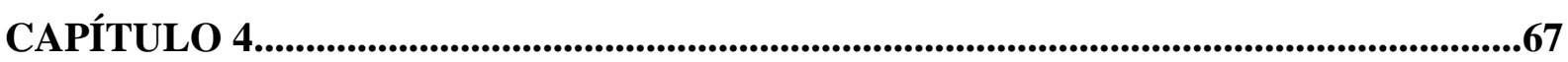

ASPECTOS RELACIONADOS AOS PARA-RAIOS................................................67

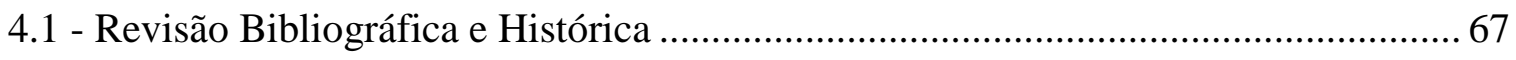

4.2 - Princípios de Funcionamento dos Para-raios ............................................................. 71

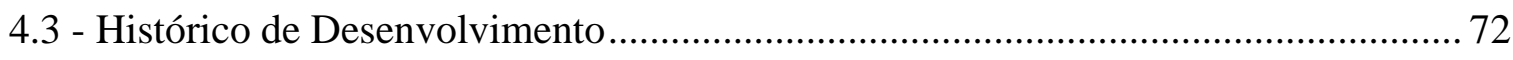

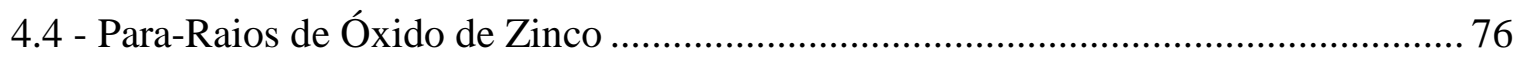

4.4.1 - Características Construtivas dos Para-Raios de ZnO ..................................... 76

4.4.1.1 - Características dos Resistores de ZnO …................................................ 77

4.4.1.2 - Tipos de Invólucros dos Para-Raios de $\mathrm{ZnO}$............................................. 81

4.4.2 - Fatores de Degradação dos Para-Raios de $\mathrm{ZnO}$.............................................. 84

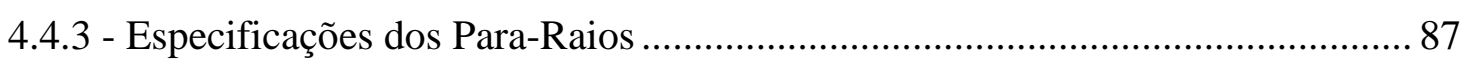

4.5 - Considerações Parciais sobre a Utilização de Para-raios de $\mathrm{ZnO}$............................. 89

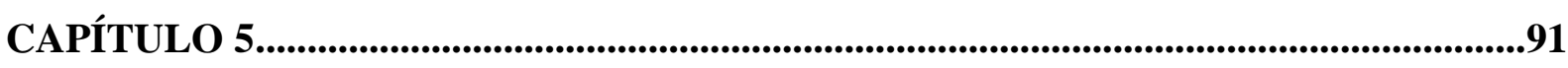

MODELAGENS E IMPLEMENTAÇÕES COMPUTACIONAIS .................................91 
5.1 - Alimentador teste de distribuição de energia elétrica.............................................91

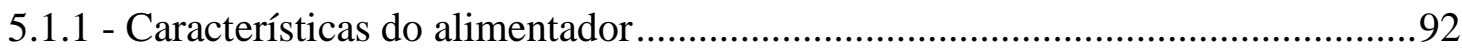

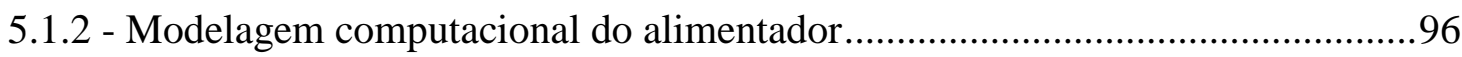

5.1.3 - Simulação da Modelagem computacional do alimentador ..............................97

5.2 - Aplicação do Modelo de Rusck para estimação de tensões induzidas por descargas

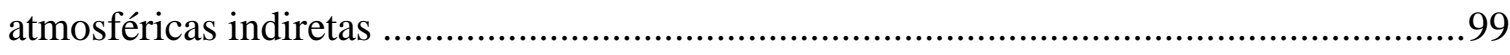

5.2.1 - Modelagem e implementação computacional..................................................99

5.2.2 - Simulação da estimação de tensões induzidas ................................................101

5.3 - Seleção e implementação computacional dos Para-raios .........................................105

5.3.1 - Parâmetros elétricos para seleção dos para-raios de $\mathrm{ZnO}$.................................105

5.3.2 - Escolha e Implementação do para-raios de ZnO ...........................................109

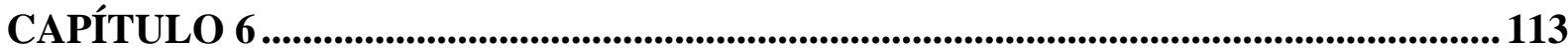

SIMULAÇÃO E ANÁLISE DA ATUAÇÃO DE PARA-RAIOS FRENTE A TENSÕES INDUZIDAS POR DESCARGAS ATMOSFÉRICAS INDIRETAS ............................... 113

6.1 - Definição dos casos das simulações e de suas variáveis .........................................113

6.1.1 - Resultados e Análises das Simulações do Grupo - 1 ......................................118

6.1.2 - Resultados e Análises das Simulações do Grupo - 2 ......................................128

6.1.3 - Resultados e Análises das Simulações do Grupo - 3 e do Grupo - 4 ..............136

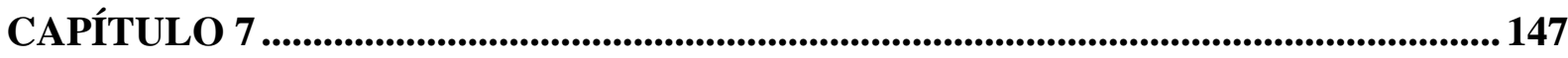

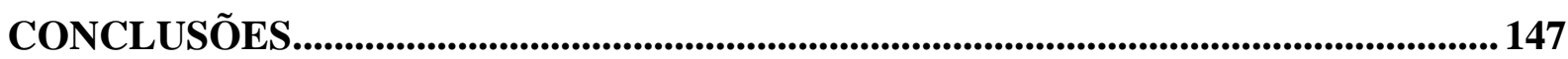

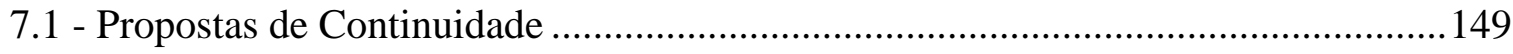

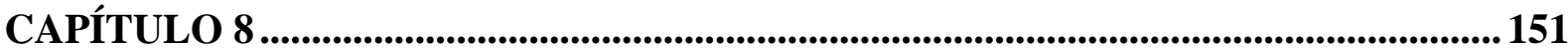

REFERÊNCIAS BIBLIOGRÁFICAS ..................................................................................... 151 



\section{CAPÍTULO 1}

\section{INTRODUÇÃO À DISSERTAÇÃO DE MESTRADO}

\section{1 - Introdução}

As descargas atmosféricas são um fenômeno natural de caráter essencialmente aleatório, as quais têm sido estudadas devido à severidade dos efeitos da incidência das mesmas sobre os sistemas elétricos de potência, e com a finalidade de obterem-se informações com relação às suas principais características.

O conhecimento das peculiares das descargas atmosféricas é de essencial importância para o desenvolvimento de métodos e critérios que objetivem otimizar a instalação de equipamentos a fim de melhorar o desempenho dos sistemas de energia frente a surtos atmosféricos. Desse modo, também se obtém maior confiabilidade na operação dos sistemas elétricos e melhoria de qualidade da energia disponibilizada aos consumidores, uma vez que as descargas atmosféricas são o principal elemento responsável pelos desligamentos não programados das linhas de transmissão e distribuição (CARVALHO, et al., 1999).

No Brasil, os problemas nos sistemas elétricos devido às descargas atmosféricas são bastante elevados em virtude da grande incidência das mesmas, da ampla extensão das linhas de transmissão e distribuição, o que torna maior a probabilidade destas serem atingidas, e em decorrência das peculiaridades pertinentes a um país com dimensões continentais. Dentre estas particularidades destacam-se a longa extensão territorial, as variações climáticas, orográficas e geológicas, e a localização em relação aos trópicos, uma vez que é cortado ao norte pelo Equador e ao sul pelo Trópico de Capricórnio. Comprovando tal afirmação, estudos realizados em 2011 pelo INPE/ELAT (Instituto Nacional de Pesquisas Espaciais / Grupo de Eletricidade Atmosférica) demonstram que o Brasil é o país com maior incidência de raios por ano do mundo, pois cerca de 57,8 milhões de raios atingem o solo brasileiro. Deste total, 11 milhões caem sobre o Amazonas, 7,38 milhões sobre o Pará, 6,81 milhões 
sobre o Mato Grosso, 5,18 milhões sobre o Rio Grande do Sul e 4,24 milhões sobre o Mato Grosso do Sul (BBC Brasil, 2012).

Os efeitos referentes à ocorrência de descargas atmosféricas estão associados à incidência direta da descarga sobre os condutores ou componentes da linha e a indução de tensão pelo campo eletromagnético gerado pela corrente de descarga incidente em um ponto próximo a linha. Contudo, tanto as descargas diretas quanto as indiretas originam sobretensões transitórias de elevada amplitude que se propagam ao longo da linha. Estas sobretensões, ao excederem os níveis de suportabilidade do sistema, podem causar descargas disruptivas, as quais evoluem para arcos de potência, promovendo o estabelecimento de faltas entre uma ou mais fases. Consequentemente faz-se necessária a atuação de dispositivos de proteção contra sobrecorrentes para eliminar tais empecilhos ao sistema (SILVEIRA, 2006).

Ressalta-se que as descargas diretas implicam em sobretensões de maior amplitude e, portanto, maior severidade ao sistema, porém a probabilidade de ocorrência desse tipo de evento é relativamente reduzida em sistemas de distribuição, os quais são o foco desta pesquisa. Em contra partida, embora as amplitudes das solicitações causadas por descargas indiretas sejam menos severas que aquelas provocadas por descargas diretas, elas são mais significativas, pois ocorrem com maior frequência e atingem principalmente os sistemas de distribuição. Nestes sistemas, as tensões induzidas podem alcançar amplitudes superiores a $300 \mathrm{kV}$, ocasionando desligamentos em linhas com tensão nominal de até $69 \mathrm{kV}$ (VISACRO, 2005).

Dessa forma, as tensões induzidas por descargas atmosféricas possuem especial relevância para redes de distribuição, e estima-se que cerca de um terço dos desligamentos das mesmas sejam causados por descargas atmosféricas (PINTO Jr.; PINTO, 2000). Tais redes podem ainda atuar como agentes introdutórios de surtos atmosféricos em unidades consumidoras de baixa tensão a elas conectadas, resultando na queima de eletrodomésticos e eletroeletrônicos.

Posto isto, devido à complexidade dos fenômenos envolvidos na análise do comportamento transitório de uma linha atingida por uma descarga atmosférica, diferentes aspectos do sistema devem ser avaliados com o objetivo de diagnosticar o desempenho de linhas de distribuição. Neste contexto, as tensões induzidas por descargas atmosféricas necessitam de uma avaliação criteriosa e cuidadosa para determinação dos seus aspectos básicos com a finalidade de se realizar estimativas a respeito da sua intensidade e atuação. Consequentemente possibilita-se o planejamento e o desenvolvimento de práticas de 
proteção, não apenas para estas linhas e seus componentes, mas também para resguardar os consumidores por elas atendidos (IEEE, 2004; BUENO et al., 2005).

Nesta perspectiva, no decorrer dos anos os principais estudos relativos a este tema têm apresentado diferentes tipos de modelagens para avaliação das tensões induzidas por descargas atmosféricas. Dentre estas modelagens se destaca o cálculo das tensões induzidas por meio de um processo iniciado a partir da determinação da distribuição de corrente ao longo do canal de descarga utilizando-se os chamados Modelos de Corrente de Retorno, com os quais se calculam os campos eletromagnéticos associados. Prossegue com a utilização dos Modelos de Acoplamento, empregados para determinar a interação entre os campos eletromagnéticos e os condutores da linha, e finaliza-se com o cálculo das tensões induzidas. Outro método por vezes utilizado, para cálculo das tensões induzidas, baseia-se no emprego dos modelos eletromagnéticos capazes de considerar de forma integrada a distribuição de corrente ao longo do canal de descarga e o acoplamento eletromagnético entre linha e canal, partindo diretamente da solução numérica das equações de Maxwell (VISACRO, 2005).

Cabe observar que devido à complexidade envolvida na modelagem e implementação das tensões induzidas a maioria dos modelos propostos na literatura faz uso de simplificações as quais em determinados casos podem comprometer a correta descrição das mesmas. Além disso, alguns parâmetros influenciam na forma e amplitude das tensões induzidas tornando ainda mais complexo o desenvolvimento de suas modelagens. Estes parâmetros são os seguintes: características associadas à forma de estabelecimento e desenvolvimento das descargas, fatores ambientais, especificações geométricas do sistema formado entre linha e canal de descarga, e peculiaridades físicas da linha.

A partir do exposto conclui-se que os sistemas de energia necessitam de proteção contra sobretensões em função da eventual incidência de descargas atmosféricas na linha ou em um ponto próximo da mesma, a fim de mantê-los operando de forma regular e de fornecer ao consumidor energia dentro dos padrões determinados pelas agências reguladoras. Nestas circunstancias, segundo literatura correlata, as linhas de energia podem ser protegidas por diversos equipamentos, dentre os quais se podem citar: para-raios, cabos para-raios, descarregadores de chifres, sistemas com neutro isolado, e sistemas de aterramento (D'AJUZ et al., 1985; MAMEDE, 2005). Entretanto, a aplicação de para-raios, sobretudo os de óxido de zinco (ZnO), de acordo com diversas pesquisas (LAT, 1987; SHORT; AMMON, 1999; TARASIEWICZ et al., 2000; ALVES, 2010), é a melhor alternativa sob aspectos técnicos e econômicos para a melhoria de desempenho frente às descargas atmosféricas. 
Os para-raios atuam limitando as sobretensões em valores aceitáveis e drenando o excesso de corrente do sistema para a terra, ao mesmo tempo em que dissipam elevada quantidade de energia, evitando a interrupção de operação de linhas de distribuição e de transmissão (D’AJUZ et al., 1985; MAMEDE, 2005). Além disso, cabe ressaltar que os locais onde a instalação dos para-raios são mais significantes também são precisamente os locais onde eles são mais exigidos, uma vez que neste pontos os mesmos estão submetidos às sobretensões com maior frequência e de maior intensidade. Como consequência disto, os níveis de energia dos para-raios serão mais elevados, fato este que deve ser analisado, pois a capacidade de absorção de energia devido às sobretensões está diretamente relacionada com a vida útil do para-raios e, por conseguinte, com a efetiva proteção oferecida ao sistema.

Nesta conjuntura, esta pesquisa desenvolve-se propondo a modelagem e simulação de tensões induzidas por descargas atmosféricas indiretas a fim de incrementar o desempenho de uma linha de distribuição através da instalação de para-raios em suas estruturas. Para tanto, serão realizados estudos sobre os mecanismos de formação das descargas atmosféricas, e de suas principais características, tipos e processos de incidência. Também, serão feitas investigações sobre a dinâmica de estabelecimento e desenvolvimento das tensões induzidas, os modelos de corrente de retorno, e os mecanismos e modelos de acoplamento entre linha e canal de descarga.

Do mesmo modo, serão avaliadas as características construtivas e de funcionamento dos para-raios de óxido de zinco, seus parâmetros de especificação e seleção, e seus fatores de degradação. E por fim, serão selecionados os modelos computacionais para implementar as características dinâmicas das tensões induzidas e dos para-raios, e serão efetuadas simulações e análises de desempenho da linha frente à ocorrência de tensões induzidas com ausência e presença de para-raios em suas estruturas.

\section{2 - Objetivos}

Os objetivos desta pesquisa são propor e implementar computacionalmente uma técnica para simular a estimação de tensões induzidas por descargas atmosféricas indiretas em sistemas de distribuição de energia elétrica, e desenvolver um procedimento de proteção frente à sobretensões de origem atmosféricas empregando para-raios de óxido de zinco, de forma que seus procedimentos e metodologias possam ser aplicados em qualquer outro 
sistema de distribuição ou transmissão de energia desde que se tenha em mãos as configurações dos mesmos.

\section{3 - Organização da Dissertação}

Para alcançar os objetivos propostos a presente dissertação foi organizada em oito capítulos, descritos a seguir.

No segundo capítulo são expostas definições e conceitos relacionados às descargas atmosféricas, à formação das cargas nas nuvens, do raio e das descargas descendentes negativas entre nuvem e solo. Ainda são descritas as características e os parâmetros da corrente de descarga, exibidos dados relativos à incidência de descargas no solo brasileiro, e demonstrados os tipos de incidência com suas respectivas consequências para os sistemas elétricos.

No terceiro capítulo é apresentado um levantamento bibliográfico e histórico dos principais trabalhos publicados sobre estudo e modelagem de descargas atmosféricas, tensões induzidas por descargas indiretas, e desempenho de linhas de distribuição e transmissão frente a estas descargas. Também, ocorre à descrição sobre o processo de estabelecimento das tensões induzidas por descargas indiretas e de parâmetros relativos à mesma, e a definição do modelo eletromagnético que será utilizado para implementação computacional e simulação destas tensões no decorrer desta pesquisa.

No quarto capítulo é realizado um levantamento bibliográfico e histórico dos principais trabalhos publicados sobre o desenvolvimento dos para-raios e a respeito da aplicação de para-raios de óxido de zinco na proteção contra sobtensões. Em seguida é efetuado um estudo mais aprofundado sobre os para-raios de óxido de zinco mostrando seus conceitos básicos de funcionamento, características construtivas e de degradação, desempenho frente a surtos atmosféricos, e parâmetros de especificação.

No quinto capítulo é feita a descrição e modelagem do alimentador de distribuição a ser analisado frente à incidência das descargas indiretas a partir de seus parâmetros e padrões definidos pelo IEEE (Institute of Electrical and Electronic Engineers). Em seguida, são apresentados os requisitos e as ferramentas empregadas para simulação de tensões induzidas por descargas atmosféricas indiretas empregando o Modelo de Rusck. Finalizando este capítulo são expostos os requisitos necessários para selecionar e implementar os para-raios 
mais adequados as configurações da linha de distribuição a ser protegida das tensões induzidas. Salienta-se que todas as modelagem e implementação deste capítulo, bem como desta dissertação, são realizadas por meio do toolbox SimPowerSystems ${ }^{\mathrm{TM}}$ presente no ambiente gráfico Simulink® e através do software MATLAB®.

No sexto capítulo são delineados os resultados de simulações para estimação de tensões induzidas por descargas indiretas na linha do alimentador teste implementado após a instalação dos para-raios. Assim, será possível determinar o número de para-raios necessário para sua proteção, a melhor localização dos mesmos, e a eficiência da proteção promovida por eles a partir das análises destas simulações.

No sétimo capítulo são expostas as conclusões e reflexões provenientes do desenvolvimento desta pesquisa por meio da avaliação da modelagem e implementação do processo de estimação de tensões induzidas aplicado, e da proteção realizada pelos para-raios de $\mathrm{ZnO}$ sobre a linha de distribuição eleita para esta investigação científica.

Por fim, no oitavo capítulo é apresentada uma lista com as referências bibliográficas utilizadas para a realização desta pesquisa e confecção desta monografia.

\section{4 - Publicações e Atividades Acadêmicas Desenvolvidas}

A partir de estudos realizados para o desenvolvimento desta dissertação e de outros trabalhos acadêmicos correlatos, e em virtude da relevância de pesquisas relacionadas a este tema na atualidade, surgiu a possibilidade de serem realizadas as seguintes publicações:

\section{- Artigos publicados em anais de congressos}

$\checkmark$ ARAujo, M. A.; FlauZinO, R. A.; BAtistA, O. E.; MORAES, L. A. Protection of the Distribution Lines against Lightning Overvoltages by Surge Arrester in the Context of Distributed Generation and Smart Grids. In: Innovative Smart Grid Technologies - IEEE ISGT Latin America, 2013, São Paulo, SP, Brasil. Proceedings of IEEE ISGT Latin America, 2013.

ARAUjO, M. A.; FlaUZINO, R. A.; BAtista, O. E.; MORAES, L. A. Application of Fuzzy System for Analysis of Lightning Overvoltages and 
Protection of Distribution Systems by Surge Arresters. In: World Congress in Computer Science, Computer Engineering, and Applied Computing (WORLDCOMP'13), 2013, Las Vegas, Nevada, USA. ICAI 2013: Expert Systems for Intelligent Automation Purposes in Power Systems, 2013.

\section{- Artigos aceitos para publicação em anais de congressos}

$\checkmark$ ARAujO, M. A.; FlauZinO, R. A.; AltafiM, R. A. C.; BATISTA, O. E.; MORAES, L. A. Modeling and Simulation of Metal-Oxide Surge Arresters for Protection of Distribution Systems against Lightning Overvoltages. In: XII International Symposium on Lightning Protection (SIPDA), 2013, Belo Horizonte, MG, Brasil. Proceedings of Lightning Protection of Medium and lowvoltage Distribution lines, 2013.

$\checkmark$ ARAujo, M. A.; FlaUZinO, R. A.; BAtista, O. E. ; MORAES, L. A. Application of Surge Arrester for Overvoltage Protection Caused by Direct Lightning on Distribution Lines. In: X Latin-American Congress on Electricity Power Generation, Transmission and Distribution (CLAGTEE), 2013, Vinã Del Mar, Chile. Proceedings of CLAGTEE, 2013.

$\checkmark$ ARAujo, M. A.; FlauZinO, R. A.; BAtistA, O. E.; MORAES, L. A. Applying a Fuzzy System for Lightning Location and Protection of Distribution Systems against Overvoltages by Surge Arresters. In: Simpósio Brasileiro de Automação Inteligente (SBAI), 2013, Fortaleza, CE, Brasil. Anais do SBAI, 2013.

\section{- Artigo submetido para publicação em periódico}

$\checkmark$ ARAujo, M. A; FlauZinO, R. A; Moro. V. C.; VIEIRA JUNiOR, J. C. M. Modeling and Simulation of Surge Arresters for Lightning Protection of Distribution Systems. Revista IEEE América Latina, 2013. (Artigo Submetido em 2012) 
Além disso, dentre as atividades acadêmicas realizadas paralelamente aos trabalhos do mestrado destacam-se as descritas a seguir:

\section{- Estágios em docência pelo Programa de Aperfeiçoamento de Ensino}

Realização de estágio acadêmico no período de 08/2012 a 12/2012 pelo Programa de Aperfeiçoamento de Ensino da Escola de Engenharia de São Carlos da Universidade de São Paulo. Estágio este, em docência na disciplina SEL0403 (Eletricidade) sob orientação e supervisão do Prof. Dr. Rogério Andrade Flauzino.

Realização de estágio acadêmico no período de 02/2013 a 06/2013 pelo Programa de Aperfeiçoamento de Ensino da Escola de Engenharia de São Carlos da Universidade de São Paulo. Estágio este, em docência na disciplina SEL0302 Circuitos Elétricos II sob orientação e supervisão do Prof. Dr. Rogério Andrade Flauzino. 


\section{CAPÍTULO 2}

\section{ASPECTOS RELACIONADOS ÀS DESCARGAS ATMOSFÉRICAS}

As descargas atmosféricas caracterizam-se por serem um fenômeno aleatório muito difícil de ser analisado e um dos causadores de distúrbios eletromagnéticos nos sistemas elétricos de potência, resultando em desligamentos não programados dos sistemas de energia e culminando em enormes perdas para consumidores residenciais, industriais, comercias e públicos.

Atualmente, devido ao processo de aquecimento e grandes alterações climáticas pelo qual o planeta passa, estas intempéries naturais estão intensificando-se e se tornando cada vez mais severas. Além disso, em regiões tropicais próximas a linha do Equador, onde se localiza o Brasil, este fenômeno se manifesta mais intensamente e em maior número, o que torna o seu estudo ainda mais relevante (PINTO Jr, 2009).

Posto isto, na conjuntura desta pesquisa serão apresentados conceitos e definições sobre a formação, o desenvolvimento, e algumas características e parâmetros das descargas atmosféricas. Os mesmos serão expostos, pois seu conhecimento é de grande importância para estimar adequadamente a severidade de fenômenos solicitantes em sistemas elétricos em virtude da ocorrência de descargas diretas e indiretas, tais como as tensões induzidas, e para a determinação de práticas de proteção mais adequadas a partir de suas análises.

Dessa forma, no presente capítulo serão descritos os conceitos básicos sobre descargas atmosféricas, como ocorre à formação das cargas nas nuvens e dos raios, como se desenvolvem as descargas entre nuvem e o solo, onde se observa maior incidência das mesmas, e quais as principais características e parâmetros da corrente de descarga. Também serão realizadas considerações sobre os mecanismos de estabelecimento de sobretensões por incidência direta e indireta de descargas atmosféricas em redes de energia elétrica. 


\section{1 - Definições e Conceitos Básicos}

Antes de descrever e caracterizar os diferentes processos envolvendo o fenômeno das descargas atmosféricas se faz necessário apresentar algumas definições e conceitos os quais seguem abaixo (VISACRO, 2005).

- Descarga elétrica: fluxo de cargas elétricas a partir de um ponto eletricamente carregado por meio de um processo disruptivo em meio isolante ou por meio de descarregamento através de meio condutor;

- Descarga atmosférica: descarga elétrica com origem atmosférica entre nuvens ou entre uma nuvem e a terra, a qual consisti em um ou mais impulsos de vários quiloampères, envolvendo efeitos elétricos, sonoros e visuais;

- Canal de Descarga: corresponde ao canal ionizado que liga nuvem e solo e por meio do qual evolui a corrente de retorno de descarga;

- Corrente de Retorno: corrente que flui pelo trajeto ionizado formado pelo canal de descarga em seguida ao fechamento do mesmo;

- Raio: representa um impulso elétrico de uma descarga atmosférica para a terra;

- Trovão: ruído produzido pelo deslocamento do ar em virtude do súbito aquecimento deste nas proximidades do canal de descarga;

- Relâmpago: luz emitida em virtude do desenvolvimento da corrente de retorno no canal de descarga;

- Índice Ceraúnico: é definido como o número de dias de trovoada em determinado lugar decorrido o período de um ano;

- Isoceraúnicas: são curvas que ligam pontos que possuem o mesmo índice ceraúnico.

\section{2 - Processo de Formação das Cargas nas Nuvens}

Mesmo com diversos estudos a formação das cargas nas nuvens é um fenômeno ainda não totalmente conhecido devido a grande quantidade de fatores envolvidos neste processo. Contudo, quase a totalidade das teorias desenvolvidas reconhece a fundamental importância da atuação do vento na separação das partículas de polaridades opostas, ainda que apresentem 
diferentes conceitos entre si a respeito da importância do papel da ionização da atmosfera, da temperatura e de outros aspectos (SALARI, 2006).

Dessa forma, o conceito comum entre tais teorias indica que as correntes de ar ascendentes, as quais são bastante úmidas, ao atingirem elevadas altitudes e depararem-se com menores temperaturas sofrem o processo de condensação de sua umidade formando gotículas de água suspensas que se agrupam até formarem gotas maiores. Essas gotas ao colidirem com outras gotas de água promovem a distribuição de cargas positivas na parte superior das nuvens e de negativas na parte inferior das mesmas, como pode ser visto na Figura 2.1. Tal separação ocorre em virtude da diferença de energia cinética destas cargas, uma vez que as gotas carregadas positivamente possuem maior energia cinética e por isso se movem ascendentemente.

Devido à concentração de cargas negativas na parte inferior da nuvem induz-se uma concentração de cargas positivas no solo com comprimento equivalente ao da nuvem, como também se vê na Figura 2.1. Estas cargas acompanham o deslocamento da nuvem em virtude da ação dos ventos promovendo o deslocamento de cargas positivas por prédios, antenas, torres, árvores, pontes, morros e carros.

Ainda, tem-se conhecimento de que os mecanismos de eletrificação e carregamento das nuvens abarcam diversos fenômenos não descritos aqui e de maior complexidade, mas é sabido que aproximadamente $95 \%$ das nuvens carregam-se pelo processo descrito acima (SARAN, 2009).

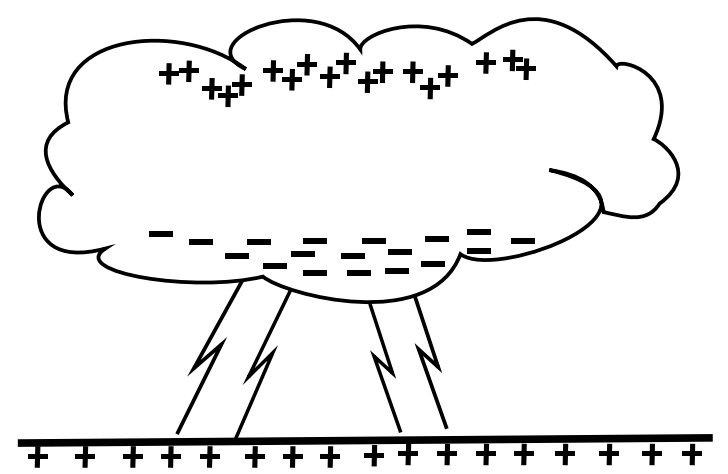

Figura 2.1: Distribuição das cargas nas nuvens e no solo [adaptada de (UMAN, 1984)].

\section{3 - Processo de Formação das Descargas Atmosféricas}

As descargas atmosféricas são descargas elétricas de grande extensão e de grande intensidade de corrente elétrica, as quais se dão em virtude da interação do acúmulo de cargas 
elétricas opostas entre nuvens ou entre a atmosfera e a terra (UMAN, 1984). Quando o campo elétrico produzido pela influência mútua destas cargas excede a rigidez dielétrica do ar ocorre uma intensa e rápida movimentação de elétrons da região de cargas negativas para a região de cargas positivas acarretando a formação de um impulso elétrico para a terra, ou raio (VISACRO, 2005).

Podem-se classificar as descargas atmosféricas segundo os locais que envolvem sua ocorrência, a sua direção de evolução e sua polaridade da seguinte forma:

- Local de ocorrência: dentro das nuvens ou intra-nuvens, entre nuvens, entre nuvens e o solo, e entre nuvens e a estratosfera;

- Direção de evolução: ascendente ou descendente;

- Polaridade: positiva ou negativa.

Esta pesquisa focar-se-á nas descargas mais severas aos estudos de proteção de sistemas elétricos, ou seja, descargas entre nuvens e o solo, e as de maior ocorrência, descendentes e negativas. Isto porque as descargas entre nuvens e o solo são mais danosas às redes de transmissão e distribuição de energia e pelo menos $90 \%$ das mesmas são descendentes e negativas, segundo (CIGRÉ, 1991) e como se pode ver pela Figura 2.2.

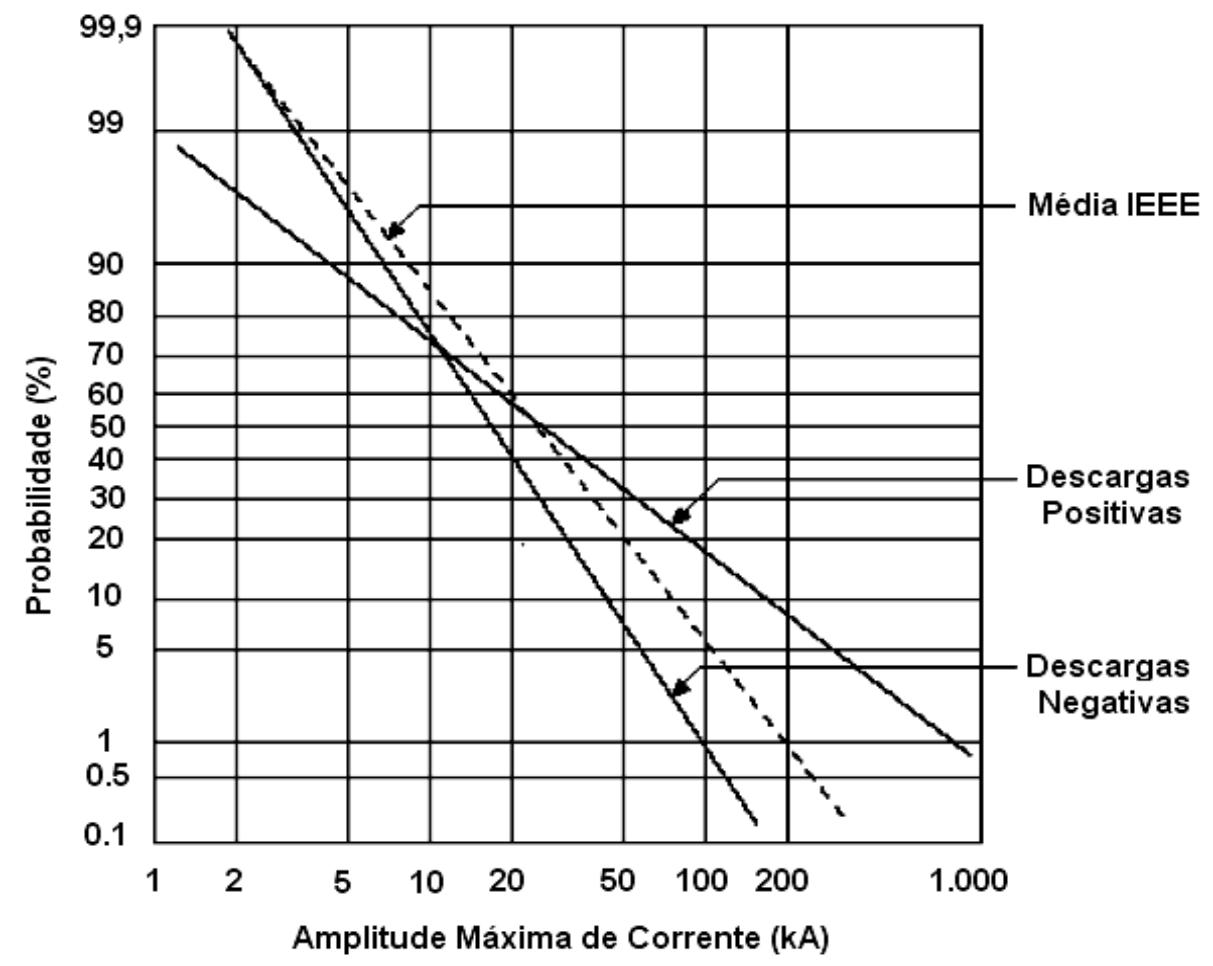

Figura 2.2: Probabilidade da amplitude máxima de corrente em virtude da polaridade da descarga [adaptado de (NOBLAT, 1994)]. 
Inicialmente, para ocorrer à formação de uma descarga nuvem/solo é necessário que campos elétricos interiores à nuvem rompam a rigidez dielétrica do ar originando um primeiro canal ionizado. Este canal ainda não é capaz de ligar a nuvem ao solo, mas promove o deslocamento de novas cargas elétricas que se agrupam formando novos canais em direção ao solo. O campo elétrico necessário para tanto é da ordem de $2 \mathrm{MV} / \mathrm{m}$ para o ar seco em condições atmosféricas normais, entretanto pode variar em virtude da presença de gotículas de água na nuvem e da altura da mesma, (UMAN, 1984; WAGNER, 1950).

Posto isto, estes canais evoluem em direção ao solo de forma aleatória por saltos ou impulsos deslocando consigo grande quantidade de cargas negativas dando origem ao canal precursor de descarga, o qual se desloca sempre em direção ao solo e se compõem por diversas ramificações que muitas vezes terminam no ar. Ao chegar às proximidades do solo ou de estruturas, tais como postes, torres, antenas e condutores de linhas de transmissão e distribuição, induz-se um campo elétrico resultante capaz de dar origem a um ou mais canais ascendentes com carga positiva. Estes canais também se deslocam por saltos e vão ao encontro do canal descendente, podendo ocorrer à conexão entre eles e o consequente fechamento do percurso caso a carga dos canais descendentes seja elevada o bastante para manter a progressão, e a distância entre ambos superar determinado valor crítico, como pode ser visto na Figura 2.3 (UMAN, 1984).

A partir de então fica estabelecido um canal condutor ionizado ligando uma região carregada de uma nuvem a terra, estabelecendo uma corrente de descarga com pico de várias dezenas de quiloampères e tempo de deslocamento de poucos microssegundos com forma de onda impulsiva. Não obstante, durante o fluxo desta corrente, designada por corrente de retorno, ocorrem dois fenômenos perceptíveis pelo ser humano, conhecidos popularmente como trovão e relâmpago.

Terminado o fluxo de corrente da descarga de retorno a descarga atmosférica pode extinguir-se ou não, pois se ocorrerem novos fluxos de cargas negativas em direção ao canal de ionização surgirá uma corrente de reacendimento do canal e se iniciarão outras descargas, denominadas descargas subsequentes. Além disso, também poderá surgir um novo precursor entre a nuvem e o solo, sem ramificações e com velocidade de propagação ainda maior que a do precursor inicial, mas que possuirá corrente de magnitude inferior, em torno de 1/3 a 1/2 da corrente inicial (WAGNER, 1950). 


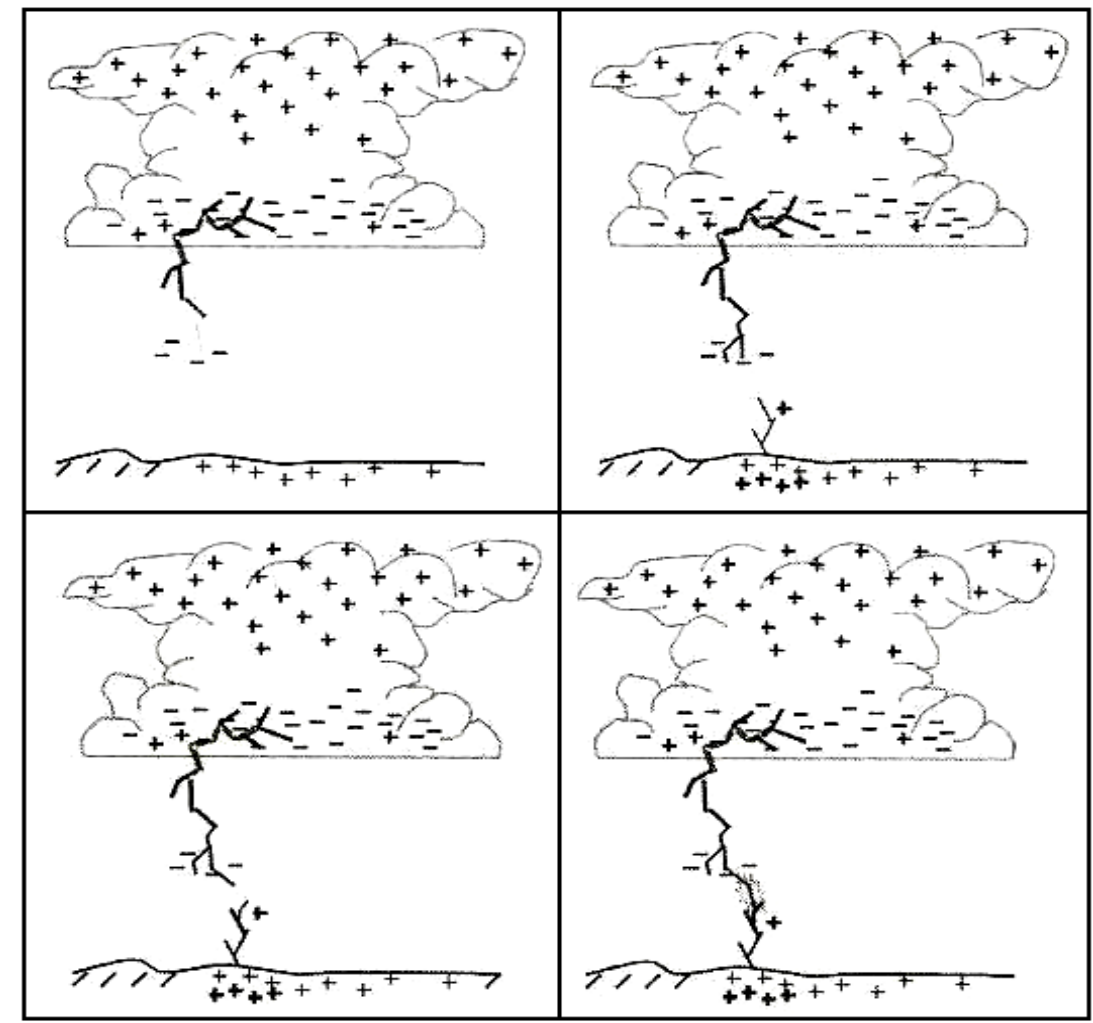

Figura 2.3: Representação da conexão entre os canais ascendentes e descendentes [adaptada de (VISACRO, 2005)].

Por fim, o processo descrito pode se repetir inúmeras vezes e outras descargas podem suceder esta segunda com magnitudes de corrente até maiores que a da primeira descarga, sendo que em média observa-se o acontecimento de 2 ou 3 descargas subsequentes. $\mathrm{O}$ procedimento do desenvolvimento das sucessivas descargas pode ser demonstrado pela Figura 2.4.

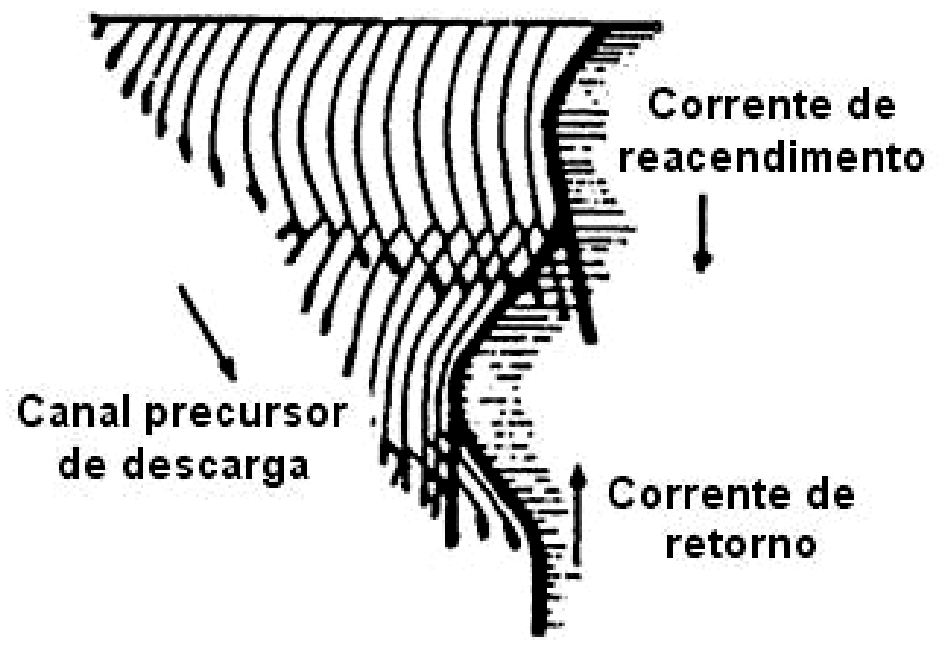

Figura 2.4: Representação da formação das descargas subsequentes [adaptada de (UMAN, 1984)]. 


\section{4 - Características e Parâmetros da Onda de Corrente de Descarga}

As características da onda de corrente de descarga são fundamentais para estudos do comportamento de linhas de transmissão e distribuição frente a descargas atmosféricas. Dentre estes características destacam-se (BERGER et al., 1975):

- Amplitude da corrente: critério de maior influência na determinação da severidade dos danos causados à linha, pois quanto maior a amplitude de corrente maior será a sobretensão gerada;

- Tempo de frente: tempo que a onda de corrente de descarga leva para alcançar seu pico, ressaltando que quanto menor o tempo maior o rigor da sobretensão causada;

- Taxa de crescimento da corrente: parâmetro que demonstra o quão rápido cresce a corrente de retorno, observando-se que quanto mais rápido é este aumento mais severa é a descarga;

- Tempo de cauda: tempo que a onda de corrente leva para retornar a 50\% do seu valor de pico desde o seu início, ou seja, representa o tempo que a linha é submetida à corrente de descarga atmosférica;

- Carga da corrente de descarga de retorno: intensidade de carga acumulada ao longo do canal precursor pelo impulso da corrente de retorno e transferida a terra pela mesma;

- Energia dissipada por unidade de resistência: expressa a potencialidade da corrente de retorno em dissipar energia.

Neste contexto, a Figura 2.5 representa uma onda característica de corrente de descarga ao longo do tempo para uma descarga nuvem-solo negativa, cuja variação do pico de corrente foi aproximada por uma distribuição log-normal, a partir da qual se pode definir e identificar alguns de seus principais parâmetros, os quais são expostos a seguir.

Além disso, na Tabela 2.1 são mostrados os dados estatísticos levantados pelo CIGRÉ (CIGRÉ, 1991) a partir de uma compilação de informações obtidas por diversos autores, com os respectivos parâmetros empregados na distribuição log-normal para representação de uma descarga negativa como a da Figura 2.5. 


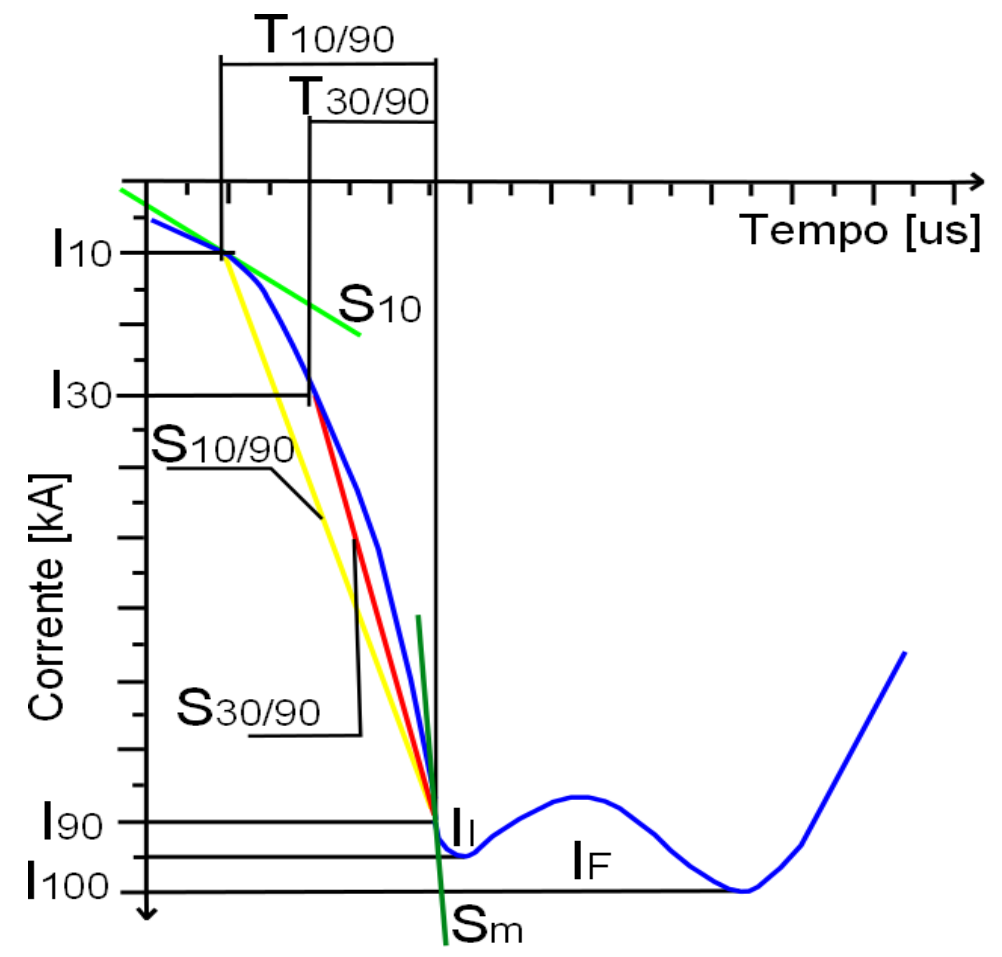

Figura 2.5: Forma de onda típica da corrente de descarga com seus principais parâmetros associados para uma descarga nuvem-solo negativa [adaptada de (CIGRÉ, 1991; IEEE, 2004)].

\section{- Amplitude máxima [kA]}

$>\mathrm{I}_{\mathrm{I}}$ - primeiro pico da corrente de descarga ou corrente inicial;

$>\mathrm{I}_{\mathrm{F}}$ - segundo pico da corrente de descarga ou corrente final, o qual geralmente é o maior valor entre os dois picos;

$>\quad \mathrm{I}_{10^{-}}$ponto no qual o módulo da corrente alcança $10 \%$ do valor de $\mathrm{I}_{\mathrm{I}}$;

$>\mathrm{I}_{30}$ - ponto no qual o módulo da corrente alcança $30 \%$ do valor de $\mathrm{I}_{\mathrm{I}}$;

$>\mathrm{I}_{90}$ - ponto no qual o módulo da corrente alcança $90 \%$ do valor de $\mathrm{I}_{\mathrm{I}}$;

$>\mathrm{I}_{100}$ - ponto no qual o módulo da corrente alcança $100 \%$ do valor de $\mathrm{I}_{\mathrm{I}}$.

\section{- Tempo de frente de onda $[\mu \mathrm{s}]$}

$>\mathrm{T}_{10 / 90}$ - intervalo de tempo entre os pontos em que o módulo da corrente vale respectivamente $10 \%$ e $90 \%$ do valor de seu primeiro pico;

$\mathrm{T}_{30 / 90}$ - intervalo de tempo entre os pontos em que o módulo da corrente vale respectivamente $30 \%$ e $90 \%$ do valor de seu primeiro pico;

\section{- Derivadas da corrente em relação ao tempo $[\mathrm{kA} / \mu \mathrm{s}]$}

$>\mathrm{S}_{\mathrm{m}}$ - derivada máxima da corrente durante o tempo de frente de onda; 
S $\mathrm{S}_{10}$ - derivada da corrente no ponto em que seu módulo vale $10 \%$ do primeiro pico;

$\mathrm{S}_{10 / 90}$ - derivada média da corrente no ponto em que seu módulo vale $10 \%$ e 90\% do primeiro pico;

$\mathrm{S}_{30 / 90}$ - derivada média da corrente no ponto em que seu módulo vale $30 \%$ e $90 \%$ do primeiro pico.

- $\mathbf{T}_{\mathrm{h}}$ - tempo de cauda $[\mu \mathrm{\mu}]$.

- $Q_{I}$ - carga do impulso da corrente de descarga [C].

- $\int I^{2}(t) d t$ - energia dissipada por unidade de resistência $\left[(k A)^{2} s\right]$.

Tabela 2.1: Compilação dos parâmetros estatísticos por distribuição log-normal para descargas descendentes negativas levantados pelo CIGRÉ [adaptada de (CIGRÉ, 1991)].

\begin{tabular}{|c|c|c|c|c|}
\hline \multirow[b]{2}{*}{ Parâmetro } & \multicolumn{2}{|c|}{ Primeira Descarga } & \multicolumn{2}{|c|}{ Descarga Subsequente } \\
\hline & Média & $\begin{array}{c}\text { Desvio Padrão } \\
\text { Logarítmico }\end{array}$ & Média & $\begin{array}{c}\text { Desvio Padrão } \\
\text { Logarítmico }\end{array}$ \\
\hline Frente de Onda $[\mu \mathrm{s}]$ & ---- & $---\cdot$ & ---- & $-\cdots--$ \\
\hline $\operatorname{td}_{10 / 90}=\mathrm{T}_{10 / 90} / 0,8$ & 5,63 & 0,576 & 0,75 & 0,921 \\
\hline $\operatorname{td}_{30 / 90}=T_{30 / 90} / 0,6$ & 3,83 & 0,553 & 0,67 & 1,013 \\
\hline Taxa de Crescimento $[\mathrm{kA} / \mu \mathrm{s}]$ & ---- & ---- & ---- & ---- \\
\hline $\mathrm{S}_{\mathrm{m}}$ máximo & 24,3 & 0,599 & 39,9 & 0,852 \\
\hline $\mathrm{S}_{10}\left(\mathrm{em} 10 \%\right.$ de $\left.\mathrm{I}_{\text {pico }}\right)$ & 2,6 & 0,921 & 18,9 & 1,404 \\
\hline$S_{10 / 90}\left(\right.$ entre $10 \%$ e $90 \%$ de $\left.I_{\text {pico }}\right)$ & 5 & 0,645 & 15,4 & 0,944 \\
\hline $\mathrm{S}_{30 / 90}\left(\right.$ entre $30 \%$ e $90 \%$ de $\left.\mathrm{I}_{\text {pico }}\right)$ & 7,2 & 0,622 & 20,1 & 0,967 \\
\hline Corrente de Crista [kA] & ---- & ---- & ---- & ---- \\
\hline $\mathrm{I}_{\mathrm{I}}$ (corrente inicial) & 27,7 & 0,461 & 11,8 & 0,53 \\
\hline $\mathrm{I}_{\mathrm{F}}($ corrente final $)$ & 31,1 & 0,484 & 12,3 & 0,53 \\
\hline $\mathrm{I}_{\mathrm{I}} / \mathrm{I}_{\mathrm{F}}$ & 0,9 & 0,23 & 0,9 & 0,207 \\
\hline $\mathrm{T}_{\mathrm{h}}[\mu \mathrm{s}]$ & 77,5 & 0,577 & 30,2 & 0,933 \\
\hline $\mathrm{Q}_{\mathrm{I}}[\mathrm{C}]$ & 4,65 & 0,882 & 0,938 & 0,882 \\
\hline $\int \mathrm{I}^{2}(\mathrm{t}) \mathrm{dt}\left[(\mathrm{kA})^{2} \mathrm{~s}\right]$ & 0,057 & 1,373 & 0,0055 & 1,366 \\
\hline Intervalo entre Descargas [ms] & ---- & ---- & 35 & 1,066 \\
\hline
\end{tabular}

Posto isto, a partir dos dados da Tabela 2.1 e de estudos específicos sobre os parâmetros das correntes de descarga pode-se aproximar a variação da corrente de pico (I) 
pela distribuição log-normal e definir a função distribuição de probabilidade da corrente de pico pela equação (2.1) (ANDERSON, 1982). Esta função traduz a probabilidade de $I$ ser maior ou igual a um determinado valor $i_{0} \mathrm{em} \mathrm{kA}$, e tem sua representação dada pelo gráfico da Figura 2.6.

$$
P \quad I \geq i_{0}=\frac{1}{1+\left(\frac{i_{0}}{31}\right)^{2.6}}
$$

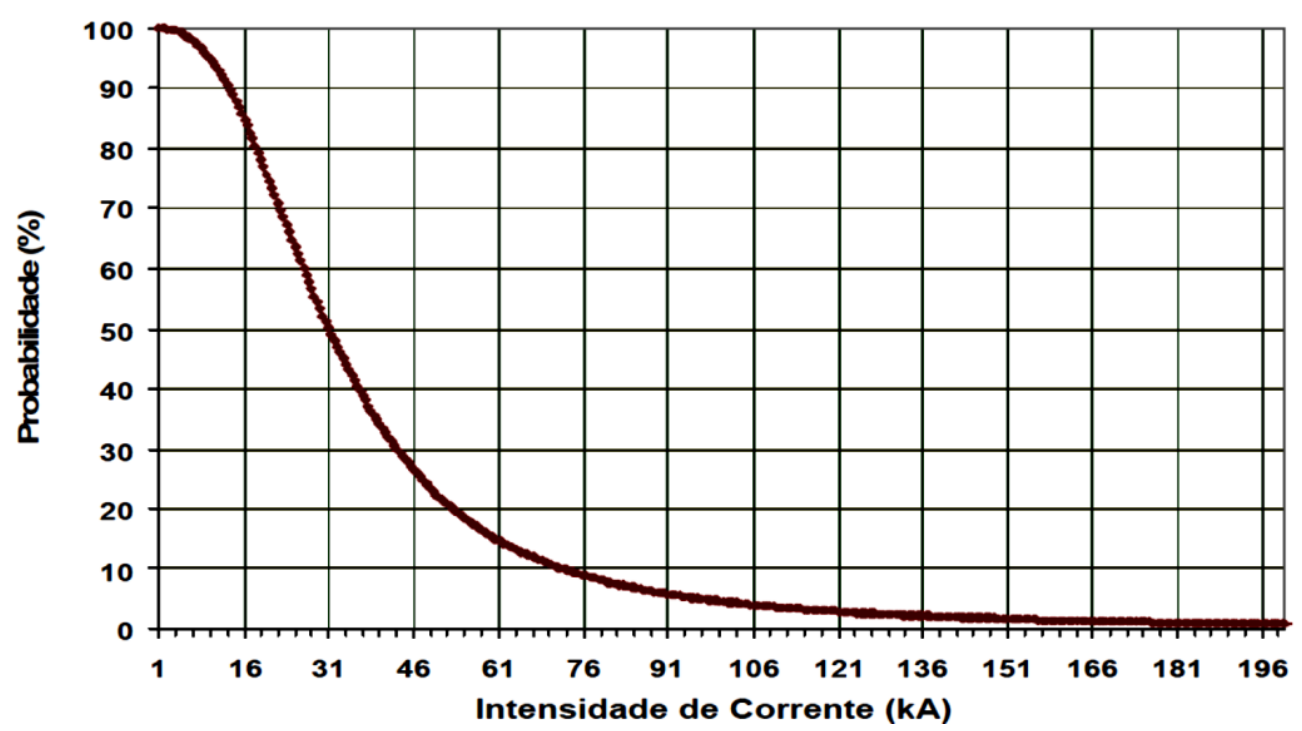

Figura 2.6: Distribuição acumulada de corrente baseada na equação de Anderson (ANDERSON, 1982).

\section{5 - Incidências de Descargas Atmosféricas}

O conhecimento da distribuição e incidência de descargas atmosféricas em determinada região é fundamental para a predição da severidade de surtos em pontos específicos do sistema elétrico. Um meio de obterem-se tais informações é pela análise de mapas isoceraúnicos, os quais ilustram o número de dias de trovoada por ano $(T d)$ em uma região especifica. Na Figura 2.7 e na Figura 2.8 são apresentados estes dados por meio das curvas isoceraúnicas para todo território brasileiro e apenas para a região Sudeste, respectivamente.

Por meio destes mapas é possível obter a densidade de descargas atmosféricas para a terra $(\mathrm{Ng})$, definida como o número de raios para a terra por quilômetros quadrados por ano. 
Sendo assim, o valor de $N g$ pode ser calculado para uma determinada região pela equação (2.2):

$$
N g=0,04 x T d^{1,25}\left[\mathrm{~km}^{2} / \mathrm{ano}\right]
$$

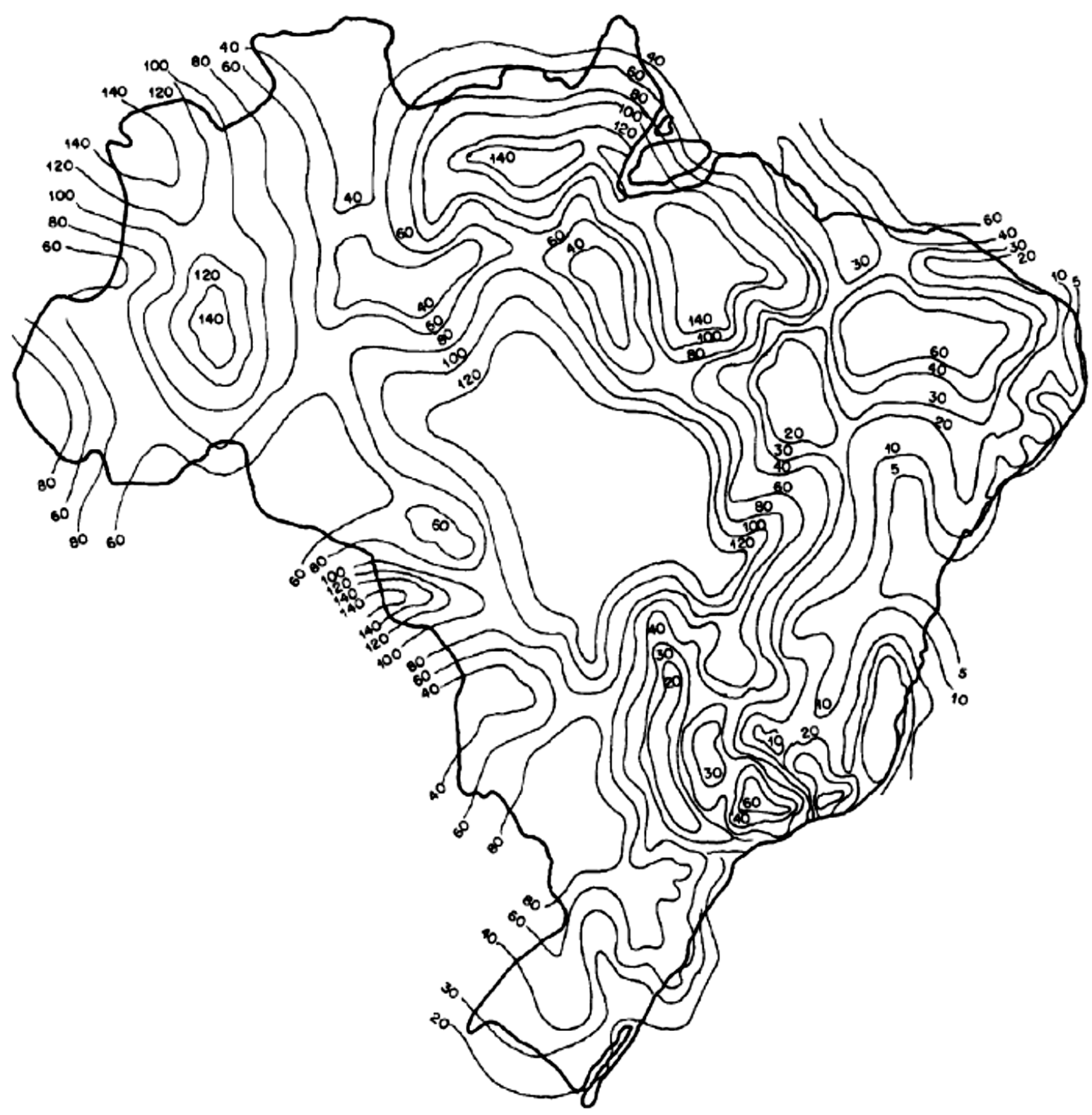

Figura 2.7: Mapa de curvas isoceraúnicas do Brasil (NBR 5419, 2005).

Além disso, podem ser obtidos mapas e dados mais precisos sobre a incidência de descargas por meio das informações disponibilizadas pela Rede Nacional de Localização de Descargas Atmosféricas (RINDAT) ou pelo Grupo de Eletricidade Atmosférica (ELAT). Tanto os sites do ELAT quanto do RINDAT disponibilizam em tempo real o mapa de 
incidência de raios no Brasil. No site do ELAT também pode ser encontrado um ranking da incidência de descargas atmosféricas por município para os biênios 2005-2006, 2007-2008 e 2009-2010 para os estados da região centro-sul do Brasil. Ressalta-se que os dados utilizados na formulação deste ranking foram obtidos pela Rede Brasileira de Detecção de Descargas Atmosféricas (BrasilDAT), que conta com equipamentos distribuídos pelo país monitorando e armazenando dados de luminosidade, intensidade, campo elétrico e direção das descargas (ELAT, 2012).

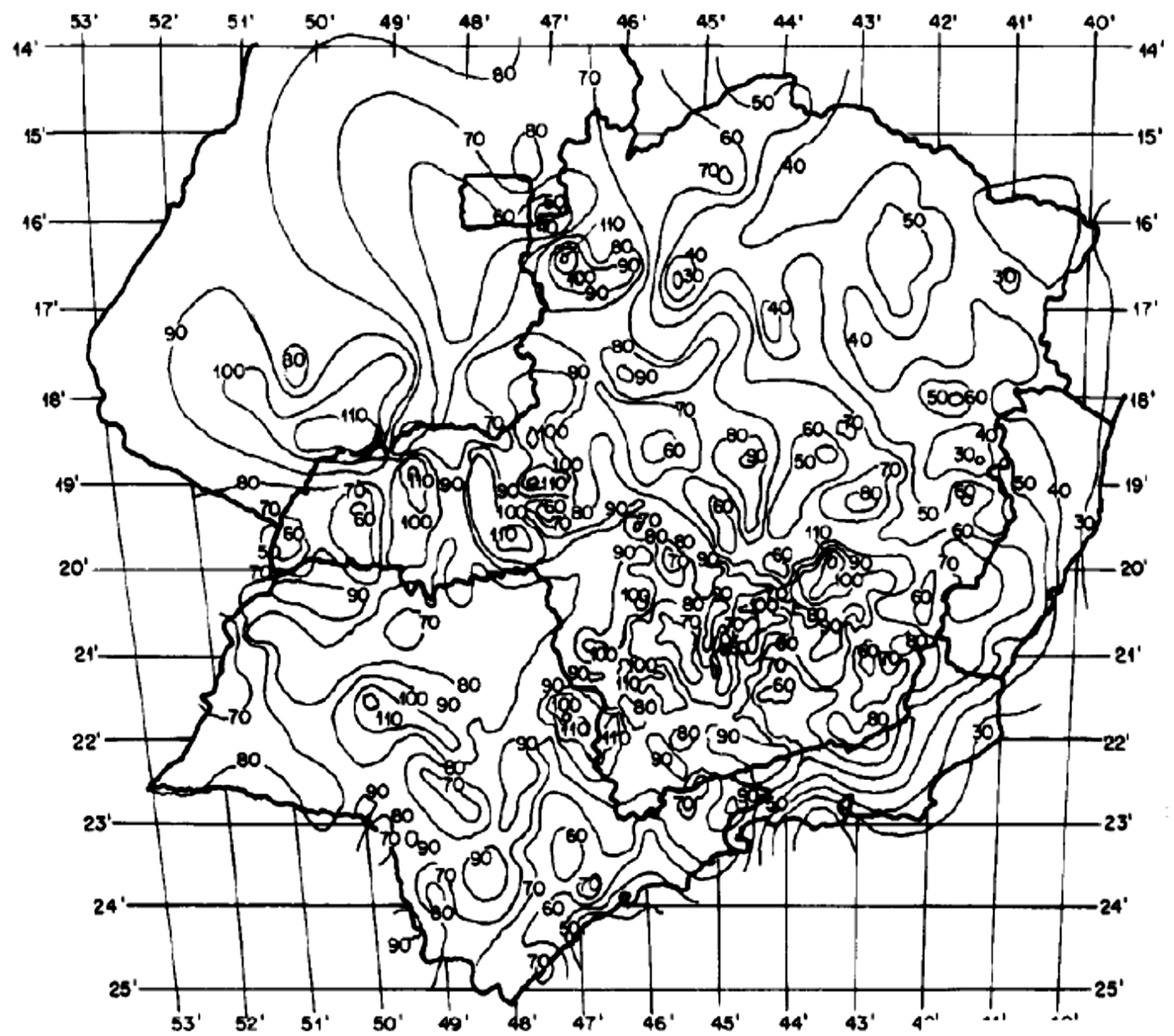

Figura 2.8: Mapa de curvas isoceraúnicas da região Sudeste para o período de 1971 a 1995 (NBR 5419, 2005).

Ainda neste contexto, em meio às pesquisas desenvolvidas por meio da coleta de dados de descargas atmosféricas nuvem-solo nos últimos 13 anos (1998-2010) destaca-se o mapa da Figura 2.9, um dos mais atualizados da área, contendo a taxa de relâmpagos nuvemsolo no Brasil neste período (NACCARATO, 2011). 
Em uma conjuntura mais atual, dentre os fenômenos averiguados pelo ELAT se sobressai o registro da formação de três raios ascendentes partindo de uma torre de transmissão de 130 metros no Pico do Jaraguá, no fim de janeiro de 2012, durante uma tempestade. Este tipo de evento nunca havia sido registrado pelos pesquisadores brasileiros, e se origina em estruturas elevadas, como torres de telecomunicação ou para-raios de edifícios altos.

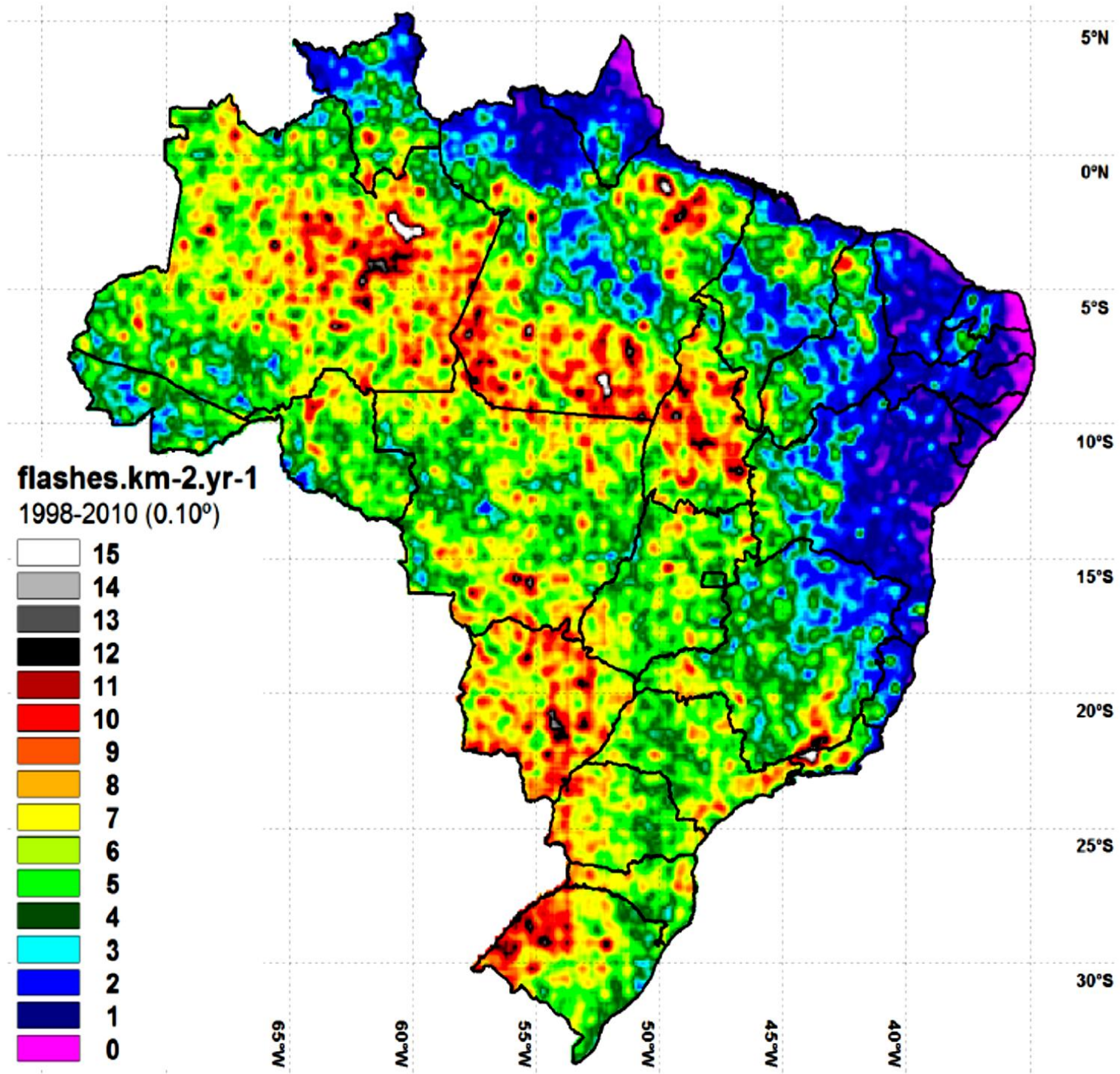

Figura 2.9: Taxa de relâmpagos nuvem-solo com dados obtidos pelo sensor de imagem de descarga nos últimos 13 anos (1998-2010) e corrigidos com resolução de $0.1^{\circ}$ (NACCARATO, 2011).

Não obstante, estudos revelam que há maior incidência de raios em pontos mais elevados do relevo, em torres, árvores, prédios, regiões de muita precipitação com fortes 
tempestades, e em locais com solos maus condutores. Neste tipo de solo a incidência é maior porque forma-se um "capacitor" entre a nuvem e o mesmo, e também porque por meio dele não acontece o escoamento dos raios, o que faz com que eles procurem caminhos de menor resistência para se distribuir. Dentre os solos com características más condutoras com maior incidência de raios destacam-se os graníticos e os xistosos, enquanto os calcários são tidos como terrenos bons condutores (KINDERMANN, 1992).

Uma forma de identificar terrenos mais propensos à incidência de raios é por meio da manifestação de um cheiro adocicado indicando a presença de ozônio em virtude da ionização do ar. Essa ionização diminui a distância de isolação entre os mesmos causando um aumento da probabilidade do raio piloto furar a camada de ar e incidir nessa região. Em países como Estados Unidos, Alemanha e França, por exemplo, foram definidos nos seus mapas locais os pontos onde é maior a probabilidade de incidência de descargas atmosféricas baseando-se na localização dos terrenos maus condutores e mais elevados do seu relevo (KINDERMANN, 1992).

\section{6 - Tipos de Incidência de Descargas Atmosféricas e Respectivas Consequências}

As descargas diretas, embora menos frequentes nos sistemas de distribuição, possuem consequências severas, podendo ocasionar o desligamento de linhas de transmissão de alta tensão. Em contra partida, as tensões induzidas pela incidência de descargas próximas à linha são fenômenos mais frequentes e que originam amplitudes de sobretensão relativamente amortizadas nos condutores da linha quando comparadas às de origem direta, situando-se seus valores máximos em aproximadamente $300 \mathrm{kV}$ (VISACRO, 2005). Tendo como base este valor, averígua-se que as sobretensões relacionadas à incidência indireta são mais relevantes para sistemas de média e baixa tensão, tais como as redes de distribuição de energia, que são o foco principal desta pesquisa.

Nesta conjuntura, baseando-se em (VISACRO, 2005), a seguir, serão expostas considerações sobre o mecanismo de estabelecimento de sobretensões em linha aéreas de quatro formas diferentes. Por incidência direta de descargas atmosféricas nos condutores energizados da linha, denominado flashover; por incidência direta nos condutores de 
blindagem, designado backflashover; por incidência direta nos cabos de blindagem a meio vão; e por incidência de descargas atmosféricas indiretas.

\subsection{1 - Características Pertinentes a Incidência Direta de Descargas Atmosféricas}

As descargas diretas que atingem francamente a rede elétrica podem afetar os condutores fase, os cabos de blindagem e para-raios, e os cabos de blindagem a meio vão, originando diferentes sobretensões. Estas sobretensões dependem de vários fatores, tais como a intensidade da corrente de descarga e a taxa de crescimento da mesma, o ponto de incidência, as características de aterramento da linha e o comportamento transitório do sistema elétrico abrangido.

\subsubsection{1 - Incidência Direta em Condutor Energizado}

O mecanismo de ruptura do isolamento relacionado à incidência de uma descarga atmosférica direta em um condutor energizado de uma linha é denominado descarga disruptiva no isolamento, ou flashover. O mesmo pode ocorrer na situação em que determinada linha não possui cabos de blindagem ou quando o sistema de blindagem existente sofre uma falha. Este segundo caso acontece em circunstâncias em que a amplitude da corrente de descarga é consideravelmente reduzida, o que possibilita a penetração desta corrente na área protegida pela blindagem sem que a mesma seja interceptada, tornando-a apta a atingir os condutores energizados.

Dessa forma, após a incidência direta da descarga na linha tem-se o estabelecimento de elevados níveis de sobretensões entre os condutores energizados e o terra, uma vez que as ondas de tensão decorrentes da corrente de descarga viajam ao longo da linha fazendo com que os isoladores sejam submetidos a elevados valores de sobretensões.

Além disso, usualmente o isolador é exposto a uma sobretensão tão elevada que ocorre o rompimento do isolamento e a formação de um arco elétrico que liga o condutor 
energizado à estrutura aterrada drenando parcialmente a corrente proveniente da descarga atmosférica em direção a terra.

Destaca-se que os equipamentos mais empregados em linhas de transmissão e distribuição para proteção contra o flashover são os para-raios e cabos de blindagem, os quais são diretamente ligados às estruturas a serem protegidas e ao solo através dos sistemas de aterramento.

Apenas a título ilustrativo, de modo simples a amplitude da sobretensão associada à incidência direta de uma descarga pode ser calculada basicamente pelo produto entre a amplitude da corrente que viaja na linha e o valor da impedância de surto $\left(Z_{S}\right)$ da mesma, impedância esta dada pela equação (2.3).

$$
Z_{S}=\frac{\bar{L}}{C}
$$

Na qual $L$ e $C$ representam a indutância a e capacitância da linha, respectivamente. Desse modo, como ilustrado na Figura 2.10, considerando uma descarga direta em uma linha que possui impedância de surto de $300 \Omega$, cuja corrente de descarga tenha valor de pico de 40 kA e sua onda viajante de corrente se divida em duas parcelas no momento da incidência, tem-se um valor de 6 MV para a amplitude da sobretensão (VISACRO, 2005).

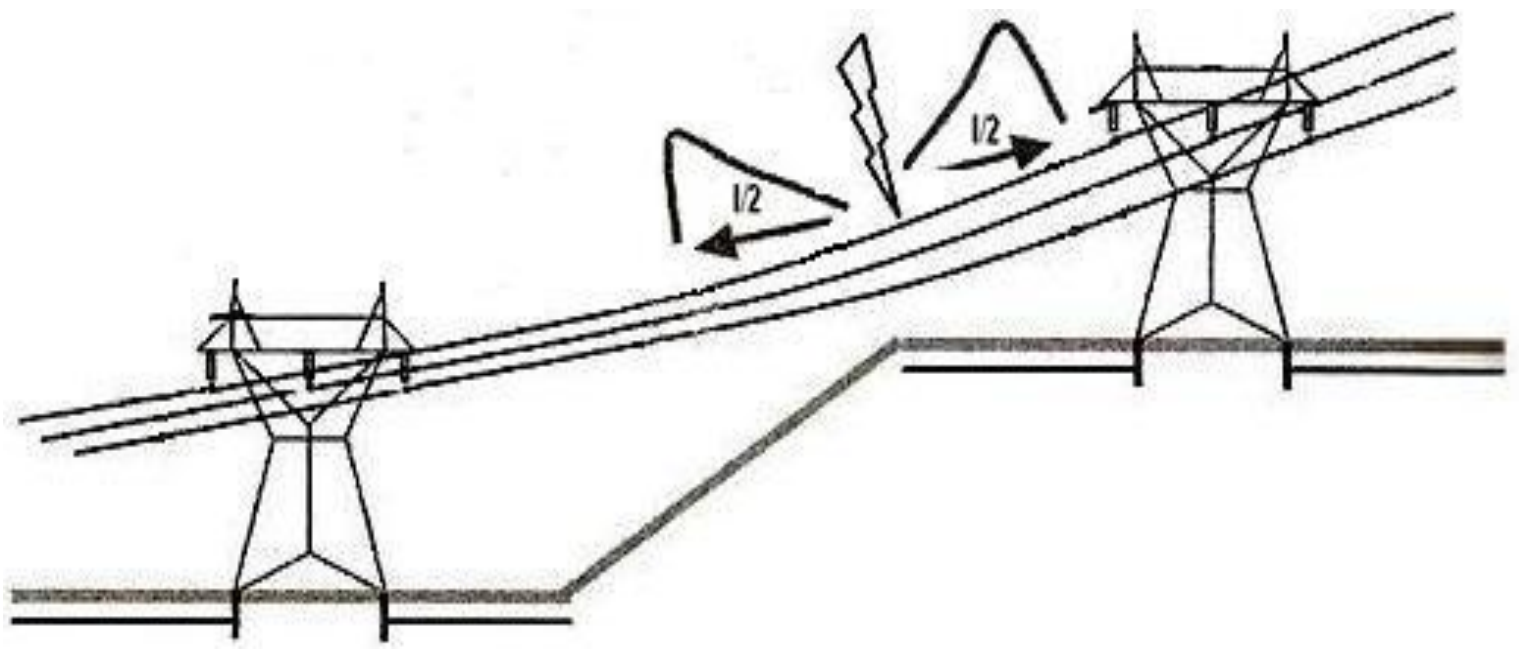

Figura 2.10: Linha de transmissão sem para-raios atingida por uma descarga atmosférica direta em um de seus condutores energizados [adaptada de (VISACRO, 2005)]. 


\subsubsection{2 - Incidência Direta em Condutor de Blindagem}

O mecanismo de ruptura do isolamento relacionado à incidência de uma descarga atmosférica direta em um condutor de blindagem da linha é designado descarga disruptiva de retorno, ou backflashover. Os cabos de blindagem são alocados acima dos condutores fase a fim de assegurar a interceptação de eventuais descargas que poderiam atingir diretamente as fases da linha. Os mesmos são ligados diretamente ao solo por condutores de descida ou por conexões elétricas à estrutura, conectadas à malha de aterramento, direcionando para o solo as correntes de eventuais descargas.

Quando ocorre a incidência de uma descarga direta sobre o condutor de blindagem, como demonstrado na Figura 2.11, francamente na estrutura aterrada da linha, ou no meio vão da mesma, a corrente de descarga viaja pelos condutores de blindagem até se deparar com as estruturas aterradas e se descarregar no solo. Ao mesmo tempo se estabelecem elevados níveis de sobretensões no topo das torres e nas cadeias de isoladores que sustentam os condutores das fases separando-os eletricamente da estrutura metálica da linha.

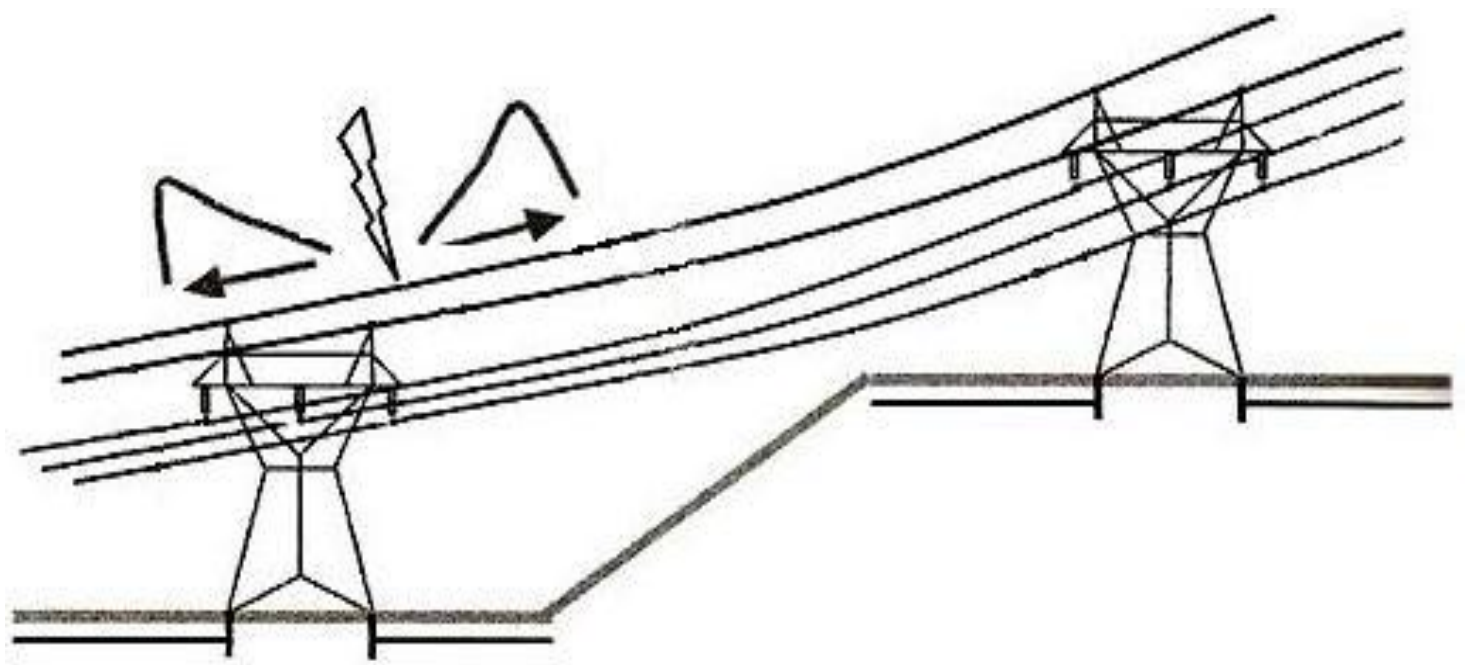

Figura 2.11: Linha de transmissão atingida em seus condutores de blindagem por uma descarga atmosférica direta [adaptada de (VISACRO, 2005)].

Assim como para um flashover, a amplitude da sobretensão originada pela ocorrência de um backflashover é dada aproximadamente pelo produto entre a amplitude da onda de corrente e a impedância de surto da linha. Quando a sobretensão advinda do backflashover em uma linha de transmissão, como a da Figura 2.11, atinge os componentes do sistema de 
aterramento sua onda sofre uma reflexão, caracterizando o fenômeno da propagação de ondas em descontinuidades. A amplitude desta onda de sobretensão refletida é intensamente dependente da relação entre a impedância da linha e a impedância do sistema de aterramento, sendo seu coeficiente de reflexão $\left(\Gamma_{r}\right)$ e a relação entre a tensão refletida $\left(V_{r}\right)$ e a tensão incidente $\left(V_{i}\right)$ dados pelas equações (2.4) e (2.5) (ZANETTA, 2003).

$$
\begin{gathered}
\Gamma_{r}=\frac{Z_{2}-Z_{1}}{Z_{2}+Z_{1}} \\
V_{r}=\Gamma_{r} V_{i}
\end{gathered}
$$

Em que $Z_{1}$ representa a impedância da linha e $Z_{2}$ a impedância do sistema de aterramento.

Ainda neste contexto, a tensão refletida no topo da linha de transmissão é obtida pela sobreposição das ondas incidente e refletida como ilustrado na Figura 2.12. Por meio desta figura, depreende-se que há reflexão total da onda incidente para a condição em que $\Gamma_{r}=-1 \mathrm{e}$ também se constata um atraso entre tais ondas igual ao dobro do tempo de transito, representado por $\tau$. Não obstante, a onda de sobretensão total resultante chega ao topo da estrutura aterrada estabelecendo o valor final da sobretensão, que é imposto entre a estrutura aterrada e os condutores energizados.

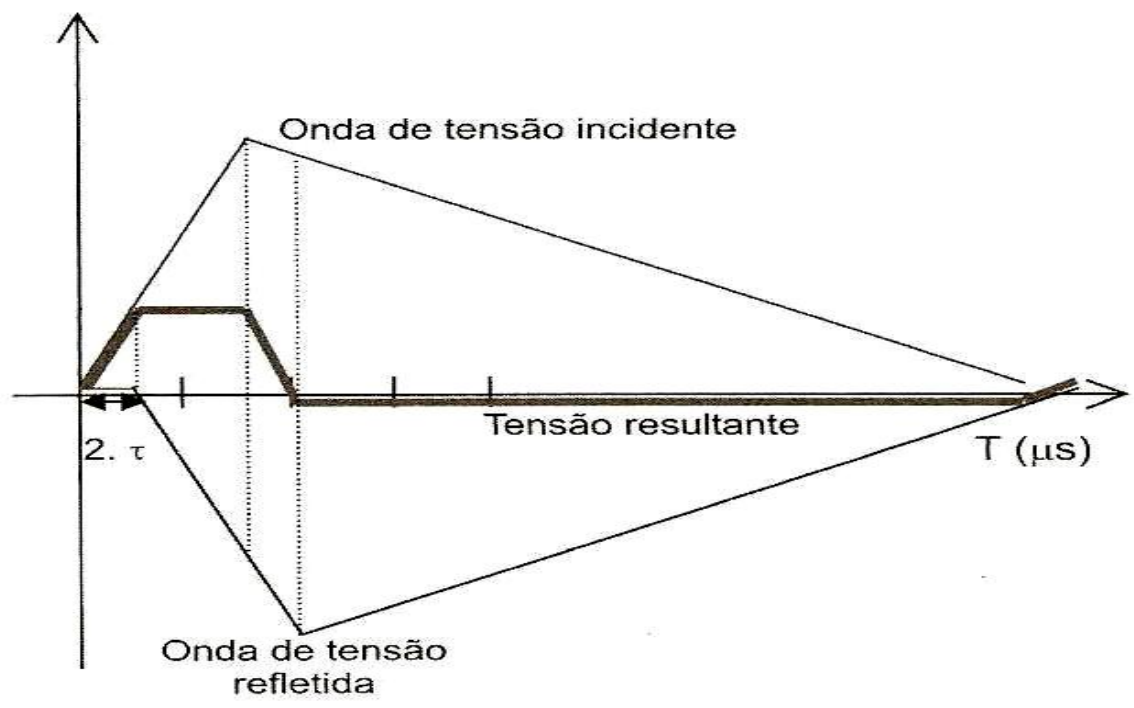

Figura 2.12: Representação da reflexão da onda de tensão e determinação da onda resultante no topo da torre [adaptada de (VISACRO, 2005)]. 
Ressalta-se que o efeito da reflexão da tensão na base da estrutura aterrada é o mais significativo dentre os diferentes efeitos relacionados às reflexões que podem suceder nos condutores de blindagem, nos eletrodos de aterramento e nas estruturas próximas a linha. Além disso, em estudos de proteção, a análise dos efeitos das sobretensões originadas pelo backflashover sobre a cadeia de isoladores recebe maior importância, pois segundo os mesmos observa-se que a impedância de aterramento tem grande influência na sobretensão estabelecida nos terminais da cadeia de isoladores. Nestas situações, em geral, as concessionárias de energia adotam a redução da resistência de pé de torre a fim de reduzir a amplitude desta sobretensão e a frequência de ocorrência das descargas disruptivas de retorno (SOARES Jr, 1996).

\subsubsection{3 - Incidência Direta em Condutor de Blindagem a Meio Vão}

Outro mecanismo de ruptura do isolamento relacionado à incidência de uma descarga atmosférica direta ocorre quando há incidência nos condutores de blindagem no meio do vão entre duas torres de transmissão que possuem vãos muito extensos, como mostrado na Figura 2.13. Neste tipo de situação é gerada uma sobretensão entre os condutores de blindagem e os condutores fase energizados muito superior a sobretensão nas cadeias de isoladores devido à incidência direta sobre os componentes da torre. Sobretensão esta, a qual pode ser três a quatro vezes maior que à sobretensão na cadeia de isoladores, causando a ruptura do isolamento do ar entre os condutores fase e os de blindagem.

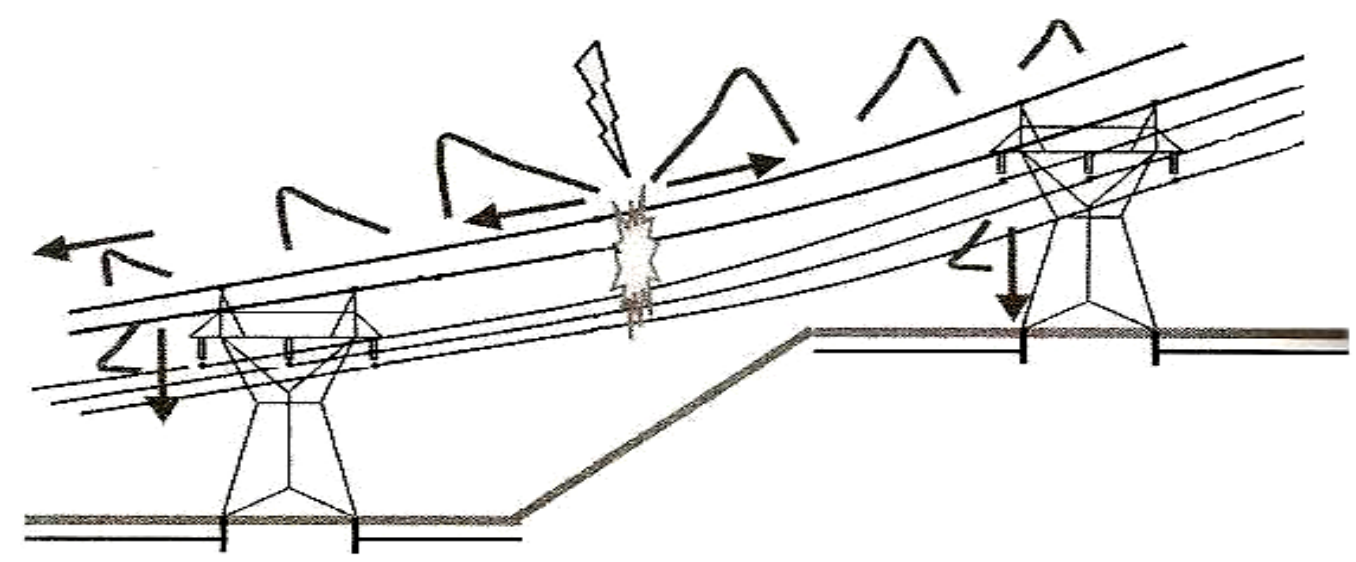

Figura 2.13: Descarga direta em um condutor de blindagem a meio vão entre duas torres de transmissão de energia [adaptada de (VISACRO, 2005)]. 
O valor de amplitude da sobretensão neste caso se deve ao fato de a incidência da descarga ocorrer em um ponto bastante distante do ponto de aterramento da linha, o que faz com que a onda de tensão negativa refletida demore muito para alcançar o ponto de incidência da descarga. Isto faz com que a onda de sobretensão resultante alcance seu valor de pico antes do efeito da onda negativa de tensão, estabelecendo uma grande solicitação, até mesmo em situações em que as correntes de descarga possuam pequenas amplitudes. Nestas circunstâncias a impedância de aterramento tem pouca influência sobre a máxima sobretensão estabelecida, e a medida mais adequada para amenizar o surgimento de tais sobretensões é a diminuição da distância entre os condutores fase e o condutor de blindagem.

Como exemplo, em uma linha que possui $900 \mathrm{~m}$ de comprimento entre duas torres sucessivas e na qual ocorre a incidência de uma descarga a meio vão, o retorno da onda de tensão refletida aconteceria após aproximadamente $3 \mu \mathrm{s}$. Sendo assim, para qualquer descarga cuja corrente tenha tempo de frente inferior a $3 \mu$ s a sobretensão resultante a meio vão atingiria o valor de crista da onda incidente (VISACRO, 2005).

Por fim, adverte-se que este tipo de ocorrência de sobretensão é mais comum em linhas de transmissão de alta tensão localizadas em relevos montanhosos nos quais se faz necessário a instalação de torres bastante elevadas e com grandes vãos entre torres adjacentes.

\subsection{2 - Características Pertinentes a Incidência Indireta de Descargas Atmosféricas}

As descargas indiretas, ou próximas, são descargas que caem nas regiões adjacentes às linhas, como ilustrado pela Figura 2.14, e que podem causar prejuízos às mesmas por meio do surgimento de tensões induzidas. Estas tensões são fruto do campo eletromagnético causado pela corrente de descarga de retorno, o qual se irradia atingindo os cabos fase energizados, cabos de blindagem, para-raios, e demais componentes das redes de energia.

A irradiação deste campo eletromagnético pode causar efeitos como interferência eletromagnética ou o surgimento de tensões induzidas, estando à intensidade dos mesmos condicionada pela taxa de crescimento da corrente de retorno na frente de onda ou pelos seus parâmetros associados (VISACRO, 2005). 


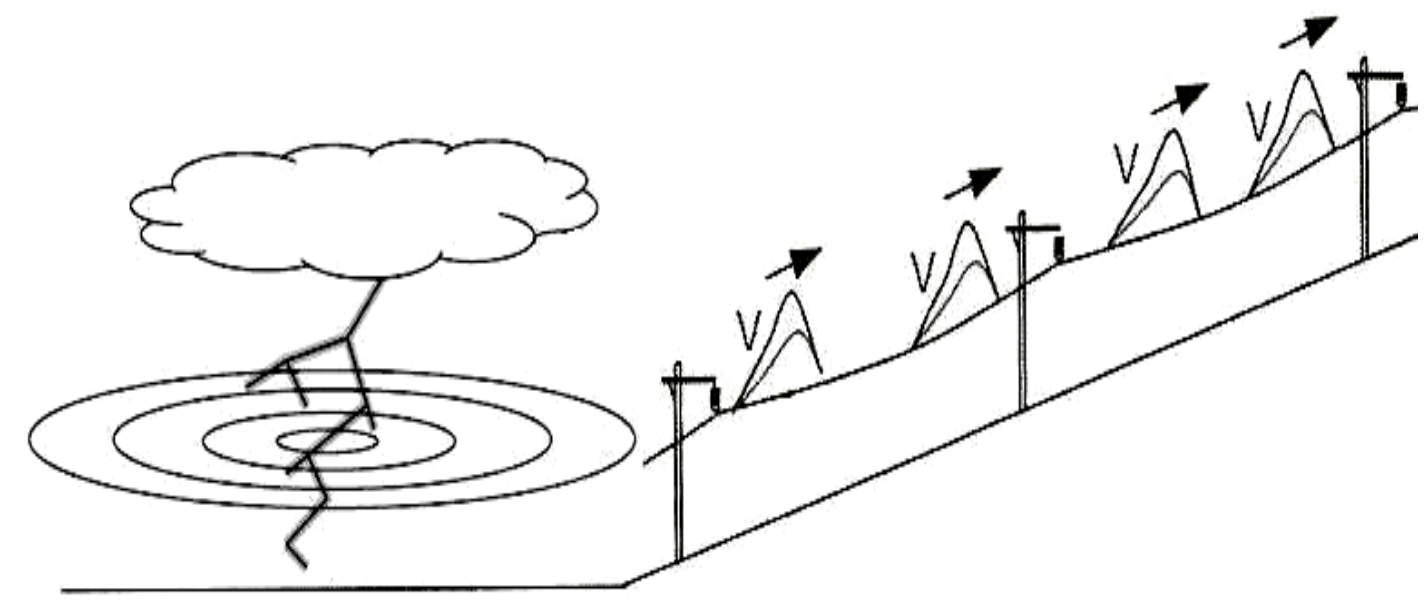

Figura 2.14: Representação de uma linha de distribuição afeta pelo campo eletromagnético gerado por uma descarga atmosférica indireta [adaptada de (VISACRO, 2005)].

A amplitude da tensão induzida é influenciada por vários fatores dentre os quais se destacam: a intensidade da corrente de descarga, o tempo de frente da onda de corrente, a velocidade de propagação da corrente no canal de descarga, a distância relativa entre o ponto de incidência e a linha, a resistividade do solo, a altura da nuvem, e a altura da linha, além da configuração e de outros parâmetros da rede (VISACRO, 2005; SILVEIRA, 2006).

As sobretensões induzidas por descargas indiretas são mais comuns em redes de distribuição uma vez que estas redes normalmente encontram-se protegidas naturalmente de descargas diretas por edificações, torres, árvores e obstáculos elevados ao redor de suas estruturas. Sendo assim, as descargas deste tipo são as grandes causadoras de falhas, desligamentos não programados e interrupções de energia, que afetam consumidores de média e baixa tensão conectados as redes de distribuição.

Segundo (BRAGA, 2009) o nível básico de isolamento (NBI) das linhas de distribuição de média tensão é relativamente baixo se comparado com o das linhas de transmissão, uma vez que varia entre $95 \mathrm{kV}$ e $170 \mathrm{kV}$. Em virtude deste fato, as descargas indiretas originam sobretensões acima do tolerável para estas linhas, já que causam sobretensões induzidas com valor máximo em torno de $300 \mathrm{kV}$.

Posto isto, no contexto das análises pleiteadas por esta pesquisa a respeito das tensões induzidas por descargas indiretas, no próximo capítulo será realizado um estudo aprofundado sobre estas tensões, bem como dos fenômenos relacionados ao seu estabelecimento. 


\section{7 - Considerações Parciais a Respeito das Descargas Atmosféricas}

A fim de proporcionar um embasamento consistente para o desenvolvimento das etapas subsequentes desta pesquisa, no presente capítulo foram apresentados os principais fundamentos e princípios sobre o elemento essencial para o surgimento das tensões induzidas avaliadas, ou seja, sobre as descargas atmosféricas. Tais conceitos são fundamentais para estimar a severidade de fenômenos solicitantes em sistemas elétricos em virtude da ocorrência de descargas diretas e indiretas, e essenciais para a decisão das práticas de proteção mais adequadas ao sistema sob análise.

A exposição de definições básicas correlatas às descargas, de considerações a respeito da formação das cargas nas nuvens, da concepção dos raios, e do desenvolvimento de descargas entre nuvem e o solo, permitiram a formação de uma base conceitual inicial sobre o fenômeno analisado. Além disso, dentre os fatores apresentados destaca-se a caracterização dos parâmetros da corrente de descarga, pois esta corrente é utilizada durante a seleção das características de proteção dos para-raios. Em conjunto com seus modelos, esta corrente é de importante para a determinação do acoplamento entre a linha e o canal de descarga durante o processo de modelagem das tensões induzidas, como será visto no Capítulo 3.

Os níveis de incidência de descargas por região também são importantes para o cálculo da densidade de raios, a qual auxilia na definição da classe de tensão do para-raios e consequentemente na sua seleção. Já os tipos de incidência e suas características revelam suas contribuições ao demonstrar o porquê do estudo da incidência de descargas indiretas em linhas de distribuição.

Dessa forma, conhecidos os conceitos e fundamentos do fenômeno causador das tensões induzidas no contexto desta pesquisa, cabe a partir de agora o estudo de elementos relacionados às mesmas e necessários para sua modelagem, implementação e simulação nos capítulos subsequentes. 


\section{CAPÍTULO 3}

\section{FUNDAMENTOS E MODELOS CORRELATOS ÀS TENSÕES INDUZIDAS POR DESCARGAS ATMOSFÉRICAS}

No presente capítulo, inicialmente será realizada uma breve revisão bibliográfica e histórica sobre alguns dos principais estudos e pesquisas relacionadas às tensões induzidas, e em seguida será descrito o modo de formação das mesmas e serão comentados alguns de seus fundamentos mais importantes para esta pesquisa. Posteriormente serão delineados e expostos os conceitos relativos à corrente de retorno e seus modelos mais significativos, bem como os mecanismos de estabelecimento do acoplamento entre linha e canal de descarga e seus principais modelos. Por fim, serão comentados de forma resumida os parâmetros centrais que influenciam a amplitude e forma de onda da tensão induzida.

\section{1 - Revisão Bibliográfica e Histórica}

Em Wagner (1908, apud RUSCK, 1957) apresenta-se um dos primeiros modelos com a finalidade de calcular as tensões induzidas em linhas de energia elétrica devido às descargas atmosféricas. Neste modelo considera-se que as tensões induzidas são causadas pela propagação de cargas elétricas induzidas nos condutores da linha durante o processo de eletrificação das nuvens. Estas tensões são calculadas por meio da multiplicação da altura da linha pelo campo elétrico vertical antes das descargas, e seus tempos de frente e de cauda são determinados pela variação do campo elétrico vertical.

Já em Bewley (1929) são expostos os resultados de novas pesquisas e ensaios avaliando o modelo proposto por Wagner (1908) e sugerindo seu ajuste por meio da introdução do tempo de liberação das cargas elétricas, acarretando no aumento dos tempos de frente e de cauda da tensão induzida. 
Prosseguimento com estas pesquisas, em Wagner e Mccann (1942) é proposto um novo modelo que serviu de base para os modelos atuais, segundo o qual a tensão induzida é calculada a partir do campo elétrico gerado pelas cargas no canal de descarga de retorno aplicando as equações de Maxwell. No mesmo a forma de onda da corrente é assumida como um degrau, considerando o canal de descarga carregado com densidade de carga uniforme, e admitindo a velocidade da descarga de retorno constante.

Como continuação, em Golde (1954) são adicionadas melhorias ao modelo desenvolvido por Wagner e Mccann (1942) visando aproximar as características do modelo às condições reais. Para tanto, admite-se e implementa-se o decaimento exponencial da densidade de cargas ao longo do canal de descarga com a altura, e ao considerar a velocidade de propagação da descarga de retorno com o tempo, procurando aproximar as características do modelo as condições reais.

Em Rusck (1957) é publicado o trabalho sobre tensões induzidas de maior aceitação até os dias atuais, também baseado no modelo de Wagner e Mccann. O Modelo de Rusck se fundamenta no cálculo da integral do campo elétrico devido às cargas no canal de descarga, configurando o potencial escalar, e no fluxo da corrente de retorno pelo canal, perfazendo o vetor potencial, assumindo algumas simplificações quanto à condutividade do solo e a descontinuidade da linha. Além disso, mesmo empregando algumas simplificações e embora tenham sido desenvolvidos outros trabalhos com ajustes e melhoras a partir deste, o mesmo continua sendo bem aceito e bastante utilizado. Associações renomadas como o CIGRÉ (International Council on Large Electric Systems) (CIGRÉ, 1991) e o IEEE (IEEE, 2004) o adotam como método para o cálculo das tensões induzidas por descargas atmosféricas indiretas.

Em Taylor, Satterwhite e Harrison (1965) é desenvolvido um modelo para cálculo da tensão induzida no domínio da frequência para linhas compostas por dois condutores a partir da influência entre campos eletromagnéticos incidentes e linhas de energia elétrica. Entretanto, para sistemas aéreos o mesmo se aplica apenas a linhas monofásicas com retorno pela terra, a qual deve ser considerada um dos condutores do sistema neste caso.

Em Chowdhuri e Gross (1967) é apresentada outra formulação para o cálculo de tensões induzidas por descargas indiretas no domínio do tempo expressa em função das tensões induzida e indutora na linha, ao invés de se basear nos potenciais escalares totais induzidos e indutores, como havia sido feito por Rusck. 
Não obstante, em Agrawal, Price e Gurbaxani (1980) é equacionado um modelo no domínio do tempo para calcular as tensões induzidas em linhas aéreas com múltiplos condutores sob influência de um campo eletromagnético não-uniforme.

Em Eriksson, Stringfellow e Meal (1982) são expostos os resultados de estudos de medições de sobretensões induzidas realizadas em uma linha trifásica experimental instalada na África do Sul, segundo os quais no transcorrer de dois anos de medição foram aferidas 300 sobretensões superiores a $12 \mathrm{kV}$ e foram identificadas mais de 20 descargas diretas. Além disso, de acordo com os autores somente em uma situação as sobretensões induzidas na linha ultrapassaram o valor máximo de $300 \mathrm{kV}$, o que indicava que a uso de níveis de isolamento superiores a $300 \mathrm{kV}$ praticamente anularia o acontecimento de disrupções devido à sobretensões induzidas em redes com características similares à avaliada.

Ao mesmo tempo, em Anderson (1982) são apresentados os resultados de seus estudos sobre desempenho de linhas de transmissão frente a descargas atmosféricas no capítulo 12 de um dos mais importantes documentos da área, intitulado Transmission Line Reference Book, e publicado pelo EPRI (Electric Power Research Institute).

Em Yokoyama et al. (1986) são evidenciados os resultados de três anos de medição de tensões induzidas em uma linha experimental com dois condutores fase e um cabo de blindagem. Como resultados foram identificadas vinte e quatro formas de onda de tensões induzidas geradas por descargas incidindo em duas torres próximas a linha, Também foi avaliada a influência que o aterramento do cabo de blindagem poderia causar nas tensões induzidas nos demais condutores, e foi analisada a relação entre o aterramento e a magnitude das tensões induzidas em diferentes pontos da linha.

Em CIGRÉ (1991) é publicado um relatório elaborado durante seis anos pelo Grupo de Trabalho 33.01, responsável pela área de descargas atmosféricas, pertencente à Comissão de Estudos 33, que desenvolve pesquisas na área de sobretensões e coordenação de isolamento. Este documento é um dos mais completos da área, é composto por dados de medição e parâmetros de descargas; avaliação da densidade e incidência de descarga, e da blindagem de linhas; e ainda contém representações de modelos e estudos sobre backflashover em linhas de transmissão.

Em Rachidi (1993) é divulgado um novo modelo para cálculo da tensão induzida no domínio da frequência cuja formulação é bastante semelhante à apresentada por Taylor et al. (1965) e Agrawal et al. (1980), mas que possuía funções forçantes definidas em termos do campo de excitação magnético. Ressalta-se que as funções denominadas forçantes representam fatores que afetam os componentes de um determinado modelo em que são 
empregadas, mas não são afetadas por eles, simulando um fluxo ou estoque externo impulsionador do sistema com o qual se relaciona, sendo concebidas geralmente na forma de equações.

Concomitantemente, em Barker et al. (1993) é desenvolvido um estudo de monitoramento das tensões e correntes de origem atmosféricas incidentes sob os para-raios de uma rede de distribuição por meio da instalação de registradores digitais, com os quais foram coletadas mais de 1300 amostras da forma de onda da corrente e da tensão. Dentre as ondas de corrente registradas aproximadamente $90 \%$ apresentaram valores de pico entre 0,3 e 2,6 kA, sendo a maior amplitude de corrente medida de $28 \mathrm{kA}$. Também, notou-se que nenhum dos para-raios monitorados registrou algum tipo de falha e não excedeu seu valor máximo de energia absorvida, delimitado em $12,6 \mathrm{~kJ}$, registrando um valor inferior a $1 \mathrm{~kJ}$ em $98 \%$ dos casos.

Em Paulino (1994) é apresentada uma metodologia para o cálculo de tensões induzidas por descargas atmosféricas em redes de distribuição aplicando o Modelo de Rusck (1957), validando seus resultados a partir da comparação com dados obtidos por medições reais. Além disso, em sua tese é estimado o desempenho de uma linha frente às tensões induzidas e é exposto um estudo de melhoria considerando a instalação de para-raios ao longo da linha, a adoção de cabos para-raios, o nível de isolamento das estruturas, e o aterramento do neutro.

Em Barker et al. (1996) são mostrados os resultado de uma pesquisa com o intuito de medir simultaneamente as correntes de descarga e as tensões induzidas em uma linha experimental empregando a técnica Rocket-Triggered Lightning para simular descargas atmosféricas próximas a linha sob análise. Neste estudo também foram aferidos os campos elétricos e magnéticos gerados e o tempo de frente das correntes de descarga, e ainda foram coletados dados de 63 correntes de descarga e de tensões induzidas. Com estes dados concluiu-se que o valor de pico das tensões induzidas era $63 \%$ maior do que o previsto pela teoria de Rusck, e os valores de pico das tensões medidas situaram-se na faixa entre $8 \mathrm{kV}$ e $100 \mathrm{kV}$, correspondendo a correntes de descarga com valores máximos entre 4 kA e $44 \mathrm{kA}$, respectivamente.

Pouco depois, o trabalho produzido em conjunto pelo CIRED/CIGRÉ (1997) (Congrès International des Réseaux Electriques de Distribution / International Council on Large Electric Systems) sobre proteção de redes de média e baixa tensão contra descargas atmosféricas analisa a ocorrência de sobretensões em redes secundárias devido a descargas diretas e indiretas utilizando para as simulações o programa LIOV/EMTP (Lightning Induced 
Over-Voltage / Electromagnetic Transients Program). Por meio do mesmo averígua-se que as tensões induzidas em redes de baixa tensão apresentam valores mais baixos que aqueles encontrados na rede primária devido à presença do condutor neutro, o qual é aterrado em vãos regulares. Também se constata que a tensão induzida no condutor neutro é limitada pelo aterramento e que a mesma atinge seu valor de pico a meio vão, já que os aterramentos se localizam nas extremidades da linha. Ademais, verifica-se que a tensão induzida no condutor fase é igualmente restringida em valores baixos devido ao elevado acoplamento entre os condutores e o neutro.

Simultaneamente, em Jankov (1997) é desenvolvido um estudo sobre os parâmetros que afetam a máxima tensão induzida em linhas aéreas devido a descargas próximas e propõem-se uma equação para o cálculo dessa tensão. Com esta equação efetua-se uma análise comparativa das máximas tensões induzidas em função da altura, da velocidade de descarga de retorno, e da distância do ponto de incidência até a linha para variações no tempo de frente e de queda da onda de corrente.

Em Nucci e Rachidi (1999) é apresentada uma pesquisa com os principais questionamentos relacionando tensões induzidas por descargas atmosféricas e suas respectivas conclusões até aquele momento segundo diversos trabalhos existentes na literatura correlata. As mais importantes conclusões apresentadas indicam que a primeira corrente de retorno é a maior responsável pela tensão induzida por causa de sua maior irradiação eletromagnética, e que a magnitude desta tensão depende expressivamente dos parâmetros da corrente de retorno, da distância, da posição relativa e da configuração da linha. Ainda apontam que a distância de abrangência em que pode haver desligamentos por tensões induzidas depende da severidade da descarga, da configuração da linha, da condutividade do solo e do nível de isolamento, e que a instalação de cabos para-raios pode reduzir a magnitude da tensão induzida de 20 a $40 \%$.

Em Martinez, Gonzalez-Molina e Chowdhuri (2000) são expostos os resultados da comparação de vários métodos utilizados para cálculos de taxas de desligamentos de linhas de distribuição frente a descargas atmosféricas diretas e indiretas. São analisadas a presença e ausência de cabos blindados admitindo-se a resistividade do solo ideal, e é demonstrado que a velocidade da corrente de retorno também pode influenciar no desempenho de linhas de distribuição.

A seguir, em Silva (2001) é implementada uma rotina para cálculo de tensões induzidas por descargas atmosféricas indiretas através do programa de cálculo de transitórios eletromagnéticos EMTP baseada no Modelo de Rusck por meio da utilização de fontes de 
corrente distribuídas ao longo da linha sob análise. Além disso, com a finalidade de validar seus resultados foram realizadas simulações empregando o modelo desenvolvido e comparadas com dados obtidos por Yokoyama et al. (1985) e Barker et al. (1996).

Em Piantini e Janiszewski (2003) é desenvolvida uma nova metodologia para cálculo de tensões induzidas baseada no Modelo de Rusck com alguns ajustes, denominada Modelo de Rusck Estendido. Em sua formulação é considerado o efeito do comprimento finito do canal da descarga e da linha sob análise no cálculo dos campos eletromagnéticos, além de ser possível o estudo de descargas ascendentes com sua aplicação, mas ainda admite-se o solo como um condutor perfeito.

Em Pokharel, Ishii e Baba (2003) é mostrado um modelo para estimação da tensão induzida empregando o código NEC (Numerical Electromagnetic Code). Com o mesmo se pode assumir o solo como um condutor perfeito ou como um meio de condutividade finita, calcula-se a distribuição de corrente e o acoplamento eletromagnético entre canal e linha em conjunto, trabalha-se com os parâmetros no domínio da frequência.

Em Thomazella (2004) apresenta-se o desenvolvimento de uma ferramenta computacional para análise e estimação de tensões induzidas em linhas de distribuição, empregando o software ATP (Alternative Transients Program) em conjunto com uma rotina desenvolvida em Visual Basic. Para tanto, foi implementado o Modelo de Rusck no ATP fazendo uso da subrotina existente na versão MICROTRAN (MICROTRAN, 1991) do EMTP denominada de CONNEC, pois com a mesma foi possível usar o método da compensação para tratar os elementos não lineares.

Logo após, em Visacro e Soares Jr. (2005) é exposta a formulação do modelo HEM (Hybrid Electromagnetic Model) por eles elaborado para cálculo de tensões induzidas no domínio da frequência. Este modelo foi estabelecido a princípio para análise de aterramentos, mas foi aprimorado para ser capaz de reproduzir a evolução do envelope de corona, calcular o acoplamento eletromagnético nos trechos de linha, e variar a velocidade de propagação da onda de corrente no canal de descarga.

Em Conti (2006) é apresentado um novo modelo de corrente de retorno chamado de DNUTL (Dynamic Non-Uniform Transmission Line Model), que é capaz de representar o canal de descarga como uma linha de transmissão não uniforme com parâmetros variáveis no tempo. Com este modelo foram realizadas análises a fim de identificar a influência da variação temporal e espacial da resistência e da capacitância do canal na propagação da corrente de retorno, nos campos eletromagnéticos associados e também em tensões induzidas em linhas aéreas. Além disso, em sua dissertação foi implementada uma metodologia para o 
cálculo de tensões induzidas no domínio do tempo adotando o modelo de acoplamento de Taylor/Agrawal e empregando o software ATP, com a finalidade de estimar a influência de diversos parâmetros nas tensões e correntes resultantes em um sistema de distribuição típico. Através dos resultados obtidos foram analisados os efeitos de descargas diretas e indiretas no sistema avaliado e foi feita uma caracterização do desempenho de para-raios de média tensão em termos da corrente e energia associadas.

A seguir, em Silva Neto e Piantini (2007) é desenvolvido um estudo sobre as características das sobretensões geradas por descargas atmosféricas próximas a uma linha de distribuição de baixa tensão, utilizando o modelo ERM (Extended Rusck Model) para cálculo das tensões induzidas. Além disso, foi avaliada a influência de alguns parâmetros sobre a amplitude e forma de onda da tensão induzida, tais como: altura do condutor fase, posição do ponto de incidência da descarga e do ponto de medição da tensão induzida, distância entre os pontos de aterramento do condutor neutro, e o comprimento do ramal de ligação.

Ao mesmo tempo, em Borghetti, Nucci e Paolone (2007) é demonstrado um procedimento para avaliação de desempenho de linhas aéreas de distribuição definido a partir da estimativa do número anual de descargas induzidas por flashovers em relação à tensão crítica de flashovers nos isoladores da linha, comparando o método proposto com o adotado pelo Guia IEEE Std. 1410 (IEEE, 2004). Observa-se neste trabalho que os dois processos diferem-se principalmente nos modelos adotados para avaliar as tensões induzidas e na aproximação estatística da corrente de pico de descarga. Também é nota-se que o procedimento do IEEE usa a fórmula simplificada de Rusck enquanto a metodologia proposta emprega um método denominado LIOV-MC, que se baseia na aplicação do método de Monte Carlo e do programa LIOV.

Concomitantemente, em Barbosa e Paulino (2007) é proposta uma melhoria ao Modelo de Rusck ao implementar em sua formulação a consideração da condutividade finita do solo, resultando em uma expressão no domínio do tempo que possibilita o cálculo do campo elétrico radial devido à descarga de retorno. Além disso, em virtude desta formulação se basear em funções elementares o campo elétrico pode ser calculado de maneira relativamente simples em diferentes pontos ao longo da linha, o que a torna uma ferramenta muito conveniente para o cálculo de tensões induzidas. Os resultados obtidos com a aplicação desta metodologia confirmam-se em comparações com dados obtidos em estudos desenvolvidos por Rubinstein (RUBINSTEIN, 1996).

Em Paulino et al. (2010) é apresentada uma formulação para estimação da tensão induzida em uma linha infinita considerando a influência da resistividade do solo, baseando- 
se no Modelo de Rusck (RUSCK, 1957) para computar o campo elétrico vertical, em (BARBOSA; PAULINO, 2007) e (BARBOSA et al., 2008) para calcular o campo elétrico horizontal, e em (AGRAWAL, 1980) para avaliar o acoplamento eletromagnético. Ademais, os resultados obtidos são comparados com os dados experimentais expostos em (BARKER et $a l .$, 1996) para fins de validação. Também é apresentada uma extensão da metodologia proposta no Guia IEEE Std. 1410 (IEEE, 2004) para incluir o efeito da condutividade finita do solo na avaliação do desempenho de linhas de distribuição devido à incidência de descargas próximas.

Em Paulino et al. (2011) é exposta uma nova formulação aproximada com ajustes e melhorias para estimar o valor de pico da tensão induzida por descargas atmosféricas em linhas infinitas. Para este fim considera-se a resistividade do solo e adota-se a corrente de retorno em uma forma trapezoidal com tempo de frente de $3,8 \mathrm{~s}$ e velocidade de propagação de $120 \mathrm{~m} / \mathrm{s}$. A nova fórmula é utilizada em uma abordagem probabilística e seus resultados são comparados com dados teóricos e experimentais disponíveis em (BORGHETTI et al., 2007) e (ERIKSSON et al., 1982), os quais mostram sua concordância e eficiência na aplicação da forma de onda trapezoidal.

Por fim, em Mota (2011) é apresentada uma metodologia para cálculo das sobretensões induzidas baseada no Modelo de Rusck (RUSCK, 1957), a qual é implementada no software ATP e seus resultados são comparados com medições realizadas por Barker et al. (1996) a fim de validá-los. Além disso, são realizadas análises da propagação da tensão induzida por uma linha de transmissão e da influência de alguns parâmetros em sua amplitude e forma de onda.

\section{2 - Formação das Tensões Induzidas por Descargas Indiretas}

O processo de formação de tensões induzidas por descargas indiretas, segundo Visacro (2005), é descrito por um processo que se inicia com a conexão dos canais ascendente e descente da descarga, a partir da qual passa a fluir uma corrente pelo canal de descarga gerando um campo eletromagnético que atinge a linha e demais obstáculos próximos ao seu ponto de incidência. Ressalta-se que a distribuição desta corrente pela 
extensão do canal de descarga e seu desenvolvimento no tempo estão sujeitos a vários fatores, que incluem as características do canal nos períodos que antecedem esta conexão e de aspectos dinâmicos. Além disso, a princípio somente os elementos do canal de descarga adjacentes ao ponto de acoplamento contribuem com a intensidade do campo eletromagnético estabelecido. Entretanto, à medida que a corrente se desloca pela linha novos elementos passam a contribuir para o mesmo, observando-se, contudo, os atrasos em virtude do tempo de propagação entre a localização do elemento no canal e a linha. Dessa forma, o campo formado passa a atingir toda a linha com o transcorrer do tempo, estabelecendo em cada ponto da mesma uma sobretensão que se propaga em conjunto com uma sobrecorrente adjunta. Posto isto, a tensão induzida em cada ponto da linha pode ser definida de forma simplificada como a solução do cálculo da integral do campo elétrico em um percurso vertical entre os condutores e o solo ou entre condutores. Pode-se também fixá-la como o resultado, em determinado ponto, da superposição entre a onda de tensão originada pela influência direta da descarga neste ponto e a onda conduzida por propagação na linha a partir de outros pontos anteriormente irradiados pelo canal de descarga para o ponto em questão.

Ainda a partir de (VISACRO, 2005) depreende-se que a onda de tensão induzida possui tempo de crescimento de frente diretamente relacionado ao tempo de crescimento da onda de corrente da descarga de retorno. Isto se deve ao fato de que após terem atingido seus valores de pico aproximadamente ao mesmo tempo, em seguida a amplitude da variação da corrente decresce substancialmente em comparação com os instantes iniciais da descarga e a tensão induzida decresce rapidamente se anulando depois de um curto período de tempo. A Figura 3.1 demonstra a ocorrência deste acontecimento e evidencia a ampla influência do campo eletromagnético originado durante o intervalo de tempo de frente da onda de corrente.

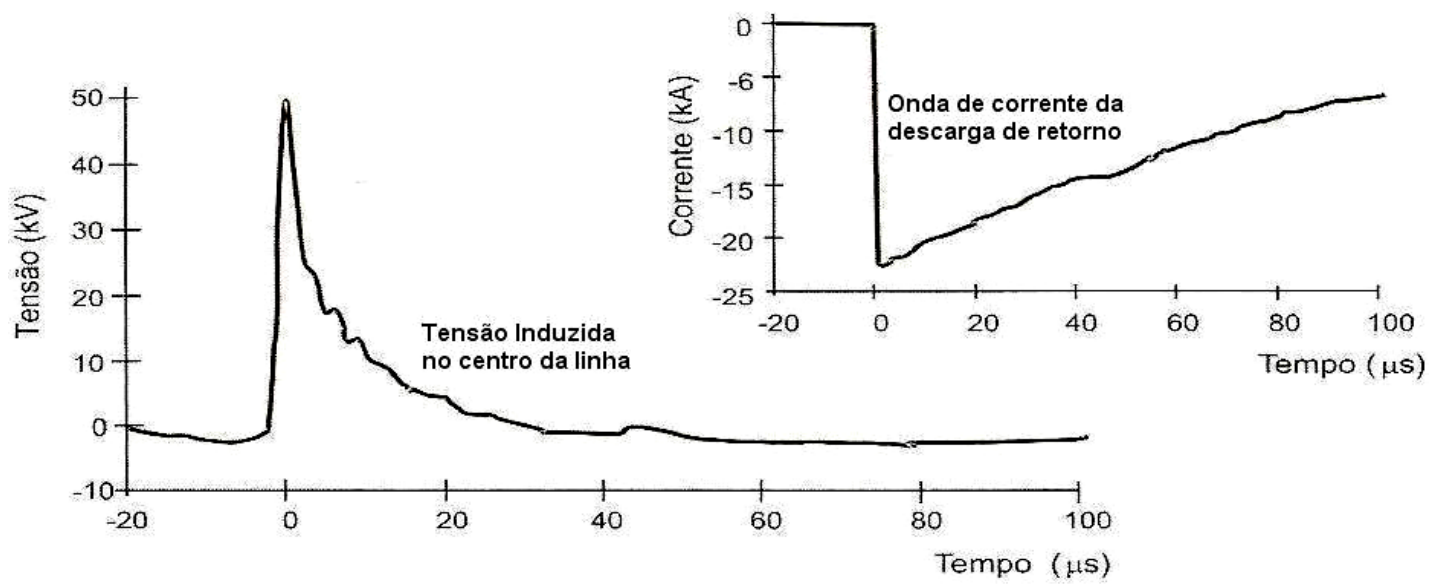

Figura 3.1: Onda de corrente da descarga de retorno e da tensão induzida medidas em uma linha de distribuição experimental (BARKER et al., 1996 apud VISACRO, 2005). 
Cabe enfatizar que as sobretensões geradas por descargas indiretas possuem intensidade menor que as causadas por descargas diretas e tempo de subida ao pico de tensão também menor, mas mesmo assim são capazes de atingir à ordem de centenas de $\mathrm{kV}$ em poucas dezenas de microssegundos. Também se pode destacar que a aproximação do solo como um condutor perfeito implica em menores níveis de sobretensões, ou seja, quanto menor a condutividade do solo, maior será a magnitude da sobretensão.

Para estudos e análises de engenharia as etapas de estabelecimento das tensões induzidas de maior relevância são a fase a partir da qual passa a fluir a corrente de retorno pelo canal de descarga e o momento em que ocorre o acoplamento entre linha e canal de descarga. Logo, o entendimento da ocorrência desse fenômeno requer o estudo da distribuição temporal e espacial da corrente de retorno ao longo do canal de descarga e do acoplamento eletromagnético entre tal canal e os condutores da linha sob apreciação.

Para descrever os parâmetros e características destes dois fatores relacionados à corrente de retorno foram desenvolvidos por diferentes pesquisadores os modelos de corrente de retorno. Os mesmos definem, a princípio, a variação da amplitude e da forma de onda de corrente ao longo do canal de descarga, e terão seus pormenores comentados na seção 3.3 a seguir, bem como, igualmente, serão apresentados os conceitos sobre a dinâmica de estabelecimento da corrente de retorno.

Conhecidos os aspectos relativos à corrente de retorno se faz necessário determinar o campo eletromagnético gerado ao redor do canal de descarga, e para tanto se considera o canal como uma composição de elementos filamentares de corrente. Nesta configuração cada um destes elementos é considerado uma fonte de campo que ao ter seus efeitos superpostos delimitam a região de abrangência do campo eletromagnético incidente estabelecido.

Assim, havendo corpos condutores, como linhas de transmissão e distribuição, nas adjacências do ponto de incidência da descarga o acoplamento eletromagnético entre as linhas energizadas e o canal de descarga passa a ser o responsável pela influência mútua entre os mesmos. O campo eletromagnético gerado leva ao surgimento das tensões induzidas nestes corpos, e consequentemente define a amplitude e forma da tensão induzida originada pela descarga indireta.

Desse modo, devido à sua grande importância para o desenvolvimento de estratégias de simulações de tensões induzidas, os tipos e modelos de acoplamento eletromagnético entre linha e canal de descarga serão expostos com mais detalhes na seção 3.4. 


\section{3 - Corrente de Retorno no Canal de Descarga}

A corrente de retorno apresenta uma variação no tempo bastante rápida, da ordem de microsegundos, gerando um campo eletromagnético intenso que se propaga e interage com os corpos condutores em regiões próximas ao ponto de incidência da descarga, implicando na formação das tensões induzidas. Dessa maneira, devido à importância da corrente de retorno no processo de assentamento da tensão induzida, o seu método de estabelecimento será apresentado a seguir, bem como sua distribuição ao longo do canal de descarga por meios dos modelos de corrente de retorno.

\subsection{1 - Dinâmica de Estabelecimento da Corrente de Retorno}

O entendimento dos procedimentos físicos envolvidos no estabelecimento da corrente no canal de descarga e dos acontecimentos posteriores à conexão dos canais ascendentes e descendentes são fundamentais para formulação dos modelos de corrente de retorno, mas para tanto são necessárias algumas simplificações que serão mencionadas no decorrer desta seção, fundamentada em (VISACRO, 2005).

A explicação deste processo se baseará na Figura 3.2, que ilustra de maneira simples a dinâmica do estabelecimento da corrente de retorno depois da conexão entre os canais ascendentes e descendentes de uma descarga atmosférica negativa descendente. Segundo a mesma, admite-se o canal como sendo uma linha de transmissão vertical onde é injetada uma corrente impulsiva no ponto de conexão entre os canais, e em que o condutor da linha é composto por um núcleo condutivo de plasma que esta envolto em uma camada de corona. Esta camada de corona é gerada pela alta densidade de cargas acumuladas ao longo do canal de descarga envolvendo o núcleo do mesmo, "alimenta" a corrente de retorno promovendo a sua gradual neutralização, e é também denominada de envelope de corona.

O processo se inicia com a formação de duas ondas de corrente de amplitude positiva no ponto de conexão, uma ascendente (onda A) e outra descendente (onda B), as quais se deslocam em direções opostas ao longo do canal, como se vê pelo primeiro passo da Figura 3.2. Cabe lembrar que neste caso admite-se a corrente no sentido do solo para a nuvem como sendo positiva, ou de forma equivalente, assume-se elétrons fluindo para o solo. 


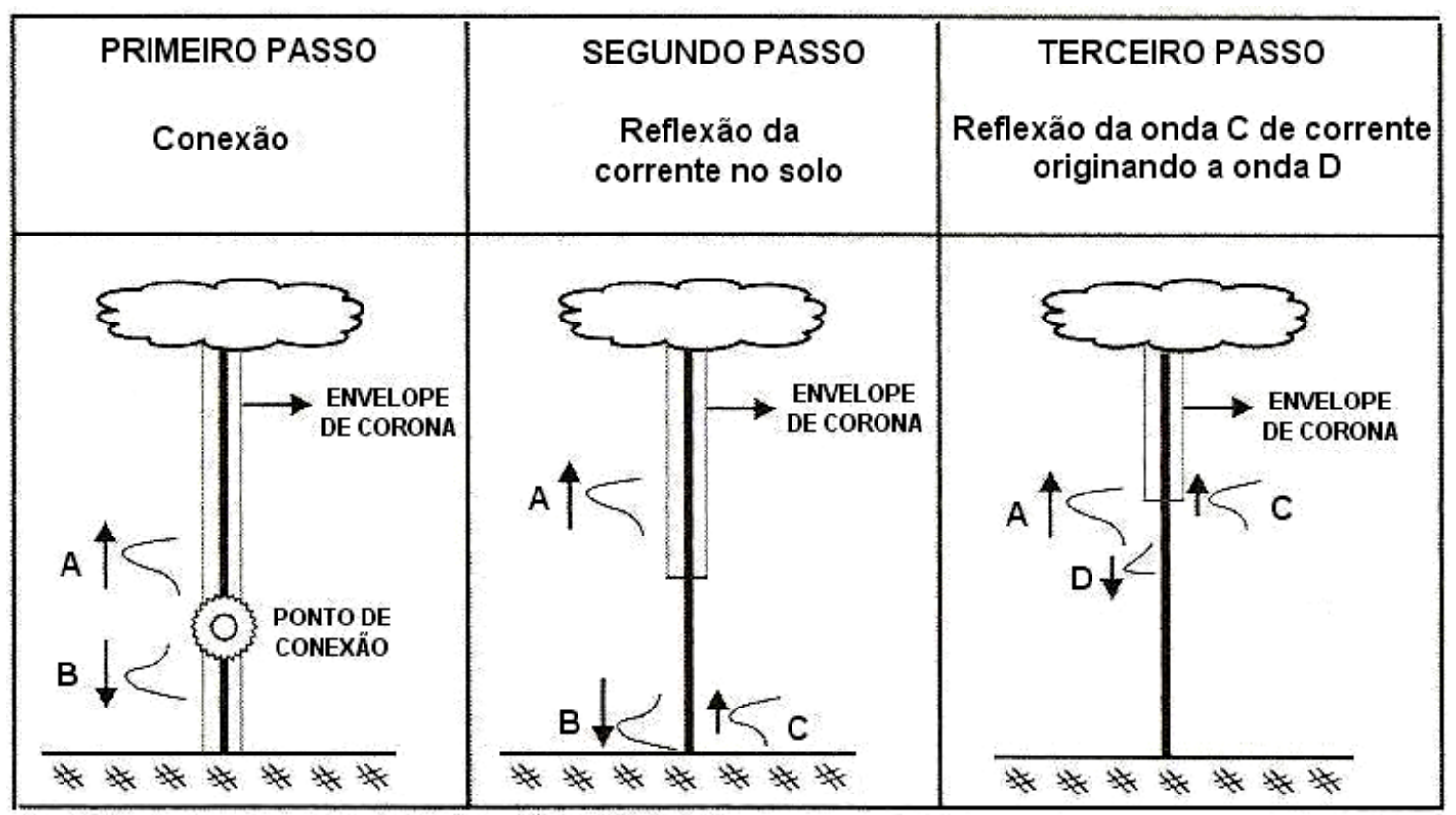

Figura 3.2: Passos iniciais da dinâmica de estabelecimento da corrente de retorno no canal de descarga [adaptada de (VISACRO, 2005)].

Além disso, como mostrado pelo primeiro passo a onda A tem um longo caminho a percorrer até chegar à nuvem, enquanto a onda $\mathrm{B}$ percorre um caminho menor já que o ponto de conexão geralmente ocorre próximo ao solo. Contudo, ambas se deslocam com uma velocidade relativamente reduzida devido à fraca ionização do núcleo do canal e também porque o mesmo ainda encontra-se envolto pelo envelope de corona.

Já de acordo com o segundo passo, ao incidir no solo uma parte da onda B é transmitida, sendo dissipada na terra, e outra parte é refletida dando origem a uma onda $\mathrm{C}$ ascendente positiva assim como a onda A. Esta onda $\mathrm{C}$ se propagará ao longo do canal defasada no tempo em relação à onda $\mathrm{A}$, mas com velocidade maior, uma vez que parte do envelope de corona se dissipou e o núcleo do canal já se encontra mais ionizado. Isto acontece porque com o fluxo das ondas $\mathrm{A}$ e $\mathrm{B}$ ocorre à drenagem das cargas previamente aglomeradas no envelope de corona e a consequente elevação no nível de ionização do núcleo do canal.

Em virtude da diferença de velocidade entre as ondas $\mathrm{A}$ e $\mathrm{C}$ as mesmas se encontraram em um ponto acima do ponto de conexão, no qual a onda $\mathrm{C}$ sofre reflexão, sendo apenas parcialmente transmitida, originado uma nova onda descendente, onda D. A onda $\mathrm{D}$ se propaga com sentido para baixo no canal e depois de um determinado período de 
tempo atinge o solo, sofrendo nova reflexão positiva de corrente e transmissão parcial, como pode ser visto pelo terceiro passo.

A reflexão da onda $\mathrm{C}$ e o surgimento da onda $\mathrm{D}$ acontecem porque as regiões do canal abaixo e acima desse ponto de encontro da onda A com a onda $\mathrm{C}$ apresentam características distintas. Este fato ocorre uma vez que o canal da parte superior ainda esta sob grande influência do envelope de corona, que possui um raio com valor significativo, além de apresentar uma ionização ainda inicial, enquanto o canal da parte inferior encontra-se com núcleo bastante ionizado e seu raio de envelope de corona reduzido.

Estas etapas de reflexão, transmissão e propagação de onda vão se desenvolvendo sucessivamente até que ocorra a extinção da corrente, ficando estabelecida dessa maneira a distribuição da corrente de retorno ao longo do canal de descarga. Cabe destacar que a onda de corrente resultante pode possuir forma e amplitude variadas em função do seu tempo de tráfego, sendo a mesma composta pela superposição das ondas viajantes descritas em qualquer ponto do canal de descarga.

O processo descrito anteriormente é característico da primeira descarga, e para as descargas subsequentes o mesmo se verifica de forma um pouco diferente, pois nestas condições a conexão entre os canais ascendente e descendente acontece muito próxima ao nível do solo. Isto faz com que o canal ascendente praticamente não exista, o que torna bastante simplificada a dinâmica de estabelecimento da onda de corrente de retorno de descargas subsequentes, uma vez que apresentam somente uma onda ascendente e consequentemente não há reflexões. Ademais, em virtude de já ter havido um fluxo de corrente de retorno pelo canal a nova corrente se propaga pelo mesmo em função do elevado nível de ionização e com reduzido valor para o raio do envelope de corona. Tal fato ocorre devido à menor concentração de cargas em relação à primeira descarga, fazendo com que a velocidade de propagação desta corrente seja maior e mais próxima da velocidade da luz.

Dentre as simplificações adotadas no processo acima descrito, destaca-se a consideração da injeção de uma onda de corrente no ponto de conexão entre os canais ascendente e descendente. Isto porque, esta onda que se propaga ao longo do canal de descarga é, na verdade, consequência do descarregamento das cargas acumuladas no envelope de corona ao redor do canal, e não de uma fonte de corrente.

Por fim, outra simplificação importante refere-se à adoção do canal de descarga como um condutor de uma linha de energia elétrica, quando, na realidade, o mesmo é formado por um núcleo de boa condutividade e raio reduzido, envolto pelo envelope de corona. Contudo, este canal possui condutividade bem menor que dos condutores de redes de energia e 
apresenta um comportamento dinâmico no tempo dado pelo nível de ionização do núcleo do canal.

\subsection{2 - Modelos de Corrente de Retorno}

Os modelos de corrente de retorno descrevem a distribuição de corrente ao longo do canal de descarga com a finalidade de estimar a influência da mesma nos sistemas elétricos de potência, e habitualmente são classificados em quatro categorias (RAKOV, 2001), a saber:

- Modelos físicos;

- Modelos de engenharia;

- Modelos eletromagnéticos;

- Modelos de circuitos a parâmetros distribuídos.

Os modelos físicos são fundamentados em equações dinâmicas de gases, as quais representam a conservação da massa, do momento e da energia no canal de descarga. Utilizam como principais parâmetros de entrada e saída a pressão, a temperatura e a resistência do canal, e distinguem-se por serem os modelos mais complexos dentre os quatro citados (RAKOV; UMAN, 1998).

Os modelos de engenharia se caracterizam pela simplicidade adotada em sua formulação e por serem os mais empregados em estudos de modelagem da corrente de retorno. Também se distinguem por definir a forma da mesma em qualquer ponto do canal de descarga e em qualquer instante de tempo de maneira diretamente relacionada à corrente injetada na base do canal através da utilização de funções analíticas (NUCCI et al., 1990; RAKOV; UMAN, 1998). Nestes modelos é analisada a concordância entre os aspetos eletromagnéticos gerados pela distribuição de corrente sem detalhamentos dos aspectos físicos envolvidos, e também são adotas simplificações. Dentre estas simplificações destacam-se a consideração da velocidade de propagação da frente de onda da corrente como constante, a adoção da redução da amplitude da onda de corrente de retorno de forma exponencial, e em alguns casos a desconsideração da atenuação de tal amplitude ao longo do canal.

Os modelos eletromagnéticos caracterizam-se por representarem o canal de descarga como uma antena com perdas formada por um conjunto de dipolos, nos quais a propagação 
da corrente de retorno ao longo do canal é modelada por meio da solução numérica das equações de Maxwell a partir do início do fluxo de corrente. Estes modelos também se diferenciam dos demais por terem maior generalidade de aplicação e por sua aplicação não necessitar da adoção de circuitos equivalentes para descrição do complexo processo das descargas atmosféricas (BABA; ISHII, 2001).

Os modelos de circuitos a parâmetros distribuídos, em sua grande maioria, adotam o canal de descarga como uma linha de transmissão vertical uniforme em sua modelagem. Entretanto, em alguns casos representam o canal como uma linha não uniforme, composta por uma sequência de circuitos cujos parâmetros por unidade de comprimento variam com a altura ao longo do canal (ALMEIDA, 2002; RODÓN et al., 2002). Além disso, nestes modelos são atribuídos valores por unidade de comprimento da linha para alguns parâmetros, tais como resistência, indutância, capacitância e condutância, em função de perdas e da geometria assumida. Utilizando-se os mesmos calcula-se a distribuição da corrente ao longo do canal em função do tempo e da altura, empregando a teoria de ondas guiadas em linhas de transmissão.

Posto isto, conhecidos o processo de formação da corrente de retorno e seus modelos, cabe agora partir para a análise do acoplamento eletromagnético entre linha e canal e de seus modelos empregados em estudos envolvendo o fenômeno das tensões induzidas.

\section{4 - Acoplamento Eletromagnético entre Linha e Canal de Descarga}

Após o estabelecimento da corrente de retorno ao longo do canal de descarga surge um campo eletromagnético que origina ondas de tensão e de corrente, em linhas próximas ao ponto de incidência da descarga, a partir do mecanismo de interação entre linha e canal denominado acoplamento eletromagnético.

Dessa forma, os tipos de mecanismo de acoplamento entre linha e canal de descarga e os principais modelos de acoplamento para cálculo da tensão induzida empregados em implementações e simulações presentes na literatura são apresentados nas seções seguintes. 


\subsection{1 - Tipos de Mecanismos de Acoplamento Eletromagnético}

Para análise e tipificação dos mecanismos de acoplamento é necessário assumir a segmentação do canal e da linha durante o fluxo de corrente ao longo do canal como mostrado na Figura 3.3, na qual o j-ésimo segmento se refere ao canal de descarga e o i-ésimo segmento à linha, considerada nesta situação como um condutor metálico isolado do solo.

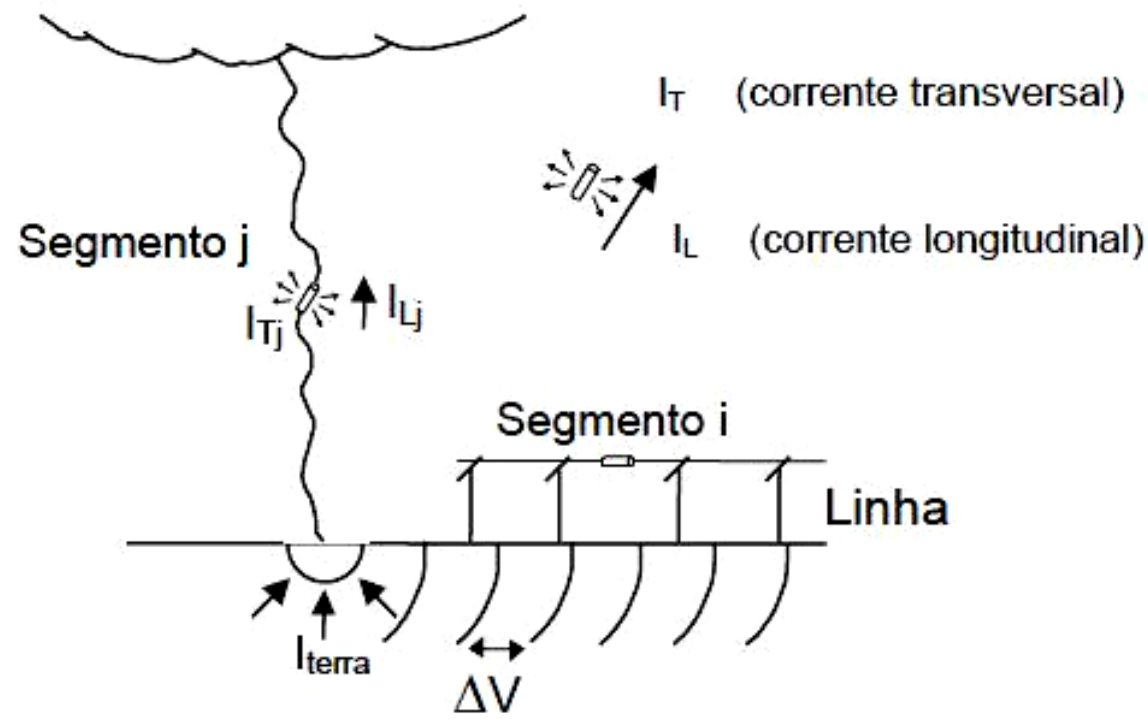

Figura 3.3: Condição inicial para a representação do estabelecimento do acoplamento eletromagnético entre linha e canal de descarga [adaptada de (VISACRO, 2005)].

Dessa forma, baseando-se em (VISACRO, 2005), a seguir, serão descritos os quatro tipos de mecanismo de acoplamento envolvendo campos elétricos e magnéticos entre linha e canal associados à ocorrência de tensão induzida por descargas atmosféricas indiretas, os quais são expostos na Figura 3.4 e subdivididos em:

- Acoplamento elétrico;

- Acoplamento magnético;

- Acoplamento irradiado;

- Acoplamento condutivo.

Acoplamento Elétrico: este mecanismo se forma entre o j-ésimo e o i-ésimo segmentos de duas formas, uma de natureza capacitiva e outra resistiva, porém no ar há ampla predominância do efeito capacitivo. 
Acoplamento Magnético: este tipo de conexão ocorre devido ao fluxo de corrente de retorno pelo canal de descarga fazendo surgir um campo magnético induzido, cujas linhas enlaçam os percursos fechados pelos condutores da linha e da superfície do solo ao seu redor.

Acoplamento Irradiado: este processo de ligação acontece em virtude da variação muito rápida da corrente de retorno no tempo, o que promove o efeito de irradiação associado à propagação de uma onda eletromagnética a partir do canal, a qual ao atingir uma linha induz tensão na mesma.

Acoplamento Condutivo: por meio do desenvolvimento do fluxo da corrente de retorno pelo canal acontecem quedas de tensão de caráter resistivo e indutivo, e instituísse uma continuidade elétrica entre canal e solo promovendo o surgimento do acoplamento condutivo associado ao efeito longitudinal no canal e divergente no solo.

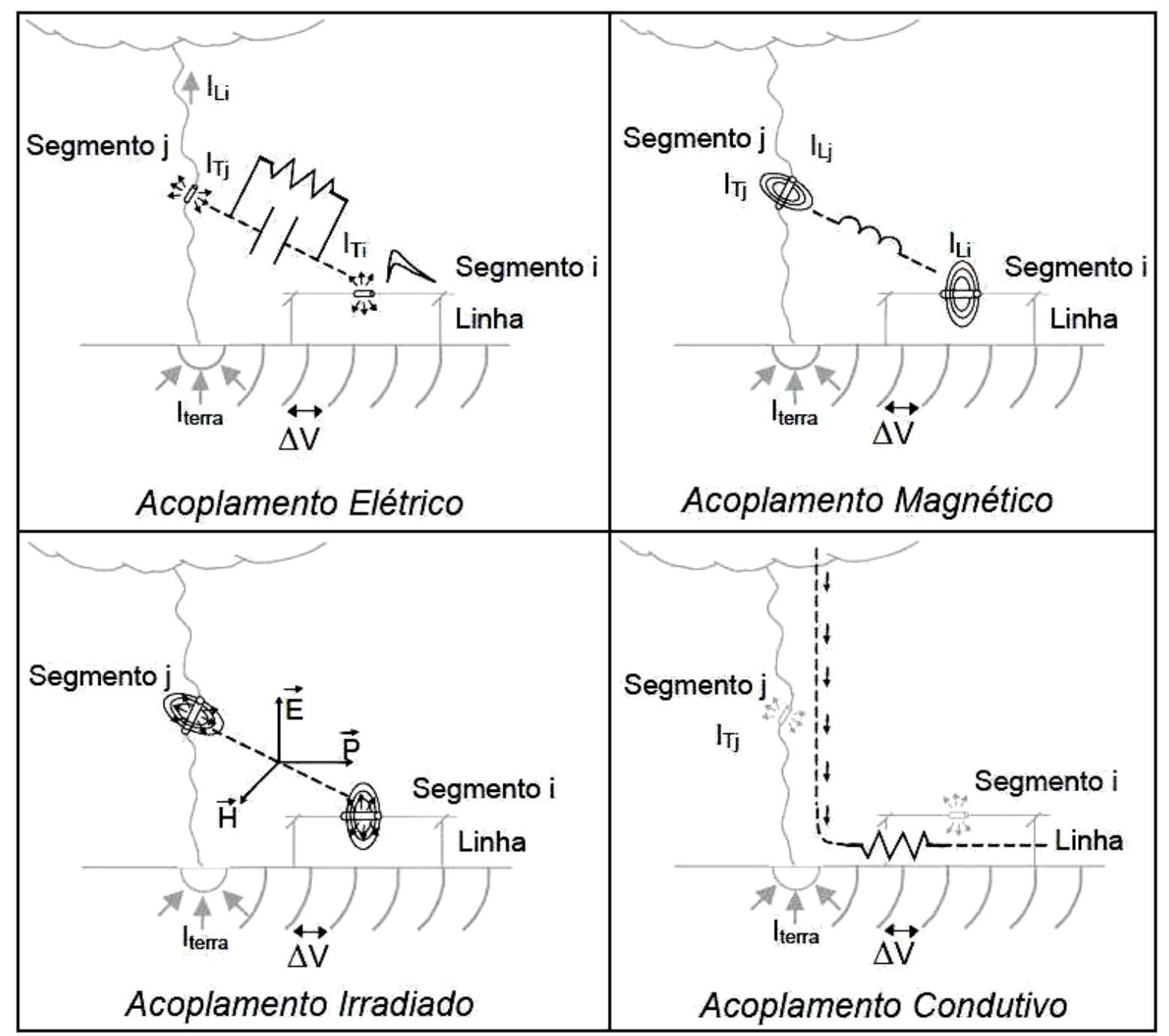

Figura 3.4: Representação do estabelecimento dos quatro tipos de acoplamento eletromagnético entre linha e canal de descarga [adaptada de (VISACRO, 2005)]. 


\subsection{2 - Modelos de Acoplamento Eletromagnético entre Linha e Canal de Descarga}

Os modelos de acoplamento eletromagnético foram desenvolvidos para representar a interação eletromagnética existente entre o canal de descarga e os condutores de linhas aéreas de transmissão e distribuição, e consequentemente para servirem como ferramentas de cálculo de tensões induzidas nestas linhas.

Dentre os modelos mais conhecidos e há mais tempo desenvolvidos destacam-se os modelos de Rusck (RUSCK, 1958), Taylor (TAYLOR et al., 1965), Agrawal (AGRAWAL et al., 1980), Rachidi (RACHIDI, 1993) e Chowdhuri (CHOWDHURI; GROSS, 1967). Os mesmos possuem formulações semelhantes, mas diferem quanto a algumas simplificações adotadas e à forma como são representadas suas funções a partir das componentes do campo eletromagnético.

Uma característica comum a estes cinco modelos é que eles adotam o modo de propagação TEM (Transverse Electromagnetic) para as ondas de tensão e de corrente induzidas na linha, o que reduz o emprego dos mesmos a situações em que os condutores são horizontais e paralelos ao plano do solo. Além disso, ao aplicar o modelo TEM deve-se admitir que as dimensões transversais da linha sejam inferiores ao menor valor do comprimento de onda do fenômeno sob análise. Isto implica em considerar a linha composta por vários segmentos ligados em cascata e atingidos progressivamente pelo campo eletromagnético incidente, método este já mencionado na seção 3.4.1, para calcular as tensões induzidas na linha.

Ainda neste contexto, foram criados os modelos HEM (VISACRO; SOARES Jr., 2005) e NEC-2 (POKHAREL et al., 2003), os quais foram formulados por meio de soluções numérica baseadas nas equações de Maxwell. Tal fato lhes permite considerar condutores com orientação espacial arbitrária no cálculo de tensões induzidas, não se limitando a situações em que os condutores são horizontais e paralelos ao plano do solo.

Recentemente um novo modelo intitulado ERM (PIANTINI, JANISZEWSKI; 2003) foi desenvolvido a partir do Modelo de Rusck, porém sua formulação apresenta algumas modificações para que seja possível considerar o tamanho finito do canal e da linha, e também o formato da linha sob estudo. 
Desse modo, a seguir serão apresentadas de forma sucinta descrições e definições dos modelos Taylor, Agrawal, HEM, NEC-2, ERM e Rusck, utilizando para isto, além das referências dos respectivos modelos, as pesquisas publicadas por Silveira $(2001,2006)$ e Felipe (2007).

\subsubsection{1 - Modelo de Taylor}

O modelo de Taylor (TAYLOR et al., 1965) foi desenvolvido no domínio da frequência com a finalidade de calcular a tensão induzida a partir do equacionamento da influência entre campos eletromagnéticos incidentes e linhas compostas por dois condutores. Entretanto no caso de sistemas aéreos de transmissão a formulação proposta por este modelo se reduz à aplicação para linhas monofásicas com retorno pela terra, e neste caso deve-se considerar a terra como um dos condutores do sistema.

Desse modo, por meio das particularidades deste modelo as características elétricas do solo podem ser inclusas em estudos que o empreguem desde que se utilizem parâmetros variáveis na frequência, ainda que a resistividade do solo em questão não seja nula.

Além disso, partindo de um campo eletromagnético incidente composto por seus vetores campo elétrico $E(x, y, z)$ e indução magnética $B(x, y, z)$, o modelo de Taylor pode ser descrito pelas equações (3.1) e (3.2).

$$
\begin{aligned}
& \frac{d V(x)}{d x}+Z I x=j \omega{ }_{0}^{h} B_{y}^{i} x, z d z \\
& \frac{d I(x)}{d x}+Y V x=-Y{ }_{0}^{h} E_{z}^{i} \quad x, z d z
\end{aligned}
$$

Nas quais $V(\mathrm{x})$ é a tensão da linha, $I(x)$ a corrente, $Z$ a impedância série, dada por (3.3) e $Y$ a admitância transversal expressa por (3.4), em que $\omega$ é a frequência angular, e $R, L$ e $C$ são a resistência, indutância e capacitância por unidade de comprimento da linha, respectivamente.

$$
\mathrm{Z}=\mathrm{R}+\mathrm{j} \omega \mathrm{L}
$$




$$
\mathrm{Y}=\mathrm{j} \omega \mathrm{C}
$$

Nas equações (3.1) e (3.2) a expressão $V(x)$ representa a tensão total na linha, composta por uma parcela de tensão induzida, associada ao campo elétrico incidente, ilustrada por $V^{i}(x)$, e uma parcela de tensão espalhada (scattered), ligada a reposta da linha à excitação gerada pelos campos eletromagnéticos incidentes, delineada por $V^{S}(x)$, como mostra a equação (3.5).

$$
V x=V^{i} x+V^{s} x
$$

\subsubsection{2 - Modelo de Agrawal}

O modelo proposto por Agrawal (AGRAWAL et al., 1980) calcula, no domínio do tempo, as tensões induzidas em linhas aéreas com múltiplos condutores situadas em um meio homogêneo e excitadas por um campo eletromagnético não-uniforme. Para tanto, foi adota a integral de linha do campo elétrico entre dois pontos em um plano transversal independente do caminho com a finalidade de expressar o campo elétrico transversal como o gradiente do potencial escalar. Também se admitiu o fluxo magnético por meio de uma faixa de uma superfície cilíndrica passando por dois pontos em qualquer plano z constante e independente do contorno da faixa.

Além disso, o modelo de Agrawal constituindo-se de forma semelhante ao modelo de Taylor, uma vez que suas formulações e grandezas são bastante parecidas diferindo quanto ao emprego dos índices $k$ e $j$. No modelo de Agrawal estes índices são usados para localizar seus elementos nas matrizes de resistência, capacitância e indutância, e também nos vetores de tensão e de corrente, como pode ser visto pelas equações (3.6), (3.7) e (3.8). Ao mesmo tempo, difere-se por trabalhar com parâmetros concentrados, enquanto Taylor emprega parâmetros distribuídos em sua modelagem.

$$
\begin{gathered}
\frac{d V_{k}^{s}(x, t)}{d x}+R_{k j} I_{k} x+L_{k j} \frac{d I_{k}(x, t)}{d t}=E_{x k}^{i}(x, h, t) \\
\frac{d I_{k}(x, t)}{d x}+C_{k j} \frac{d V_{k}^{s}(x, t)}{d t}=0
\end{gathered}
$$




$$
V_{k} x=V_{k}^{i} x+V_{k}^{s}(x)
$$

\subsubsection{3 - Modelo HEM}

O modelo HEM (Hybrid Electromagnetic Model) (VISACRO; SOARES Jr., 2005) foi desenvolvido a princípio com o intuito de avaliar o comportamento de sistemas de aterramento, e posteriormente por meio de novos estudos foi incrementado e passou a ser empregado em análises de distúrbios em sistemas elétricos frente à ocorrência de descargas atmosféricas.

Para estudos de tensões induzidas este modelo assume um condutor decomposto em diversos segmentos, os quais possuem uma componente de corrente transversal $\left(I_{T}\right)$ e uma componente longitudinal $\left(I_{L}\right)$, consideradas constantes para um determinado segmento e podendo apresentar variação de um segmento para o outro. O mesmo ainda é capaz de reproduzir os desdobramentos do envelope de corona através do incremento do raio do canal para a corrente transversal, e calcular o acoplamento eletromagnético para cada par de segmentos com inserção do efeito de propagação de ondas e da influência do solo em relação aos condutores avaliados. Igualmente, está apto a modificar a velocidade de propagação da onda de corrente no canal por meio da alteração dos valores de permissividade elétrica e permeabilidade magnética do meio que circunda o canal.

Este modelo trabalha com parâmetros no domínio da frequência, mas suas tensões e correntes resultantes podem ser obtidas no domínio do tempo por meio da aplicação da Transformada de Inversa de Fourier. Uma de suas grandes vantagens consiste no fato de computar a distribuição de corrente ao longo do canal de descarga ao mesmo tempo em que define o acoplamento eletromagnético entre linha e canal.

Entretanto, o modelo HEM tem uma limitação quanto à representação do desempenho dinâmico do canal, pois foi desenvolvido no domínio da frequência, o que compromete sua capacidade em simular características como a variação temporal da resistência do canal e a diminuição do raio de corona à medida que a corrente se propaga ao longo do canal.

Segundo o modelo HEM a propagação da corrente de retorno ao longo do canal de descarga cria um campo elétrico conservativo relacionado à corrente transversal de natureza divergente e um campo elétrico não-conservativo relativo à corrente longitudinal, os quais originam as tensões induzidas nas linhas de transmissão e distribuição. Estas tensões, por sua 
vez, são calculadas pela integral do campo elétrico total estabelecido, ou seja, pela soma das parcelas do campo elétrico conservativo e não-conservativo, como pode ser depreendido pelas equações de (3.9) a (3.14), a seguir.

Cabe frisar que para o acoplamento entre dois segmentos de linha, um é considerado como emissor, recebendo o índice " $j$ ”, e o outro como receptor, recebendo o índice “ $i$ ”, conforme foi utilizado nas equações abaixo.

$$
\begin{gathered}
E_{\text {Total }}=E_{\text {conservativo }}+E_{\text {nao-conservativo }} \\
E_{\text {conservativo }}=-\nabla \Phi \\
T I_{\text {conservativo }}=\Phi=\frac{1}{4 \pi \sigma \omega+j \omega \varepsilon(\omega)} \frac{I_{T j}}{L_{j}} \frac{e^{-\gamma r}}{r} d I_{j} \\
E_{n a ̃ o-c o n s e r v a t i v o}=-j \omega A \\
A=\frac{\mu}{4 \pi}{ }_{L j} I_{L j} \frac{e^{-\gamma r}}{r} d I_{j} \\
T I_{n a ̃ o-c o n s e r v a t i v o}=j \omega{ }_{0}^{h} A d I
\end{gathered}
$$

Nas equações acima $T I$ é a tensão induzida, $A$ o vetor potencial magnético, $\Phi$ o potencial escalar elétrico, $d I j$ a magnitude do vetor unitário do segmento emissor, $L j$ o comprimento do segmento emissor, $h$ a altura do condutor da linha, $r$ o raio do núcleo do canal, $\omega$ a frequência angular, $\mu, \varepsilon$ e $\sigma$ a permeabilidade magnética, a permissividade dielétrica e a condutividade elétrica do meio em que o segmento do condutor está imerso respectivamente, e $\gamma$ a constante de propagação do meio, dada por (3.15).

$$
\gamma=\overline{j \omega \mu(\sigma+j \omega \varepsilon)}
$$




\subsubsection{4 - Modelo NEC-2}

Inicialmente a modelagem NEC (Numerical Electromagnetic Code) foi desenvolvida por Burke e Poggio (1977) para a avaliação dos campos eletromagnéticos gerados em torno de segmentos condutores, sobretudo em estudos relacionados a antenas. Mas devido a seu código ser de domínio público, novos modelos foram implementados e aplicados a outros problemas a partir do modelo original, como o modelo de interesse da presente pesquisa, o qual se relaciona a aplicações para cálculo de tensões induzidas como empregado em (POKHAREL et al., 2003; BABA e ISHII, 2001, 2003).

Neste contexto, destaca-se o modelo NEC-2 (POKHAREL et al., 2003) o qual trabalha no domínio da frequência e pode representar o solo como um condutor perfeito ou como um meio de condutividade finita. O mesmo ainda é capaz de computar de forma integrada a distribuição de corrente ao longo do canal de descarga e o acoplamento eletromagnético entre canal e linha sem a necessidade de usar um modelo de acoplamento específico, assim como o modelo HEM. Além disso, para este modelo é preciso determinar a resistência e indutância por unidade de comprimento do canal para calcular a distribuição da corrente ao longo do mesmo. E assim empregar o Método dos Momentos (HARRINGTON, 1968) em equações integrais para os campos elétricos e magnéticos com a finalidade de determinar os campos eletromagnéticos gerados.

Para implementação deste modelo são usadas fontes de tensão para promover a excitação do sistema obtendo-se as correntes induzidas para cada segmento da estrutura sob análise e consequentemente calculam-se suas respectivas tensões induzidas.

\subsubsection{5 - Modelo ERM}

O modelo ERM (Extended Rusck Model) foi idealizado por Piantini e Janiszewski (2003) a partir de um estudo realizado por ambos e apresentado em (PIANTINI; JANISZEWSKI, 1996). Segundo o mesmo, analisando diferentes teorias para cálculo de tensões induzidas, conclui-se que o Modelo de Rusck, embora alcance resultados consistentes, possui algumas restrições em virtude das simplificações que são assumidas em sua modelagem, descritas na seção 3.4.2.6 a seguir, e que necessitam ser melhoradas. 
O modelo ERM foi desenvolvido a partir do Modelo de Rusck para superar estas restrições, permitir a avaliação da incidência de descargas em objetos elevados e em componentes metálicos, e considerar a presença de condutor neutro ou multi-aterrado e de equipamentos como transformadores e para-raios nas linhas sob análise. Ao mesmo tempo, este modelo admiti estudos envolvendo linhas com varias secções de diferentes direções, consideradas através da evolução dos atrasos de propagação para os componentes elementares de tensão, que determinam a tensão induzida em um dado ponto da linha.

O cálculo de tensões induzidas pelo modelo ERM baseia-se na determinação dos potenciais elétrico e magnéticos gerados pelas cargas e corrente ao logo do canal de descarga. O potencial elétrico, associado com as cargas, atua como uma fonte distribuída e é responsável pela geração de ondas que se propagam ao longo dos condutores. Por outro lado, o potencial magnético, relativo às correntes, contribui com seu derivativo de tempo do total da tensão induzida em cada ponto da linha (PIANTINI, 2008).

Desse modo, como exposto em (PIANTINI, 2008), considerando uma descarga em uma estrutura metálica elevada, pelo modelo ERM assume-se que a corrente na estrutura e no canal de descarga possui mesma magnitude e polaridade, mas diferentes velocidades e direções de propagação. Isto se deve ao fato de a corrente através da estrutura se propagar a uma velocidade muito próxima à da luz no espaço livre, enquanto que no canal sua velocidade é uma fração desse valor. Sendo assim, a tensão induzida em uma linha nas proximidades de uma estrutura metálica é obtida pela soma da componente eletrostática com a componente magnética, como mostrado pela equação (3.16).

$$
U x, t=V x, t+{ }_{0}^{h} \frac{\partial A i(x, t)}{\partial t} d z+{ }_{0}^{h} \frac{\partial A i_{t}(x, t)}{\partial t} d z
$$

Nesta equação $V(x, t)$ representa o potencial escalar induzido, $A i(x, t)$ o vetor potencial eletrostático, $A i_{t}(x, t)$ o vetor potencial magnético, e $h$ a altura da linha. Devido a complexidade do procedimento para obtenção de $A i(x, t)$ e de $A i_{t}(x, t)$ e da dificuldade do entendimento de suas expressões sem uma descrição cuidadosa e criteriosa suas equação não serão exposta nesta seção, mas são encontradas em (PIANTINI; JANISZEWSKI, 1998). 


\subsubsection{6 - Modelo de Rusck}

O modelo desenvolvido por Rusck (RUSCK, 1958) constitui-se em um dos primeiros equacionamentos do fenômeno das tensões induzidas por descargas atmosféricas, o qual ainda hoje é bastante empregado em estudos relativos a este tema. Este modelo foi embasado no desenvolvimento de expressões analíticas para o cálculo do valor de pico da tensão induzida em linhas aéreas infinitas através da apresentação de formulações para o acoplamento entre linha e canal, e também propôs as bases de um modelo de corrente de retorno.

A teoria de Rusck foi abalizada em algumas premissas e simplificações de fundamental importância para o seu desenvolvimento, as quais são:

- O canal de descarga é assumido como ionizado, carregado, e disposto verticalmente sem ramificações ou tortuosidades;

- A linha é considerada como sendo infinita e sem descontinuidades, sendo esta hipótese a mais discutida dentre as adotadas no equacionamento de Rusck. Isto se deve porque ao assumi-la não será avaliado o efeito das ondas viajantes, que podem fazer com que a onda de tensão analisada diminua ou aumente consideravelmente, e consequentemente as tensões induzidas, dependendo dos parâmetros da linha;

- A onda de corrente de retorno é considerada em forma de degrau, deslocando-se do solo em direção à nuvem com velocidade constante, e como se estivesse sendo injetada na base do canal de descarga;

- O solo é adotado com resistividade nula como um plano condutor perfeito, o que possibilita a utilização do método das imagens para o cálculo dos campos associados à corrente do canal de descarga;

- O campo no solo é tomado como sendo o mesmo que nos condutores da linha, pois a distância entre solo e linha é pequena quando comparada ao comprimento do canal de descarga;

- A distribuição de cargas no canal de descarga é admitida uniforme, uma vez que em pequenas altitudes esta distribuição varia pouco devido a sua proximidade com o solo. Sendo nesta faixa de altitude que a mesma tem maior influência na amplitude do pico da onda de tensão induzida bem como em sua taxa de variação. 
A partir de seus estudos Rusck concluiu que a tensão induzida em uma linha devido a descargas atmosféricas indiretas é diretamente dependente da taxa de variação do campo elétrico produzido, ou seja, varia com a derivada do campo elétrico no tempo. Assim, para o cálculo das mesmas faz-se necessário determinar o potencial escalar e o vetor potencial magnético que compõem os campos eletromagnéticos produzidos pela incidência da descarga, os quais serão determinados no decorrer desta seção.

Partindo das considerações acima e das simplificações descritas, ilustradas na Figura 3.5, e utilizando as equações de Maxwell em um sistema de coordenadas retangulares XYZ como o da Figura 3.6, Rusck obteve expressões analíticas para a interação entre os campos gerados pelas descargas atmosféricas e as linhas em sua vizinhança, e consequentemente as fórmulas para o cálculo da tensão induzida.

Na Figura 3.5 $L_{0}$ indica a distância entre a linha e ponto do canal de descarga sob análise, $h$ a altura da linha, e $y$ a distância entre a linha e o ponto de incidência da descarga atmosférica no solo.

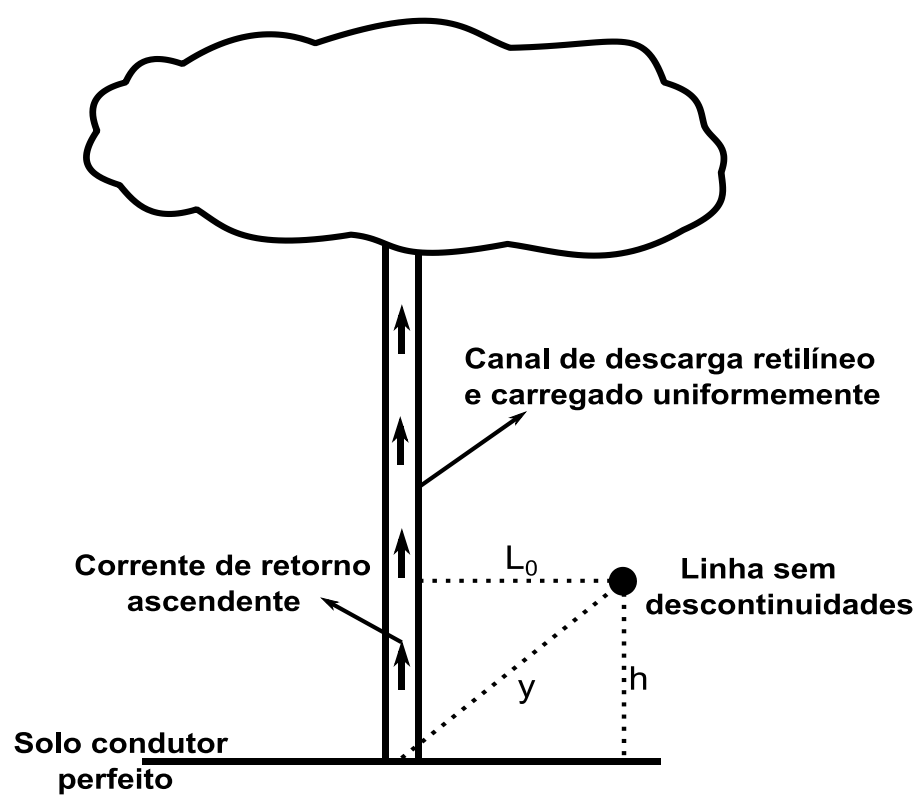

Figura 3.5: Disposição da linha e do canal de descarga em relação ao solo para a metodologia de cálculo de tensões induzidas pelo Modelo de Rusck com suas respectivas simplificações [adaptada de (MOTA, 2011)].

Já a Figura 3.6 esboça, em uma linha trifásica, o arranjo espacial considerado por Rusck para o desenvolvimento de sua modelagem, lembrando que o equacionamento por ele proposto abrange linhas polifásicas. Nesta representação o plano XY refere-se à superfície do solo, uma linha infinita e isolada é posicionada paralelamente ao eixo $\mathrm{X}$, e seus condutores $a$, 
$b$, e $c$ se situam a alturas $h_{a}, h_{b}$ e $h_{c}$ em relação ao solo e possuem espaçamento $y_{a b}, y_{b c}$ e $y_{a c}$ entre si, respectivamente.

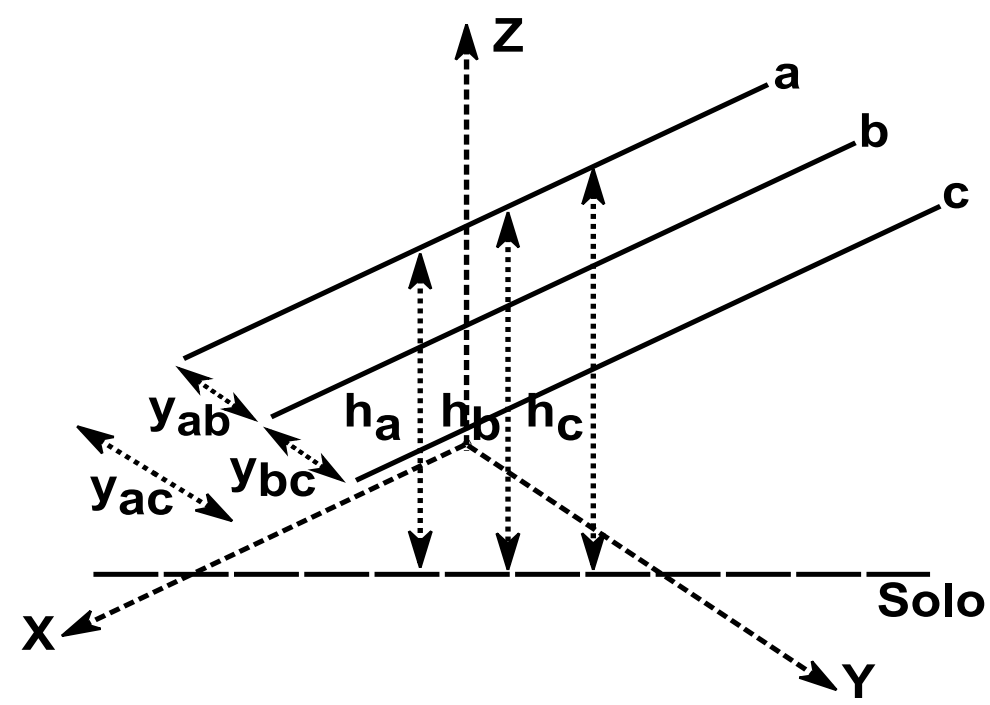

Figura 3.6: Disposição espacial dos condutores empregada para o desenvolvimento do Modelo de Rusck [adaptada de (SILVEIRA, 2006)].

A partir destas configurações as cargas $q_{a}, q_{b}$ e $q_{c}$ presentes no canal de descarga e sua corrente de retorno induzem as correntes $I_{a}, I_{b}$ e $I_{c}$ e os potenciais escalares $\Phi_{a}, \Phi_{b}$ e $\Phi_{c}$ nos condutores da linha. Admitindo que as distribuições de correntes e cargas presentes nos condutores da linha não modificam as distribuições de correntes e cargas do canal de descarga, o potencial escalar na superfície destes condutores pode ser expresso pela equação (3.17).

$$
\left[\Phi_{\mathrm{n}}\right]=\left[\Phi_{\mathrm{in}}\right]+\left[\mathrm{k}_{\mathrm{nn}}\right] \cdot\left[\mathrm{q}_{\mathrm{n}}\right]
$$

$\mathrm{Na}$ qual $\Phi_{n}$ representa o potencial escalar induzido no n-ésimo condutor, $\Phi_{i n} \mathrm{o}$ potencial escalar indutor no $n$-ésimo condutor, $k_{n n}$ os elementos da matriz de coeficientes de potencial, e $q_{n}$ a carga induzida no n-ésimo condutor. Os coeficientes de potencial são definidos pelas equações (3.18) e (3.19):

$$
\begin{aligned}
& K_{a a}=\frac{1}{2 \pi \epsilon_{0}} \ln \frac{2 \mathrm{~h}_{\mathrm{a}}}{\mathrm{r}_{\mathrm{a}}} \\
& K_{a b}=\frac{1}{2 \pi \varepsilon_{0}} \ln \frac{d_{a b}^{\prime}}{d_{a b}}
\end{aligned}
$$


Em que $h_{a}$ indica a altura de um condutor específico $a, r_{a}$ o raio do condutor $a, d_{a b}$ a distância entre os condutores $a$ e $b, d^{\prime}$ a distância entre o condutor $a$ e a imagem do condutor $b$, e $\varepsilon_{0}$ é a permissividade elétrica do vácuo.

$\mathrm{O}$ vetor potencial na direção da linha, ou seja, na direção $\mathrm{X}$, é determinado pela corrente induzida ao longo dos condutores, já que o vetor potencial indutor associado à corrente de retorno do canal de descarga é perpendicular à direção dos condutores, e é expresso pela equação (3.20):

$$
\left[\mathrm{A}_{\mathrm{xn}}\right]=\left[\mathrm{L}_{\mathrm{nn}}\right] \cdot\left[\mathrm{I}_{\mathrm{n}}\right]
$$

Na qual $A_{x n}$ remete ao vetor potência do $n$-ésimo condutor na direção X, e $L_{n n}$ e $I_{n}$ a indutância e a corrente induzida no n-ésimo condutor, respectivamente.

A intensidade do campo elétrico ao longo da superfície do condutor é determinada pela equação (3.21), a qual ao ser substituída na equação (3.20) e ao considerar a condutividade infinita dos condutores expressa pela equação (3.22) resulta na equação (3.23), como mostrado a seguir:

$$
\begin{gathered}
E_{r}=-\nabla \Phi_{i}-\frac{\partial A_{i}}{\partial t} \\
E=\frac{1}{\sigma} J \rightarrow \sigma=\infty \quad \therefore E=0 \\
\frac{\partial \Phi}{\partial x}=-L \quad \frac{\partial I}{\partial t}
\end{gathered}
$$

Em que $E_{r}$ é campo elétrico resultante, $\Phi i$ o potencial escalar, $A_{\mathrm{i}}$ o vetor potencial magnético, $\sigma$ a condutividade dos condutores, $J$ a densidade de corrente, e $[L]$ a matriz de indutâncias. A matriz $[L]$ é definida por (3.24) na qual $v_{0}$ é a velocidade da luz no vácuo e [Z] é a matriz de impedâncias de surto, expressa em (3.25).

$$
L=\frac{1}{v_{0}} \times Z
$$




$$
Z=\begin{array}{cccc}
Z_{a a} & Z_{a b} & Z_{a c} & \cdots \\
Z_{b a} & Z_{b b} & Z_{b c} & \cdots \\
Z_{c a} & Z_{c b} & Z_{c c} & \cdots \\
& \vdots & \vdots &
\end{array}
$$

Baseando-se na equação da continuidade indicada por (3.26), a qual define que a corrente em um ponto é igual à variação da densidade de carga neste mesmo ponto, Rusck admitiu a relação de condição entre a variação da corrente e a variação das cargas como apresentado pela equação (3.27). Substituindo (3.17) em (3.27) obteve a equação (3.28), em que $\rho$ representa a densidade de cargas, $I$ a corrente em um condutor, e $[K]$ a matriz de coeficientes de potencial de Maxwell indicada por (3.29).

$$
\begin{gathered}
\nabla J+\frac{\partial \rho}{\partial t}=0 \\
\frac{\partial I}{\partial x}=-\frac{\partial q}{\partial t} \\
\frac{\partial I}{\partial x}=-\frac{1}{K} \quad \frac{\partial \Phi}{\partial t}+\frac{1}{K} \frac{\partial \Phi_{j}}{\partial t} \\
K=v_{0} \times Z
\end{gathered}
$$

Posto isto, substituindo (3.23) em (3.24) e (3.29) em (3.28) obtém-se (3.30) e (3.31) respectivamente, que formam um sistema de equações com o qual se alcançam as correntes e potenciais escalares nos condutores em análise.

$$
\begin{gathered}
\frac{\partial \Phi}{\partial x}=-\frac{1}{v_{0}} \times Z \times \frac{\partial I}{\partial t} \\
\frac{\partial I}{\partial x}=-\frac{1}{v_{0} \times Z} \frac{\partial \Phi}{\partial t}+\frac{1}{v_{0} \times Z} \frac{\partial \Phi_{I}}{\partial t}
\end{gathered}
$$

A partir de algumas simplificações e da resolução do sistema acima mencionado pode-se determinar o potencial escalar dado pela equação (3.32), na qual $\varepsilon_{0}$ é a permissividade elétrica do vácuo, $t$ o tempo decorrido a partir do início da corrente de retorno 
e $L_{0}$ a distância da linha até o ponto do canal de descarga sob análise, como indicado na Figura 3.5.

$$
\Phi_{i}=\frac{1}{4 \pi \varepsilon_{0}} \quad{ }_{-\infty}^{\infty} \frac{q s, t-\frac{L_{0}}{v_{0}}}{L_{0}} d s
$$

Retomando a equação (3.21) cabe agora determinar o vetor potencial magnético a partir das correntes nos condutores também definidas pela resolução do sistema anteriormente citado. Este vetor é chamado de conservativo porque sua força sobre uma carga depende da velocidade da mesma e do ângulo que ela faz com as linhas do campo, e pode ser definido pela equação (3.33), em que $\mu_{0}$ é a permeabilidade magnética do vácuo.

$$
A l=\frac{\mu_{0}}{4 \pi} \quad \infty_{-\infty} \frac{I s, t-\frac{L_{0}}{v_{0}}}{L_{0}} d s
$$

Relacionando as equações de linha de transmissão com o campo elétrico total na superfície do condutor e seus potências escalar e vetor magnético, as equações de linha do Modelo de Rusck são (3.34) e (3.35).

$$
\begin{gathered}
\frac{\partial u^{\varphi}(x, t)}{\partial x}+i R+L \frac{\partial i(x, t)}{\partial t}=0 \\
\frac{\partial i(x, t)}{\partial x}+C \frac{\partial u^{\varphi}(x, t)}{\partial t}=C \frac{\partial \Phi^{\mathrm{i}}(\mathrm{x}, \mathrm{h}, \mathrm{t})}{\partial t}
\end{gathered}
$$

Nas quais $u^{\varphi}$ é a tensão induzida na linha associada ao potencial escalar do campo incidente, e $R, L$ e $C$ a resistência, indutância e capacitância por unidade de comprimento da linha, respectivamente.

Nesta conjuntura, Rusck definiu a tensão induzida em uma linha por uma descarga indireta como apresentado na equação (3.36).

$$
u x, t=\Phi x, t+{ }_{0}^{h} \frac{\partial A_{z}^{i} x, z, t}{\partial t} d z
$$


Substituindo (3.32) e (3.33) em (3.36) obtém-se a expressão da tensão máxima induzida considerando a incidência de uma descarga indireta próxima ao centro da linha dada por (3.37).

$$
U_{\max }=\frac{Z_{0} I h}{y} \quad 1+\frac{1}{\overline{2}} \frac{v}{v_{0}} \frac{1}{\overline{1-\frac{1}{2}{\frac{v}{v_{0}}}^{2}}}
$$

Nesta equação $U_{\max }$ é máxima tensão induzida no condutor, $I$ o valor de pico da corrente de descarga, $h$ a altura da linha em relação ao solo, $y$ a distância entre o ponto de incidência da descarga e a linha, $v$ a velocidade de propagação da onda de corrente de descarga, $v_{0}$ a velocidade da luz no vácuo, e $Z_{0}$ a impedância característica da linha expressa por (3.38), em que $\mu_{0}$ é a permeabilidade do vácuo e $\varepsilon_{0}$ a permissividade elétrica do vácuo.

$$
Z_{0}=\frac{1}{4 \pi} \quad \frac{\overline{\mu_{0}}}{\varepsilon_{0}}
$$

Contudo, para implementar computacional o método de Rusck é preciso representar sua máxima tensão induzida $\left(\mathrm{U}_{\max }\right)$ no domínio do tempo, o que pode ser conseguido por meio da equação (3.39).

$$
U x, t=Z_{0} \operatorname{Ih} \beta \frac{c t-x}{y^{2}+\beta^{2} c t-x^{2}} \quad 1+\frac{x+\beta^{2} c t-x}{\beta c t^{2}+1-\beta^{2} x^{2}+y^{2}}
$$

Em que $x$ é um ponto ao longo do trecho da linha, $t$ é um determinado intervalo de tempo, $c$ é a velocidade da luz no vácuo, $I, h, y$ e $Z_{0}$ são variáveis definidas do mesmo modo com foi feito para a equação (3.37). Já $\beta$ é a razão entre a velocidade de propagação da onda de corrente de descarga ( $v$ ) e a velocidade da luz no vácuo $(c)$, ou seja, $\beta=v / c$.

Posto isto, a tensão induzida total no domínio do tempo em um ponto x ao longo da linha é dada pela equação (3.41).

$$
V x, t=U x, t+U(-x, t)
$$


Além disso, para situações em que se deseja calcular o valor de pico da tensão induzida para pontos na linha relativamente distantes do canal de descarga pode-se desconsiderar a velocidade de propagação da corrente no canal e adotar a equação (3.42), cujas variáveis são as mesma da equação (3.37).

$$
U_{\max }=\frac{Z_{0} I h}{y}
$$

Posto isto, terminada a exposição dos modelos de acoplamento serão apresentadas as variáveis que mais influenciam a amplitude e forma de onda das tensões induzidas.

\section{5 - Variáveis que Influenciam na Amplitude e Forma das Tensões Induzidas}

Há diversas variáveis que podem influenciar a amplitude e a forma de onda das tensões induzidas por descargas atmosféricas diretas e indiretas, relacionadas a diferentes fatores como:

- Formação do canal de descarga;

- Corrente desenvolvida ao longo do canal;

- Acoplamento entre linha e canal;

- Características da linha;

- Parâmetros ambientais;

- Estabelecimento do campo eletromagnético entre solo e condutor ou entre condutores.

Dessa maneira, podem definir-se os fatores de maior relevância para a determinação da amplitude e a forma de onda da tensão induzida como: parâmetros de descarga, parâmetros da linha, parâmetros de configuração entre linha e canal de descarga, e parâmetros ambientais.

Sendo assim, fundamentando-se em (VISACRO, 2005) e (SILVEIRA, 2001, 2006) estes parâmetros serão descritos, cabendo à ressalva de que se poderia realizar um estudo 
específico a respeito da influência dos mesmos sobre as tensões induzidas devido à complexidade e relevância por eles apresentadas.

\subsection{1 - Parâmetros de Descarga}

O principal parâmetro de descarga que altera de forma aproximadamente proporcional a amplitude da tensão induzida é a taxa de crescimento da corrente de retorno, a qual influência o valor de pico e o tempo de frente da corrente de descarga, e é definida como o valor médio da derivada da frente de onda da corrente em relação ao tempo. Neste contexto, resultados de simulações e medições demonstram que a amplitude da tensão induzida é proporcional ao valor do pico de corrente e inversamente proporcional ao tempo de frente da onda de corrente.

Analisando a ocorrência das descargas atmosféricas averígua-se que as descargas subsequentes possuem valor de amplitude de corrente aproximadamente igual a um terço do valor das primeiras descargas, e tempo de frente aproximadamente seis vezes menor do que das primeiras descargas. Tal fato leva a uma perspectiva de que as amplitudes das tensões induzidas oriundas de descargas subsequentes possuam valores aproximadamente iguais ao dobro dos proporcionados pelas primeiras descargas, quando analisadas descargas negativas. Esta situação não ocorre com as descargas positivas por estas possuírem tempo de frente muito elevado e valor mediano da amplitude pouco superior aquele das primeiras descargas, implicando em amplitudes de tensão induzida diminutas.

A altura do ponto de conexão entre os canais ascendente e descendente também pode influenciar na amplitude da tensão induzida implicando geralmente na redução da mesma, embora em determinadas situações possa ocasionar o seu aumento. Isto se explica, pois na ocorrência de uma primeira descarga negativa este ponto ocorre a uma altura considerável do solo levando a formação de uma onda ascendente e de uma descendente que podem somar-se ou subtrair-se.

A atenuação da amplitude da corrente ao longo do canal de descarga, o processo de formação do envelope de corona, as perdas no núcleo do canal, a velocidade de propagação da corrente de retorno, e as tortuosidades ao longo do canal, são parâmetros de descarga relevantes, mas que acarretam menor influência sobre a amplitude e forma de onda da tensão induzida. 


\subsection{2 - Parâmetros da Linha}

Dentre os parâmetros de linha relacionados com a determinação das tensões induzidas destaca-se a altura, a qual contribuiu com o percurso de integração do campo elétrico formado entre a linha e o solo, influenciando de maneira aproximadamente proporcional a amplitude das mesmas, assim como ocorre com a distância entre os condutores fase e neutro.

Já os cabos de blindagem e de aterramento promovem uma discreta redução da tensão induzida devido ao acoplamento eletromagnético entre tais cabos e os condutores fase da linha, sendo esta redução expressiva somente quando os cabos aterrados estão muito próximos do condutor energizado e conectados a aterramentos adjacentes ao ponto sob análise.

$\mathrm{Na}$ ocorrência de pequenos espaçamentos entre os aterramentos de neutro ou do cabo de blindagem acontecem alterações das ondas de tensão e corrente no cabo aterrado devido a reflexões do surto induzido no solo, o que em conjunto com o acoplamento entre os cabos promove a redução das tensões induzidas nas fases. Ainda nesta conjuntura, a resistência de aterramento das terminações à terra dos cabos de blindagem e dos cabos neutros acarreta diminuta influência na amplitude da tensão induzida, e o aumento do número destas terminações implica na redução das amplitudes das mesmas no condutor fase.

Ressalta-se que os cabos para-raios, usualmente empregados na proteção de linha contra descargas diretas, também promovem alterações nas tensões induzidas por meio do acoplamento entre seus componentes e os cabos fase, e pela sua atuação drenando as correntes induzidas nas linhas ao oferecer um caminho preferencial de baixa resistência as mesmas.

\subsection{3 - Parâmetros de Configuração entre Linha e Canal de Descarga}

Dentre as configurações de estabelecimento do acoplamento entre linha e canal de descarga se destaca a posição relativa entre a linha e o canal, pois quanto menor a distância entre os mesmos maior o campo eletromagnético incidente sobre a linha e, portanto maior a amplitude de tensão induzida. 
Outro parâmetro importante é a inclinação do canal em relação à linha, uma vez que à medida que esta característica aproxima ou afasta os elementos de corrente geradores do campo eletromagnético, promove, respectivamente, o aumento ou diminuição da amplitude da tensão induzida.

Por fim, a altura do ponto de conexão entre os canais ascendente e descendente e a localização do mesmo em relação à linha também se caracteriza como um parâmetro de configuração entre linha e canal e influência a tensão induzida conforme exposto nas seções 3.5.1 e 3.5.2.

\subsection{4 - Parâmetros Ambientais}

Os parâmetros ambientais de maior relevância no contexto de tensões induzidas são relevo e resistividade do solo. O primeiro está associado à maneira com a qual o campo eletromagnético atinge os condutores da linha, pois dependendo da disposição e inclinação do solo pode ocorrer aumento ou diminuição da intensidade de campo sobre a linha, e consequentemente acréscimo ou redução da tensão induzida.

Já a resistividade do solo afeta a tensão induzida através da alteração do campo eletromagnético ao longo do percurso de propagação entre o ponto de incidência da descarga e os pontos atingidos da linha. Do mesmo modo, influência na determinação dos parâmetros longitudinais e transversais da linha, podendo acarretar o aumento ou a diminuição da amplitude da tensão induzida em virtude do ponto de incidência e de análise.

\section{6 - Considerações Parciais sobre a Modelagem de Tensões Induzidas}

Por meio dos conceitos apresentados neste capítulo conclui-se que a corrente de retorno do canal de descarga possui influência direta na formação e no estabelecimento das tensões induzidas. Isto ocorre, pois a mesma é responsável pelo campo eletromagnético que se propaga e interage com os condutores da linha, determinando o acoplamento entre linha e 
canal de descarga. Em virtude deste fato foram descritas a dinâmica de assentamento da mesma e sua distribuição ao longo do canal por meio dos modelos de corrente de retorno.

Com a finalidade de representar computacionalmente as tensões induzidas foram avaliados os tipos de acoplamento eletromagnético e os modelos de acoplamento entre linha e canal de descarga disponíveis na literatura correlata.

Desse modo, a partir do exposto e da avaliação destes modelos conclui-se que o Modelo de Rusck caracteriza-se pela sua simplicidade, rapidez de cálculo e aceitáveis aproximações, porém ainda é bastante criticado devido às simplificações realizadas em seu desenvolvimento. Entretanto, traz resultados satisfatórios para estudos que envolvem a modelagem de tensões induzidas por descargas atmosféricas indiretas em LDs e LTs, e teve sua eficácia comprovada por meio de sua aplicação em vários projetos de pesquisa, como em: (FONSECA, 1990), (BOAVENTURA, 1990), (PAULINO, 1994), (SILVA, 2001), (CARVALHO, 2004), (SILVA NETO, 2004) e (SEKIOKA, 2005), demonstrando ser uma excelente ferramenta de engenharia.

Além disso, a aceitação do Modelo de Rusck é tão notória que até mesmo associações renomadas como o IEEE e o CIGRÉ o adotam para o cálculo de tensões induzidas, como pode ser verificado em (IEEE, 1997, 2004) e (CIGRÉ, 1991). Este modelo ainda compreende uma teoria completa do fenômeno atmosférico simples de ser compreendida e de fácil implementação computacional. Ademais, a partir das expressões dos modelos anteriores expostos averígua-se que o Modelo de Rusck fornece uma expressão analítica para o cálculo da tensão induzida, enquanto que as demais teorias fornecem expressões iterativas e de grande custo computacional, o que lhe confere um grande diferencial.

Por fim, considera-se a aplicação do Modelo de Rusck inadequada apenas em casos específicos como em estudos em que se queira analisar a influência da impedância do solo ou a descontinuidade da linha, por exemplo.

Dessa forma, para o desenvolvimento desta pesquisa será implementado o Modelo de Rusck para simulação de tensões induzidas por descargas indiretas em uma linha de distribuição por meio do ambiente gráfico Simulink®, do software MATLAB®, como será visto no capítulo 5 .

Determinado o modelo para simulação das tensões induzidas cabe agora partir para um estudo mais aprofundado sobre os para-raios, equipamentos estes que serão utilizados para proteger a linha sob análise contra as sobretensões de origem atmosférica. 


\section{CAPÍTULO 4}

\section{ASPECTOS RELACIONADOS AOS PARA-RAIOS}

Dentre os equipamentos utilizados na proteção contra sobretensões nos sistemas elétricos de potência destacam-se os para-raios, mais especificamente os para-raios de óxido de zinco $(\mathrm{ZnO})$. Estes são projetados para proteção contra sobretensões originadas por ocorrências no próprio sistema, pela incidência direta de descargas atmosféricas, ou por indução devido a descargas indiretas, e os quais visam mitigar as sobretensões a fim de aumentar a confiabilidade e a continuidade de operação dos sistemas elétricos.

Nesta conjuntura, a fim de prover condições para o conhecimento do comportamento e das características dos para-raios, este capítulo apresenta uma revisão bibliográfica e históricas sobre os principais trabalhos e estudos correlatos aos para-raios, sobretudo os pararaios de $\mathrm{ZnO}$. Também são expostos seus princípios de funcionamento, histórico de desenvolvimento deste equipamento de proteção, vantagens de utilização dos para-raios de $\mathrm{ZnO}$ em relação aos de carboneto de silício $(\mathrm{SiC})$, e conceitos mais aprofundados sobre o para-raios de $\mathrm{ZnO}$, com relação a suas características construtivas, fatores de degradação e especificações.

\section{1 - Revisão Bibliográfica e Histórica}

O desenvolvimento dos para-raios iniciou-se em 1892 a partir do surgimento do centelhador, primeiro equipamento com a função de limitar sobretensões, e em seguida em 1920 pelos para-raios propriamente ditos, do tipo expulsão. Desde 1930 há registros na literatura técnica de projetos de proteção de linhas frente a descargas atmosféricas pela aplicação destes dispositivos. Entretanto, é somente em 1940 que Peterson et al. publicam um dos principais estudos neste segmento, no qual expõem os resultados de oito anos de pesquisas e aplicações de para-raios em linhas de 13,8 a $230 \mathrm{kV}$. Por meio da experiência 
adquirida, o documento por eles publicado busca resumir a concepção da teoria de operação, demonstra os fatores que devem ser considerados nas características do dispositivo e do sistema em que serão utilizados, e em seguida sugere uma padronização para facilitar sua aplicação.

Posteriormente, em Matsuoka (1971) é apresentado um estudo pioneiro na aplicação do óxido de zinco para construção de para-raios. No mesmo, é avaliada a microestrutura cerâmica deste material em relação às suas propriedades ôhmicas, resistividade elétrica, geração de campo elétrico e dependência com a temperatura, constatando-se ser este um excelente material para este tipo de aplicação.

Em Matsuoka (1981) são publicados os resultados e conclusões de pesquisas sobre o progresso de desenvolvimento dos varistores de $\mathrm{ZnO}$. As mesmas analisam a aplicação de vários aditivos para incrementar o desempenho destes dispositivos a fim de elevar sua eficiência, absorção de energia e dissipação de calor, agrupados, segundo suas funções, em três classes: formação da estrutura básica, propriedades não ôhmicas e estabilidade. Além disso, por meio destas pesquisas foi proposta a clássica formulação de Matsuoka para composição dos varistores de $\mathrm{ZnO}$, ainda hoje muito utilizada na maioria dos varistores comerciais nas mais diferentes faixas de aplicação, com pequenas modificações em determinadas situações.

Já em Lat e Kortschinski (1989) é apresentada uma visão geral de um guia de aplicação de para-raios em redes de distribuição de 2,4 a $50 \mathrm{kV}$ elaborado pela Ontario Hydro e patrocinado pela Canadian Electricity Association (CEA), com especial destaque para os para-raios de óxido de zinco. Além disso, baseando-se no guia mencionado também são expostos os resultados de uma pesquisa entre as causas e efeitos de descargas atmosféricas para a terra nas proximidades de um sistema de distribuição a fim de avaliar o formato da linha, os locais de instalação dos para-raios, e a coordenação de isolamento da mesma.

Em IEEE (1992) o Grupo de Trabalho 3.4.11 do IEEE a partir da análise de informações sobre as características de para-raios de óxido de zinco mostrou que havia uma dependência significativa de suas características com a frequência em estudos de sobretensões de origem atmosférica. Ademais, foi proposto um modelo para representar as características dinâmicas dos mesmos, envolvendo a ocorrência de descargas atmosféricas e outros picos de frente de onda rápidos, incluindo um método para gerar os parâmetros do modelo a partir de dados obtidos em manuais de fabricantes de para-raios. 
Em IEEE (1997) é publicado o Guia IEEE Std 1410 com informações sobre métodos para melhorar o desempenho de linhas de distribuição de até $69 \mathrm{kV}$ frente à incidência de descargas atmosféricas. Este guia expõe técnicas de construção de linhas e de melhoria de desempenho considerando o material da estrutura, a geometria da linha, o tipo de blindagem, o nível de isolamento, os métodos de aterramento e a utilização de para-raios, a fim de minimizar os problemas causados pela incidência direta e indireta de descargas atmosféricas.

A seguir, em Durbak (2001) são discutidas as etapas a serem realizadas para se obter os parâmetros necessários para representar para-raios de óxido metálico na plataforma de simulações de transitórios EMTP. Este trabalho inclui um resumo da representação matemática, dos procedimentos de conversão utilizados para obtenção de parâmetros, e de diretrizes para escolha dos parâmetros mais adequados.

Posteriormente, em IEEE (2004) é publicada uma revisão do Guia IEEE Std 1410 (IEEE, 1997) com a adição de novas técnicas de melhoria de desempenho a partir de modernas pesquisas e informações divulgadas sobre o tema.

Ao mesmo tempo, em Thanasaksiri (2004) é exibido um estudo sobre melhoria de desempenho de linhas aéreas de distribuição de $22 \mathrm{kV}$ frente a descargas atmosféricas empregando o modelo computacional desenvolvido pelo EPRI. Para tanto, são analisados o desempenho da proteção de determinada linha inicialmente com inclusão de cabos de blindagem e posteriormente com para-raios, além de ser avaliada a influência do tamanho dos cabos de blindagem e da impedância de aterramento.

Em Bueno et al. (2005) são expostos os resultados da composição de um método simplificado de engenharia para análise e melhoria de desempenho de linhas aéreas de distribuição frente a descargas atmosféricas. Para tanto, são empregadas simulações de sobretensões induzidas no programa ATP e realizado um estudo estatístico de simulação de descargas atmosféricas com o programa LIOV. Seus resultados mostram onde devem ser instalados os para-raios de surto na linha, os quais não devem ultrapassar uma distância máxima de 200 m um do outro para garantir a proteção efetiva esperada.

Concomitantemente, em Meister (2005) é apresentada uma avaliação técnica comparativa da modelagem de varistores de óxido de zinco e a definição de qual modelo de para-raios é o mais apropriado para tipos específicos de estudos. Ressalta-se que sua principal contribuição é a validação e análise destes modelos no software ATP, e a aplicação dos mesmos em um estudo de coordenação de isolamento de uma subestação de $500 \mathrm{kV}$. Os modelos descritos e validados são: modelo convencional ou modelo do resistor não linear; modelo proposto por Tominaga et al. (TOMINAGA et al., 1979); modelo proposto por Kim 
et al. (KIM et al., 1996); modelo do IEEE (IEEE, 1992); modelo proposto por Pinceti e Giannettoni (PINCETI; GIANNETTONI, 1999); e modelo proposto por Fernandez e Diaz (FERNANDEZ; DIAZ, 2001).

Em Saran (2009) é abordado o estudo de uma ampla gama de efeitos e impactos das descargas atmosféricas sobre linhas de distribuição reais, a fim de estabelecer os principais pontos de intervenção para a melhoria de desempenho das mesmas por meio da análise das respostas de equipamentos instalados na rede, como transformadores, isoladores e para-raios. Para tanto, é utilizado o software ATP para simulação e modelagem de surtos devido a descargas diretas e de tensões induzidas por descargas indiretas, além de realizar a modelagem da linha e de seus componentes como um todo. Também é criado um programa computacional para o tratamento, exibição e utilização das informações de bancos de dados geoposicionais do sistema sob estudo, e são feitas simulações e análises estocástica, probabilística e estatística da ocorrência e geração de surtos por descargas atmosféricas.

Simultaneamente, em IEEE (2009) é publicado um dos guias mais completos da área de proteção de sistemas elétricos de corrente alternada por aplicação de para-raios, o qual aborda o emprego de para-raios de óxido metálico para proteger equipamentos com tensão nominal de operação acima de $1 \mathrm{kV}$ contra sobretensões. Este guia fornece informações sobre as características de para-raios de óxido de zinco para proteção de equipamentos de subestações, sistemas de distribuição, linhas aéreas, e grandes máquinas elétricas, e é uma atualização dos guias publicados em (IEEE, 1991; 1997).

Em Alves (2010) é desenvolvida uma ferramenta de cálculo de tensão induzida por descargas atmosféricas indiretas, baseada no Modelo de Rusck, para análise de sistemas polifásicos com grande quantidade de estruturas e de para-raios de $\mathrm{ZnO}$, a qual foi implementada no software de transitórios eletromagnéticos EMTP. Adicionalmente, para a validação de seus resultados foram realizados testes de cálculo da tensão induzida em uma linha de distribuição trifásica variando-se o ponto de incidência da descarga indireta, a quantidade e o posicionamento dos dissipadores de surto.

Em Munukutla et al. (2010) é apresentado um projeto de proteção contra descargas atmosféricas para uma linha de transmissão de $115 \mathrm{kV}$ com a utilização de para-raios baseando-se em dados obtidos em estudos de campo e empregando o software ATP. São propostos vários procedimentos a fim maximizar a confiabilidade do serviço nesta linha utilizando um número mínimo de para-raios, alocando um número diferente dos mesmos por torre, variando a distância entre torres com para-raios, e analisando a dependência dessas configurações em relação à resistência de pé de torre. 
Em EPRI (2011) é publicado um guia com procedimentos para melhoria de desempenho de linhas de transmissão frente a descargas atmosféricas e sobre técnicas de aterramento, baseado em relatórios publicados anteriormente. O seu conteúdo inclui a teoria de formação e a definição dos parâmetros das descargas atmosféricas, os impactos das descargas sobre linhas de transmissão, e os fundamentos, aspectos práticos e de projeto de aterramento de linhas. Também constam no mesmo diretrizes para melhorar o desempenho de linhas, teoria e práticas de instalação de para-raios contra descargas, e diretrizes de aplicação do software TFlash.

Posto isto, finalizada esta revisão bibliográfica e histórica sobre os estudos e trabalhos publicados de maior relevância a respeito de para-raios, principalmente os de $\mathrm{ZnO}$, em seguida serão expostos conceitos e princípios sobre o funcionamento destes equipamentos.

\section{2 - Princípios de Funcionamento dos Para-raios}

Os para-raios atuam como agentes limitadores, impedindo que tensões acima de um determinado nível pré-estabelecido possam alcançar os equipamentos para os quais fornecem proteção (D’AJUZ et al., 1985; MAMEDE, 2005). Atualmente, há diversos tipos de pararaios disponíveis para proteção de linhas de alta tensão, transformadores, banco de capacitores, reguladores, e para linhas de distribuição em média tensão, como será empregado nesta pesquisa, dependendo de suas características construtivas e de sua classe de tensão.

Além disso, em todos estes tipos de aplicação, em uma situação ideal, espera-se que os mesmos atuem da seguinte forma (CEPEL, 1977; D'AJUZ et al., 1985; MAMEDE, 2005):

- Apresentando impedância infinita entre os seus terminais nas condições de regime permanente do sistema;

- Comportando-se como um circuito aberto até a ocorrência de uma sobretensão;

- Possuindo a capacidade instantânea de entrar em condução quando da ocorrência de uma sobretensão com valor de pico próximo ao da tensão nominal do sistema;

- Mantendo sua tensão de início de condução durante toda a ocorrência da sobretensão;

- Parando de conduzir e retomando a condição de circuito aberto assim que a tensão do sistema voltar ao seu estado inicial. 
Entretanto, os para-raios disponíveis não têm a capacidade de operar dessa forma ideal, mas as novas tecnologias construtivas empregadas em sua fabricação vêm aperfeiçoando seu funcionamento desde o surgimento dos mesmos aproximando-os do ideal, como será visto a seguir.

\section{3 - Histórico de Desenvolvimento}

O primeiro dispositivo desenvolvido para proteção contra sobretensões foi o centelhador, ilustrado na Figura 4.1a, instalado entre fase e terra nas terminações de linhas e equipamentos. O mesmo utilizava como meio dielétrico o próprio ar e possuía seu funcionamento baseado no rompimento do dielétrico entre seus dois polos, a fim de limitar o valor da sobretensão a qual era exposto. Entretanto, o mesmo tinha o inconveniente de ocasionar curtos-circuitos frequentemente durante sua operação, requerendo a atuação conjunta de um mecanismo de proteção contra esse tipo de falta. Também sofria forte influência das condições atmosféricas em suas características disruptivas, e a incapacidade de interromper as correntes subsequentes (D’AJUZ et al., 1985; CEPEL, 1977).

Ainda neste contexto, surgiram os centelhadores do tipo chifre que devido a sua forma geométrica obtiveram uma redução da ocorrência de curto-circuito acidental em relação ao centelhador simples. Também apareceram os para-raios tipo expulsão, constituídos basicamente por dois centelhadores dispostos em um tubo isolante e conectados em série, cujo princípio de funcionamento é o mesmo atualmente adotado para os elos fusíveis de expulsão (D'AJUZ et al., 1985; MAMEDE, 2005).

Posteriormente, com o intuito de evitar o estabelecimento de curtos-circuitos no sistema, como ocorria com a aplicação dos centelhadores, foram desenvolvidos os para-raios constituídos por um resistor não linear em série com um centelhador, como mostrado na Figura 4.1b. Esta configuração possuía a finalidade de limitar a corrente de descarga, e seu resistor possuía uma resistência muito elevada, o que implicava na formação de uma tensão residual nos terminais destes para-raios (D’AJUZ et al., 1985; CEPEL, 1977; MAMEDE, 2005).

Em seguida, foram desenvolvidos os para-raios compostos por centelhador e resistores não lineares a base de carboneto de silício ( $\mathrm{SiC}$ ), como apontado na Figura 4.1c, com limitadores de corrente em virtude da necessidade provocada pelo aumento nos níveis de 
tensão dos sistemas elétricos, fazendo com que os para-raios tivessem que ser dotados de um centelhador ativo. $\mathrm{O}$ funcionamento destes instrumentos baseava-se no alongamento do arco elétrico através do centelhador com o auxílio de um campo magnético, e no descarregamento para a terra através do resistor não linear ao atingir o nível de tensão de proteção (D’AJUZ et al., 1985; CEPEL, 1977).

Apesar das melhorias sucessivas a utilização de centelhadores com limitadores de corrente demonstrou-se inapropriada ao proporcionar o surgimento de transitórios indesejáveis na tensão. Dessa maneira, diversas pesquisas sobre diferentes materiais para composição dos para-raios foram realizas até que sugiram os resistores não lineares de óxido de zinco cuja corrente de fuga é bem menor que a dos elementos compostos por SiC. Os para-raios empregados atualmente compõem-se apenas por resistores não lineares de $\mathrm{ZnO}$, como exposto na Figura 4.1d, e dispensam a utilização de centelhadores porque seu comportamento VxI resulta em correntes mínimas, da ordem de dezenas de miliampéres, para sua tensão de operação.

(a)

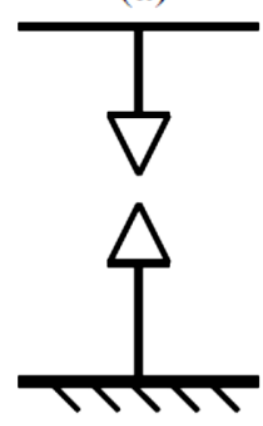

(b)

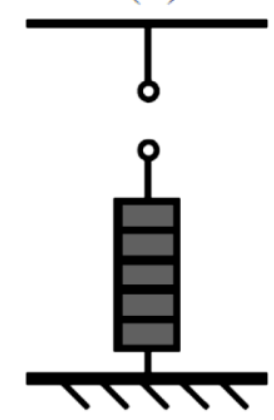

(c)

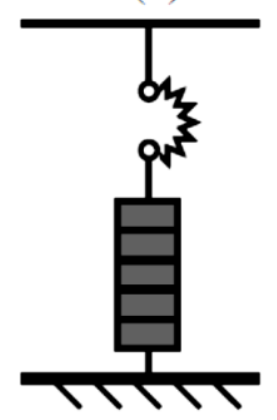

(d)

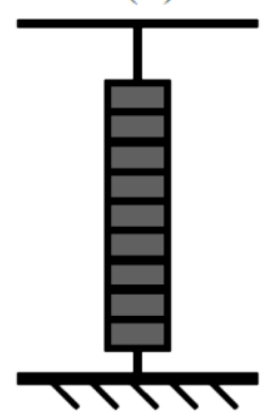

Figura 4.1: Evolução dos dispositivos de proteção contra sobretensões (D'AJUZ et al., 1985).

Como se observa na Figura 4.2, para níveis de tensão até o valor da tensão de operação $\left(U_{o p}\right)$ os para-raios de $\mathrm{SiC}$ frente a pequenas variações de tensão apresentam grandes variações na corrente de fuga drenada, da ordem de centenas de ampères, como indicado pelo ponto A. Enquanto que para estas mesmas variações de tensão a corrente de fuga nos para-raios de $\mathrm{ZnO}$ possuem valores extremamente baixos, da ordem de miliampéres, como indicado pelo ponto $\mathrm{B}$. Assim, devido à elevada não linearidade característica do $\mathrm{ZnO}$ a corrente de fuga em para-raios com este material é menor que em compostos por $\mathrm{SiC}$, sendo esta característica de corrente o fator determinante para que os mesmos sejam conectados diretamente ao sistema elétrico de potência sem a presença de centelhadores. 
Ainda na Figura 4.2 é possível identificar o ponto C, em que os para-raios entram em condução ao atingir a tensão de descarga $\left(U_{d}\right)$, a partir da qual flui no para-raios uma corrente de descarga de alta intensidade. Observa-se também o ponto $\mathrm{D}$, em que idealmente os pararaios deveriam limitar a tensão a um valor máximo $\left(U_{m}\right)$ pré-estabelecido drenado o excesso de corrente do sistema. Por fim, visualiza-se a curva representativa de um para-raios com comportamento ideal expressando a necessidade de um varistor com elevado grau de não linearidade, pois quanto maior o grau de não linearidade melhor o desempenho de atuação do para-raios (ZANETTA Jr., 2003; MAMEDE, 2005).

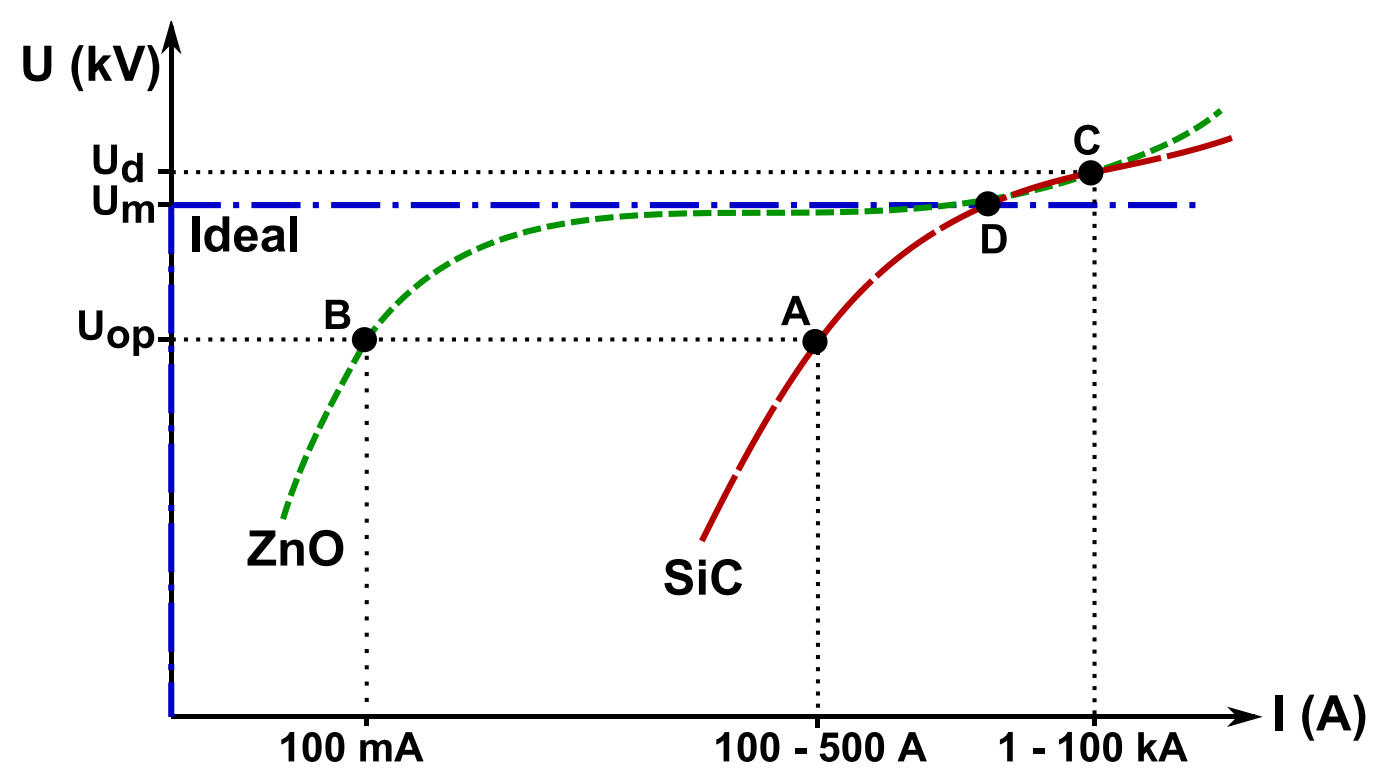

Figura 4.2: Curvas de tensão e corrente de para-raios de $\mathrm{ZnO}$, de $\mathrm{SiC}$ e ideal [adaptada de (MAMEDE, 2005)].

Contudo, quando se utilizam para-raios de $\mathrm{ZnO}$ sem centelhadores os mesmo podem ser solicitados por sobretensões temporárias ou transitórias impondo-lhes uma grande quantidade de energia que necessita ser dissipada a fim de garantir sua estabilidade térmica. Assim, os para-raios a $\mathrm{ZnO}$ sem centelhadores podem sofrer um fenômeno de avalanche térmica conhecido por Thermal Runaway. O mesmo consiste no aumento descontrolado da temperatura, a qual pode subir rapidamente e danificar o para-raios por meio da formação de pontos de superaquecimento, fusão e tensões devido aos elevados gradientes da mesma (SANTOS, 2007).

Segundo D’AJUZ et al. (1985) analisando a equação (4.1), que representa a característica não linear dos resistores a $\mathrm{ZnO}$ e $\mathrm{SiC}$, verifica-se que o $\mathrm{SiC}$ tem expoente $n$ de 
ordem 4 enquanto que o $\mathrm{ZnO}$ apresenta um expoente $n$ de ordem 25 , demonstrando à alta não linearidade do $\mathrm{ZnO}$.

$$
\mathrm{I}=\mathrm{kV}^{\mathrm{n}}
$$

Além disso, tomando como referência (MODRUSAN, 1983), (D’AJUZ et al., 1985), (SAKSHAUG, 1991), (FRANCO, 1993, 2001), (RINGLER et al., 1997), (DE NIGRIS et al., 1998) e (MELCHIOR, 2003), pode-se destacar algumas das vantagens em se utilizar os pararaios com resistores de $\mathrm{ZnO}$ quando comparados aos constituídos por resistores de $\mathrm{SiC}$, as quais são:

- Característica não linear do $\mathrm{ZnO}$ superior à do $\mathrm{SiC}$ na região de intensidade de baixas correntes;

- Construção mais simples, menor tempo de fabricação, e significativa redução de tamanho devido à ausência de centelhadores;

- Tempo de resposta reduzido frente a fenômenos transitórios e a impulsos de corrente;

- Desempenho superior na região de operação;

- Boa estabilidade quando continuamente solicitados pela tensão nominal de operação;

- Baixa tensão residual;

- Maior grau de confiabilidade;

- Estabilidade térmica;

- Elevada capacidade de absorção de energia para sobretensões temporárias e transitórias.

Ressalta-se que algumas destas vantagens podem ser identificadas por meio da Figura 4.2, como já foi exposto anteriormente, e através da Figura 4.3, que expõem as características não lineares entre tensão e corrente para o $\mathrm{ZnO}$ e o $\mathrm{SiC}$ em diferentes temperaturas. $\mathrm{Na}$ Figura 4.3 observa-se que os elementos de $\mathrm{ZnO}$ apresentam pequena dependência da temperatura apenas na zona de baixos valores de corrente, enquanto os de $\mathrm{SiC}$ exibem comportamento semelhante em uma zona de correntes mais elevadas.

Portanto, a partir do exposto conclui-se que as características de para-raios de $\mathrm{ZnO}$ possuem varias vantagens em relação aos de SiC que determinam seu melhor desempenho, o que justifica a substituição dos de $\mathrm{SiC}$ pelos de $\mathrm{ZnO}$ atualmente. Desse modo, por serem os únicos fabricados nos dias atuais e por se adequarem a esta pesquisa os para-raios de óxido de zinco serão abordados com mais detalhes a seguir. 


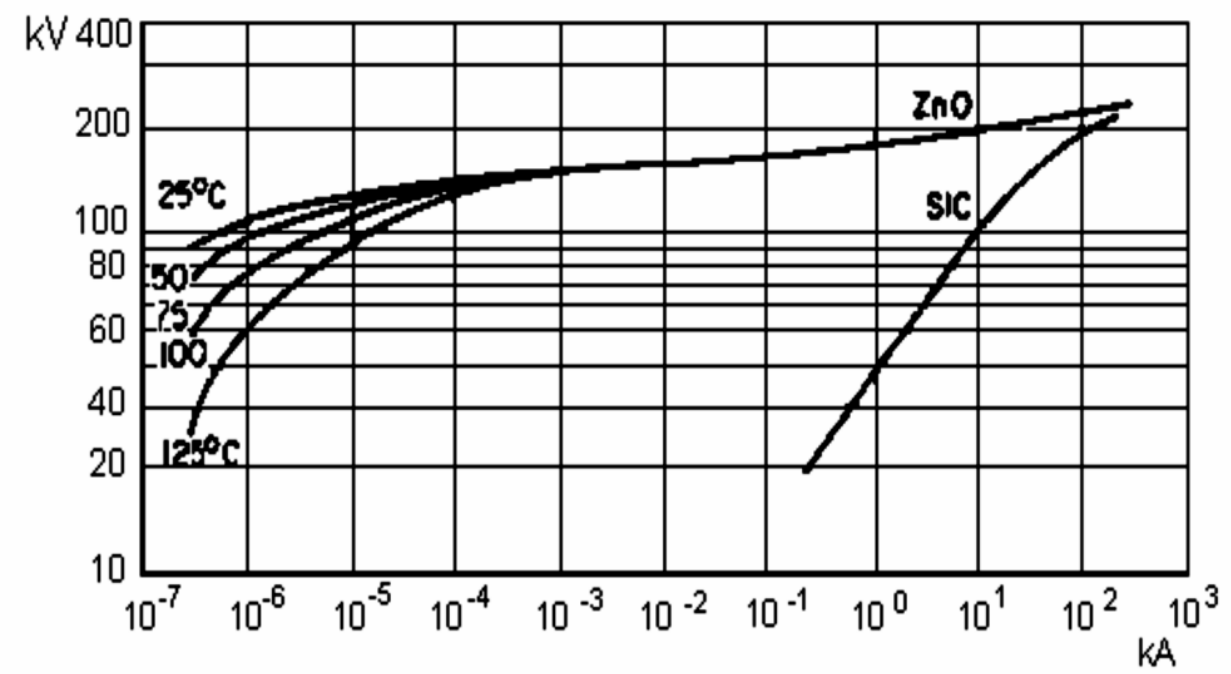

Figura 4.3: Característica de tensão e corrente para o carboneto de silício e o óxido de zinco (D'AJUZ et al., 1985).

\section{4 - Para-Raios de Óxido de Zinco}

Devido a superioridade de performance dos para-raios de $\mathrm{ZnO}$ e por estes serem os encontrados comercialmente hoje em dia, a seguir serão fornecidas as características construtivas dos mesmo, as particularidades de seus resistores e dos seus tipos de invólucros, alguns de seus fatores de degradação, e a descrição de algumas de suas especificações.

\subsection{1 - Características Construtivas dos Para-Raios de ZnO}

Os para-raios de $\mathrm{ZnO}$ são constituídos basicamente por blocos resistores de óxido de zinco dispostos em série, os quais determinam as características não lineares que definem a limitação das sobretensões, e são formados por um invólucro polimérico ou de porcelana, responsável pela proteção mecânica, isolação e estanqueidade dos componentes internos.

Dentre os elementos auxiliares que fazem parte da composição dos para-raios destacam-se os enumerados a seguir, que têm sua geometria e aplicabilidade determinadas de acordo com a necessidade do projeto do para-raios (ABB, 2012).

- Espaçadores de alumínio;

- Terminais de ligação; 
- Molas de compressão;

- Mecanismos de alívio de sobrepressão;

- Elementos de vedação;

- Duto de ventilação;

- Terminal de linha;

- Flange;

- Suporte de fixação.

Não obstante, a seguir serão descritos os dois componentes fundamentais aos pararaios citados acima, ou seja, os resistores de $\mathrm{ZnO}$ e os tipos de invólucro.

\subsubsection{1 - Características dos Resistores de ZnO}

Os resistores, ou varistores, de $\mathrm{ZnO}$ são dispositivos cerâmicos semicondutores com propriedades resistivas altamente não lineares, dependentes da tensão elétrica que existe entre seus terminais. Geralmente possuem formato cilíndrico e alta densidade de óxido metálico, da ordem de $5,4 \mathrm{~g} / \mathrm{cm}^{3}$ a $5,6 \mathrm{~g} / \mathrm{cm}^{3}$, sendo obtidos por meio de moldagem a altas pressões e sinterização a altas temperaturas sob atmosfera oxidante.

A primeira formulação proposta para composição dos varistores de $\mathrm{ZnO}$ foi desenvolvida por Matsuoka (1981) após aproximadamente uma década de estudos do mesmo sobre os óxidos que poderiam melhorar o desempenho destes varistores. Esta formulação clássica serviu como ponto de partida para diversas pesquisas neste segmento que culminaram com os varistores modernos de grande capacidade não linear e tempo de vida útil, a qual é mostrada na Tabela 4.1.

Tabela 4.1: Composição química clássica dos varistores de ZnO (OLIVEIRA, 2004).

\begin{tabular}{|c|c|}
\hline Componente & \% Molar \\
\hline $\mathrm{ZnO}$ & 96,5 \\
\hline $\mathrm{Bi}_{2} \mathrm{O}_{3}$ & 0,5 \\
\hline $\mathrm{Sb}_{2} \mathrm{O}_{3}$ & 1,0 \\
\hline $\mathrm{CoO}$ & 1,0 \\
\hline $\mathrm{MnO}$ & 0,5 \\
\hline $\mathrm{Cr}_{2} \mathrm{O}_{3}$ & 0,5 \\
\hline
\end{tabular}


Atualmente, os varistores de $\mathrm{ZnO}$ são produzidos por diferentes processos industriais que determinam, em conjunto com o tipo de aplicação requerida, suas características para garantir respostas compatíveis frente aos impulsos de corrente, sua capacidade de absorção de energia e tensão nominal demandada, tais como (FRANCO, 1993):

- Pureza e qualidade dos materiais usados;

- Variedade de óxidos empregados;

- Concentração dos dopantes;

- Homogeneidade da mistura;

- Área do eletrodo;

- Forma de prensagem dos pós de óxido metálico;

- Dimensão, geometria e massa do varistor.

Nesta conjuntura, na Tabela 4.2 são apresentadas as particularidades dos principais componentes empregados na fabricação dos varistores de $\mathrm{ZnO}$ produzidos hoje em dia.

Tabela 4.2: Características dos óxidos mais utilizados na fabricação de varistores de $\mathrm{ZnO}$

(FRANCO, 1993).

\begin{tabular}{|c|c|c|c|c|c|c|}
\hline Óxido & Fórmula & $\begin{array}{c}\text { Peso } \\
\text { Molecular }\end{array}$ & $\begin{array}{c}\text { Densidade } \\
\left(\mathrm{g} / \mathrm{cm}^{3}\right)\end{array}$ & $\begin{array}{c}\text { Ponto de } \\
\text { Fusão } \\
\left({ }^{\circ} \mathrm{C}\right)\end{array}$ & $\begin{array}{c}\text { Pureza } \\
(\%)\end{array}$ & $\begin{array}{c}\text { Tamanho Médio } \\
\text { das Partículas } \\
(\mu \mathrm{m})\end{array}$ \\
\hline Zinco & $\mathrm{ZnO}$ & 81,37 & 5,61 & 1975 & 99,9 & $0,1-0,5$ \\
\hline Bismuto & $\mathrm{Bi}_{2} \mathrm{O}_{3}$ & 465,96 & 8,9 & 825 & 99,9 & $5-10$ \\
\hline Cobalto & $\mathrm{Co}_{2} \mathrm{O}_{3}$ & 165,86 & 5,18 & 895 & 99,9 & $1-5$ \\
\hline Manganês & $\mathrm{MnO}_{2}$ & 86,94 & 5,03 & 535 & 99,9 & $5-10$ \\
\hline Antimônio & $\mathrm{SB}_{2} \mathrm{O}_{3}$ & 291,5 & 5,2 & 656 & 99,9 & $1-5$ \\
\hline Níquel & $\mathrm{NiO}^{2}$ & 74,71 & 6,67 & 1984 & 99,9 & $1-5$ \\
\hline Cromo & $\mathrm{Cr}_{2} \mathrm{O}_{3}$ & 151,99 & 5,21 & 2266 & 99,9 & $1-5$ \\
\hline
\end{tabular}

Por outro lado, em virtude do seu arranjo, as junções óxido de zinco - camada intergranular apresentam cargas fixas que formam regiões de depleção, o que faz com que ocorra a formação de barreiras simétricas ao redor dos grãos de $\mathrm{ZnO}$ e na camada intergranular que os envolvem, conhecidas como Barreiras de Schottky. Estas barreiras simétricas causam o desempenho não linear destas junções e, consequentemente, dos 
resistores, o que torna possível afirmar que cada conjunto camada intergranular - grão de óxido de zinco - camada intergranular opera como um circuito ceifador, com tensão de corte em torno de 2,5 V a $3 \mathrm{~V}$ de crista (SANTOS, 2007).

A não linearidade, propriedade mais importante dos varistores de $\mathrm{ZnO}$, é caracterizada pela curva de tensão (V) versus corrente (I) como ilustrado na Figura 4.4, em que são destacadas suas três regiões de operação que podem ser explicadas por meio da atuação das Barreiras de Schottky, definidas como:

- Região - I: região linear de baixas densidades de corrente, ou região de pré-ruptura;

- Região - II: região de operação altamente não linear, ou região de ruptura;

- Região - III: região linear para altas densidades de corrente, ou região de retorno.

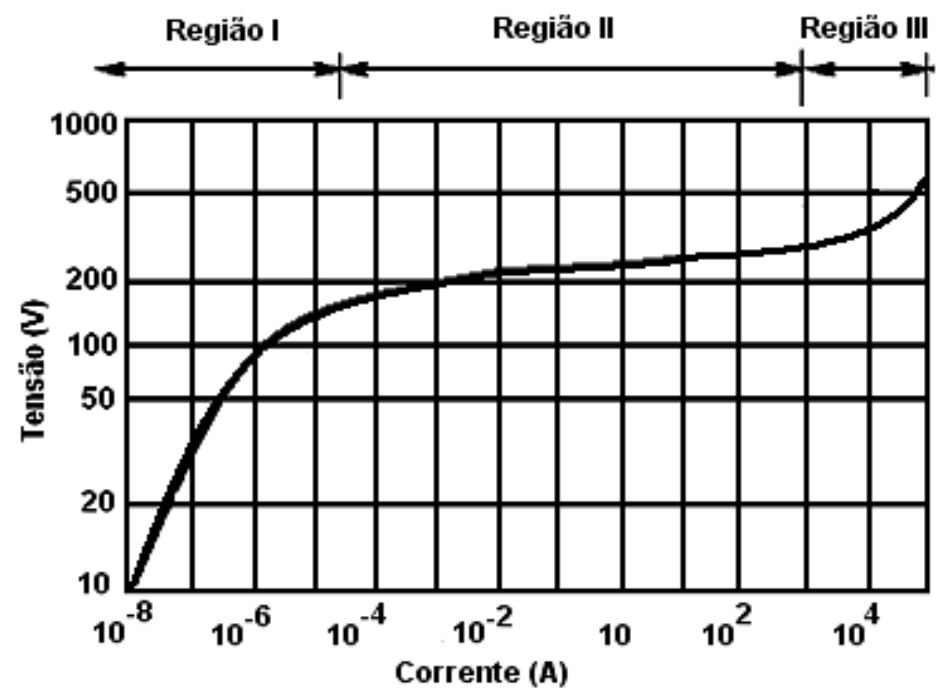

Figura 4.4: Curva característica de $\mathrm{V}$ versus $\mathrm{I}$ para um resistor não linear de ZnO [adaptada de (OLIVEIRA, 2004)].

A Região - I é definida como a região de baixa densidade de corrente correspondendo à atuação do varistor na ausência de sobretensões, na qual o mesmo pode encontrar-se submetido a uma tensão máxima menor ou igual a sua máxima tensão de operação. Estas tensões resultam em um campo elétrico de baixa densidade, insuficiente para promover uma diminuição expressiva na altura das suas barreiras de potencial. Como consequência o resistor a $\mathrm{ZnO}$ apresenta comportamento característico de um resistor linear de alto valor fazendo com que por ele passe apenas uma corrente de fuga dependente da temperatura (FRANCO, 1993; SANTOS, 2007).

Já a Região - II é definida como a região de média densidade de corrente, relativa à essência da ação de um resistor não linear de $\mathrm{ZnO}$, uma vez que na mesma o varistor conduz 
de modo crescente ampla quantidade de corrente elétrica para um pequeno incremento de tensão. Este aumento de tensão acarreta um acréscimo do campo elétrico, e, por conseguinte, causa uma redução da altura das barreiras de potencial, obrigando o resistor de $\mathrm{ZnO}$ a apresentar desempenho altamente não linear. Além disso, é por meio desta região que se defini o nível de proteção dos para-raios quando submetidos às correntes de impulso atmosférico ou de manobra, e na mesma a característica $\mathrm{V}$ x I é quase independente da temperatura. Contudo, para se obter o correto funcionamento dos varistores de $\mathrm{ZnO}$ nesta região é fundamental que seus caminhos de corrente apresentem um mesmo número de barreiras. Isto ocorre, pois qualquer heterogeneidade do material provoca uma distribuição não uniforme de corrente e o consequente aquecimento localizado do varistor, o qual pode levar a sua perfuração ou trinca quando submetidos aos surtos de tensão e corrente (FRANCO, 1993; SANTOS, 2007).

E na Região - III a característica V x I é novamente linear, análoga aquela da Região I, mas com a tensão aumentando mais rapidamente com a corrente devido à resistência própria finita dos grãos de $\mathrm{ZnO}$ da estrutura do varistor. Tal fato também se deve a redução das barreiras de potencial até certo limite a partir do qual o resistor a $\mathrm{ZnO}$ volta a proporcionar um comportamento igual ao de um resistor linear de baixo valor (FRANCO, 1993; SANTOS, 2007).

O coeficiente de não linearidade $(\alpha)$, principal parâmetros dos varistores de óxido de zinco, define-se como o recíproco da inclinação da curva I x V ou da curva $J$ x E (densidade de corrente elétrica versus intensidade do campo elétrico aplicado), na região não linear, e pode ser calculado pela equação (4.2).

$$
\alpha=\frac{d[\log I]}{d[\log V]}
$$

Por fim, ressalta-se que quanto maior o valor de $\alpha$ maior a não linearidade do varistor e melhor seu desempenho, e que para os varistores à base de $\mathrm{ZnO}$ este parâmetro pode variar na faixa de 25 a 100, mas na maioria das aplicações comerciais $\alpha$ varia entre 25 e 60 . Ademais, o valor de $\alpha$ é inversamente proporcional às condições de temperatura e pressão sob as quais o varistor está submetido, já que diminui com o incremento de ambas, e também decresce com o aumento da densidade de corrente, como mostrado pela Figura 4.5. Fato este, que pode ser amenizado por meio da diminuição da resistividade elétrica dos grãos de $\mathrm{ZnO}$ mediante uma dopagem moderada por Al (Alumínio), Ga (Gálio) ou In (Índio), pois o 
excesso destes elementos pode levar a uma elevada redução do valor de $\alpha$ (FURTADO, 2005).

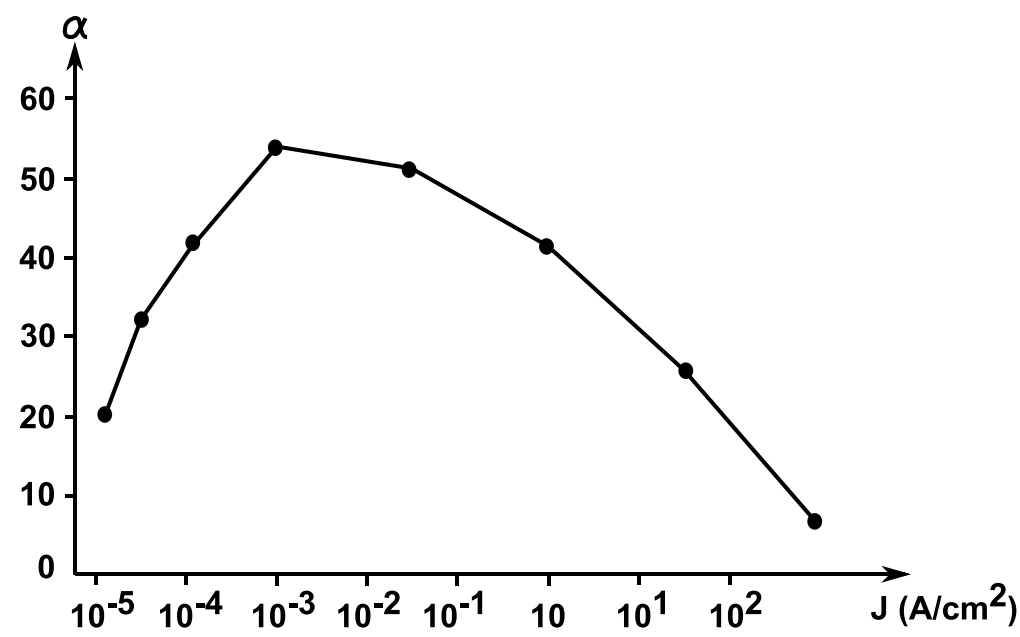

Figura 4.5: Dependência do coeficiente não linear $(\alpha)$ em relação à densidade de corrente elétrica [adaptada de (FURTADO, 2005)].

\subsubsection{2 - Tipos de Invólucros dos Para-Raios de ZnO}

Os para-raios de ZnO com invólucros de porcelana datam da década de 1970 e são montados com os resistores de forma concêntrica dentro do invólucro com geometria para minimizar os efeitos da distribuição não uniforme de campo elétrico e de ionização interna, mesmo sob condições severas de poluição externa. Também possuem mecanismos de alívio de sobrepressão dentro dos flanges terminais para evitar que o para-raios sofra algum tipo de explosão devido a solicitações superiores às especificadas, evitando a danificação de outros equipamentos e o risco de acidentes para pessoas localizadas em suas adjacências.

A Figura 4.6 mostra em detalhe um para-raios de distribuição com invólucro de porcelana com seus respectivos componentes indicados e numerados, a saber (HINRICHSEN, 2001):

1 - Mola de compressão;

2 - Diafragma de alívio de pressão;

3 - Terminal de terra com interruptor;

4 - Terminal de alta tensão;

5 - Invólucro de porcelana;

6 - Pilha de resistor de óxido metálico com apoio para construção; 
7 - Suporte de montagem;

8 - Anel de vedação;

9 - Flange com ventilação de saída.

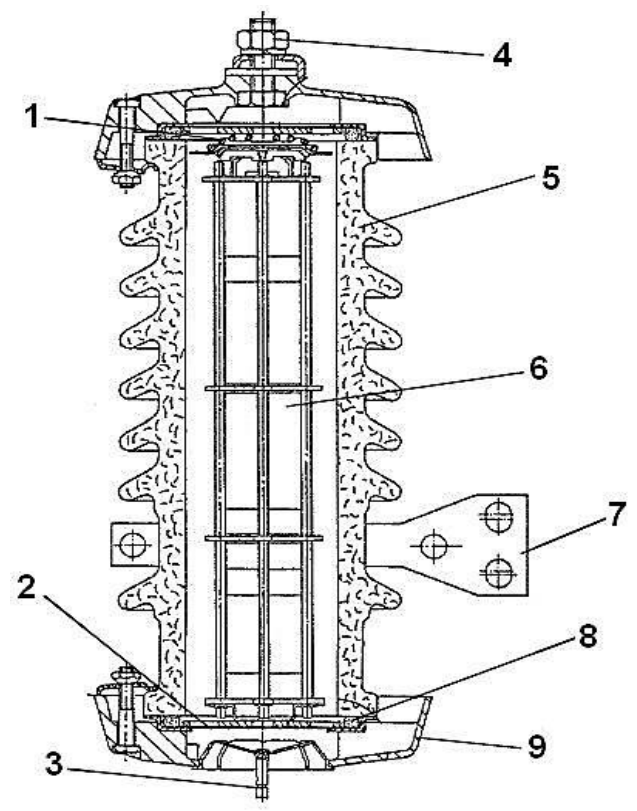

Figura 4.6: Constituição de um para-raios de distribuição com invólucro de porcelana [adaptada de (HINRICHSEN, 2001)].

Posteriormente, em meados da década de 80 surgiram os para-raios com invólucro polimérico que proporcionaram melhorias quanto às características mecânicas, físicas e de desempenho, os quais são subdivididos em duas categorias, com e sem espaçamento interno de ar.

Os para-raios com espaços internos de ar são montados de maneira semelhante aos com invólucro de porcelana, sendo o polímero do invólucro injetado sobre um tubo de fibra de vidro de alta resistência mecânica. Os blocos de $\mathrm{ZnO}$ são inseridos dentro do invólucro, formando-se o espaçamento interno de ar entre a parte interior do polímero e os blocos de $\mathrm{ZnO}$, o que acarreta a necessidade de utilização de dispositivos de alívio de sobrepressão.

Nos para-raios sem espaços internos de ar os blocos de $\mathrm{ZnO}$ são envoltos em um tubo de fibra de vidro impregnado em resina epóxi, e o invólucro polimérico é aplicado sobre o tubo pelo processo de injeção de borracha ou de moldagem. Como este tipo é mais comum do que o com espaços de ar, na Figura 4.7, é exposto um para-raios de distribuição com invólucro polimérico sem espaços internos de ar com seus respectivos elementos apontados e numerados a seguir (HINRICHSEN, 2001): 
1 - Ancoragem com terminal de alumínio;

2 - Invólucro polimérico de borracha de silicone;

3 - Pilha de resistores de óxido metálico;

4 - Hastes reforçadas de fibra de vidro plástico.

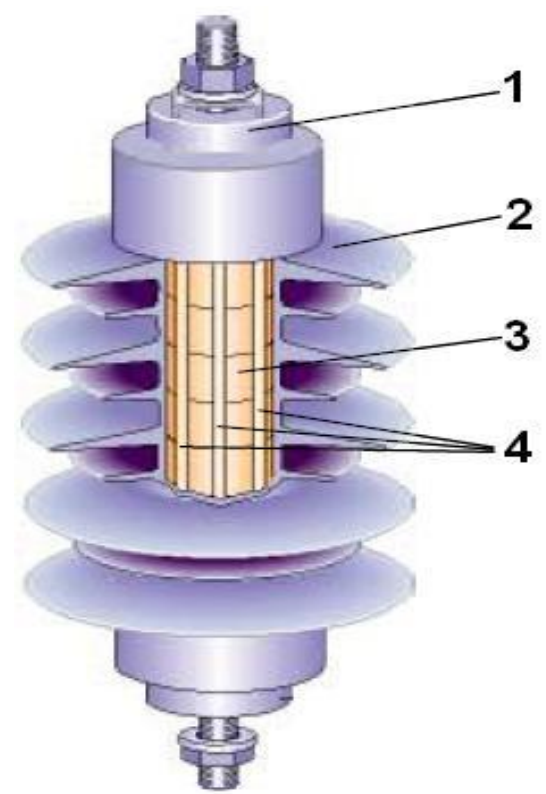

Figura 4.7: Constituição de um para-raios de distribuição com invólucro polimérico [adaptada de (HINRICHSEN, 2001)].

Além disso, devido às diferentes necessidades e formas de montagem os para-raios poliméricos podem ser compostos por apenas uma ou varias seções, e por uma ou mais colunas dispostas em paralelo. Ressalta-se que os para-raios multi-colunas são empregados em situações nas quais é preciso maior capacidade de absorção de energia, seus blocos de resistores de $\mathrm{ZnO}$ podem estar dentro de um mesmo invólucro ou em invólucros separados. Ainda, em virtude do arranjo série e paralelo dos seus blocos de resistores deve-se atentar para que a repartição de corrente seja a mais uniforme possível garantindo seu correto funcionamento.

Cabe observar que os para-raios com invólucro polimérico possuem algumas vantagens técnicas e econômicas em relação aos de porcelana, o que tem tornado sua utilização cada vez maior, as quais seguem a seguir (COLOMBO et al., 1996; DE NIGRIS et al., 1998; LAHTI et al., 2001):

- Desempenho superior sob contaminação;

- Maior nível de segurança em caso de falha; 
- Facilidade de transporte, armazenamento, manuseio e instalação;

- Melhor performance mecânica;

- Menor peso e tamanho do invólucro;

- Menor corrente de fuga, e consequente redução das perdas de energia;

- Maior capacidade de absorção de energia devido a uma melhor capacidade de dissipação de calor.

\subsection{2 - Fatores de Degradação dos Para-Raios de ZnO}

A degradação do funcionamento dos varistores de para-raios de $\mathrm{ZnO}$ está associada a diversos fatores técnicos e ambientais que podem ser de origem elétrica, térmica, mecânica ou química. Em geral conduzem a um aumento da dissipação de energia provocando elevação excessiva da temperatura, que ao ultrapassar os limites especificados para atuação dos mesmos podem resultar em sérios problemas comprometendo o seu desempenho e reduzindo sua vida útil.

Dentre estes fatores, a perda de estanqueidade por trincas no invólucro ou deterioração da vedação dos dispositivos de alívio de sobrepressão, ao unir-se com o efeito do depósito de resíduos e da penetração de umidade, causa alterações expressivas dos níveis e da distribuição de tensão, e a elevação do valor da corrente de fuga comprometendo o isolamento externo. Como consequência ocorre à redução da capacidade de absorção de energia dos mesmos em casos de distúrbios no sistema elétrico, e o aquecimento excessivo e envelhecimento dos seus blocos de ZnO (FRANCO, 1993).

Já a contaminação do invólucro por chuva, fumaça ou deposição de resíduos de poluição é mais crítica em para-raios de porcelana do que nos poliméricos. Esta é capaz de gerar descargas internas que dão origem a gases que podem alterar as propriedades químicas e dielétricas do material isolante que recobre os varistores. Tal fato acaba acelerando seu envelhecimento e desviando correntes para sua superfície, o que também compromete a adequada atuação dos mesmos (SCHEI; FRANCO, 1999).

Outro fator importante que influi na degradação dos varistores de $\mathrm{ZnO}$ são solicitações transitórias de longa duração e de alta intensidade e curta duração. As primeiras quando não consideradas durante o projeto e seleção do para-raios ao ocorrer podem acarretar a queima ou rachadura dos blocos cerâmicos, e as do segundo tipo podem originar a 
perfuração dos blocos devido à concentração da corrente em um único ponto. A degradação proveniente de solicitações transitórias gera redução gradual da máxima temperatura para a qual o varistor tem a capacidade de dissipar a energia proveniente destes surtos, ou seja, diminui a capacidade de absorção de energia dos varistores (FRANCO, 1993).

Atualmente há três gerações de resistores a óxido de zinco cujo desempenho frente a uma determinada tensão em frequência industrial sugere que os resistores mais modernos possuem uma tendência a se auto estabilizarem quando submetidos a estas solicitações. A vida operacional dos mesmos pode ser decomposta em três regiões, as quais são demonstradas na Figura 4.8 e definidas da seguinte maneira (SANTOS, 2007):

- Região I: região estável na qual ocorre o envelhecimento do resistor;

- Região II: região em que acontece um pequeno acréscimo na taxa de crescimento da corrente de fuga tornando difícil a manutenção do equilíbrio térmico, evidenciando o início do processo de instabilidade;

- Região III: região na qual se processa um grande aumento na taxa de crescimento da corrente de fuga e perda do equilíbrio térmico, ratificando o processo de instabilidade, e onde se averigua o acontecimento do fenômeno Thermal Runaway, citado na seção 4.3.

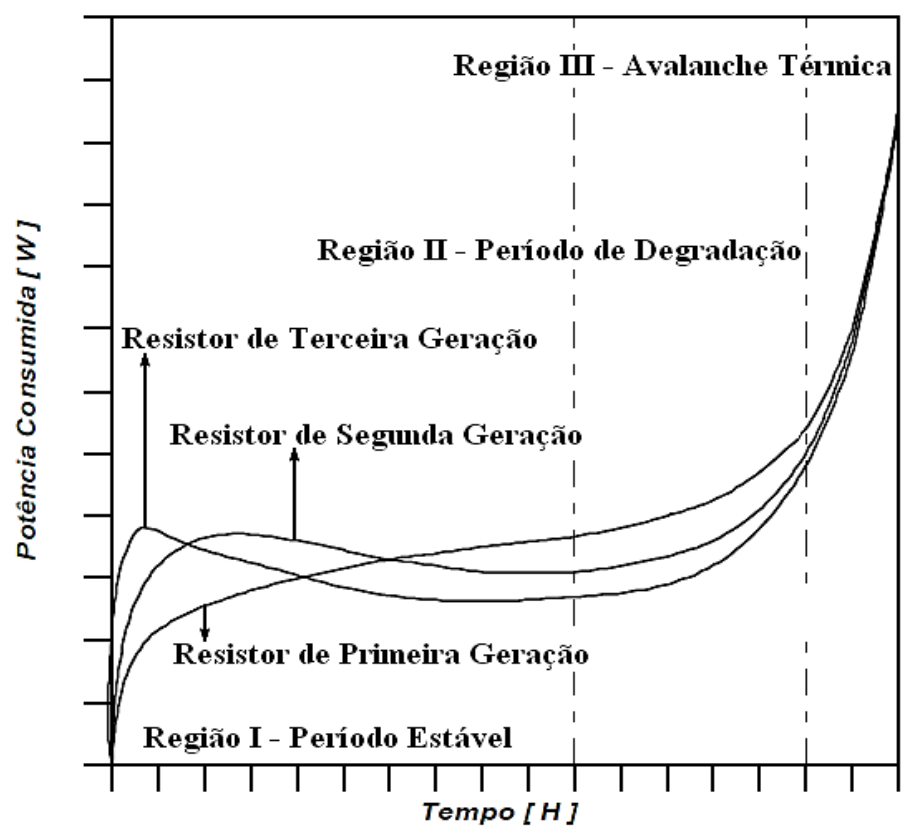

Figura 4.8: Característica potência consumida versus tempo para resistores de $\mathrm{ZnO}$ de primeira, segunda e terceira geração (SANTOS, 2007).

$\mathrm{O}$ envelhecimento dos resistores a $\mathrm{ZnO}$ também se origina das descargas de surtos de corrente de origem atmosférica e de manobra, sendo que o mesmo é fundamentalmente 
condicionado à forma do impulso da descarga, a densidade de corrente através do resistor, a temperatura do resistor, a polaridade dos surtos e número de descargas, como se observa na Figura 4.9 e na Figura 4.10. Estas se referem a impulsos atmosféricos e a impulsos de manobra respectivamente, e por meio delas se conclui que quanto maior a densidade de corrente imposta aos resistores de $\mathrm{ZnO}$ maior será o aumento na corrente de fuga.

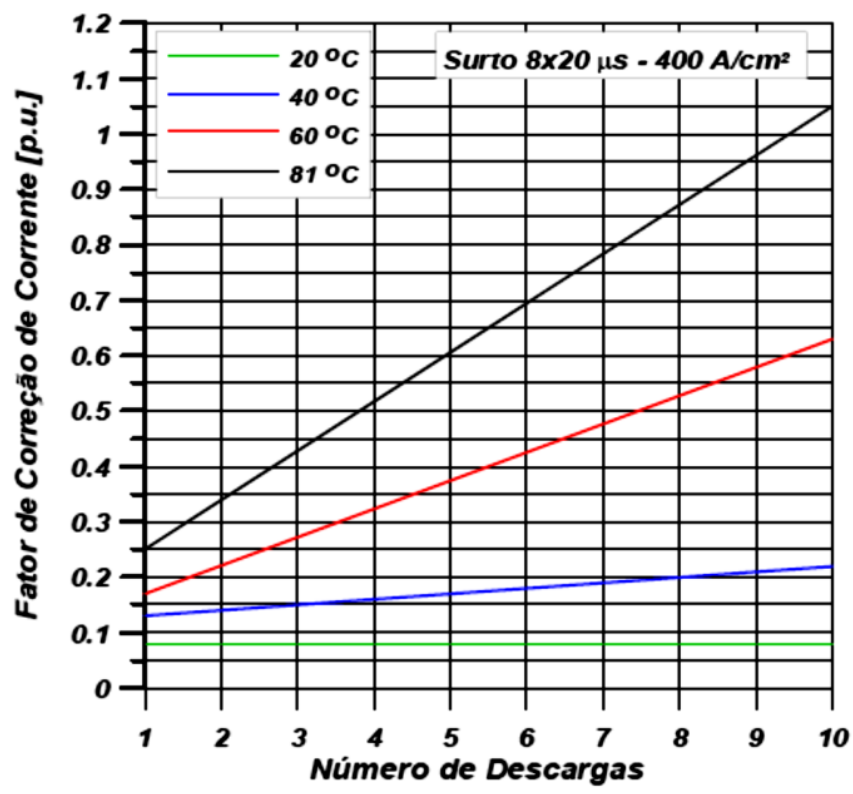

Figura 4.9: Fator de correlação da corrente de fuga com o número de descargas para um resistor a óxido de zinco típico para um surto de 8x20 $\mu \mathrm{s}-400 \mathrm{~A} / \mathrm{cm}^{2}$ (SANTOS, 2007).

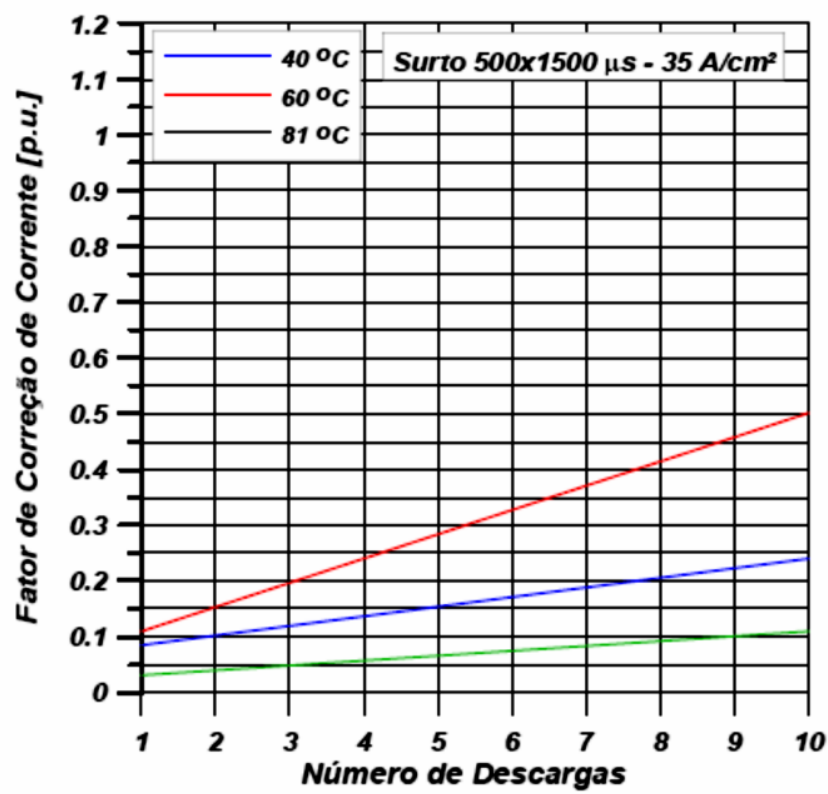

Figura 4.10: Fator de correlação da corrente de fuga com o número de descargas para um resistor a óxido de zinco típico para um surto de 500x1500 $\mu \mathrm{s}-35 \mathrm{~A} / \mathrm{cm}^{2}$ (SANTOS, 2007). 


\subsection{3 - Especificações dos Para-Raios}

A correta seleção e especificação de um para-raios para adequada proteção de um equipamento, ou de um grupo de equipamentos, deve levar em consideração uma série de fatores. Dentre os mesmos, os mais relevantes a esta pesquisa serão expostos a seguir baseando-se nas definições apresentadas por Franco (2008), D’Ajuz et al. (1985) e ABB (2012), para um para-raios de $\mathrm{ZnO}$ sem centelhador.

- Tensão Nominal: é um parâmetro de referência para a especificação das características de proteção e operação do para-raios. É definida como a tensão eficaz, na frequência industrial, que pode ser aplicada ao para-raios sem que o mesmo perca sua estabilidade térmica ou deixe de operar corretamente, quando submetido a uma sobretensão por 10 segundos depois de ter sido aquecido a $60^{\circ} \mathrm{C}$, e após absorver uma energia prévia definida no ensaio de ciclo de operação.

- Tensão Residual: é o máximo valor da tensão que se estabelece entre os terminais do para-raios quando este é atravessado por uma corrente de descarga na forma $8 \times 20 \mu$ s. Seu valor é determinado em função da forma, amplitude e taxa de crescimento da corrente de impulso a qual o para-raios é submetido.

- Tensão Máxima de Disparo para Impulso Atmosférico: é o maior valor de tensão de disparo do para-raios quando submetido a impulsos do tipo $1,2 \times 50 \mu \mathrm{s}$.

- Máxima Tensão Contínua de Operação (MCOV): é a máxima tensão eficaz em frequência industrial para a qual o para-raios é projetado e que pode ser aplicada continuamente aos seus terminais sem que altere suas propriedades elétricas ou térmicas.

- Capacidade de Sobretensão Temporária (TOV): é determinada em função da característica de suportabilidade tensão versus duração, em que é indicada a quantidade de tempo para a qual é permitida a aplicação de uma tensão superior a tensão máxima de operação em regime continuo nos terminais do para-raios. 
- Capacidade de Curto-circuito: é a capacidade de um para-raios de, na eventualidade de uma sobrecarga por qualquer motivo, conduzir a corrente de curto-circuito resultante do sistema sem abalos violentos que possam danificar os equipamentos próximos ou ferir pessoas. Após tal operação, o para-raios deve ser substituído.

- Capacidade do Isolamento Externo: é o valor máximo da tensão aplicada, com uma forma de onda específica, que não causa descarga disruptiva em um para-raios. Ao contrário de outros equipamentos, os para-raios são projetados para descarregar internamente e a tensão através do seu encapsulamento não pode nunca exceder os níveis de proteção. Assim, o isolamento externo está autoprotegido se a sua capacidade for superior à dos níveis de proteção corrigidos para a altitude de instalação.

- Capacidade de Absorção de Energia: é o valor da maior quantidade de energia a que pode ser submetido um para-raios, em condições preestabelecidas, sem que as suas características sofram alterações significativas após o retorno às condições normais de operação.

- Corrente de Descarga Nominal: é a corrente impulsiva que flui pelo para-raios quando o mesmo é submetido a uma sobretensão, e cujo valor nominal é determinado como o valor de crista da corrente na forma de impulso $8 / 20 \mu$ s utilizado para classificar o para-raios.

- Corrente de Referência: é o valor de crista da componente resistiva da corrente de frequência industrial aplicada ao para-raios para definir sua tensão de referência, e seus valores típicos se situam na faixa entre 1 e $20 \mathrm{~mA}$.

- Tensão de Referência: é o valor de crista da tensão de frequência fundamental dividida por 2, que se estabelece nos terminais do para-raios quando por ele circula a corrente de referência, definindo o ponto de transição entre as regiões de baixas correntes e de alta não linearidade.

Posto isto, o conhecimento da curva associado às especificações nela contidas é importante para a escolha de um para-raios pelo projetista do sistema de proteção de uma 
subestação, linha de transmissão ou linha de distribuição. A título de ilustração a Figura 4.11 mostra o esboço de uma curva característica de um varistor de $\mathrm{ZnO}$ com alguns dos valores típicos das especificações descritas anteriormente.

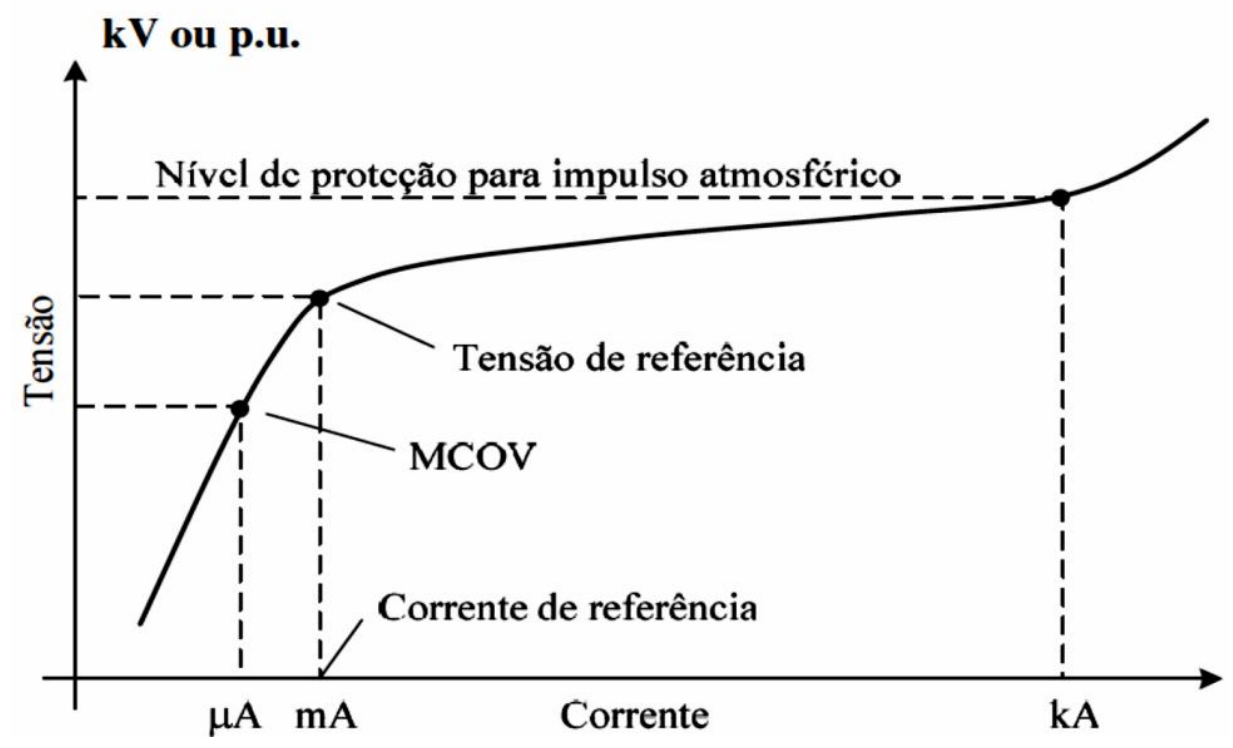

Figura 4.11: Curva característica típica de um varistor de ZnO (FRANCO, 2008).

\section{5 - Considerações Parciais sobre a Utilização de Para- raios de $\mathrm{ZnO}$}

Por meio do exposto nas seções anteriores deste capítulo averígua-se que a aplicação dos para-raios como equipamentos de proteção contra sobretensões de origem atmosférica condiz com suas especificações e características de funcionamento. Fato este, demonstrado uma vez que estes dispositivos atuam como agentes limitadores, tentando impedir que tensões acima de um determinado nível pré-estabelecido possam alcançar os equipamentos para os quais fornecem proteção.

Como apresentado os para-raios de óxido metálico, fabricados atualmente, empregam os matérias mais adequados para composição dos seus varistores a fim de obterem-se resistores com características altamente não lineares e que possuam correntes de fuga reduzidas. Somados ao seu comportamento VxI que resulta em correntes mínimas, da ordem de miliampéres, para sua tensão de operação, estes fatores evitam o estabelecimento de curtos-circuitos entre seus terminais possibilitando que os mesmos sejam conectados 
diretamente ao sistema elétrico de potência sem a presença de centelhadores, o que facilita sua instalação e minimiza seus custos de aplicação.

Também foram descritas e mostradas por meio de gráficos às características e parâmetros de tensão e corrente destes equipamentos para sua entrada e saída em condução, seus tipos de invólucros, fatores de degradação, e alguns de seus critérios de especificação. Aspectos estes que devem ser avaliados e analisados conjuntamente com as características da linha durante a seleção dos para-raios para que seja escolhida a adequada configuração dos mesmos, tal como será realizado no capítulo 7.

Posto isto, a seguir serão mostradas as técnicas e os procedimentos utilizados para modelagem e implementação computacional de um alimentador de distribuição de energia elétrica, do sistema para estimação de tensões induzidas pelo Modelo de Rusck, e dos pararaios de óxido de zinco responsáveis pela proteção do sistema de distribuição. 


\section{CAPÍtUlO 5}

\section{MODELAGENS E IMPLEMENTAÇÕES COMPUTACIONAIS}

Com a finalidade de dar prosseguimento a esta pesquisa no presente capítulo serão efetuadas as modelagens e implementações computacionais da linha de distribuição a ser analisada, do subsistema para estimação de tensões induzidas pelo Modelo de Rusck, e dos para-raios de óxido de zinco adequados ao sistema de distribuição desta pesquisa.

Toda a modelagem e implementação será realiza utilizando o ambiente gráfico Simulink® e o software MATLAB®, por meio das quais serão executadas simulações para conferência e verificação do comportamento da modelagem do alimentador, do modelo de estimação de tensões induzidas e dos para-raios escolhidos.

Dessa forma, serão obtidos parâmetros da linha e dados sobre seu comportamento em regime permanente, e informações relativas às tensões induzidas por descargas indiretas, os quais serão necessários para definição das características elétricas dos para-raios a serem modelados.

\section{1 - Alimentador teste de distribuição de energia elétrica}

Com a finalidade de avaliar a influência das tensões induzidas em sistemas de distribuição foi escolhido um alimentador teste para implementação computacional de forma que as proposições desse trabalho fossem passíveis de estudo. Os parâmetros deste alimentador serão empregados para definição das características elétricas dos para-raios a serem modelados e para análise da proteção exercida pelos mesmos. Dessa forma, a seguir, serão expostas as características dos componentes do alimentador teste de 13 nós do IEEE (IEEE 13 Node Test Feeder) e sua modelagem. 


\subsection{1 - Características do alimentador}

O alimentador selecionado tem seus parâmetros apresentados em (KERSTING, 2001) e em (IEEE, 2013), e como diferencial, alguns resultados de simulações computacionais para conferência de sua modelagem e implementação, tais como:

- Listagem das matrizes de impedância e admitância fase por milha para cada uma das configurações utilizadas no alimentador. A matriz impedância assume uma resistividade de $100 \Omega / \mathrm{m}$ e a matriz admitância uma permissividade relativa de 2,3 ;

- Sumário do fluxo radial: resumo da entrada do sistema, carga total e perdas totais;

- Perfil de tensão: magnitude e ângulo da tensão por fase em cada nó, sendo que estas magnitudes são dadas em pu;

- Dados do regulador de tensão: resumo das configurações e dos seus ajustes finais de tap;

- Fluxo de potência radial: dados completos do nó incluindo os fluxos de linha em ampères e graus por fase. Perdas de energia da linha por fase e total trifásica também são dadas.

Apesar de pequeno o IEEE 13 Node Test Feeder foi selecionado devido a suas variadas particularidades e de seus elementos constituintes, e por seus dados serem de livre acesso, o que possibilita a realização de outras pesquisas no mesmo segmento desta para fins de comparação e avaliação. Dentre suas características destacam-se as seguintes (KERSTING, 2001):

- Curto e relativamente altamente carregado para um alimentador de $4,16 \mathrm{kV}$;

- Possui um regulador de tensão para a subestação composto por três unidades monofásicas ligadas em Y;

- Linhas aéreas e subterrâneas com variação de fase e de suas propriedades físicas e elétricas para cada um dos seus trechos;

- Bancos de capacitores em derivação;

- Transformador rebaixador na subestação e em um ramo da linha;

- Cargas desbalanceadas concentradas e distribuídas. 
Pormenorizando os elementos constituintes deste alimentador tem-se 1 transformador, conectado diretamente a subestação, 1 transformador rebaixador de linha, 2 modelos de bancos de capacitores em derivação; 8 tipos de cargas concentradas e 1 tipo de carga distribuída. As especificações de cada um dos componentes do alimentador a ser modelado, bem como a localização de cada nó, são apresentadas nas Tabelas de 5.1 a 5.5, abaixo.

Tabela 5.1: Parâmetros dos transformadores (IEEE, 2013).

\begin{tabular}{|c|c|c|c|c|c|}
\hline & kVA & kV-Alta & kV-Baixa & R - \% & X -\% \\
\hline Subestação & 5.000 & $115-\mathrm{D}$ & $4,16-\mathrm{Yg}$ & 1 & 8 \\
\hline XFM -1 & 500 & $4,16-\mathrm{Yg}$ & $0,48-\mathrm{Yg}$ & 1,1 & 2 \\
\hline
\end{tabular}

Tabela 5.2: Parâmetros dos capacitores de derivação (IEEE, 2013).

\begin{tabular}{|c|c|c|c|}
\hline \multirow{2}{*}{ Nó } & Fase-A & Fase-B & Fase-C \\
\cline { 2 - 4 } & kVAr & kVAr & kVAr \\
\hline 675 & 200 & 200 & 200 \\
\hline 611 & & & 100 \\
\hline Total & 200 & 200 & 300 \\
\hline
\end{tabular}

Tabela 5.3: Características da carga distribuída (IEEE, 2013).

\begin{tabular}{|c|c|c|c|c|c|c|c|c|}
\hline \multirow{2}{*}{ Nó A } & \multirow{2}{*}{ Nó B } & \multirow{2}{*}{$\begin{array}{l}\text { Modelo } \\
\text { da carga }\end{array}$} & Fase-1 & Fase-1 & Fase-2 & Fase-2 & Fase-3 & Fase-3 \\
\hline & & & $\mathrm{kW}$ & $\mathrm{kVAr}$ & $\mathrm{kW}$ & $\mathrm{kVAr}$ & $\mathrm{kW}$ & $\mathrm{kVAr}$ \\
\hline 632 & 671 & Y-PQ & 17 & 10 & 66 & 38 & 117 & 68 \\
\hline
\end{tabular}

Tabela 5.4: Características das cargas concentradas (IEEE, 2013).

\begin{tabular}{|c|c|c|c|c|c|c|c|}
\hline \multirow{2}{*}{ Nó } & \multirow{2}{*}{$\begin{array}{c}\text { Modelo da } \\
\text { carga }\end{array}$} & Fase-1 & Fase-1 & Fase-2 & Fase-2 & Fase-3 & Fase-3 \\
\cline { 3 - 8 } & kW & kVAr & $\mathrm{kW}$ & $\mathrm{kVAr}$ & $\mathrm{kW}$ & $\mathrm{kVAr}$ \\
\hline 634 & Y-PQ & 160 & 110 & 120 & 90 & 120 & 90 \\
\hline 645 & Y-PQ & 0 & 0 & 170 & 125 & 0 & 0 \\
\hline 646 & $\mathrm{D}-\mathrm{Z}$ & 0 & 0 & 230 & 132 & 0 & 0 \\
\hline 652 & Y-Z & 128 & 86 & 0 & 0 & 0 & 0 \\
\hline 671 & D-PQ & 385 & 220 & 385 & 220 & 385 & 220 \\
\hline 675 & Y-PQ & 485 & 190 & 68 & 60 & 290 & 212 \\
\hline 692 & D-I & 0 & 0 & 0 & 0 & 170 & 151 \\
\hline 611 & Y-I & 0 & 0 & 0 & 0 & 170 & 80 \\
\hline & Total & 1.158 & 606 & 973 & 627 & 1.135 & 753 \\
\hline
\end{tabular}


Tabela 5.5: Distância entre os nós dos diferentes segmentos de linha, adaptada de (IEEE, 2013).

\begin{tabular}{|c|c|c|c|c|}
\hline Nó A & Nó B & Comprimento [ft] & Configuração & Fase \\
\hline 632 & 645 & 500 & 603 & C B N \\
\hline 632 & 633 & 500 & 602 & C A B N \\
\hline 633 & 634 & 0 & XFM-1 & - - \\
\hline 645 & 646 & 300 & 603 & C B N \\
\hline 650 & 632 & 2.000 & 601 & B A C N \\
\hline 684 & 652 & 800 & 607 & A N \\
\hline 632 & 671 & 2.000 & 601 & B A C N \\
\hline 671 & 684 & 300 & 604 & A C N \\
\hline 671 & 680 & 1.000 & 601 & B A C N \\
\hline 671 & 692 & 0 & Switch & \\
\hline 684 & 611 & 300 & 605 & C N \\
\hline 692 & 675 & 500 & 606 & A B C N \\
\hline
\end{tabular}

Cabe salientar a simbologia das ligações dos transformadores e dos modelos de carga, as quais seguem a descrição a seguir:

- D: ligação em delta;

- Yg: ligação em estrela aterrada;

- D - PQ: ligação em delta com potência ativa e reativa constantes;

- Y - PQ: ligação em estrela com potência ativa e reativa constantes;

- D - Z: ligação em delta com impedância constante;

- Y - Z: ligação em estrela com impedância constante;

- D - I: ligação em delta com corrente constante;

- Y - I: ligação em estrela com corrente constante.

Posto isto, cabe aqui ressaltar que na presente investigação o regulador de tensão parametrizado em (KERSTING, 2001) não foi modelado, uma vez que se pretende analisar os efeitos das sobretensões induzidas sobre os elementos deste alimentador sem a influência da melhora do perfil de tensão exercida pelo regulador.

Assim sendo, considerando a chave entre os nós 671 e 692 sempre fechada e retirando o regulador de tensão do sistema, a disposição espacial do referido alimentador é ilustrada na Figura 5.1, na qual são demarcadas as distância entre cada um de seus nós a partir dos dados expostos na Tabela 5.5. 


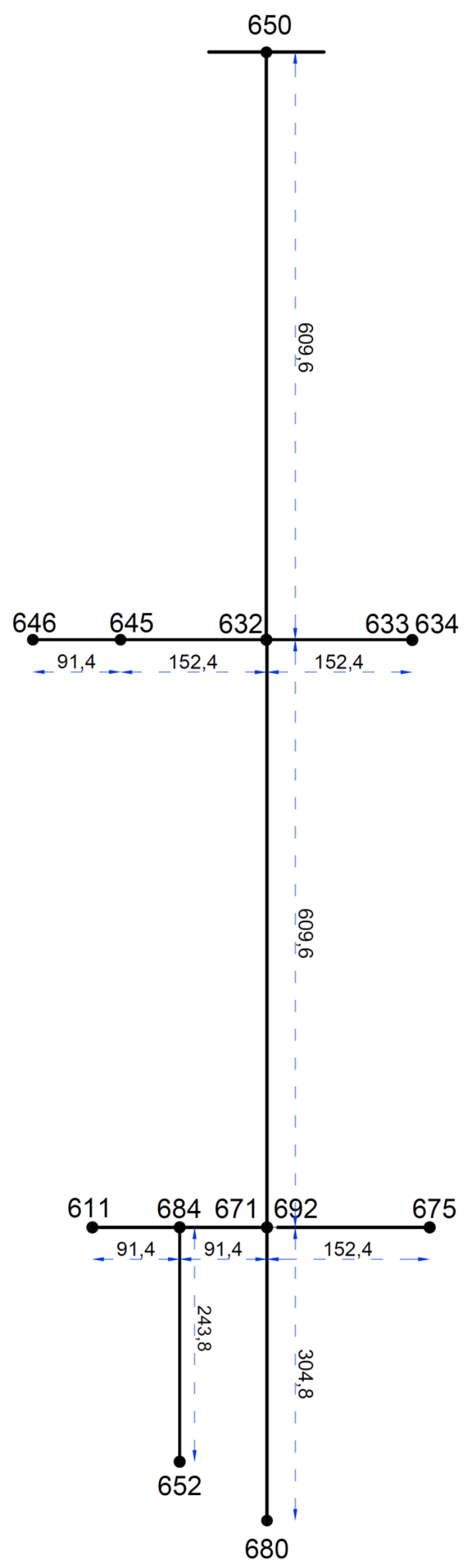

Figura 5.1: Disposição espacial do alimentador IEEE 13 Node Test Feeder. 


\subsection{2 - Modelagem computacional do alimentador}

Adverte-se que para o desenvolvimento da modelagem do IEEE 13 Node Test Feeder foram utilizados os dados disponíveis em (KERSTING, 2001) e (IEEE, 2013), além das informações já apresentadas nas Tabelas de 5.1 a 5.5.

Sendo assim, a subestação foi representada pelo seu equivalente composto por uma fonte com tensão e por uma impedância série com ramo resistivo-indutivo. Já o transformador da subestação foi implementado a partir dos dados da Tabela 5.1 com ligação delta (D) para estrela aterrada (Yg) e defasagem angular de $30^{\circ}$ por meio do cálculo dos parâmetros de seus enrolamentos, de forma a promover um rebaixamento da tensão de 115 $\mathrm{kV}$ para $4.16 \mathrm{kV}$. Foi aplicado o mesmo procedimento para o transformador rebaixador de linha conectado entre os nós 633 e 634 ligado em Yg-Yg, de maneira a alimentar a carga ligada ao nó 634 com $480 \mathrm{~V}$.

Para a modelagem dos segmentos da linha de distribuição do alimentador foram avaliados os modelos de linha a parâmetros concentrados, parâmetros distribuídos e dependes da frequência por meio das seguintes referências (GROSS, 1986; MARTINEZ, 2005; STEVENSON, 1986). Após a análise destes modelos decidiu-se optar pela modelagem através de parâmetros concentrados, mais especificamente o Modelo PI. Este foi escolhido, pois é o mais recomendado para linhas curtas com comprimento inferior a $80 \mathrm{~km}$ (STEVENSON, 1986), nas quais o tempo de viagem da onda é menor que o tempo de integração da solução, e porque o maior trecho deste alimentado é de apenas $1,5 \mathrm{~km}$, como pôde ser visto na Figura 5.1. Ressalta-se que, no entanto, tal modelo é impróprio para linhas com comprimentos superiores, e nestes casos a teoria de ondas viajantes é usada no desenvolvimento de modelos mais realistas (WATSON e ARRILLAGA, 2003).

Vale frisar que se escolheu o Modelo PI por esta pesquisa tratar de um estudo sobre os efeitos de tensões induzidas por descargas indiretas em redes de distribuição, no qual a averiguação da dependência da frequência não tão necessária como em estudos relacionados à incidência direta de descargas atmosféricas. Outra observação importante refere-se à adoção da modelagem dos trechos de linha deste alimentador com neutro solidamente aterrado, e trechos de linha subterrâneos por seus equivalentes aéreos.

Além disso, para a presente pesquisa é necessária à ponderação da altura da linha e do espaçamento entre os cabos, mas no Modelo PI da toolbox SimPowerSystems ${ }^{\mathrm{TM}}$ isto não é possível, pois não há como entrar com estes dados. Contudo, este obstáculo foi superado uma 
vez que os dados fornecidos em (KERSTING, 2001; IEEE, 2013) para a resistência e indutância pela matriz de impedância série $(Z=R+j \omega L)$ e para a susceptância (B) foram calculados empregando as equações de Carson (CARSON, 1926).

Isto ocorre, pois como as linhas de distribuição são redes tipicamente desbalanceadas e não transpostas, a formulação para o cálculo dos parâmetros concentrados não deve realizar aproximações referentes às suas dimensões, ao espaçamento dos condutores e a existência de transposição (KERSTING, 2002). Assim, fez-se necessária a utilização da formulação desenvolvida por Carson, a qual resulta nas impedâncias próprias e mútuas de um número qualquer de condutores, independentemente de sua topologia construtiva (CARSON, 1926).

A seguir, foram modeladas as cargas, destacando-se que a carga distribuída foi modelada pelo seu equivalente como carga concentrada, e foram implementados os capacitores em derivação em conjuntos com as cargas 675 e 611 a partir dos dados da Tabela 5.2, perfazendo a modelagem de todos os elementos do alimentador teste.

\subsection{3 - Simulação da Modelagem computacional do alimentador}

A fim de validar a modelagem realizada e obter as amplitudes de pico das tensões e correntes sobre cada elemento do alimentador, foi executada a simulação do sistema implementado em regime permanente, com os resultados da qual foi possível a construção da Tabela 5.6. Além disso, esta simulação é importante, pois com ela são definidos os valores máximos de tensão por fase a partir dos quais se poderá constatar a influência das tensões induzidas pelas descargas indiretas sobre as cargas e os transformadores, além de averiguar a atuação dos para-raios.

Ainda com os dados desta simulação em regime permanente foi elaborado o histograma da Figura 5.2, o qual demonstra de forma gráfica os valores de pico das tensões por fase para cada elemento do alimentador a ser analisado. Deve-se notar que a sigla TRF $\mathrm{S}$ refere-se ao transformador da subestação, TRF - L ao transformador da linha, e C as cargas, designadas por seus respectivos números.

Além disso, ressalta-se que para o gráfico da Figura 5.2, assim como para todos os gráficos apresentados no Capítulo 6, a tensão base é de $4,16 \mathrm{kV}$ para os dois transformadores e todas as cargas, exceto para a carga $\mathrm{C}-634$, localizada após o transformador rebaixador, cuja tensão base é de $480 \mathrm{~V}$. 
Tabela 5.6: Pico de tensão por fase para as cargas e os transformadores sob regime permanente.

\begin{tabular}{|c|c|c|c|}
\hline \multirow{2}{*}{ Componente do Alimentador } & \multicolumn{3}{|c|}{ Tensão [pu] } \\
\cline { 2 - 4 } & $\mathrm{Va}$ & $\mathrm{Vb}$ & $\mathrm{Vc}$ \\
\hline Transformador da Subestação & 0,981 & 0,986 & 0,984 \\
\hline Transformador da Linha & 0,998 & 1,027 & 1,016 \\
\hline Carga 632-671 & 0,992 & 1,031 & 1,008 \\
\hline Carga 646 & -- & 1,026 & 0,994 \\
\hline Carga 645 & -- & 1,022 & 0,989 \\
\hline Carga 634 & 0,981 & 1,017 & 0,992 \\
\hline Carga 671 & 0,932 & 0,949 & 0,937 \\
\hline Carga 611 & -- & -- & 0,943 \\
\hline Carga 652 & 0,941 & -- & -- \\
\hline Carga 692 & 0,929 & 0,944 & 0,937 \\
\hline Carga 675 & 0,932 & 0,943 & 0,916 \\
\hline
\end{tabular}

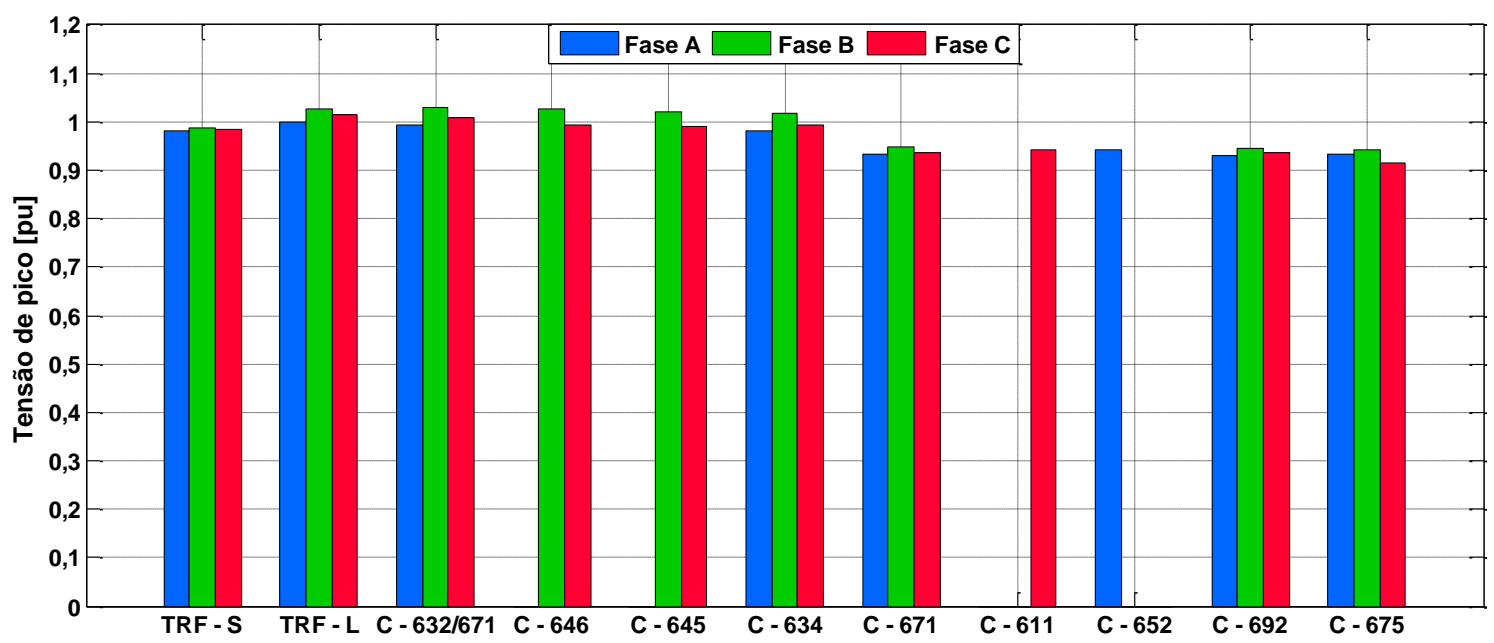

Figura 5.2: Amplitude de pico das tensões por fase para as cargas e os transformadores com o sistema do alimentador teste operando em regime permanente.

Sendo assim, por meio da Tabela 5.6 e da Figura 5.2 observa-se que a fase com maior pico de tensão para os elementos do alimentador teste é a Fase B, com exceção das cargas 611 e 652, nas quais predominam a Fase C e a Fase A, respectivamente. 


\section{2 - Aplicação do Modelo de Rusck para estimação de tensões induzidas por descargas atmosféricas indiretas}

Nesta seção será exposta a forma com que foi modelada e implementada a estimação de tensões induzidas por descargas atmosféricas indiretas, bem como os fundamentados e conceitos necessários para adequar o Modelo de Rusck as necessidades da presente pesquisa. Também serão exibidos os resultados de simulações computacionais a fim de averiguar a influência dos parâmetros da modelagem concebida sobre as tensões induzidas avaliadas pela aplicação do método aqui definido.

\subsection{1 - Modelagem e implementação computacional}

Para modelagem das tensões induzidas, inicialmente, é necessário fazer a adaptação da metodologia desenvolvida por Rusck para que seja possível à aplicação de formas de onda de corrente de descarga semelhantes às encontradas em situações reais na natureza.

Para tanto, em vez de adotar a dedução elaborada por Rusck que considera a corrente de retorno em forma de degrau, será empregado o princípio da integral de Duhamel para representar a onda de corrente por uma série de degraus defasados no tempo (GREENWOOD, 1992). Esta adequação se justifica, pois medições em campo demonstram que as características da forma de onda de corrente, tais como amplitude, tempo de subida e tempo de pico, influenciam significativamente as características da onda de tensão induzida (ERIKSSON, et al., 1982).

Outro ponto importante a ser analisado para implementação do Modelo de Rusck em linhas trifásicas de distribuição, como a do alimentador escolhido para esta pesquisa, referese à amplitude, forma e polaridade da onda de tensão induzida em cada uma das fases da linha.

Este aspecto deve ser ponderado, pois a metodologia de Rusck considera a altura das linhas em sua formulação, mas não faz menção a influência do espaçamento entre seus condutores. Contudo, como no plano horizontal a distância entre os condutores é 
proporcionalmente muito menor que a distância entre o ponto de incidência da descarga e a linha, pode-se admitir que as tensões induzidas nas três fases sejam praticamente as mesmas.

É possível comprovar esta proposição pela apreciação dos resultados de medições realizadas na África do Sul em uma linha de $11 \mathrm{kV}$ trifásica (ERIKSSON, et al., 1982). Examinado as formas de onda da tensão induzida aferida, apresentada na Figura 5.3, observase que a amplitude, forma e polaridade da onda são muito semelhantes para cada uma de suas fases.

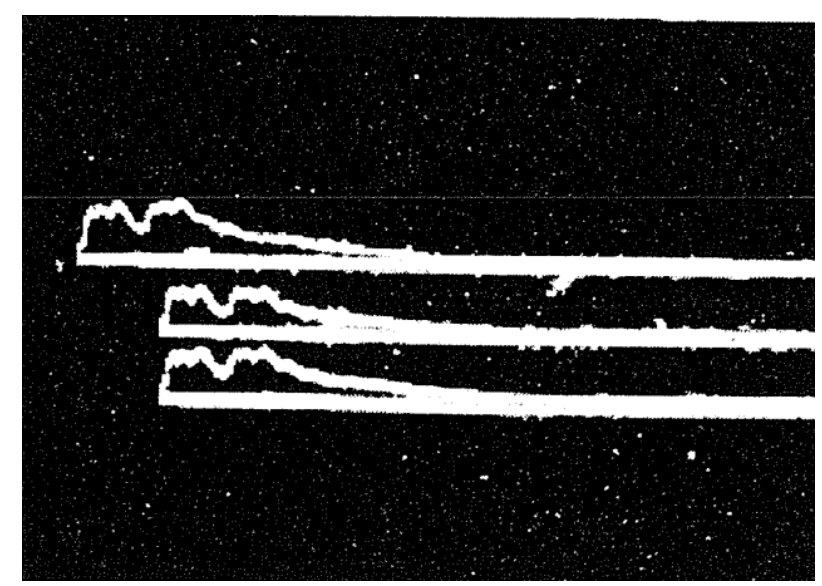

Figura 5.3: Tensões induzidas em uma linha trifásica (ERIKSSON, et al., 1982).

Posto isto, a fim de implementar computacional a metodologia de Rusck no domínio do tempo foram utilizadas as equações (5.1) e (5.2), anteriormente expostas na seção 3.4.2.6 do Capítulo 3, em que $\mathrm{V}(\mathrm{x}, \mathrm{t})$ é a tensão total induzida, em volts, em um ponto $\mathrm{x}$ ao longo da linha, dado em metros, para um intervalo de tempo t, em segundos.

$$
\begin{gathered}
V x, t=U x, t+U(-x, t) \\
U x, t=Z_{0} \operatorname{Ih} \beta \frac{c t-x}{y^{2}+\beta^{2} c t-x^{2}} 1+\frac{x+\beta^{2} c t-x}{\beta c t^{2}+1-\beta^{2} x^{2}+y^{2}}
\end{gathered}
$$

$\mathrm{Na}$ equação (5.2) $\mathrm{Z}_{0}$ é a impedância característica da linha, em ohms; $I$ o valor de pico da corrente de descarga, em amperes; $h$ é a altura da linha, em metros; $y$ é a distância entre a linha e o ponto de incidência da descarga, também em metros; e $c$ é a velocidade da luz no vácuo, em $\mathrm{m} / \mathrm{s}$. Já a variável $\beta$, é a razão entre a velocidade de propagação da onda de corrente de descarga $(v)$ e a velocidade da luz no vácuo $(c)$, ambas em $\mathrm{m} / \mathrm{s}$. 
Alguns dos parâmetros acima apresentados são constantes e não serão alterados durante as simulações, sendo assim podem ser definidos aqui. A velocidade de propagação da onda de corrente de descarga será considerada igual a $120 \mathrm{~m} / \mu \mathrm{s}$ a partir das referências (CIGRE, 1991; IEEE, 1996), mas poderia assumir valor entre $80 \mathrm{~m} / \mu \mathrm{s}$ e $220 \mathrm{~m} / \mu \mathrm{s}$, e a velocidade da luz no vácuo é por definição 299792458 m/s (HALLIDAY, 2012).

Dessa forma, $\beta$ é igual a 0,4 , e a partir da equação (3.38) calcula-se a impedância característica da linha, cujo valor é igual a $30 \Omega$. Adverte-se que em todas as simulações que serão realizadas estes parâmetros assumiram os valores acima especificados, salvo quando diferentemente for mencionado, e que as demais variáveis, ou seja, $I, h, y, t$ e $x$, serão definidas no momento das simulações.

Por fim, ressalta-se que apesar de a tensão induzida ser equacionada analiticamente como uma fonte de tensão, sua implementação será realizada por meio de seu equivalente composto por uma fonte de corrente e uma impedância, para que sua propagação seja percebida em toda a linha.

\subsection{2 - Simulação da estimação de tensões induzidas}

Esta seção tem a finalidade de apresentar o resultado da modelagem e implementação delineada anteriormente e de avaliar a influência de alguns dos parâmetros do equacionamento adotado sobre a tensão induzida estabelecida sobre um trecho de linha de distribuição.

Em um primeiro momento será simulada a estimação da tensão induzida no centro de um trecho de linha, convencionalmente no ponto em que $\mathrm{x}=0$, para um caso típico. Caso este, em que o valor de pico da corrente de descarga atmosférica é $10 \mathrm{kA}$, a altura de linha é $10 \mathrm{~m}$, a distância do ponto de incidência da descarga ao centro da linha é $100 \mathrm{~m}$, e o intervalo de tempo é de $10 \mathrm{~ms}$. O resultado desta simulação pode ser visto na Figura 5.4, em que se observa a forma de onda e amplitude da tensão induzida a partir do efeito dos procedimentos adotados anteriormente. 


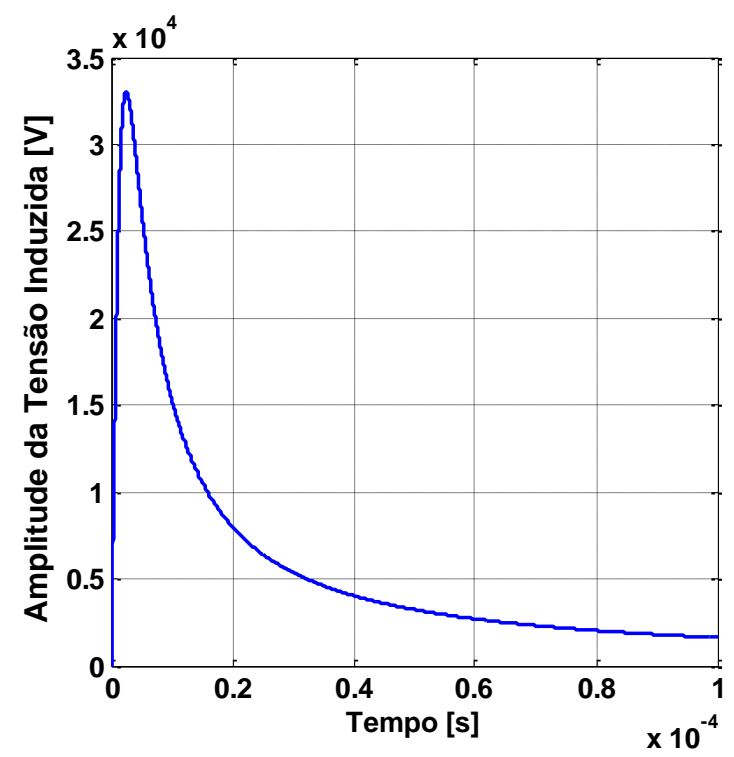

Figura 5.4: Tensão induzida medida no centro de um trecho de linha, cuja altura é de $10 \mathrm{~m}$, para uma descarga atmosférica de $10 \mathrm{kA}$ incidindo a $100 \mathrm{~m}$ de distância do centro da mesma.

Já na Figura 5.5 são expostas as curvas da tensão induzida medidas em diferentes pontos de um trecho de linha, em uma simulação com a mesma característica da situação anterior. Através desta figura se pode averiguar a alteração do formato de onda e da sua amplitude em função da distância entre o ponto de máxima tensão, neste evento o centro da linha, e os demais pontos situados ao longo da mesma. Estas alterações advêm da dissipação de energia nos condutor metálico e de atenuações ao longo da linha.

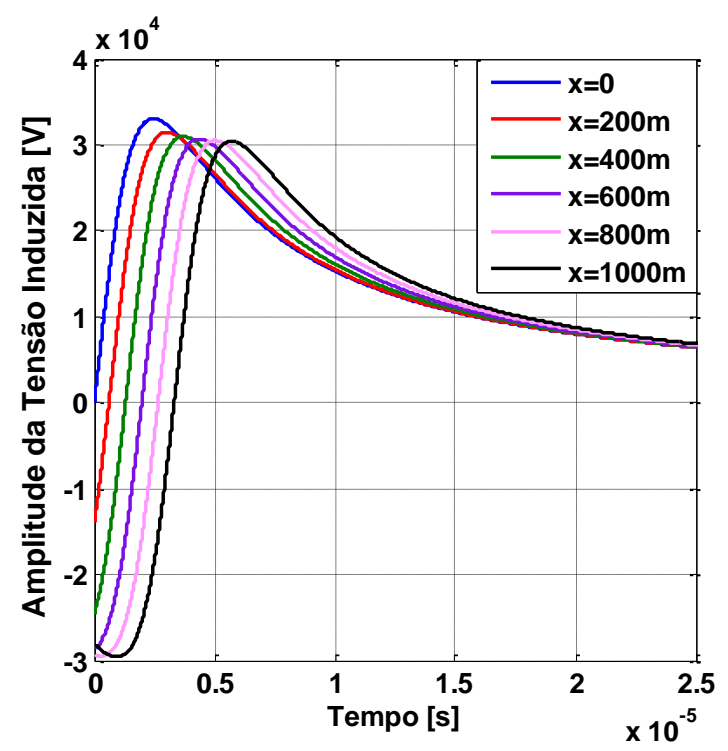

Figura 5.5: Tensões induzidas medidas em diferentes pontos de uma linha com 10m de altura, para uma descarga atmosférica de $10 \mathrm{kA}$ incidindo a $100 \mathrm{~m}$ de distância do centro da mesma. 
Neste contexto, para análise da influência da distância entre o ponto de incidência da descarga e a linha, foram efetuadas quatro simulações considerando-se a variável y igual a 50, 200, 500 e $1000 \mathrm{~m}$, e medidas as tensões geradas no centro da linha. Seus resultados, mostrados pela Figura 5.6, demonstram a diminuição da amplitude de tensão induzida com o aumento da distância entre o ponto de incidência da descarga e a linha, causada pela redução da intensidade do campo eletromagnético irradiado.

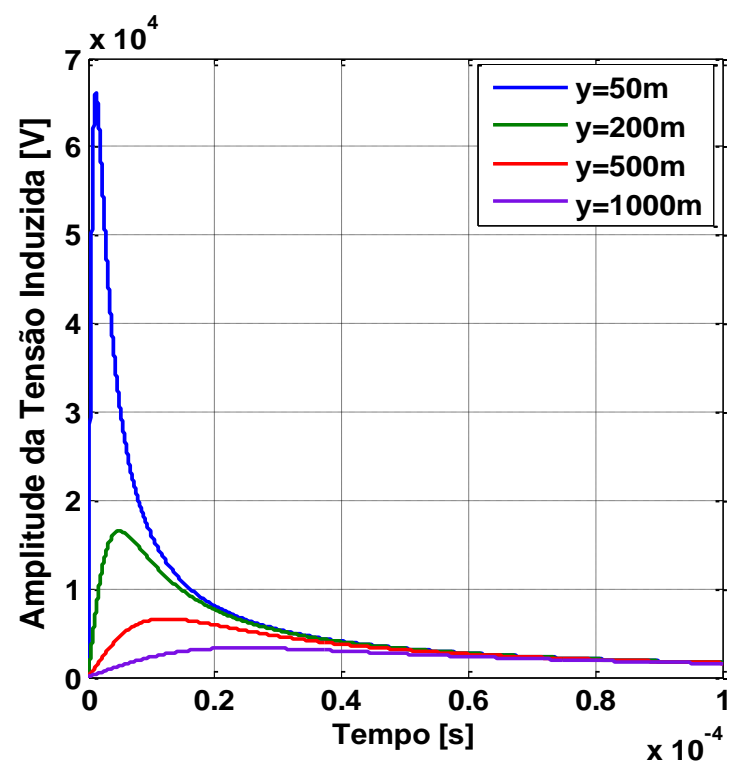

Figura 5.6: Tensões induzidas para quatro distâncias diferentes entre o ponto de incidência de uma descarga de $10 \mathrm{kA}$ e um trecho de linha, e mensuradas no ponto central deste segmento.

Analisando agora a ação da variação da altura da linha sobre a tensão induzida, conclui-se que há um aumento diretamente proporcional da amplitude de tensão com a elevação da altura da linha, que pode ser explicado pelo acréscimo da área de enlace do fluxo magnético formada entre o condutor da linha e a superfície do solo.

A Figura 5.7 ilustra este fato para uma simulação em que foram adotas 3 diferentes alturas para a linha e foram mensuradas as tensões em um ponto localizado no centro da mesma. 


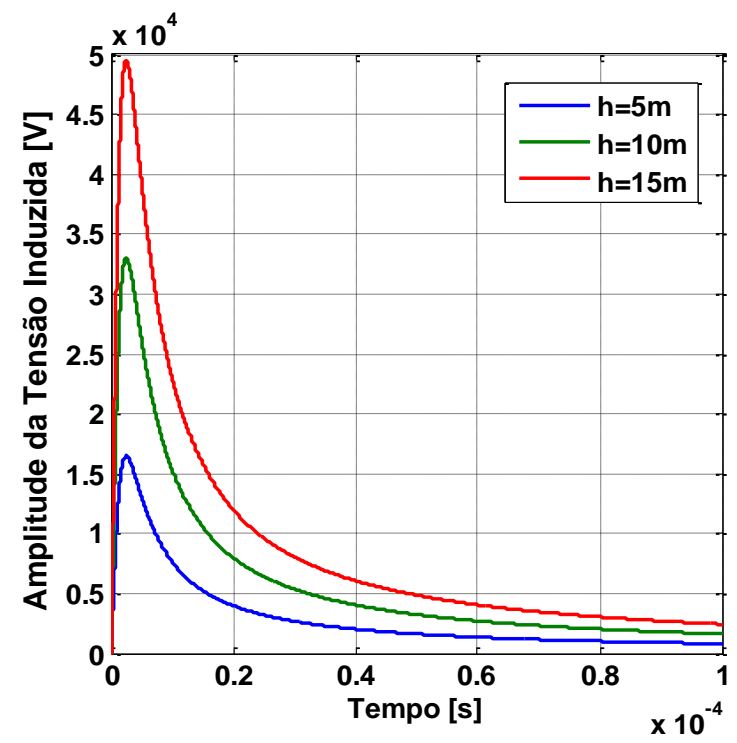

Figura 5.7: Tensões induzidas para três diferentes alturas das estruturas de uma linha, para uma descarga atmosférica de $10 \mathrm{kA}$ incidindo a 100m de distância do centro da mesma, e aferidas em um ponto localizado no centro da linha.

Por fim, foram desempenhadas mais três simulações com $I$ assumindo o valor de 10 , 20 e $30 \mathrm{kA}$, por meio das quais foi possível verificar que a tensão induzida também cresce de maneira diretamente proporcional ao aumento da amplitude da corrente de descarga. Tal fato ocorre em detrimento do maior acoplamento magnético entre os campos da linha e do canal da corrente de descarga, e pode ser visualizado na Figura 5.8.

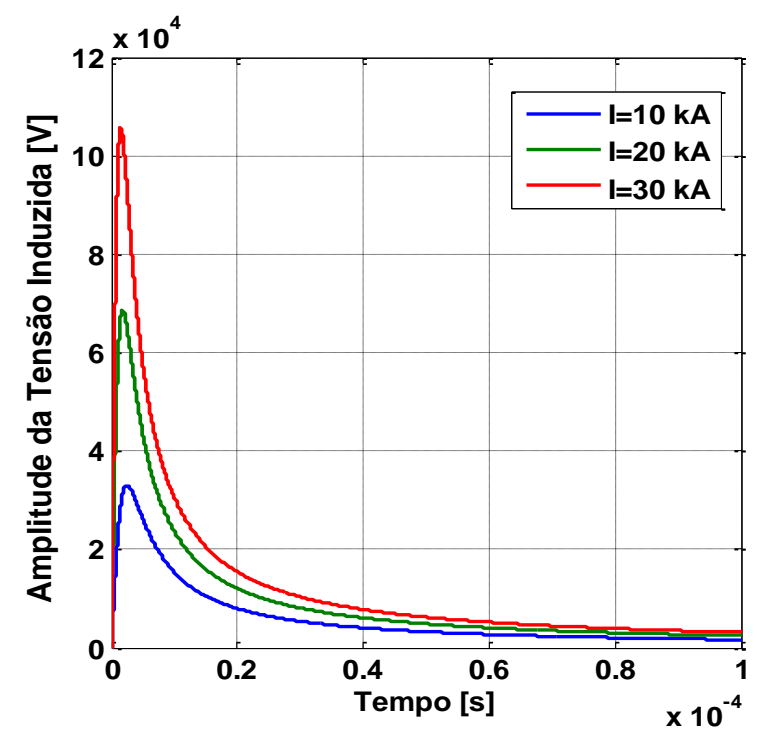

Figura 5.8: Tensões induzidas para três diferentes amplitudes da corrente de descarga, incidindo a 100m de distância do centro de uma linha de altura $10 \mathrm{~m}$, e estimadas em um ponto localizado no centro da mesma. 


\section{3 - Seleção e implementação computacional dos Para- raios}

Nesta seção serão apresentados os procedimentos para seleção e implementação do para-raios de $\mathrm{ZnO}$ mais adequado às características do alimentador teste avaliado nesta pesquisa. Para tanto, far-se-á a análise das especificações de para-raios comercialmente disponíveis e dos requisitos do modelo de para-raios disponível na toolbox SimPowerSystems ${ }^{\mathrm{TM}}$ do ambiente gráfico Simulink®.

\subsection{1 - Parâmetros elétricos para seleção dos para-raios de ZnO}

A partir do embasamento obtido com o levantamento bibliográfico e histórico sobre o desenvolvimento dos para-raios, e mais especificamente por meio do estudo aprofundado a respeito dos para-raios com varistores de óxido metálico, define-se os para-raios de $\mathrm{ZnO}$ como os equipamentos de proteção a serem aplicados neste estudo.

Assim, tendo em mãos os dados de operação da linha e informações sobre as descargas atmosféricas e as tensões por elas induzidas, procedeu-se então com uma pesquisa a respeito dos para-raios de óxido de zinco acessíveis comercialmente. Foram examinados guias, manuais e datasheets de vários fabricantes, e decidiu-se utilizar os para-raios de média tensão tipo 3EK4 com invólucro de silicone da Siemens (SIEMENS, 2013).

Este tipo de para-raios foi escolhido, pois dentre suas principais características destacam-se seus atributos construtivos, uma vez que é formado por hastes de plástico ultra resistentes e reforçadas com fibra de vidro, o que lhes proporcionam maior resistência mecânica e otimizam a relação entre desempenho e peso. Possuem um invólucro polimérico $100 \%$ de silicone moldado/vulcanizado diretamente sobre os blocos varistores de óxido metálico sem espaçamento interno de ar. Sua moldagem é feita por injeção à alta pressão e a elevadas temperaturas, o que suprimi de forma eficaz as descargas parciais e a penetração de umidade, garantindo longa vida útil aos mesmos (SIEMENS, 2013). Ademais, cabe observar que os para-raios com invólucro polimérico possuem algumas vantagens técnicas e econômicas em relação aos de porcelana, como já foi exposto na seção 4.4.1.2 do Capítulo 4. 
Definido o tipo de para-raios, é necessário agora selecionar suas características elétricas, para que os mesmos forneçam proteção adequada ao sistema elétrico por eles coberto, ao mesmo tempo em que operem de forma contínua e estável. Neste contexto, proteção adequada significa que sobretensões no dispositivo a ser protegido devem permanecer sempre abaixo de sua tensão suportável, com uma margem de segurança suficiente. Já operação contínua estável significa que os para-raios devem ser capazes de lidar com todas as tensões de longa duração, temporárias ou transitórias, que resultem do funcionamento da rede, mantendo-se eletricamente e termicamente estáveis sob todas as condições (HINRICHSEN, 2012).

Estes requisitos básicos não podem ser cumpridos de forma independente, uma vez que uma redução do nível de proteção implica automaticamente em uma tensão elétrica específica superior durante a operação contínua. Inversamente, a tensão contínua de funcionamento de um para-raios não pode ser aumentada de forma arbitrária, sem aumentar o seu nível de proteção também (HINRICHSEN, 2012).

Desse modo, fundamentando-se no exposto em (HINRICHSEN, 2012), primeiramente, necessita-se estabelecer a mínima tensão de operação contínua $\left(U_{c}\right)$ da linha, mas para tanto é preciso saber o tipo de aterramento da mesma, uma vez que o tipo de ligação à terra do sistema é determinante para se definir $U_{c}$. Para um sistema com neutro solidamente aterrado define-se $U_{c}$ pela equação (5.3), já para um sistema com neutro aterrado isolado ou ressonante aplica-se a equação (5.4), nas quais $U_{s}$ é a máxima tensão de fase do sistema.

$$
\begin{gathered}
U_{c} \geq \frac{1,05 U_{s}}{\overline{3}} \\
U_{c} \geq U_{s}
\end{gathered}
$$

Após ter pré-definido $U_{c}$ deve determinar a tensão nominal inicial do para-raios $\left(U_{r 1}\right)$ pela equação (5.5) para um sistema com neutro solidamente aterrado, e pela equação (5.6) para um sistema com neutro aterrado isolado ou ressonante, como exposto a seguir.

$$
\begin{gathered}
U_{r 1} \geq 1,25 \times \frac{1,05 U_{s}}{\overline{3}} \\
U_{r 1} \geq 1,25 U_{s}
\end{gathered}
$$


No entanto, para um sistema com neutro solidamente aterrado as sobretensões transitórias podem atingir valores de até 1,4 vezes a tensão máxima de fase em um período de tempo de 10 segundo, sendo neste caso necessário o cálculo de uma segunda tensão nominal para o para-raios $\left(U_{r 2}\right)$ por meio da equação (5.7).

$$
U_{r 2} \geq 1,4 U_{s}
$$

Então, é necessário determinar a tensão nominal final dos para-raios definindo $U_{r}$ como o maior valor entre $U_{r 1}$ e $U_{r 2}$, e se $U_{r 2}$ for maior que $U_{r 1}$ é preciso redefinir $U_{c}$ por meio da equação (5.8).

$$
U_{c} \geq \frac{U_{r 2}}{1,25}
$$

Após a determinação da tensão de operação contínua e da tensão nominal, o pararaios pode ser geralmente definido, não só para um funcionamento contínuo normal estável, mas também para as condições de sobretensão no sistema. É, no entanto, recomendado que uma classificação ligeiramente superior à classificação mínima descrita anteriormente seja selecionada, desde que o nível de proteção do para-raios não se torne indevidamente elevado. Este procedimento se justifica, porque uma classificação elevada aumenta a estabilidade do para-raios e proporciona segurança adicional, por exemplo, em um ambiente poluído, ou quando sobretensões inesperadamente mais elevadas ocorrem. Por esta razão, normalmente encontram-se para-raios nos sistemas que têm funcionamento contínuo e tensões nominais superiores aos minimamente necessários (HINRICHSEN, 2012).

Posto isto, deve-se definir a corrente nominal de descarga $\left(I_{n}\right)$ do para-raios de acordo com sua tensão nominal, por meio da Tabela 5.7, a qual segue os padrões da norma (IEC 60099-4, 2009).

Tabela 5.7: Corrente nominal de descarga de acordo com a norma IEC 60099-4, adaptado de (HINRICHSEN, 2012).

\begin{tabular}{|c|c|}
\hline $\begin{array}{c}\text { Corrente nominal de } \\
\text { descarga }[\mathrm{kA}]\end{array}$ & $\begin{array}{c}\text { Tensão nominal do } \\
\text { para-raios }[\mathrm{kV}]\end{array}$ \\
\hline 1,5 & Sob consideração \\
\hline 2,5 & $\mathrm{U}_{\mathrm{r}} \leq 36$ \\
\hline 5,0 & $\mathrm{U}_{\mathrm{r}} \leq 132$ \\
\hline 10 & $3 \leq \mathrm{U}_{\mathrm{r}} \leq 360$ \\
\hline 20 & $360 \leq \mathrm{U}_{\mathrm{r}} \leq 756$ \\
\hline
\end{tabular}


Ressalta-se que para sistemas de distribuição a corrente nominal de descarga, via de regra, assume valor igual a $5 \mathrm{kA}$, mas devido aos elevados níveis ceraúnicos de determinadas regiões pode-se assumir o valor de $10 \mathrm{kA}$. Além disso, na pratica, está se tornando cada vez mais comum adotar o valor de $10 \mathrm{kA}$ para $I_{n}$ devido à diminuição da diferença de preço entre os para-raios com $I_{n}$ de $5 \mathrm{kA}$ e $10 \mathrm{kA}$. Esta pratica também é comum, sobretudo, porque há vantagens logísticas em se utilizar apenas um tipo de para-raios para todo o sistema, uma vez que na maioria dos sistemas de transmissão e distribuição utilizam-se para-raios com $I_{n}=10$ kA (HINRICHSEN, 2012).

Por fim, é possível determinar a classe de descarga da linha, o que pode ser feito através da análise da Tabela 5.8 em função da máxima tensão de fase do sistema. Outrossim, ao definir a classe de descarga da linha, o diâmetro do resistor de óxido de zinco do pararaios é automaticamente escolhido, contendo a Tabela 5.9 uma orientação para o diâmetro mínimo dos mesmos (HINRICHSEN, 2012).

Tabela 5.8: Classe de descarga da linha de acordo com a norma IEC 60099-5, adaptado de (HINRICHSEN, 2012).

\begin{tabular}{|c|c|}
\hline Classe de descarga da linha & $\mathrm{U}_{\mathrm{s}} / \mathrm{kV}$ \\
\hline 1 & $\leq 245$ \\
\hline 2 & $\leq 300$ \\
\hline 3 & $\leq 420$ \\
\hline 4 & $\leq 550$ \\
\hline 5 & $\leq 800$ \\
\hline
\end{tabular}

Tabela 5.9: Atribuição típica para o diâmetros dos resistores de óxido de zinco para classe de descarga da linha, adaptado de (HINRICHSEN, 2012).

\begin{tabular}{|c|c|}
\hline $\begin{array}{c}\text { Diâmetro do resistor de óxido } \\
\text { de zinco }[\mathrm{mm}]\end{array}$ & $\begin{array}{c}\text { Classe de descarga } \\
\text { da linha }\end{array}$ \\
\hline 50 & 1 \\
\hline 60 & 2 \\
\hline 70 & 3 \\
\hline 80 & 4 \\
\hline 100 (ou 2 vezes 70 em paralelo) & 5 \\
\hline
\end{tabular}




\subsection{2 - Escolha e Implementação do para-raios de ZnO}

Para implementação e teste do para-raios mais adequado à apreciação desta pesquisa, inicialmente deve-se definir os parâmetros acima listados para o para-raios de média tensão tipo 3EK4 escolhido.

Como já mencionado na seção 5.1.1 do presente capítulo a tensão nominal do alimentador teste é $4,16 \mathrm{kV}$ e seu sistema possui neutro solidamente aterrado, logo sua máxima tensão de fase $\left(U_{s}\right)$ é $3,39 \mathrm{kV}$ e sua tensão de operação contínua $\left(U_{c}\right)$, calculada utilizando a equação (5.3), deve ser maior ou igual a $2,09 \mathrm{kV}$.

Desse modo, para o presente caso, pela equação (5.5) obtém-se a primeira tensão nominal do para-raios $\left(U_{r l}\right)$, cujo valor deve ser maior ou igual a $2,61 \mathrm{kV}$, e por meio da equação (5.7) $U_{r 2} \geq 2,92 \mathrm{kV}$. Assim, é preciso determinar a tensão nominal final dos pararaios tomando $U_{r}$ como o maior valor entre $U_{r 1}$ e $U_{r 2}$, ou seja, $U_{r} \geq 2,92 \mathrm{kV}$, e então redefinir $U_{c}$ por meio da equação (5.8), segundo a qual se obtém $U_{c} \geq 2,34 \mathrm{kV}$.

Calculados estes parâmetros elétricos, por meio da avaliação dos dados do Guia de Para-raios do tipo 3EK4 (SIEMENS, 2013) será realizada a seleção do para-raios especifico para este estudo. Vale lembrar, no entanto, que é recomendado que uma classificação ligeiramente superior à classificação mínima descrita anteriormente seja selecionada, desde que o nível de proteção do para-raios não se torne indevidamente elevado.

Dessa forma, examinado a Tabela 4 do guia citado, Tabela 5.10 desta dissertação, deve-se assumir $U_{r}=6 \mathrm{kV}$ e $U_{c}=4,8 \mathrm{kV}$ definindo o modelo 3EK4 060-1CB3 como o pararaios a ser utilizado.

A Tabela 5.10 ainda fornece outros dados importantes sobre este modelo de pararaios, como os valores máximos das tensões residuais $\left(U_{\max , \text { residual }}\right)$ para diferentes formas de ondas e correntes, e informação sobre a suportabilidade do seu invólucro por meio da tensão suportável a impulso atmosférico de 1,2/50 $\mu \mathrm{s}\left(\mathrm{U}_{1,2 / 50 \mu \mathrm{s}}\right)$ e da tensão suportável de frequência industrial, 1 min, sob chuva ( $\left.\mathrm{U}_{\text {freq,industrial }}\right)$. 
Tabela 5.10: Modelos e características elétricas dos para-raios do tipo 3EK4, adaptado de (SIEMENS, 2013).

\begin{tabular}{|c|c|c|c|c|c|c|c|c|c|}
\hline \multirow{2}{*}{$\begin{array}{c}\mathrm{U}_{\mathrm{r}} \\
{[\mathrm{kV}]}\end{array}$} & \multirow{2}{*}{$\begin{array}{c}\mathrm{U}_{\mathrm{c}} \\
{[\mathrm{kV}]}\end{array}$} & Modelo & $8 / 20 \mu \mathrm{s}$ & $8 / 20 \mu \mathrm{s}$ & $8 / 20 \mu \mathrm{s}$ & $8 / 20 \mu \mathrm{s}$ & $30 / 60 \mu \mathrm{s}$ & \multicolumn{2}{|c|}{$\begin{array}{c}\text { Suportabilidade do } \\
\text { Invólucro }\end{array}$} \\
\cline { 4 - 9 } & & & $1 \mathrm{kA}$ & $5 \mathrm{kA}$ & $10 \mathrm{kA}$ & $20 \mathrm{kA}$ & $500 \mathrm{~A}$ & $\begin{array}{c}\mathrm{U}_{1,2 / 50 \mu \mathrm{s}} \\
{[\mathrm{kV}]}\end{array}$ & $\begin{array}{c}\mathrm{U}_{\text {freq, industrial }} \\
{[\mathrm{kV}]}\end{array}$ \\
\hline 3 & 2,4 & $3 \mathrm{EK} 4030-1 \mathrm{CB} 3$ & 6,5 & 7,4 & 8,0 & 9,1 & 6,1 & 57 & 24 \\
\hline 6 & 4,8 & $3 \mathrm{EK} 4060-1 \mathrm{CB} 3$ & 13 & 14,8 & 15,9 & 18,3 & 12,2 & 57 & 24 \\
\hline 9 & 7,2 & $3 \mathrm{EK} 4090-1 \mathrm{CB} 3$ & 19,6 & 22,2 & 23,9 & 27,4 & 18,4 & 80 & 33 \\
\hline 12 & 9,6 & $3 \mathrm{EK} 4120-1 \mathrm{CB} 3$ & 26,1 & 29,6 & 31,8 & 36,6 & 24,5 & 80 & 33 \\
\hline 15 & 12 & $3 \mathrm{EK} 4150-1 \mathrm{CB} 3$ & 32,6 & 37 & 39,8 & 45,7 & 30,6 & 99 & 41 \\
\hline
\end{tabular}

Prosseguindo, por meio da Tabela 5.7 e utilizando $U r=6 \mathrm{kV}$ é possível definir a corrente nominal de descarga do para-raios igual a 10 kA. Já por meio da Tabela 5.8 determina-se a classe de descarga da linha igual a 1 , tendo em vista que $U_{s}=3,39 \mathrm{kV}$, e com este dado e por meio da Tabela 5.9 fica estabelecido que o diâmetro do resistor de óxido de zinco do para-raios deve possuir no mínimo $50 \mathrm{~mm}$. A Tabela 5.11 demonstra que os valores definidos para a corrente nominal de descarga e para a classe de descarga da linha são condizentes com os especificados no modelo de para-raios selecionado.

Tabela 5.11: Dados técnicos gerais relativos aos para-raios do tipo 3EK4, adaptado de (SIEMENS, 2013).

\begin{tabular}{|c|c|}
\hline Corrente de descarga nominal $-8 / 20 \mu \mathrm{s}$ & $10 \mathrm{kA}$ \\
\hline Classe de descarga da linha & 1 \\
\hline Impulso de corrente de longa duração - $2 \mathrm{~ms}$ & $325 \mathrm{~A}$ \\
\hline Suportabilidade a alta corrente de curto-circuito & $20 \mathrm{kA}$ \\
\hline Suportabilidade a baixa corrente de curto-circuito & $600 \mathrm{~A}$ \\
\hline Impulso de alta corrente $-4 / 10 \mu \mathrm{s}$ & $100 \mathrm{kA}$ \\
\hline Carga especifica de longa duração & $175 \mathrm{Nm}$ \\
\hline Carga especifica de curta duração & $250 \mathrm{Nm}$ \\
\hline Capacidade de absorção de energia & $3,5 \mathrm{~kJ} / \mathrm{kUr}$ \\
\hline
\end{tabular}

Feito isto, o próximo passo é a implementação do modelo de para-raios selecionado empregando o elemento Surge Arrester do toolbox SimPowerSystems ${ }^{\mathrm{TM}}$ presente no ambiente gráfico Simulink® (The MathWorks, Inc., 2013). Este elemento possui uma grande vantagem sobre outros existentes em diferentes softwares, porque foi desenvolvido para representar as 
características não lineares de para-raios formados por varistores de óxido de zinco, o que é bastante relevante para esta pesquisa.

A característica não linear entre tensão e corrente deste componente é apresentada na Figura 5.9 e é expressa analiticamente pela equação (5.9), a seguir.

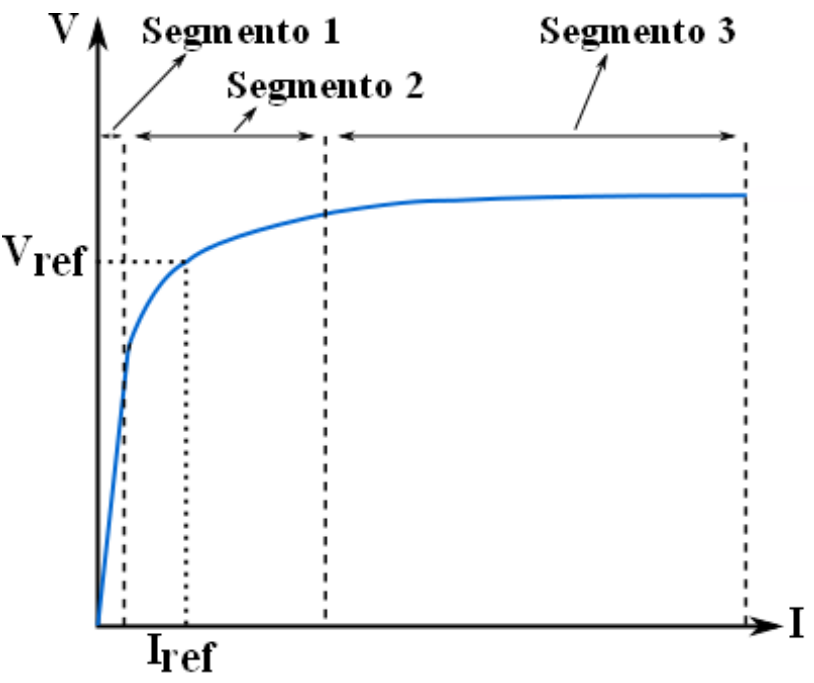

Figura 5.9: Características VxI do elemento Surge Arrester do Simulink (The MathWorks, Inc., 2013).

$$
\frac{V}{V_{r e f}}=k_{i}{\frac{I}{I_{r e f}}}^{\frac{1}{\alpha_{i}}}
$$

$\mathrm{Na}$ equação (5.9) $\mathrm{V}_{\text {ref }}$ representa a tensão de proteção do para-raios e $\mathrm{I}_{\text {ref }}$ a corrente de referência usada para especificar a tensão de proteção. $k_{i}$ e $\alpha_{i}$ simbolizam os parâmetros padrão dos três segmentos ilustrados na Figura 5.11 os quais determinam o quão não linear é o varistor, parâmetros estes que independem de $\mathrm{V}_{\text {ref }}$ e $\mathrm{I}_{\text {ref }}$. V e I retratam a tensão e a corrente sobre o varistor de óxido de zinco, respectivamente, obtidas a partir da definição dos parâmetros anteriores.

Dessa maneira, com as características elétricas dos para-raios definidas anteriormente e fazendo as devidas correspondências, deve-se tomar $\mathrm{V}_{\text {ref }}=6 \mathrm{kV}$ e $\mathrm{I}_{\text {ref }}=10 \mathrm{kA}$ para que sejam calculados $\mathrm{k}_{\mathrm{i}}$ e $\alpha_{\mathrm{i}}$, os quais devem assumir os seguintes valores no momento da implementação computacional: $\mathrm{k}_{1}=1, \alpha_{1}=40, \mathrm{k}_{2}=1, \alpha_{2}=20, \mathrm{k}_{3}=0,05$ e $\alpha_{3}=1$.

Por fim, implementando o para-raios com os dados obtidos acima e realizando uma simulação para testar o seu comportamento frente a uma descarga atmosférica com forma de onda 1,2x50 $\mu$ s e corrente de descarga 10 kA, obtém-se o resultado da Figura 5.10. 


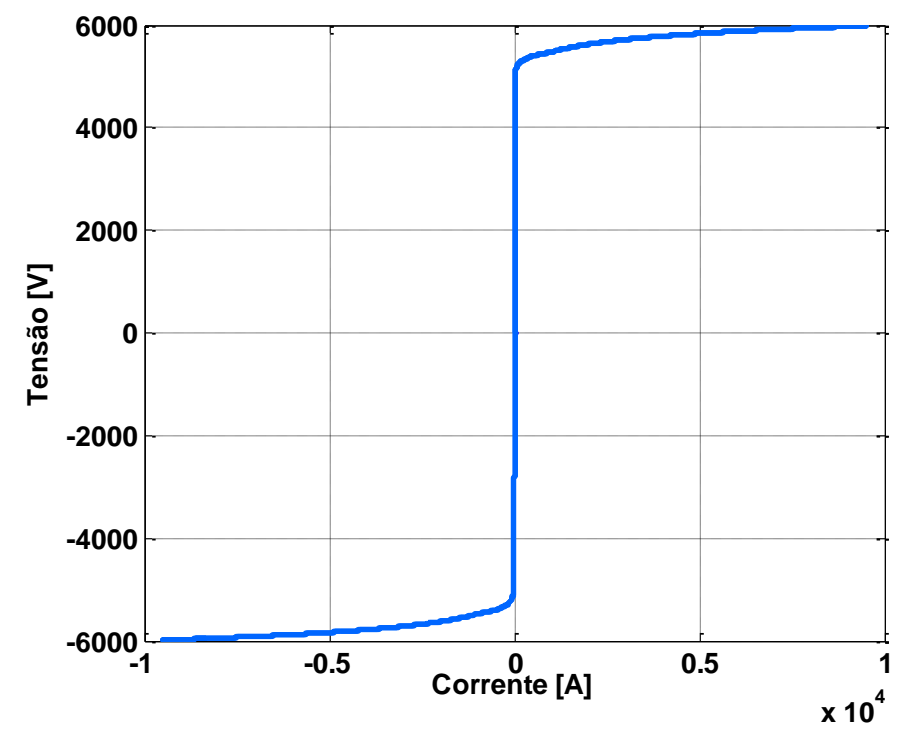

Figura 5.10: Atuação do modelo de para-raios selecionado frente a uma descarga de $10 \mathrm{kA}$.

A partir da Figura 5.10 depreende-se que o modelo de para-raios implementado está operando corretamente, pois a partir do momento em que foi submetido a uma tensão superior a sua tensão nominal passou a atuar com baixa impedância dissipando a corrente de impulso atmosférico, limitando o valor da sobretensão resultante e recuperando seu alto valor de impedância após o término da solicitação da tensão.

Posto isto, terminadas as modelagens e implementações computacionais, cabe agora examinar a influência das sobretensões induzidas por descargas indiretas, e avaliar a atuação dos para-raios frente a estas sobretensões. Para tanto, no próximo capítulo serão expostos os resultados das simulações realizadas bem como uma análise dos mesmos a partir de toda a modelagem aqui descrita. 


\section{CAPÍTULO 6}

\section{SIMULAÇÃO E ANÁLISE DA ATUAÇÃO DE PARA-RAIOS FRENTE A TENSÕES INDUZIDAS POR DESCARGAS ATMOSFÉRICAS INDIRETAS}

Neste capítulo serão apresentados os resultados de simulações para estimação de tensões induzidas por descargas atmosféricas indiretas em diferentes pontos do alimentador teste de distribuição. Também serão expostas as consequências da proteção exercida pelos para-raios instalados nas diversas estruturas da linha que compõem o referido alimentador.

Por meio da apreciação dos resultados destas simulações será determinado o melhor cenário de proteção para o sistema avaliado, definindo-se o número de pararaios necessários e a localização dos mesmos.

\section{1 - Definição dos casos das simulações e de suas variáveis}

Para realização das simulações, inicialmente, é necessária a definição de alguns parâmetros e procedimentos relativos às variáveis do equacionamento da estimação das tensões induzidas, e aos pontos de alocação do subsistema das mesmas e dos para-raios.

A fim de simular a estimação das tensões induzidas a velocidade de propagação da onda de corrente de descarga, a velocidade da luz no vácuo, e a impedância característica da linha, assumirão os valores definidos da seção 5.2.1 do capítulo 5 . Além disso, serão estimadas tensões sempre em relação ao centro da linha, assim $x=0$, e em relação à altura do trecho onde estiver localizado o subsistema de tensões induzidas, para o período de tempo correspondente a dois ciclos na frequência de $60 \mathrm{~Hz}$, ou seja, $\mathrm{t}=0,034 \mathrm{~s}$. 
Já para o pico da corrente de descarga será adotado o valor de $10 \mathrm{kA}$, valor este definido a partir de Diesendorf (1974) e Barker et al. (1993). De acordo com o primeiro, $65 \%$ das descargas atmosféricas possuem uma corrente igual ou inferior a $10 \mathrm{kA}$. Não obstante, por meio dos estudos de monitoramento de tensões e correntes de origem atmosférica sob para-raios de uma rede de distribuição, o segundo observou que dentre as ondas de corrente registradas aproximadamente $90 \%$ apresentaram valores de pico entre 0,3 e 2,6 kA. Além disso, aplicando a função distribuição de probabilidade expressa pela equação (2.1), presente na seção 2.4 do capítulo 2, obtém-se a probabilidade de ocorrência de 94,9\% para o pico da corrente de descarga de $10 \mathrm{kA}$, reforçando a escolha feita.

Com relação à distância entre a linha e o ponto de incidência das descargas atmosféricas serão tomados quatro valores distintos, 50, 150, 250 e $350 \mathrm{~m}$, conforme o caso a ser simulado. Não foram assumidos valores maiores que $350 \mathrm{~m}$ devido ao comprimento reduzido dos trechos da linha e a amplitude relativamente baixada das tensões induzidas para distâncias maiores. Também não foram tomados valores menores que $50 \mathrm{~m}$ em virtude da ocorrência de descargas diretas para distâncias inferiores a esta, devido ao raio de atração dos elementos do sistema de distribuição.

A partir da análise do comprimento dos trechos de linha do alimentador teste e da conexão ou não de cargas aos seus nós, foram definidas a localização dos subsistemas representativos do estimador de tensões induzidas e as posição dos pararaios para cada uma das fases do sistema.

Os subsistemas de estimação de tensões induzidas (SETIs) foram dispostos ao longo dos ramos do alimentador de forma a cobrir o maior comprimento de linha pela ação das suas tensões induzidas, sendo localizados em relação aos extremos dos trechos do mesmo. Dessa maneira, foram pontuados no centro dos trechos entre os nós 650 e 632, 646 e 645, 632 e 633, 632 e 671, 611 e 684, 652, 692 e 675, e 671 e 680, como ilustrado pela Figura 6.1, perfazendo um total de 7 subsistemas.

Já os para-raios (PRs) foram alocados nas estruturas das terminações dos trechos de linha, representados pelos nós 650, 632, 646, 645, 633, 611, 652, 684, 671, 675 e 680, como também mostrado na Figura 6.1, a fim de salvaguardar as cargas (Cs) e transformadores (TRFs) do alimentador.

Ressalta-se que na Figura 6.1 a sigla PR simboliza os para-raios conectados em todas as fases de determinado nó específico do alimentador, e os números em conjunto com a letra $\mathrm{C}$ as cargas deste sistema de distribuição. 


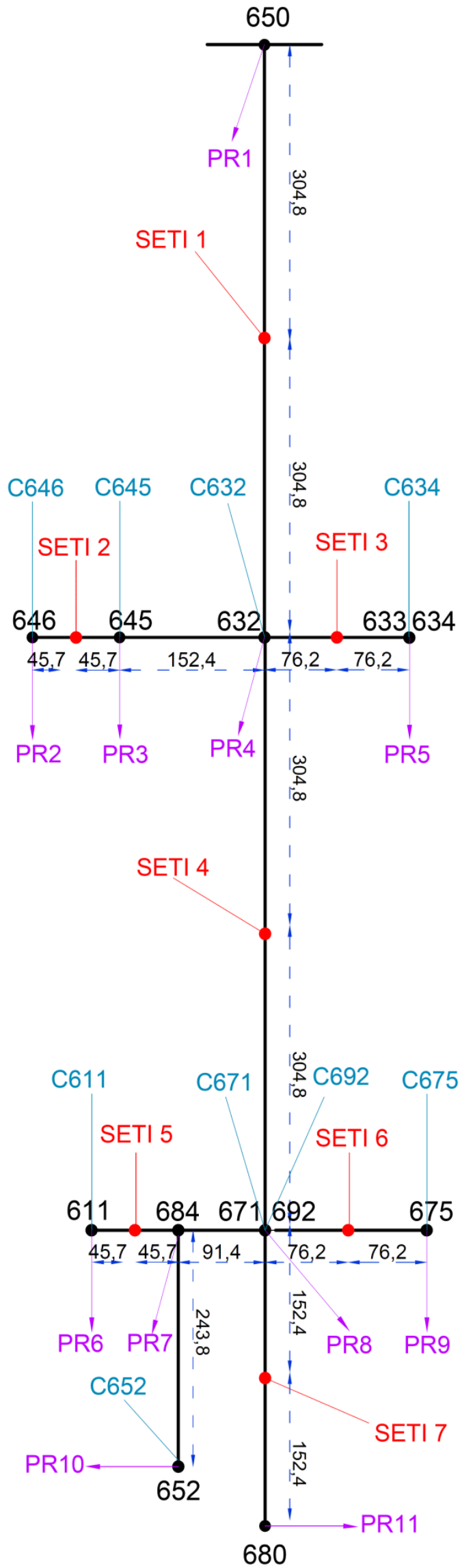

Figura 6.1: Pontos de alocação dos para-raios (PRs), dos subsistemas para estimação das tensões induzidas (SETIs), e das cargas (Cs) no alimentador teste. 
Cabe aqui a observação de que os 7 subsistemas para estimação das tensões induzidas são compostos por um mecanismo de chaveamento para que em cada simulação possa ocorrer a variação da ativação ou não dos mesmos. Assim escolhido um dos quatro valores acima citados para a distância entre a linha e o ponto de incidência da descarga atmosférica $(y)$, serão realizadas 128 simulações com o chaveamento destes 7 subsistemas, conforme estabelecido na Tabela 6.1.

Tabela 6.1: Relação entre número da simulação e número do Subsistema de Estimação de Tensão Induzida (SETI) ativo.

\begin{tabular}{|c|c|c|c|c|c|c|c|}
\hline $\begin{array}{c}\mathrm{N}^{\circ} \mathrm{da} \\
\text { simulação }\end{array}$ & $\begin{array}{l}\mathrm{N}^{\circ} \text { do } \\
\text { SETI } \\
\text { ativo }\end{array}$ & $\begin{array}{c}\mathrm{N}^{\mathrm{o}} \mathrm{da} \\
\text { simulação }\end{array}$ & $\begin{array}{l}\mathrm{N}^{\circ} \text { do } \\
\text { SETI } \\
\text { ativo }\end{array}$ & $\begin{array}{c}\mathrm{N}^{\circ} \mathrm{da} \\
\text { simulação }\end{array}$ & $\begin{array}{l}\mathrm{N}^{\circ} \text { do } \\
\text { SETI } \\
\text { ativo }\end{array}$ & $\begin{array}{c}\mathrm{N}^{\mathrm{o}} \mathrm{da} \\
\text { simulação }\end{array}$ & $\begin{array}{c}\mathrm{N}^{\mathrm{o}} \text { do SETI } \\
\text { ativo }\end{array}$ \\
\hline 1 & -- & 33 & $1 / 2 / 6$ & 65 & $1 / 2 / 3 / 4$ & 97 & $3 / 4 / 6 / 7$ \\
\hline 2 & 1 & 34 & $1 / 2 / 7$ & 66 & $1 / 2 / 3 / 5$ & 98 & $3 / 5 / 6 / 7$ \\
\hline 3 & 2 & 35 & $1 / 3 / 4$ & 67 & $1 / 2 / 3 / 6$ & 99 & $4 / 5 / 6 / 7$ \\
\hline 4 & 3 & 36 & $1 / 3 / 5$ & 68 & $1 / 2 / 3 / 7$ & 100 & $1 / 2 / 3 / 4 / 5$ \\
\hline 5 & 4 & 37 & $1 / 3 / 6$ & 69 & $1 / 2 / 4 / 5$ & 101 & $1 / 2 / 3 / 4 / 6$ \\
\hline 6 & 5 & 38 & $1 / 3 / 7$ & 70 & $1 / 2 / 4 / 6$ & 102 & $1 / 2 / 3 / 4 / 7$ \\
\hline 7 & 6 & 39 & $1 / 4 / 5$ & 71 & $1 / 2 / 4 / 7$ & 103 & $1 / 2 / 3 / 5 / 6$ \\
\hline 8 & 7 & 40 & $1 / 4 / 6$ & 72 & $1 / 2 / 5 / 6$ & 104 & $1 / 2 / 3 / 5 / 7$ \\
\hline 9 & $1 / 2$ & 41 & $1 / 4 / 7$ & 73 & $1 / 2 / 5 / 7$ & 105 & $1 / 2 / 3 / 6 / 7$ \\
\hline 10 & $1 / 3$ & 42 & $1 / 5 / 6$ & 74 & $1 / 2 / 6 / 7$ & 106 & $1 / 2 / 4 / 5 / 6$ \\
\hline 11 & $1 / 4$ & 43 & $1 / 5 / 7$ & 75 & $1 / 3 / 4 / 5$ & 107 & $1 / 2 / 4 / 5 / 7$ \\
\hline 12 & $1 / 5$ & 44 & $1 / 6 / 7$ & 76 & $1 / 3 / 4 / 6$ & 108 & $1 / 2 / 4 / 6 / 7$ \\
\hline 13 & $1 / 6$ & 45 & $2 / 3 / 4$ & 77 & $1 / 3 / 4 / 7$ & 109 & $1 / 2 / 5 / 6 / 7$ \\
\hline 14 & $1 / 7$ & 46 & $2 / 3 / 5$ & 78 & $1 / 3 / 5 / 6$ & 110 & $1 / 3 / 4 / 5 / 6$ \\
\hline 15 & $2 / 3$ & 47 & $2 / 3 / 6$ & 79 & $1 / 3 / 5 / 7$ & 111 & $1 / 3 / 4 / 5 / 7$ \\
\hline 16 & $2 / 4$ & 48 & $2 / 3 / 7$ & 80 & $1 / 3 / 6 / 7$ & 112 & $1 / 3 / 4 / 6 / 7$ \\
\hline 17 & $2 / 5$ & 49 & $2 / 4 / 5$ & 81 & $1 / 4 / 5 / 6$ & 113 & $1 / 3 / 5 / 6 / 7$ \\
\hline 18 & $2 / 6$ & 50 & $2 / 4 / 6$ & 82 & $1 / 4 / 5 / 7$ & 114 & $1 / 4 / 5 / 6 / 7$ \\
\hline 19 & $2 / 7$ & 51 & $2 / 4 / 7$ & 83 & $1 / 4 / 6 / 7$ & 115 & $2 / 3 / 4 / 5 / 6$ \\
\hline 20 & $3 / 4$ & 52 & $2 / 5 / 6$ & 84 & $1 / 5 / 6 / 7$ & 116 & $2 / 3 / 4 / 5 / 7$ \\
\hline 21 & $3 / 5$ & 53 & $2 / 5 / 7$ & 85 & $2 / 3 / 4 / 5$ & 117 & $2 / 3 / 4 / 6 / 7$ \\
\hline 22 & $3 / 6$ & 54 & $2 / 6 / 7$ & 86 & $2 / 3 / 4 / 6$ & 118 & $2 / 3 / 5 / 6 / 7$ \\
\hline 23 & $3 / 7$ & 55 & $3 / 4 / 5$ & 87 & $2 / 3 / 4 / 7$ & 119 & $2 / 4 / 5 / 6 / 7$ \\
\hline 24 & $4 / 5$ & 56 & $3 / 4 / 6$ & 88 & $2 / 3 / 5 / 6$ & 120 & $3 / 4 / 5 / 6 / 7$ \\
\hline 25 & $4 / 6$ & 57 & $3 / 4 / 7$ & 89 & $2 / 3 / 5 / 7$ & 121 & $1 / 2 / 3 / 4 / 5 / 6$ \\
\hline 26 & $4 / 7$ & 58 & $3 / 5 / 6$ & 90 & $2 / 3 / 6 / 7$ & 122 & $1 / 2 / 3 / 4 / 5 / 7$ \\
\hline 27 & $5 / 6$ & 59 & $3 / 5 / 7$ & 91 & $2 / 4 / 5 / 6$ & 123 & $1 / 2 / 3 / 4 / 6 / 7$ \\
\hline 28 & $5 / 7$ & 60 & $3 / 6 / 7$ & 92 & $2 / 4 / 5 / 7$ & 124 & $1 / 2 / 3 / 5 / 6 / 7$ \\
\hline 29 & $6 / 7$ & 61 & $4 / 5 / 6$ & 93 & $2 / 4 / 6 / 7$ & 125 & $1 / 2 / 4 / 5 / 6 / 7$ \\
\hline 30 & $1 / 2 / 3$ & 62 & $4 / 5 / 7$ & 94 & $2 / 5 / 6 / 7$ & 126 & $1 / 3 / 4 / 5 / 6 / 7$ \\
\hline 31 & $1 / 2 / 4$ & 63 & $4 / 6 / 7$ & 95 & $3 / 4 / 5 / 6$ & 127 & $2 / 3 / 4 / 5 / 6 / 7$ \\
\hline 32 & $1 / 2 / 5$ & 64 & $5 / 6 / 7$ & 96 & $3 / 4 / 5 / 7$ & 128 & $1 / 2 / 3 / 4 / 5 / 6 / 7$ \\
\hline
\end{tabular}


Dessa forma, as simulações foram divididas em quatro grupos conforme mostrado abaixo, com cada um contendo 128 simulações, cujas tensões induzidas para cada dos mesmos são representadas na Figura 6.2.

- Grupo - 1: $\mathrm{y}=50 \mathrm{~m}$;

- Grupo - 2: $\mathrm{y}=150 \mathrm{~m}$;
- Grupo - 3: $\mathrm{y}=250 \mathrm{~m}$;

- Grupo - 4: $\mathrm{y}=350 \mathrm{~m}$.

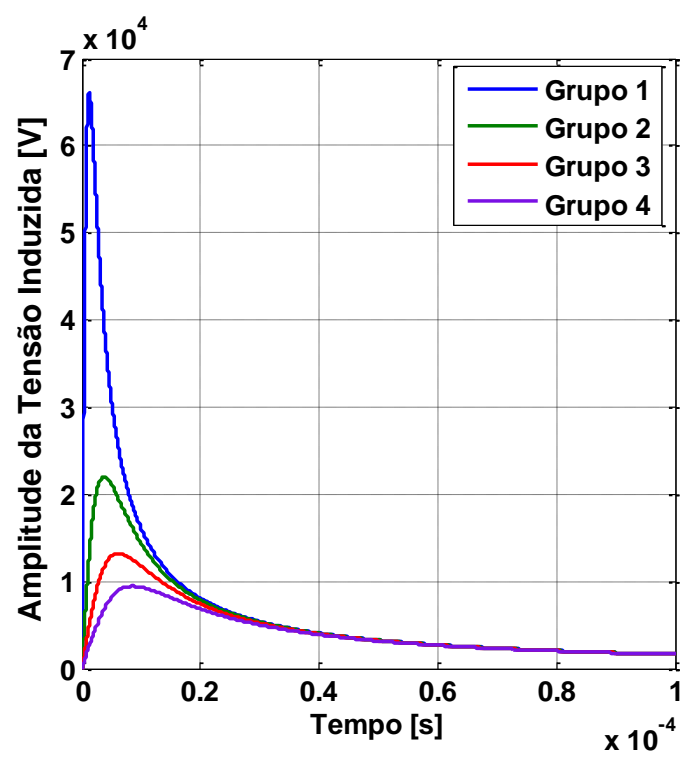

Figura 6.2: Tensões induzidas para os quatro casos a serem simulados.

Ainda com relação à conformação do sistema para as simulações, foram alocados medidores de tensão em cada uma das cargas e dos transformadores, bem como em todos os para-raios. Contudo, devido a grande quantidade de dados obtida e para uma melhor visualização dos resultados será mostrada a ação das tensões induzidas e da performance dos para-raios nas fases identificadas com maior pico de tensão para estes elementos. Assim sendo, serão apresentados os valores de pico de tensão em pu da seguinte forma:

- Transformador da subestação $(\mathrm{TRF}-\mathrm{S})=$ Fase B;

- Transformador de Linha $(\mathrm{TRF}-\mathrm{L})=$ Fase B;

- Carga 632/671 (C - 632/671) = Fase B;

- Carga $646(\mathrm{C}-646)=$ Fase B;

- Carga $645(\mathrm{C}-645)=$ Fase B;

- Carga $634(\mathrm{C}-634)=$ Fase B;

- $\operatorname{Carga} 671(\mathrm{C}-671)=$ Fase B;

- Carga $611(\mathrm{C}-611)=$ Fase $\mathrm{C}$; 
- $\operatorname{Carga} 652(\mathrm{C}-652)=$ Fase A;

- Carga $692(\mathrm{C}-692)=$ Fase B;

- $\operatorname{Carga} 675(\mathrm{C}-675)=$ Fase B.

Posto isto, cabe agora apresentar e discutir os resultados dos quatro casos acima listados para as simulações computacionais.

\subsection{1 - Resultados e Análises das Simulações do Grupo - 1}

Nas simulações deste primeiro grupo serão observados os maiores picos de sobretensões sobre os transformadores e cargas do alimentador teste, uma vez que como visto na Figura 6.2 quanto menor a distância entre a linha e o ponto de incidência das descargas maiores são as tensões induzidas.

Em decorrência deste fato, ainda é prevista uma maior atuação dos para-raios a fim de proteger a linha e seus componentes da forma mais eficiente possível evitando danos ao sistema como um todo para este grupo de simulações.

Antevê-se também que as maiores sobretensões se estabelecerão conforme for ocorrendo simultaneamente um maior número de descargas e de acordo com a posição relativa do elemento avaliado em relação ao ponto de ativação do SETI para determinada simulação. Porém, de forma geral, seguindo a ordem de simulações estabelecidas pela Tabela 6.1, as maiores sobretensões serão verificas quando o número da simulação se aproximar de 128 , ou seja, da ultima simulação, uma vez que na mesma todos os SETIs estarão ligados.

Além disso, para as simulações deste grupo cada um dos SETIs está, na verdade, estimando as tensões induzidas para duas possibilidades de incidência de descargas atmosféricas, como se pode ver na Figura 6.3. Isto porque segundo a teoria de Rusck, aqui implementada, o vetor potencial indutor associado à corrente de retorno do canal de descarga é perpendicular à direção dos condutores, como definido na seção 3.4.2.6 do capítulo 3. Logo, a distância entre o ponto de incidência da descarga e a linha deve ser tomada de forma perpendicular, o que leva a conclusão de que este grupo com 128 simulações esta representando, na realidade, $2^{7} \times 128$ (16.384) possibilidades de incidências de descargas atmosféricas nas proximidades deste alimentador teste. 


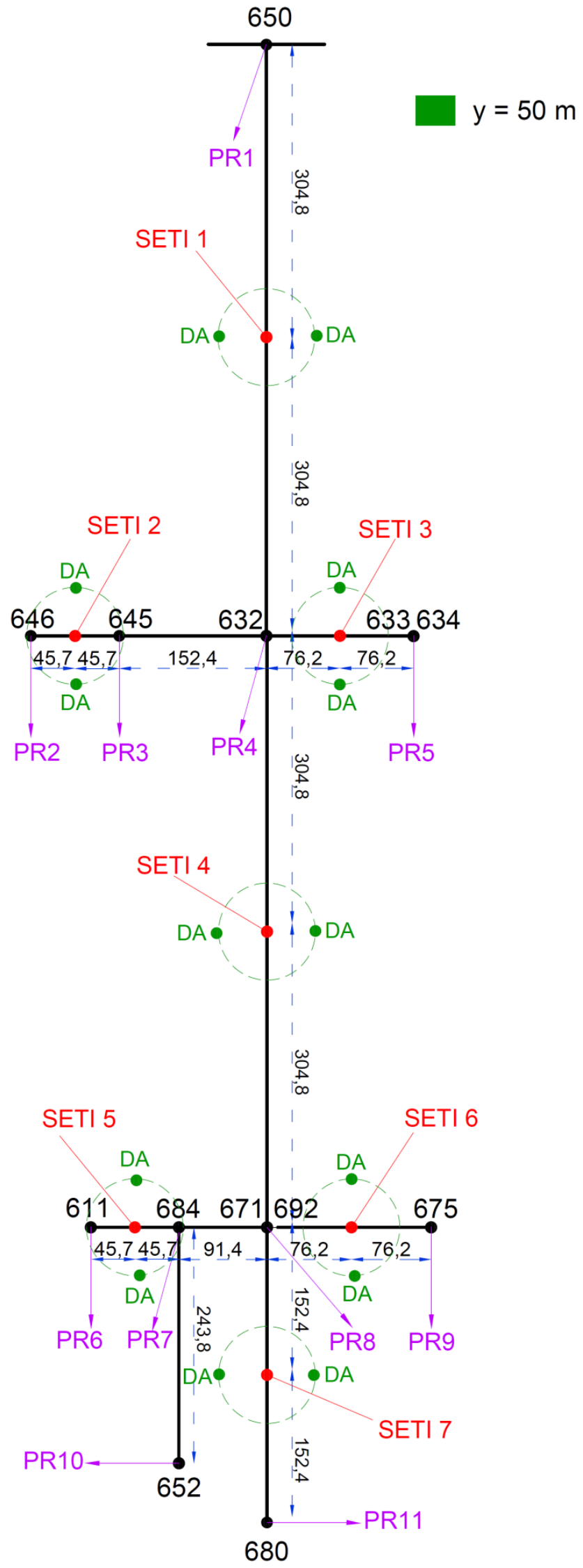

Figura 6.3: Correlação entre os pontos de localização dos subsistemas para estimação das tensões induzidas (SETIs) e os pontos de incidência das descargas atmosféricas (DA) em relação ao alimentador teste para $y=50 \mathrm{~m}$. 
Posto isto, analisando o perfil de tensão do transformador da subestação, pela Figura 6.4, pode-se notar a influência da relação direta entre a distância do ponto de incidência das descargas e o crescimento das tensões induzidas, e também a soma dos efeitos das tensões induzidas por varias descargas ocorrendo ao mesmo tempo.

Avaliando as 8 primeiras simulações vê-se que a situação de maior tensão sobre o transformador acontece quando o SETI 1 está ativo, o qual é o mais próximo do transformador. Em seguida, examinando as demais simulações, contata-se que à medida que vão sendo acionados outros SETIs em conjunto com o de número 1 a tensão sobre o transformador vai aumentando até encontrar seu valor máximo na simulação 128 , quando todos os SETIs estão ligados.

Averiguando as simulações de 2 a 8 ainda pode-se estabelecer em ordem decrescente e de forma individual, quais os SETIs que promovem as maiores tensões sobre o transformador de acordo com o SETI ativo, pela seguinte ordem: $1-6-5-7-$ $3-2-4$.

Observa-se que apesar de os SETIs 2 e 3 estarem próximos ao transformador a influência de suas tensões induzidas sobre o transformador é reduzida, mesmo quando somado o efeito dos demais SETIs, desde que não se inclua o SETI 1. Isto é comprovado pela análise das simulações de 15 a 29, 45 a 64, 85 a 99, 115 a 120, e, sobretudo, pela simulação 127, na qual todos os SETIs estão ativos com exceção do número 1. Por meio das mesmas verifica-se que a maior tensão sobre o transformador para estes casos é próxima de $1 \mathrm{pu}$, e que na maior parte das vezes é menor que para a situação inicial de regime permanente, mostrada pela simulação de número 1.

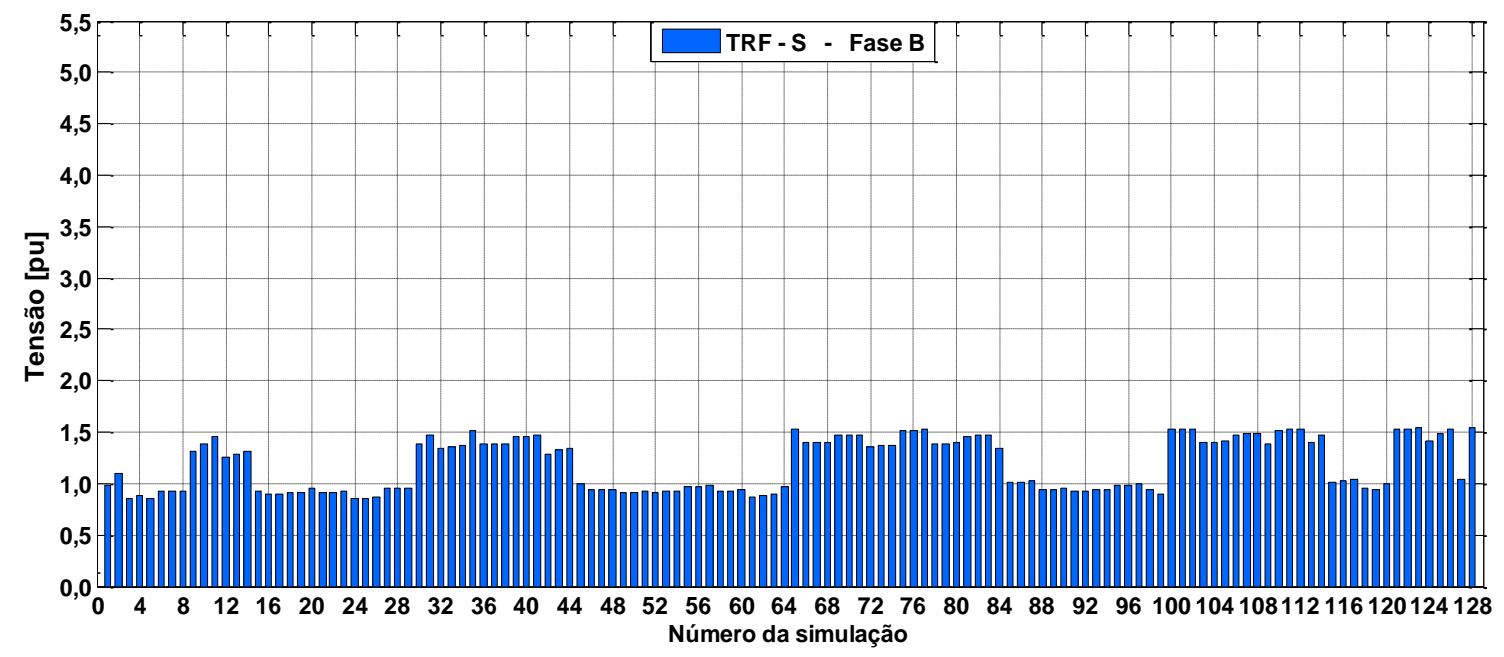

Figura 6.4: Tensão sobre o transformador da subestação para as 128 simulações do Grupo 1 $(\mathbf{y}=\mathbf{5 0 m})$. 
Pela apreciação da Figura 6.5 verifica-se a maior sensibilidade do transformador de linha em relação ao da subestação, uma vez que a maior tensão aferida sobre o mesmo é de aproximadamente 5 pu, enquanto para o outro é de pouco menos que 1,7 pu. Devido a sua maior sensibilidade também se observa que o mesmo fica submetido a elevados níveis de tensão em um número maior de simulações, e que com exceção da simulação 1, na qual o sistema esta em regime permanente, nas demais o nível de tensão sobre o mesmo sempre é maior que $1 \mathrm{pu}$.

Estas diferenças entre os transformadores e a maior sensibilidade do transformador de linha se devem as características dos mesmos, mostradas na seção 5.1.5 do capítulo 5, e da relação entre seus nós de alocação e dos parâmetros de linha em seu entorno.

Novamente, analisando as simulações de 2 a 8 pode-se definir em ordem decrescente e de forma individual, quais os SETIs que promovem as maiores tensões sobre o transformador de acordo com o SETI ativo, pela seguinte escala: $3-4-2-1-$ $7-6-5$. E mais uma vez averígua-se que a situação de maior tensão ocorre quando o SETI mais próximo esta ativo, neste caso o SETI 3.

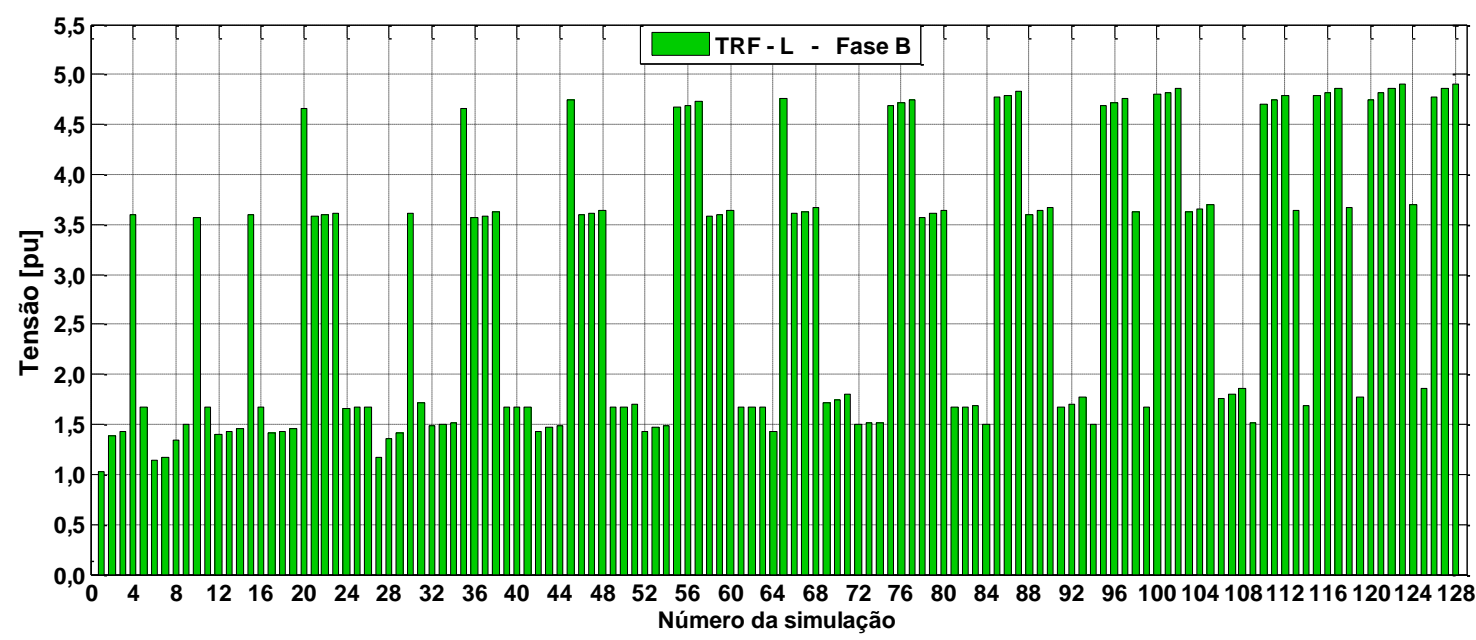

Figura 6.5: Tensão sobre o transformador da linha para as 128 simulações do Grupo 1 (y=50 m).

Já da Figura 6.6 até a Figura 6.14 são exibidos os comportamentos das cargas frente às tensões induzidas pelas 128 simulações propostas, por meio das quais se vê que após a ativação de qualquer um dos SETIs nenhuma das cargas opera com a mesma tensão que operava quando em regime permanente.

Analisando os máximos valores de tensão a que cada uma das cargas foi submetida nas 128 simulações também é possível definir uma escala de máximas 
tensões sobre as mesmas de forma crescente, da seguinte maneira: $C-652, C-645, C$ -611, C-692, C -671, C-646, C - 675, C - 632/671 e C - 634. Portanto, a carga que mais sofre a ação das tensões induzidas é a $\mathrm{C}-634$, carga esta conectada ao nó do transformador de linha, e que tem seu comportamento praticamente idêntico ao do mesmo, uma vez que entre eles não há nenhum tipo de equipamento de proteção.

Por outro lado, a carga menos sensível e consequentemente mais robusta é a C 652, fato este que em parte pode ser ocasionado por suas características, mas que certamente se deve a sua localização no alimentador em relação aos para-raios alocados. Retomando a Figura 6.3 pode-se ver que para as tensões induzidas pelo SETI 5, mais próximos à carga $\mathrm{C}-652$, atingirem esta carga, elas se deparariam com a proteção em cascata de 2 para-raios ( $\mathrm{PR}-7$ e $\mathrm{PR}$ - 10), fato este não encontrado para nenhuma outra carga, e que prova a eficiência e a necessidade da proteção concebida pelos para-raios.

Ainda examinado os valores máximos de tensão nas cargas esperava-se que as cargas C - 671, C - 692 e C - 632/671 apresentassem sensibilidades muito próximas devido a sua localização central em relação aos ramos do alimentador e a sua exposição às tensões induzidas pelos SETIs localizados de forma semelhante em relação às mesmas. Entretanto, como observado pela Figura 6.6, Figura 6.10 e Figura 6.13 isto não ocorreu, uma vez que as máximas tensões sobre as cargas C - 671, C - 692 e C 632/671 são aproximadamente 3,55 pu, 3,52 pu e 4,2 pu, respectivamente.

Averiguando as simulações de 2 a 8 para a carga $C-632 / 671$ pode-se constituir uma escala decrescente para os SETIs que promovem as maiores tensões sobre a mesma, pela subsequente ordem: $4-3-2-1-7-6-5$.

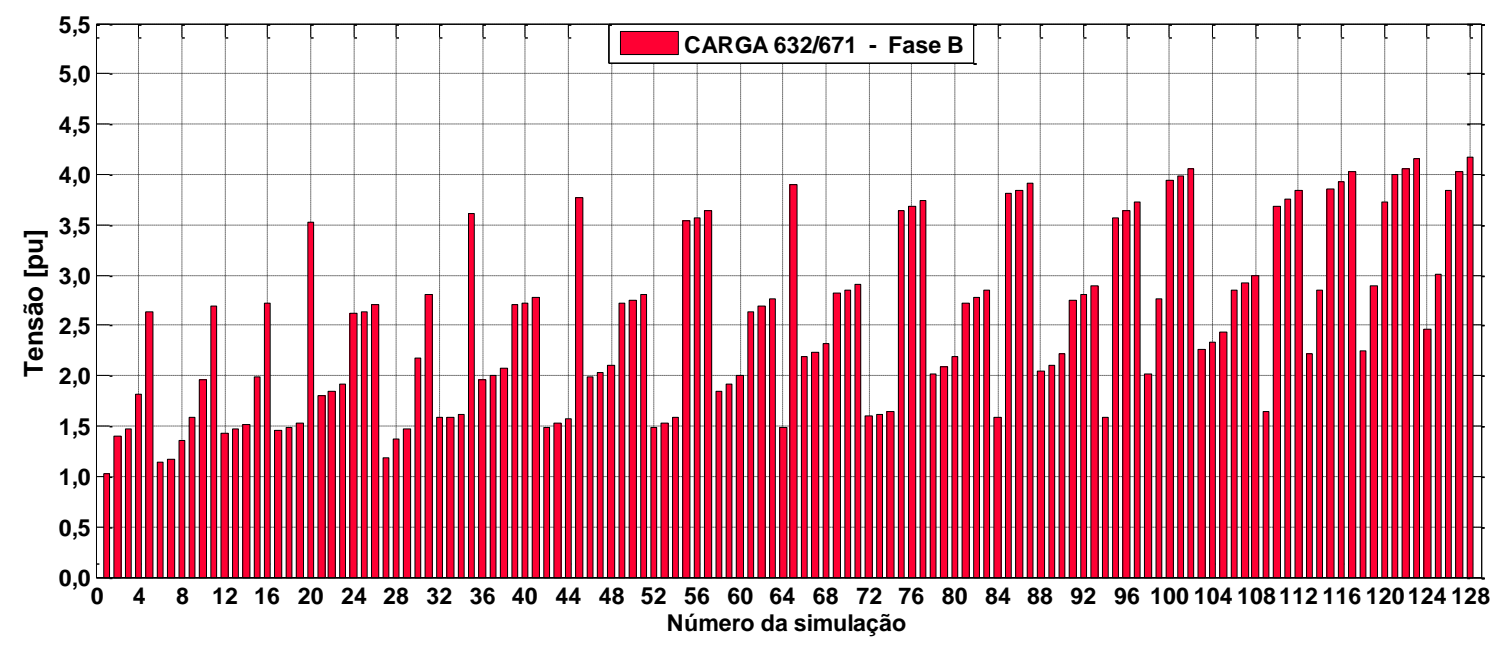

Figura 6.6: Tensão sobre a carga 632/671 para as 128 simulações do Grupo 1 (y=50 m). 
Agora, ponderando as simulações de 2 a 8 para as cargas C - 646, C - 645 e C 634 também pode-se compor uma escala decrescente para os SETIs que promovem as maiores tensões sobre as mesmas, por meio das seguinte séries, respectivamente:

- $\mathrm{C}-646: 2-4-3-1-7-6-5$;

- $\mathrm{C}-645: 2-4-3-1-7-6-5$;

- $\mathrm{C}-634: 3-4-2-1-7-6-5$.

Por meio destas três séries e da série definida para a carga $\mathrm{C}$-632/671 observase que os SETIs 7, 6 e 5 são os menos influentes para as mesmas, uma vez que são os mais distantes.

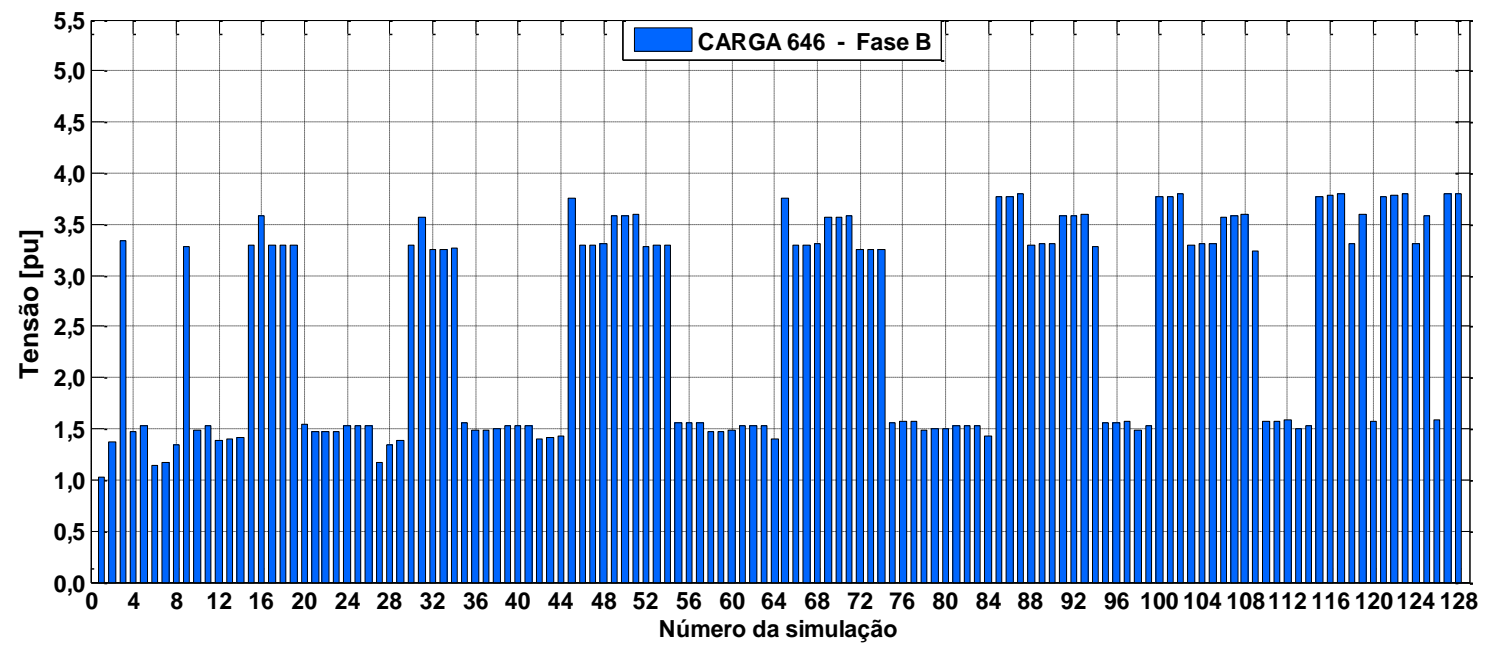

Figura 6.7: Tensão sobre a carga 646 para as 128 simulações do Grupo 1 (y=50 m).

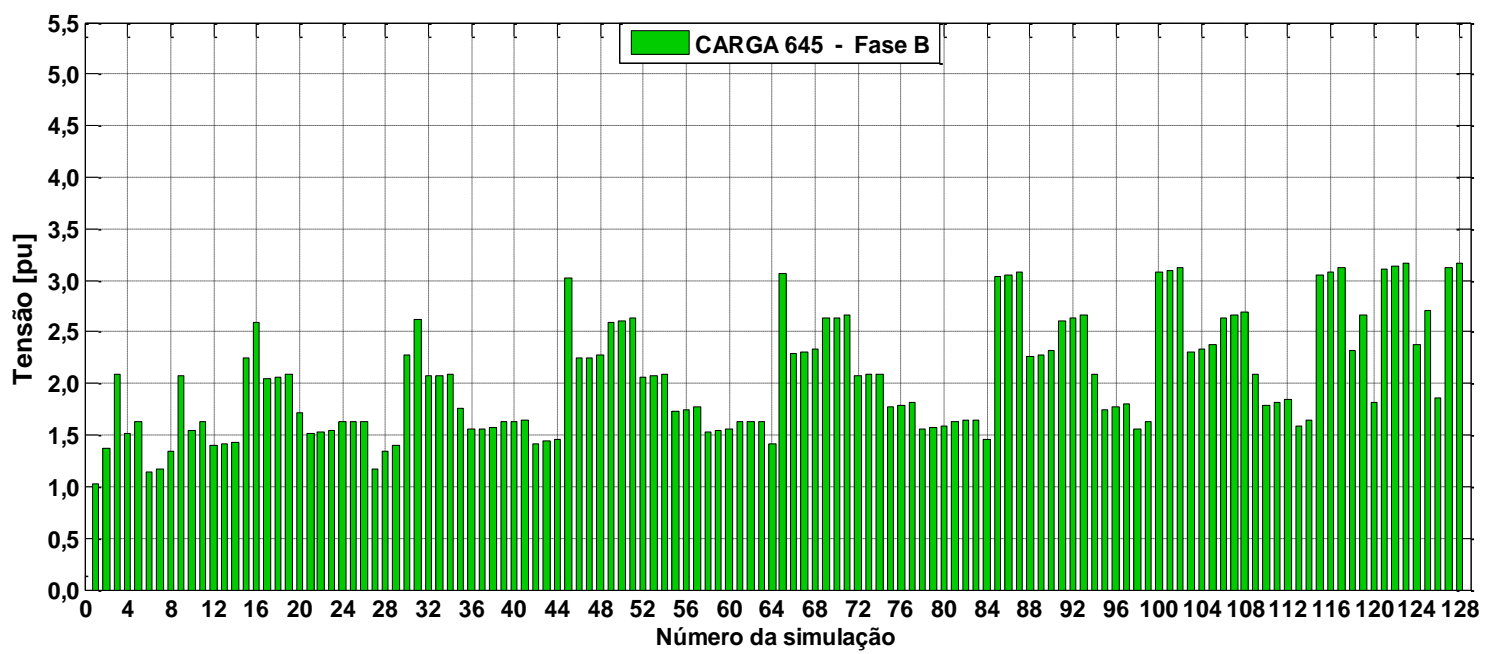

Figura 6.8: Tensão sobre a carga 645 para as 128 simulações do Grupo 1 (y=50 m). 


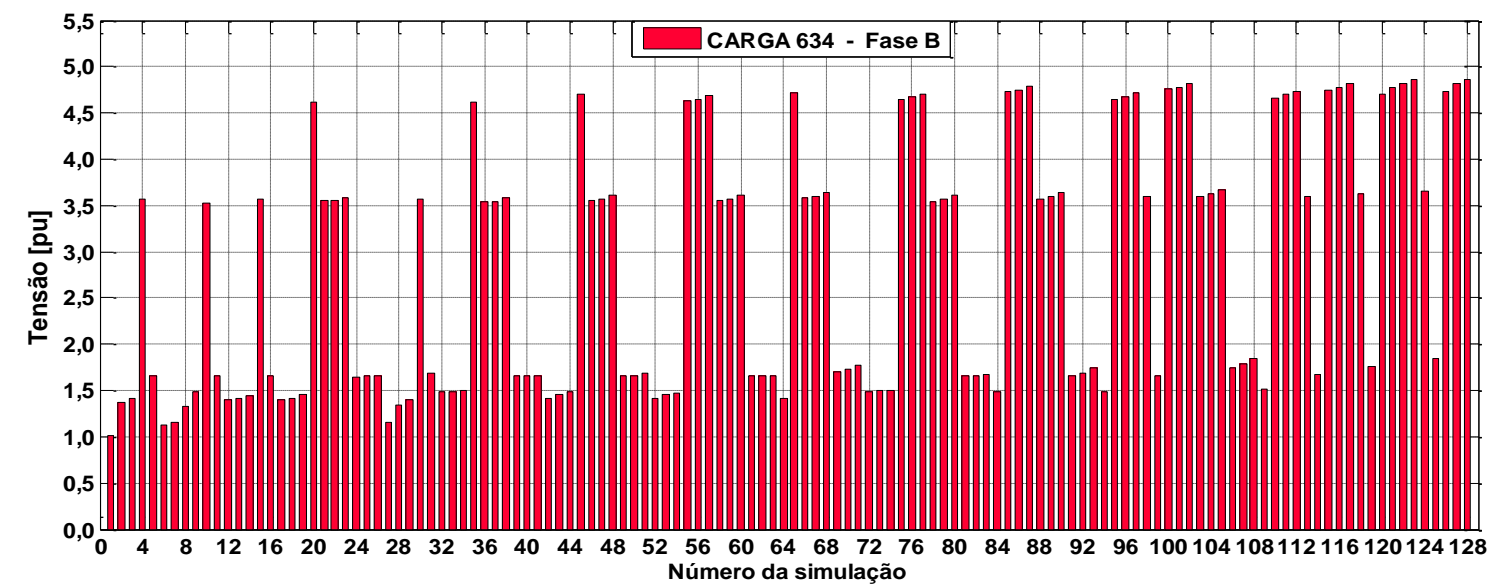

Figura 6.9: Tensão sobre a carga 634 para as 128 simulações do Grupo 1 (y=50 m).

De igual maneira, examinado as simulações de 2 a 8 para as cargas $\mathrm{C}-671, \mathrm{C}-$ 611, C - 652, C - 692 e C - 675 pode-se determinar uma escala decrescente para os SETIs que promovem as maiores tensões sobre as mesmas, pelas seguintes sequências:

- C-671: $7-6-4-5-3-2-1$;

- $\mathrm{C}-611: 5-7-6-4-3-2-1$;

- $\mathrm{C}-652: 5-7-6-4-3-2-1$;

- $\mathrm{C}-692: 7-6-4-5-3-2-1$;

- C-675: $6-7-5-4-3-2-1$.

Analisando estas sequências é fácil notar que os SETIs 3, 2 e 1 são os menos influentes para estas cargas, já que são os mais afastados, e a igualdade entre as séries das cargas $\mathrm{C}-671$ e C - 692 conectadas ao mesmo nó. Também se verifica a igualdade entre as sequências das cargas C - 611 e C - 652, as quais estão sob ação dos SETIs de forma igual, pois não há SETI ligado entre os nós 684 e 652.

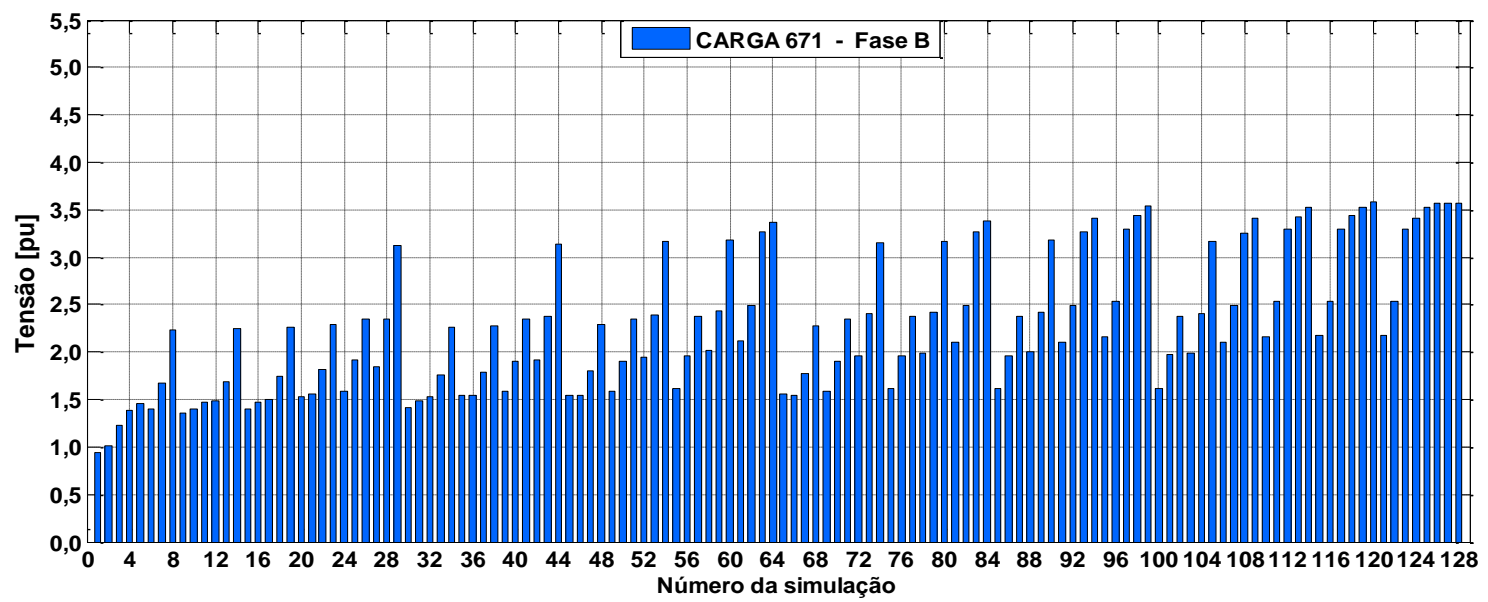

Figura 6.10: Tensão sobre a carga 671 para as 128 simulações do Grupo 1 (y=50 m). 


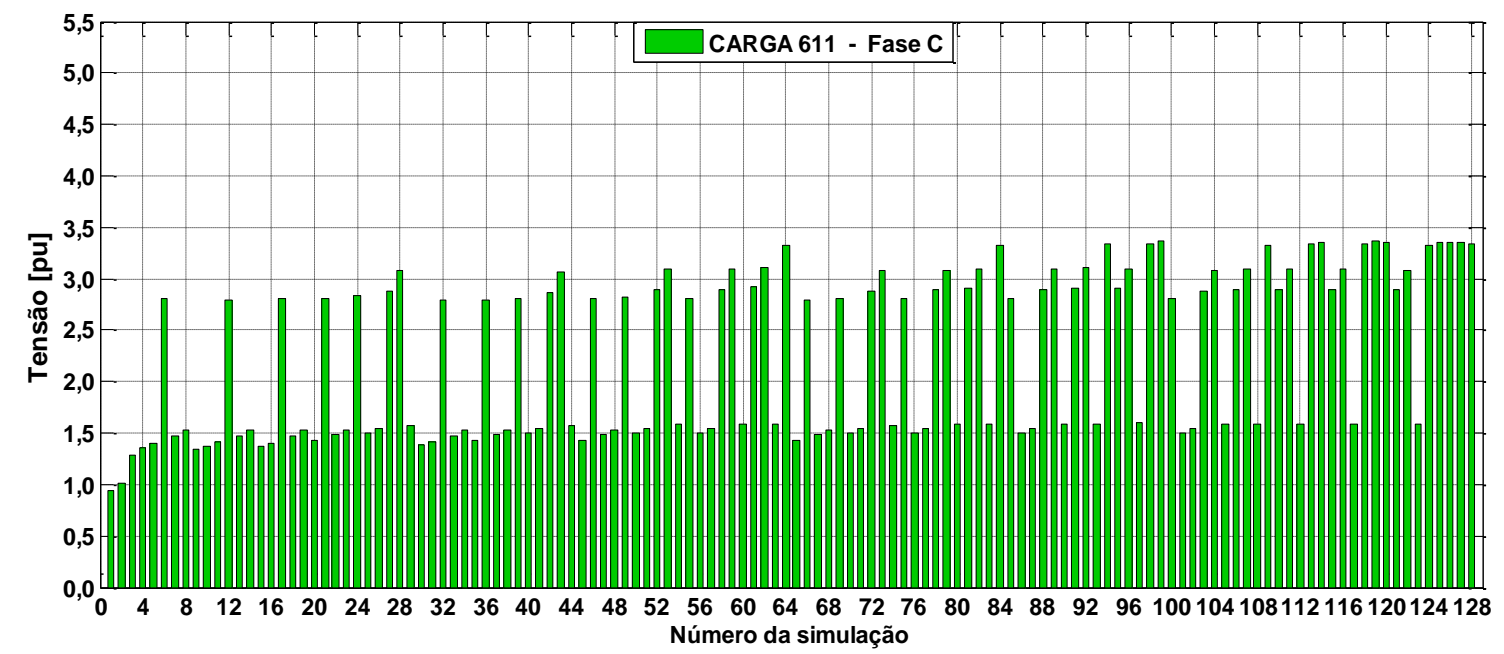

Figura 6.11: Tensão sobre a carga 611 para as 128 simulações do Grupo 1 (y=50 m).

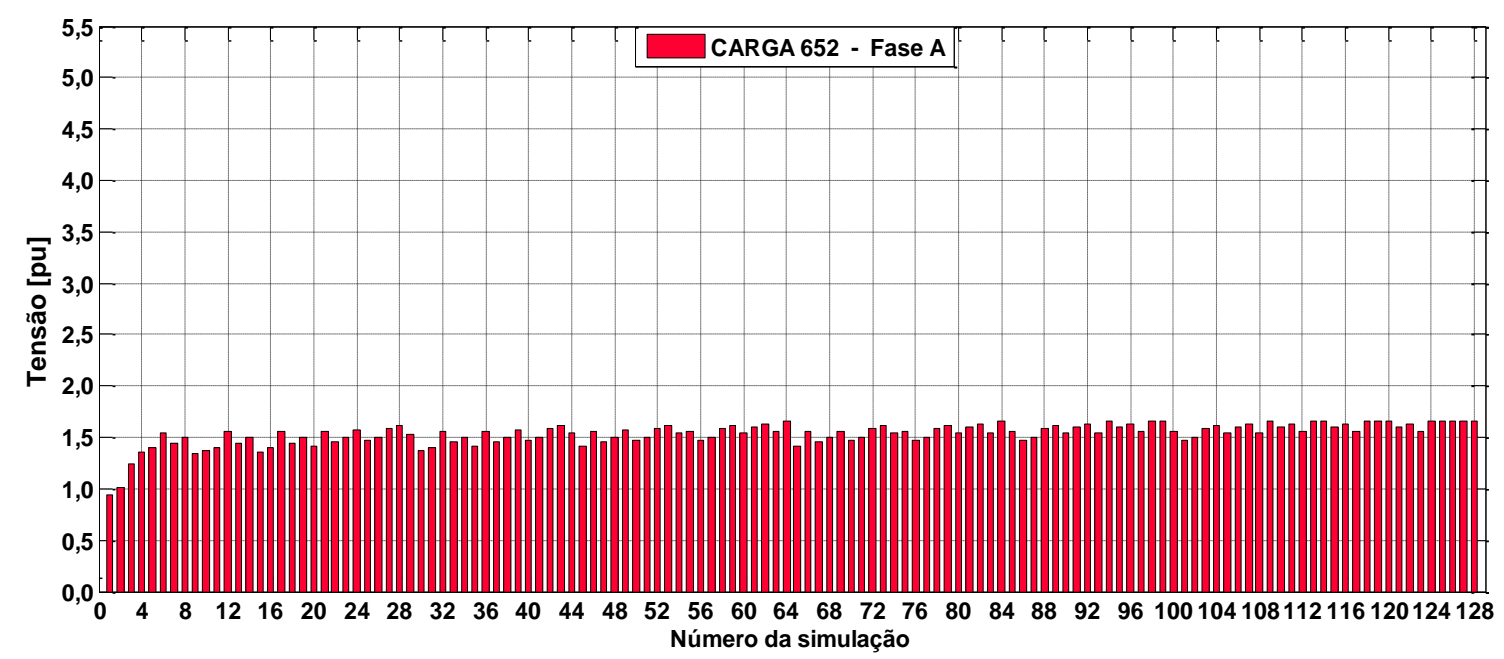

Figura 6.12: Tensão sobre a carga 652 para as 128 simulações do Grupo 1 (y=50 m).

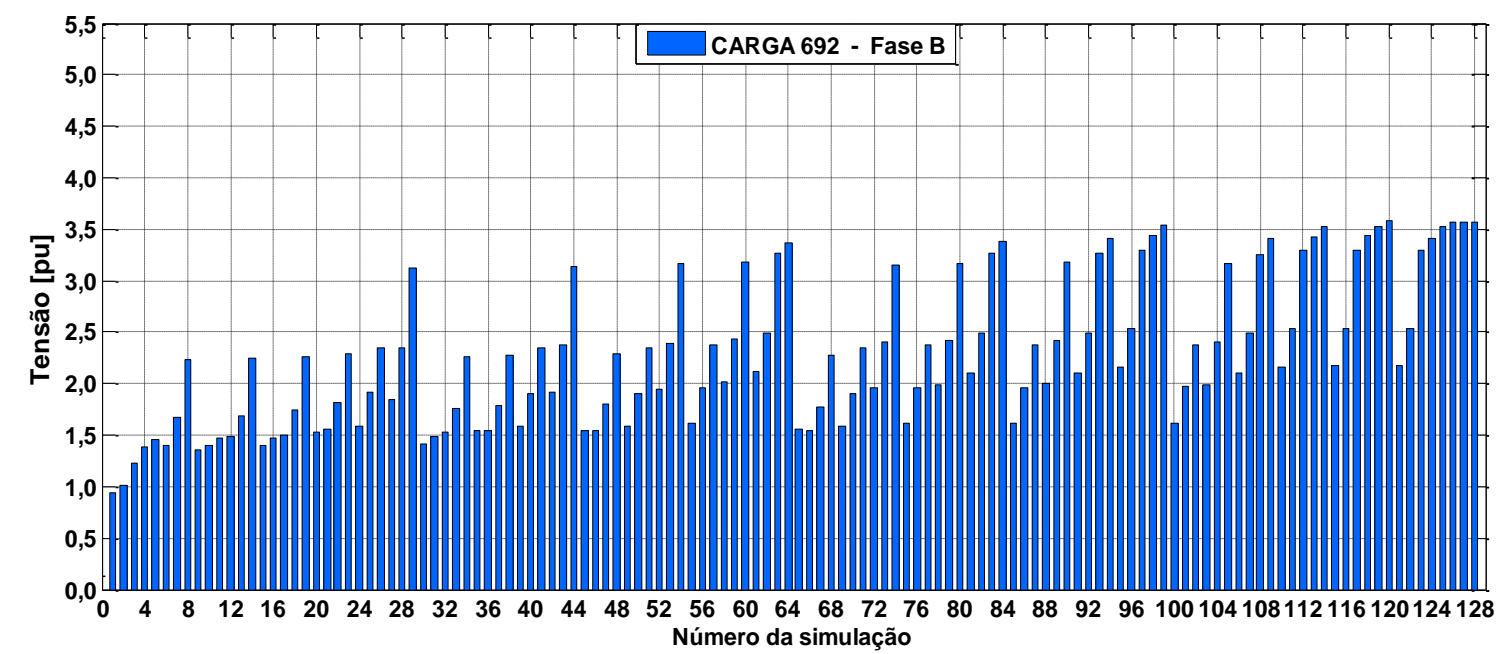

Figura 6.13: Tensão sobre a carga 692 para as 128 simulações do Grupo 1 (y=50 m). 


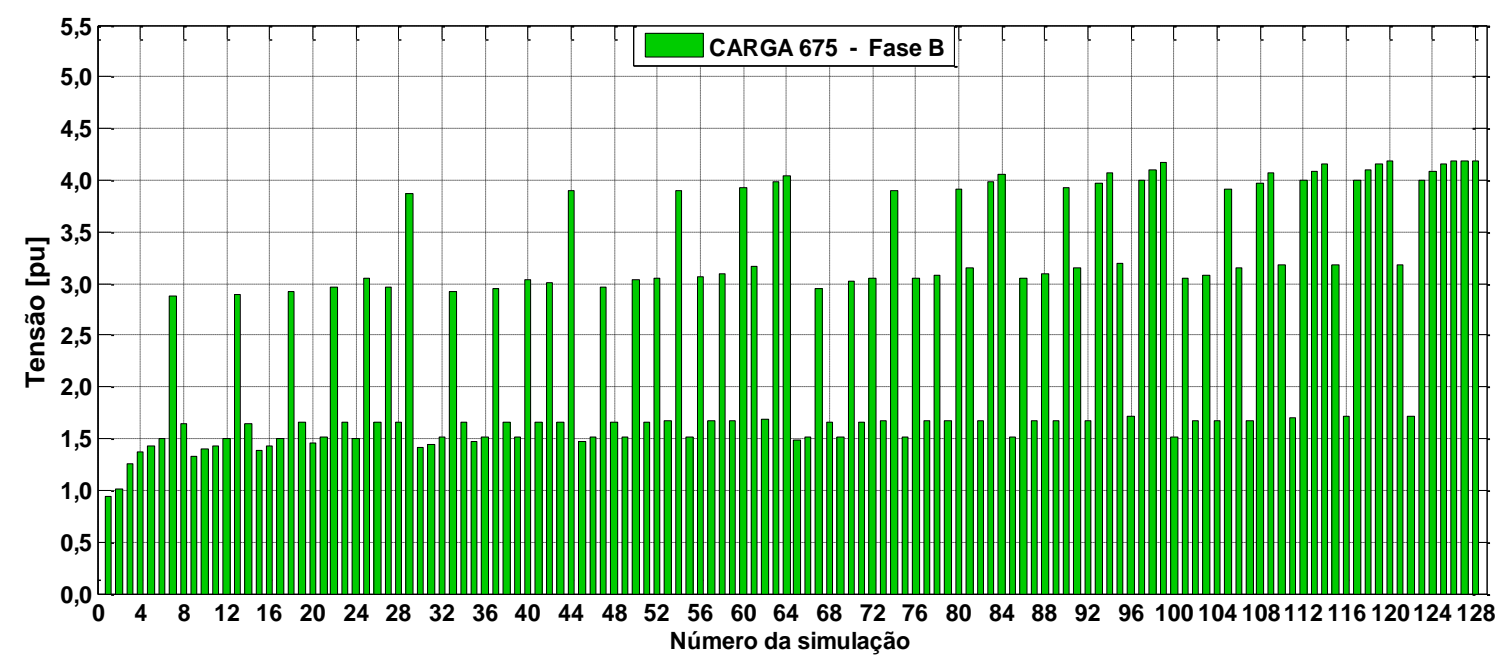

Figura 6.14: Tensão sobre a carga 675 para as 128 simulações do Grupo 1 (y=50 m).

Não obstante, com as tensões medidas sobre cada um dos para-raios em cada uma das 128 simulações foram construídos os gráficos da Figura 6.15 e da Figura 6.16.

Pela Figura 6.15 é possível notar que os para-raios que mais atuam, e, portanto, os mais necessários para o sistema, considerando as fases $\mathrm{A}, \mathrm{B}$ e $\mathrm{C}$ do alimentador, em ordem decrescente são: 9B, 8B, 4B, 11B, 5B, 7A, 6C, 3B, 2B, 10A e 1B, como pode ser contabilizado pela Figura 6.16.

Por meio da Figura 6.15 também se pode verificar que as tensões mais elevadas sobre o alimentador afetam a fase $\mathrm{B}$ e as menos elevadas a fase A, uma vez que quanto maior a tensão maior será o número de vezes que o para-raios entrará em condução.

Além disso, corroborando com as tensões vistas na Figura 6.4 sobre o transformador da subestação, que em grande parte das simulações se mantiveram abaixo de 1 pu, os para-raios de número 1 conectados ao nó 650 são os que menos operaram.

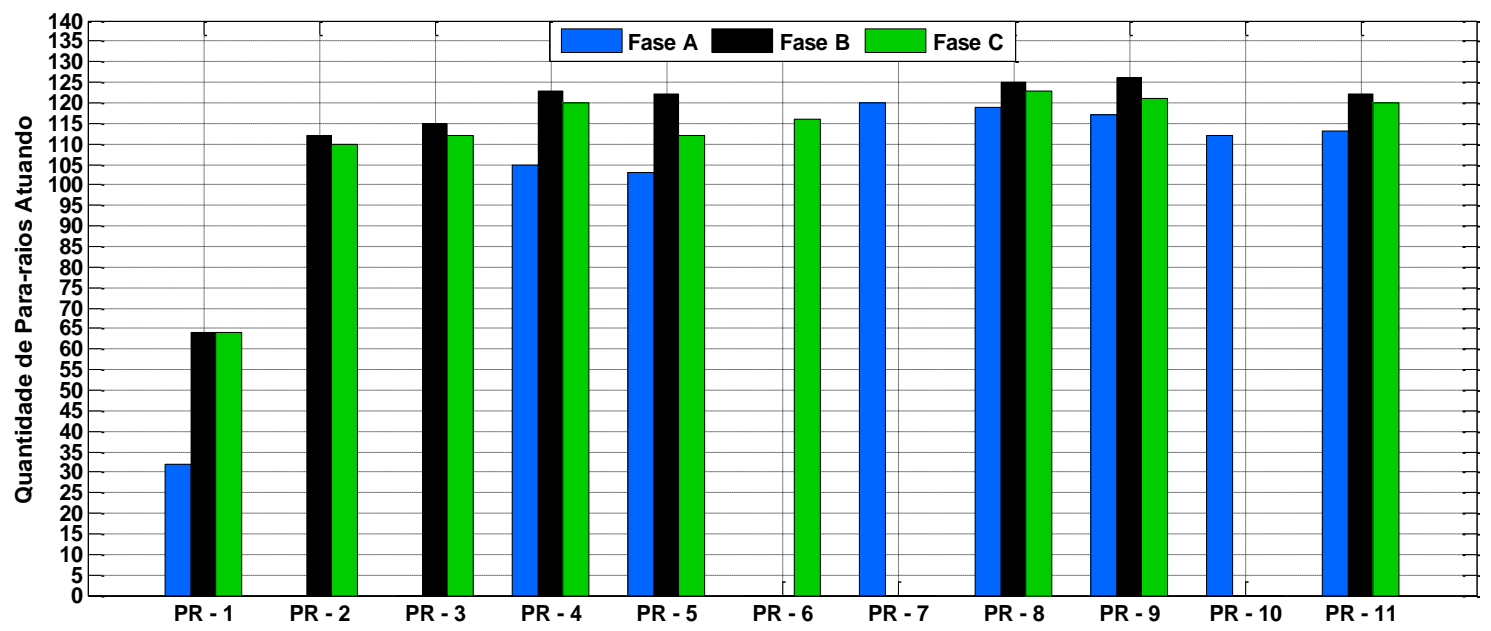

Figura 6.15: Contabilização do número de atuações dos para-raios nas 128 simulações do Grupo 1 $(\mathbf{y}=\mathbf{5 0} \mathbf{m})$. 
Por fim, pela Figura 6.16 é possível observar caso a caso os para-raios que atuam para todas as 128 simulações, e verificar que quanto maior o número de SETIs ligados, maiores são as sobretensões sobre a rede do alimentador, e, portanto, maior a quantidade de para-raios operando.

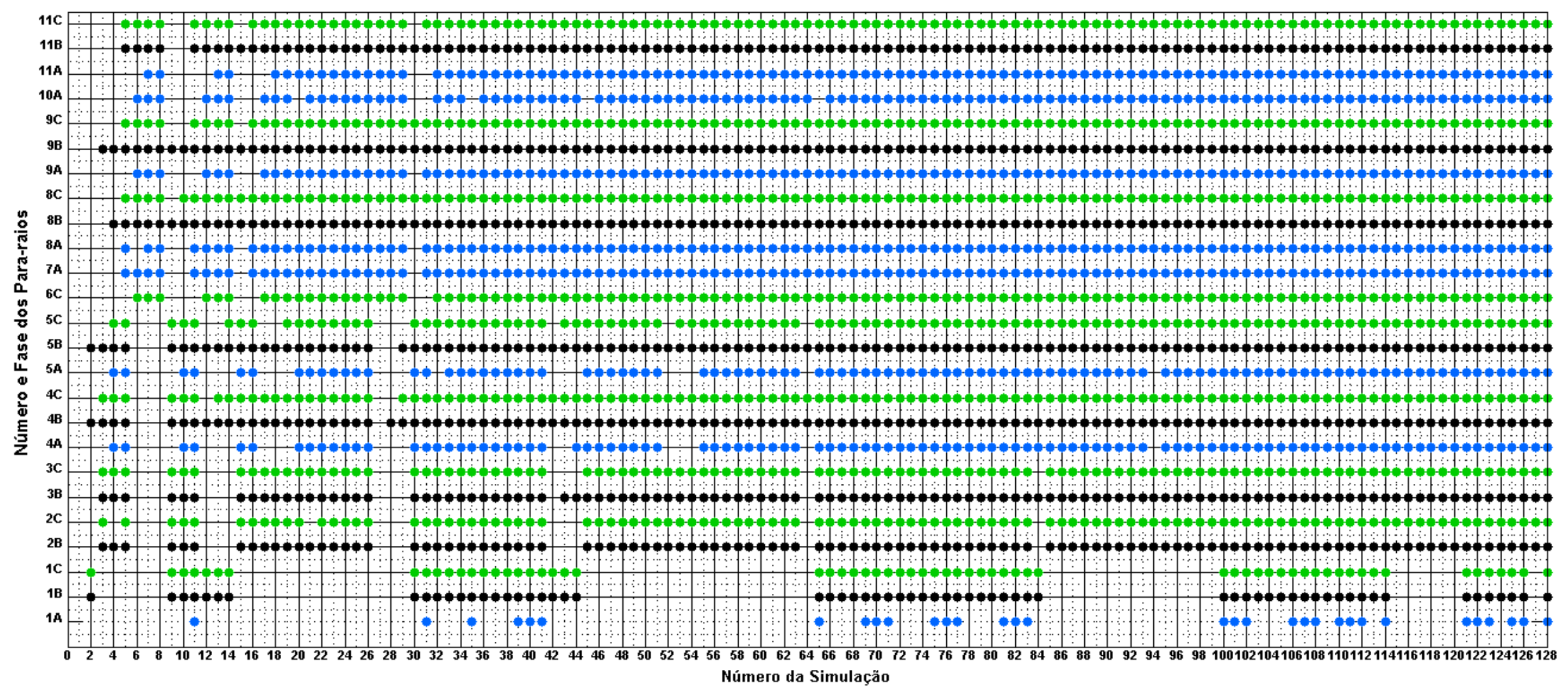

Figura 6.16: Indicação dos para-raios em atuação para cada uma das 128 simulações do Grupo 1 (y=50 m). 


\subsection{2 - Resultados e Análises das Simulações do Grupo - 2}

Para as simulações do segundo grupo, como a distância entre o ponto de incidências das descargas em relação à linha foi triplicada o pico das tensões induzidas foi reduzido, passando de $66 \mathrm{kV}$ para $22 \mathrm{kV}$, como visto na Figura 6.2.

Assim como no caso anterior, as maiores sobretensões se estabelecerão de acordo com a posição relativa do elemento avaliado em relação ao ponto de ativação do SETI, e para as simulações nas quais estiver o maior número de SETIs ligados.

Ademais, para as simulações deste grupo os SETIs 1, 4 e 7 estão, a rigor, estimando as tensões induzidas para duas possibilidades de incidência de descargas atmosféricas, e os SETIs 2, 3, 5, e 6 para três, como se pode observar na Figura 6.18. Logo, estas 128 simulações estão concebendo, na verdade, $2^{3} \times 3^{4} \times 128$ (82.944) possibilidades de incidências de descargas atmosféricas em relação ao alimentador teste.

Avaliando o perfil de tensão do transformador da subestação por meio da Figura 6.17, constata-se que apesar de todos os para-raios alocados no nó 650 estarem desativamos, como pode ser visto na Figura 6.29, a tensão sobre o transformador se mantém praticamente estável entre 0,8 e 0,9 pu. Este fato demonstra a robustez promovida pela subestação ao nó 650 , fazendo com as sobretensões e sobrecorrentes do sistema tomem outra direção que não a deste nó e permitindo que o alimentador opere de forma continua.

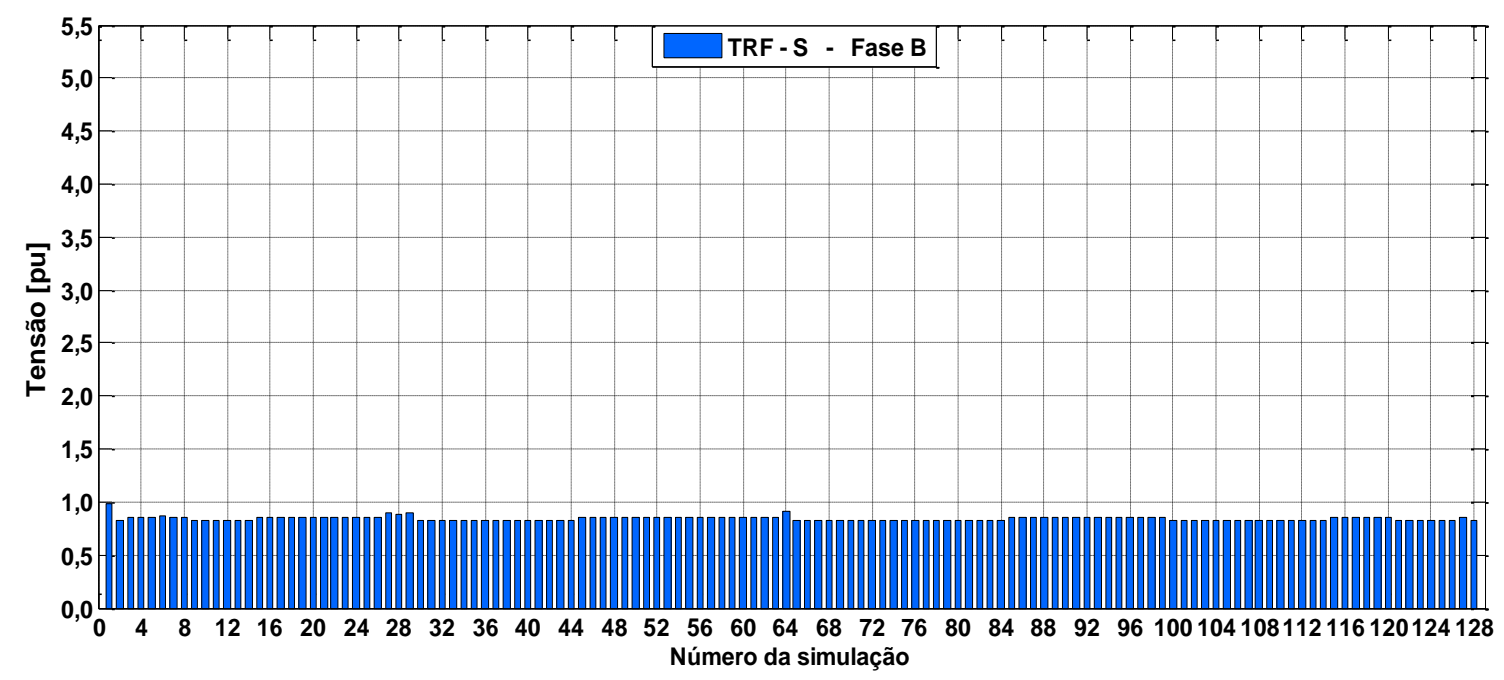

Figura 6.17: Tensão sobre o transformador da subestação para as 128 simulações do Grupo 2 $(\mathbf{y}=150 \mathrm{~m})$. 


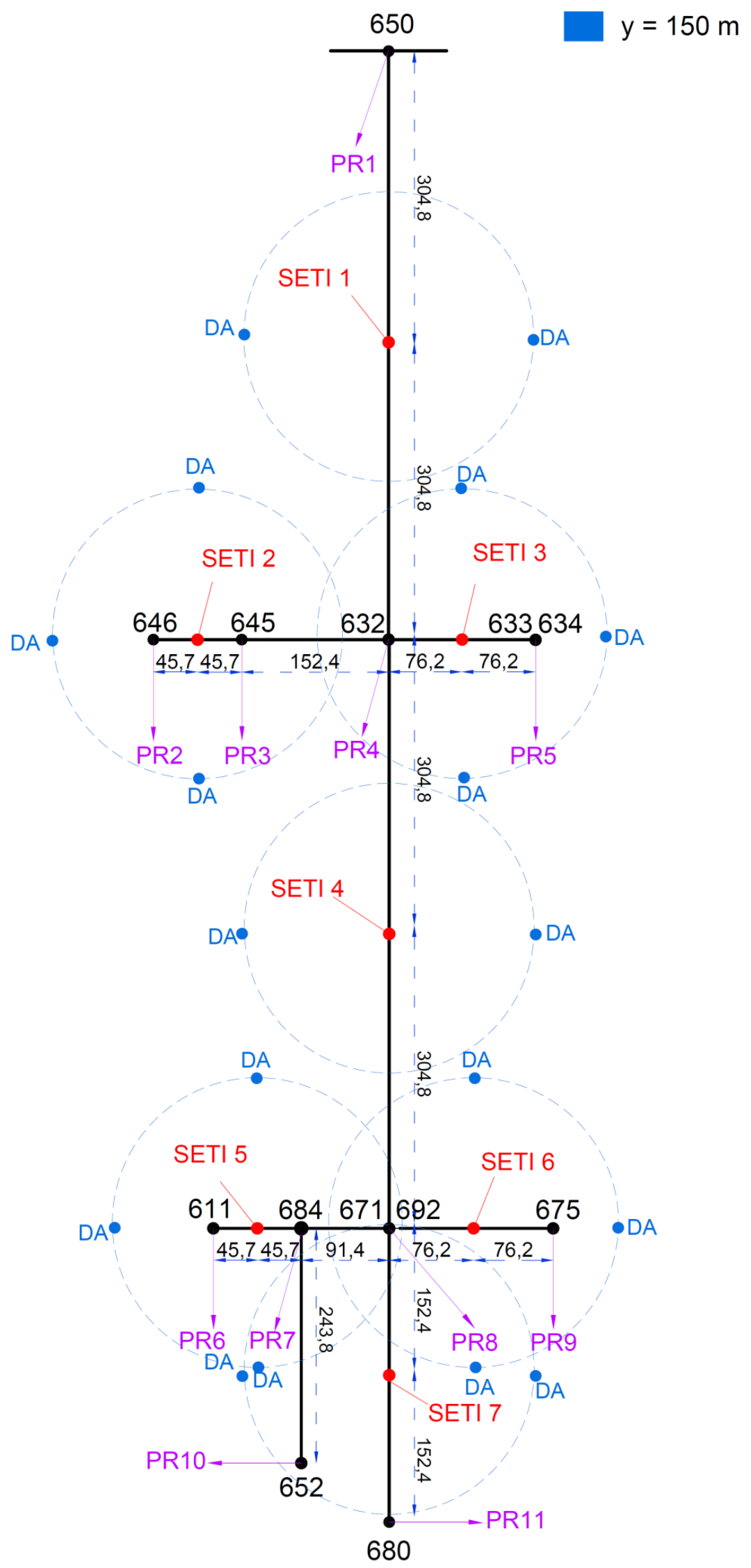

Figura 6.18: Correlação entre os pontos de localização dos subsistemas para estimação das tensões induzidas (SETIs) e os pontos de incidência das descargas atmosféricas (DA) em relação ao alimentador teste para $\mathrm{y}=\mathbf{1 5 0} \mathrm{m}$. 
Já para os demais elementos do alimentador averígua-se uma diminuição da tensão sobre os mesmos quase proporcional à redução do pico das tensões induzidas, com exceção da carga $\mathrm{C}$ - 652, conforme mostrado da Figura 6.19 a Figura 6.28. Essa redução de tensão não é diretamente proporcional devido à influência que um SETI exerce sobre o outro, uma vez que mesmo distantes há uma contribuição de tensão induzida que afeta os pontos mais afastados dos SETIs ativos.

Contudo, para a carga $\mathrm{C}-652$ observa-se um abaixamento menos acentuado da tensão devido à mesma já operar com tensões mais próximas a de seu regime permanente mesmo para as simulações do Grupo 1. Como já foi dito, isto se deve principalmente a maior proteção concebida a esta carga pelos para-raios PR - 7 e PR 10 , e também as suas próprias características, tornando-a mais robusta frente às tensões induzidas.

Além disso, examinando os máximos valores de tensão a que cada uma das cargas foi submetida nas 128 simulações, observa-se novamente que a carga que tem maior elevação de tensão é a $\mathrm{C}-634$ e a que tem menor aumento é a C - 652. Desse modo, constitui-se uma escala crescente igual à estabelecida para as simulações do Grupo1 com relação às máximas tensões sobre as cargas, com a seguinte ordenação: $\mathrm{C}$ 652, C - 645, C-611, C - 692, C - 671, C - 646, C - 675, C - 632/671 e C - 634.

Ainda, considerado as simulações de 2 a 8 para todas as cargas definem-se em ordem decrescente e de forma individual, quais os SETIs que promovem as maiores tensões sobre as cargas para as simulações do Grupo 2 pelas sequências abaixo, as quais são idênticas às definidas para o Grupo 1:

- $\mathrm{C}-632 / 671: 4-3-2-1-7-6-5$;

- $\mathrm{C}-646: 2-4-3-1-7-6-5$;

- $\mathrm{C}-645: 2-4-3-1-7-6-5$;

- $\mathrm{C}-634: 3-4-2-1-7-6-5$.

- $\mathrm{C}-671: 7-6-4-5-3-2-1$;

- $\mathrm{C}-611: 5-7-6-4-3-2-1$;

- $\mathrm{C}-652: 5-7-6-4-3-2-1$;

- $\mathrm{C}-692: 7-6-4-5-3-2-1$;

- $\mathrm{C}-675: 6-7-5-4-3-2-1$. 


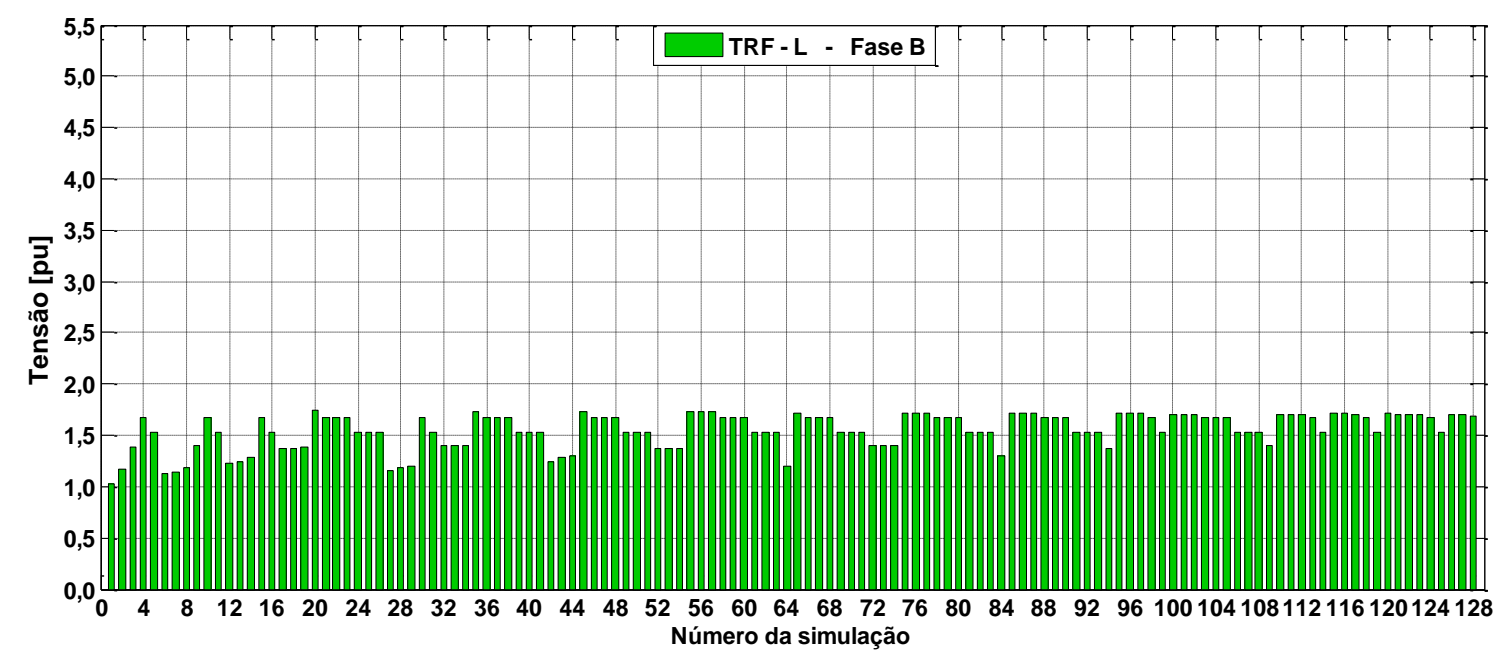

Figura 6.19: Tensão sobre o transformador da linha para as 128 simulações do Grupo 2 ( $(y=150 \mathrm{~m})$.

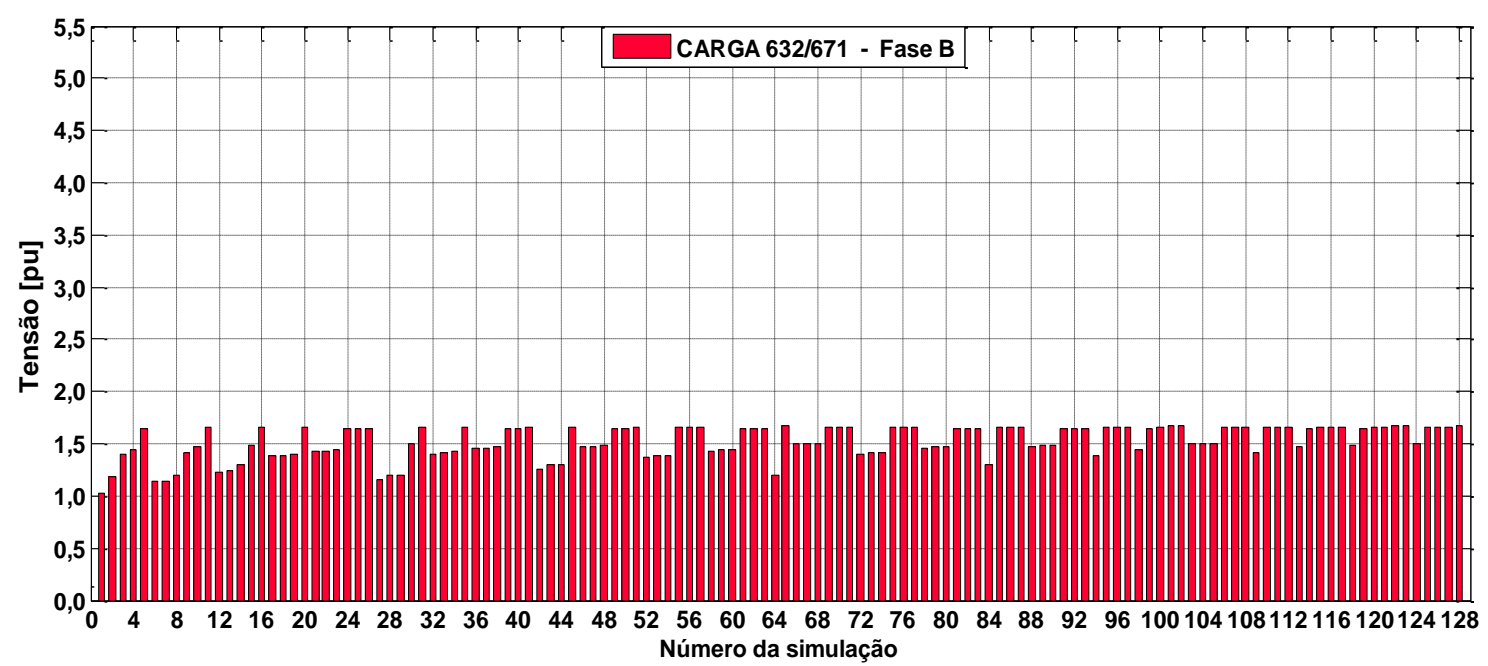

Figura 6.20: Tensão sobre a carga 632/671 para as 128 simulações do Grupo 2 (y=150 m).

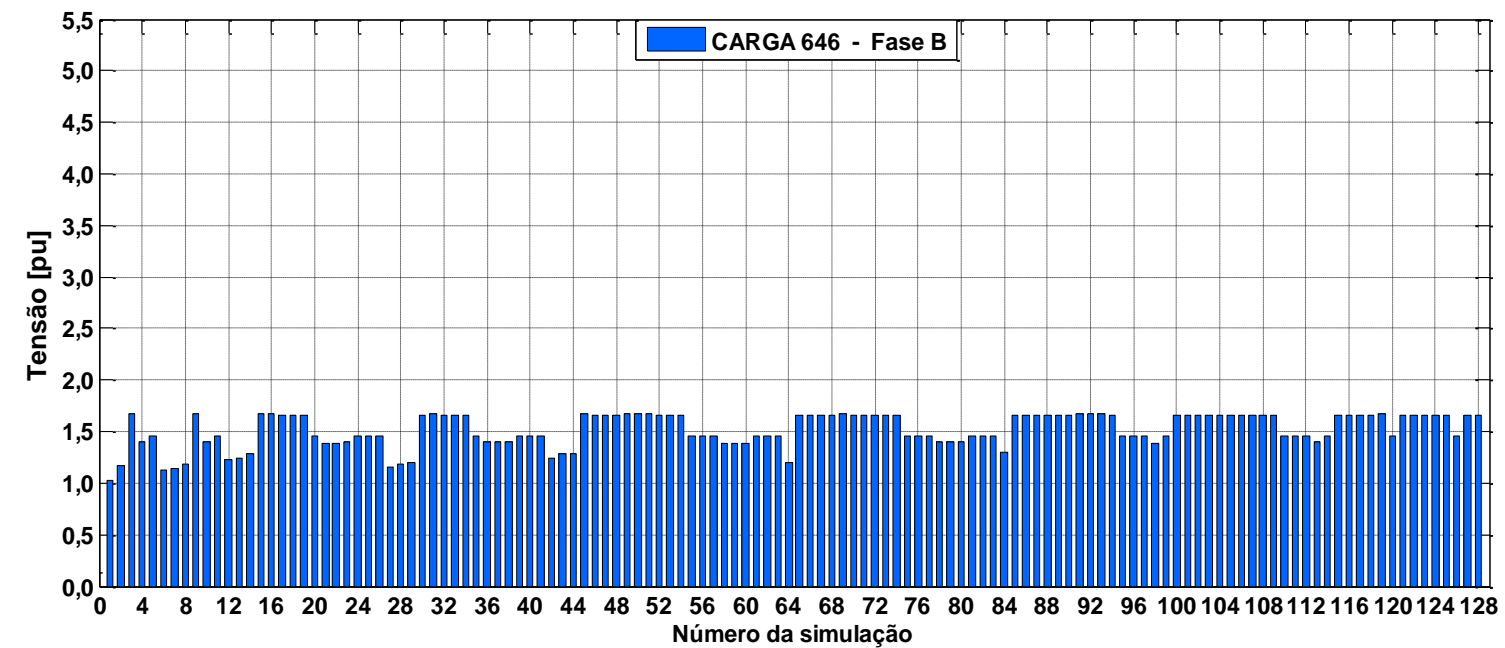

Figura 6.21: Tensão sobre a carga 646 para as 128 simulações do Grupo 2 (y=150 m). 


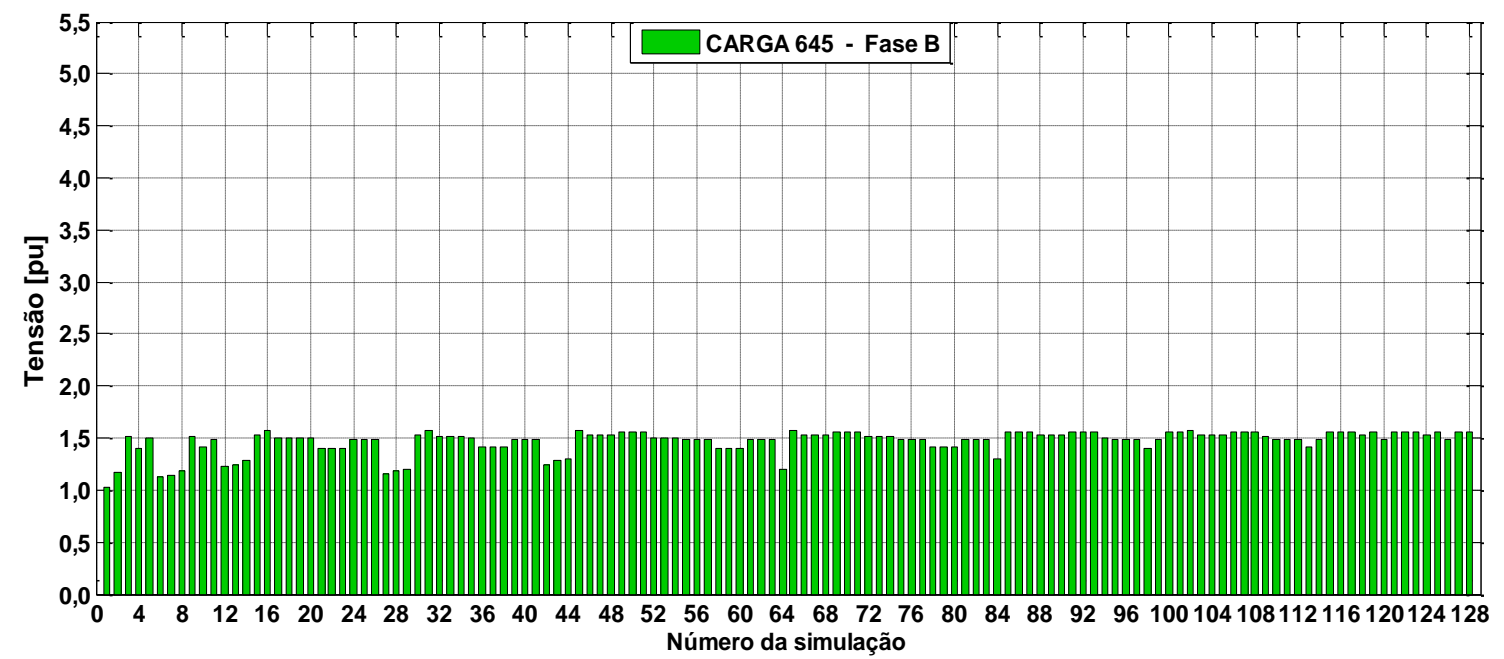

Figura 6.22: Tensão sobre a carga 645 para as 128 simulações do Grupo 2 (y=150 m).

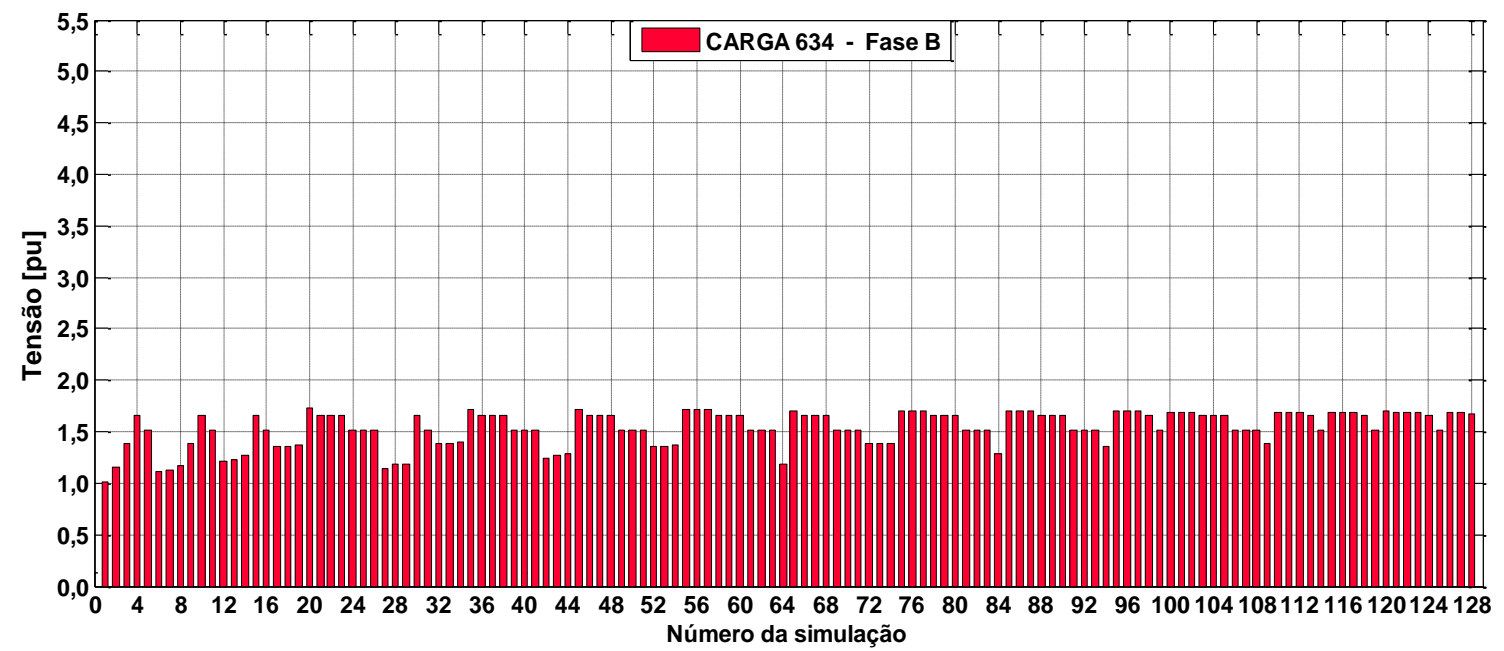

Figura 6.23: Tensão sobre a carga 634 para as 128 simulações do Grupo $2(\mathrm{y}=150 \mathrm{~m})$.

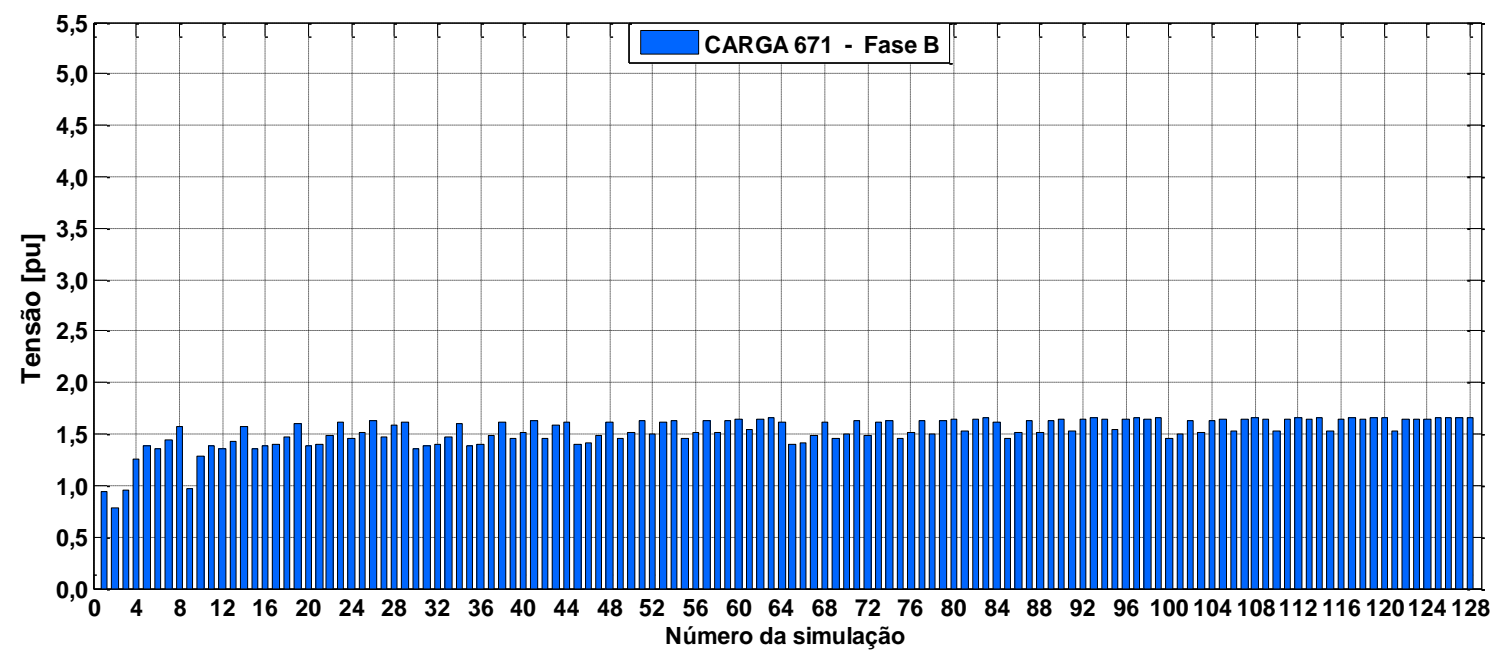

Figura 6.24: Tensão sobre a carga 671 para as 128 simulações do Grupo 2 (y=150 m). 


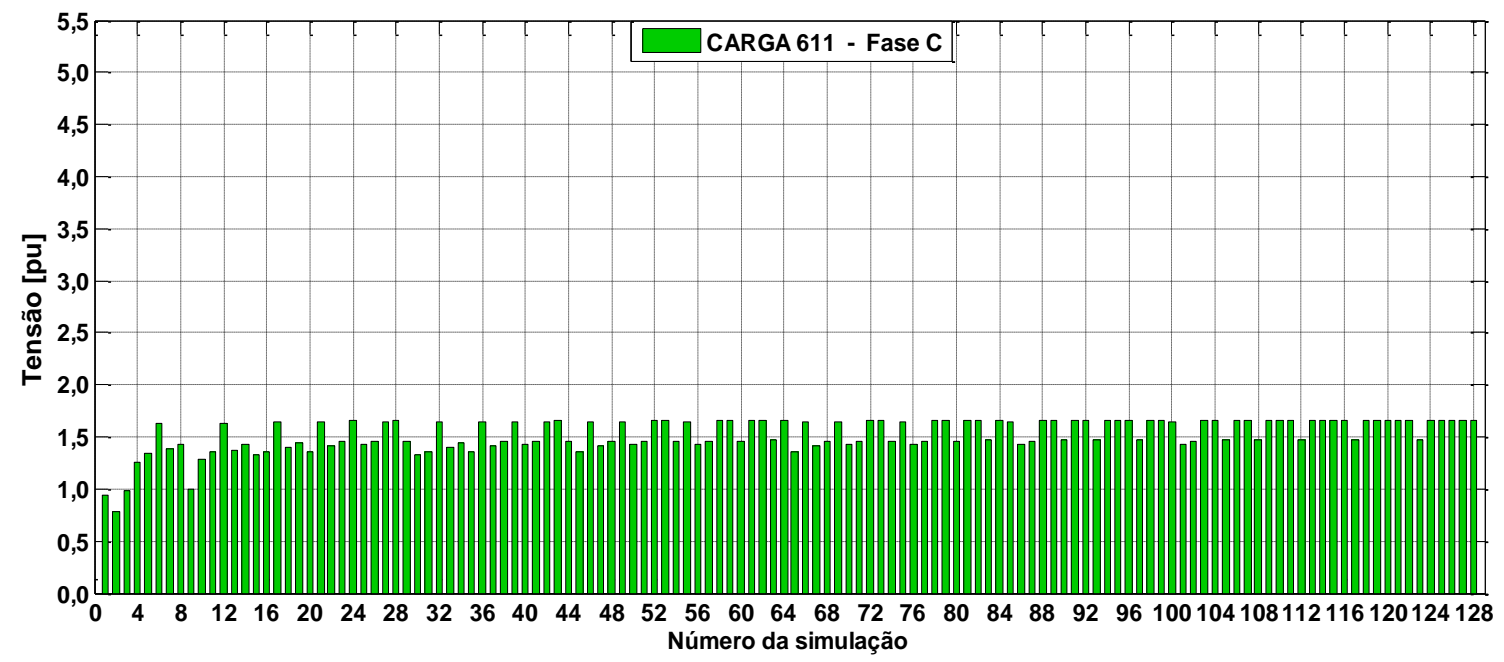

Figura 6.25: Tensão sobre a carga 611 para as 128 simulações do Grupo 2 (y=150 m).

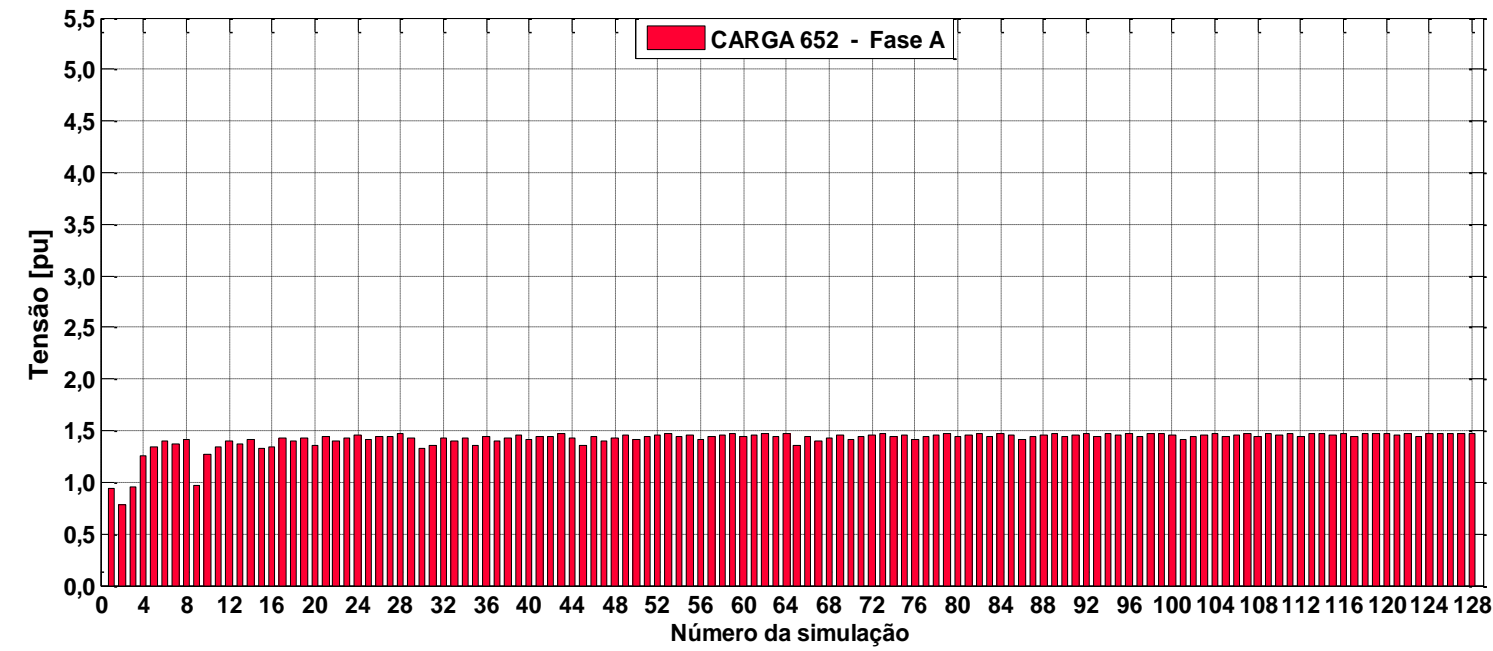

Figura 6.26: Tensão sobre a carga 652 para as 128 simulações do Grupo $2(\mathrm{y}=150 \mathrm{~m})$.

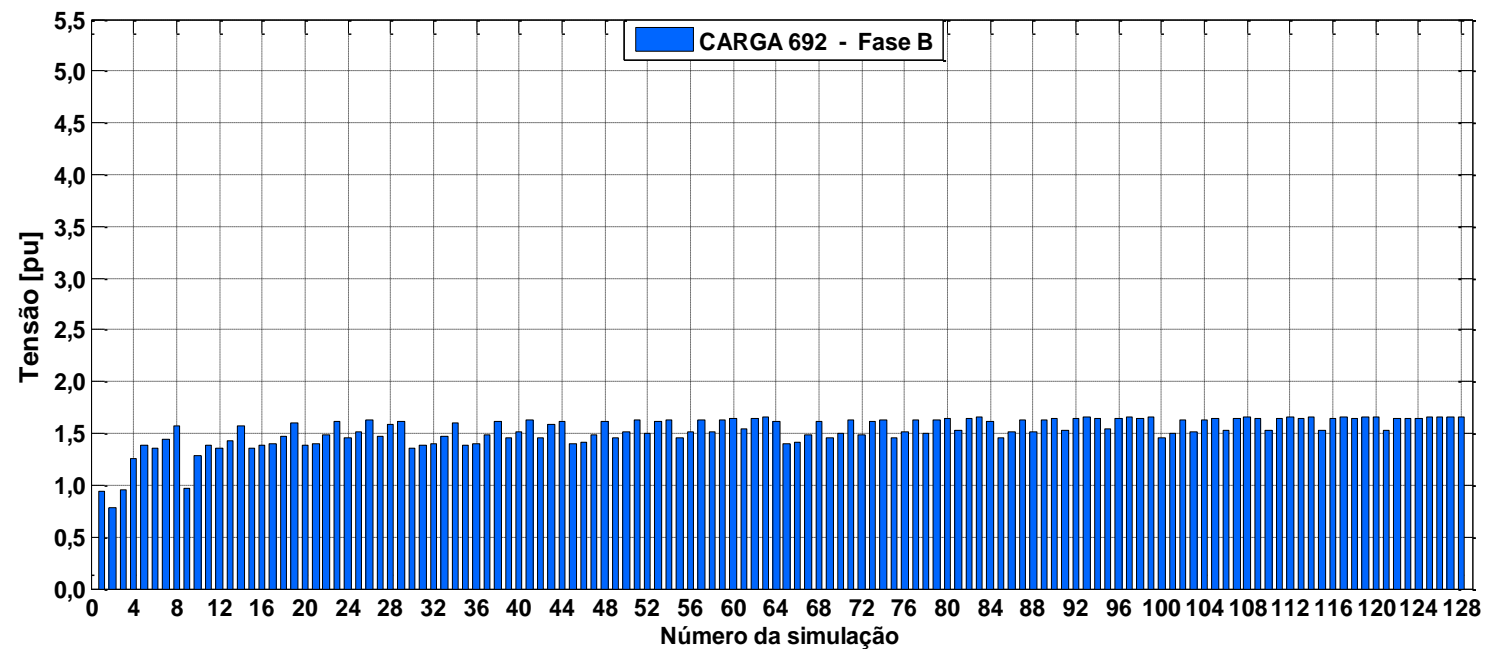

Figura 6.27: Tensão sobre a carga 692 para as 128 simulações do Grupo 2 (y=150 m). 


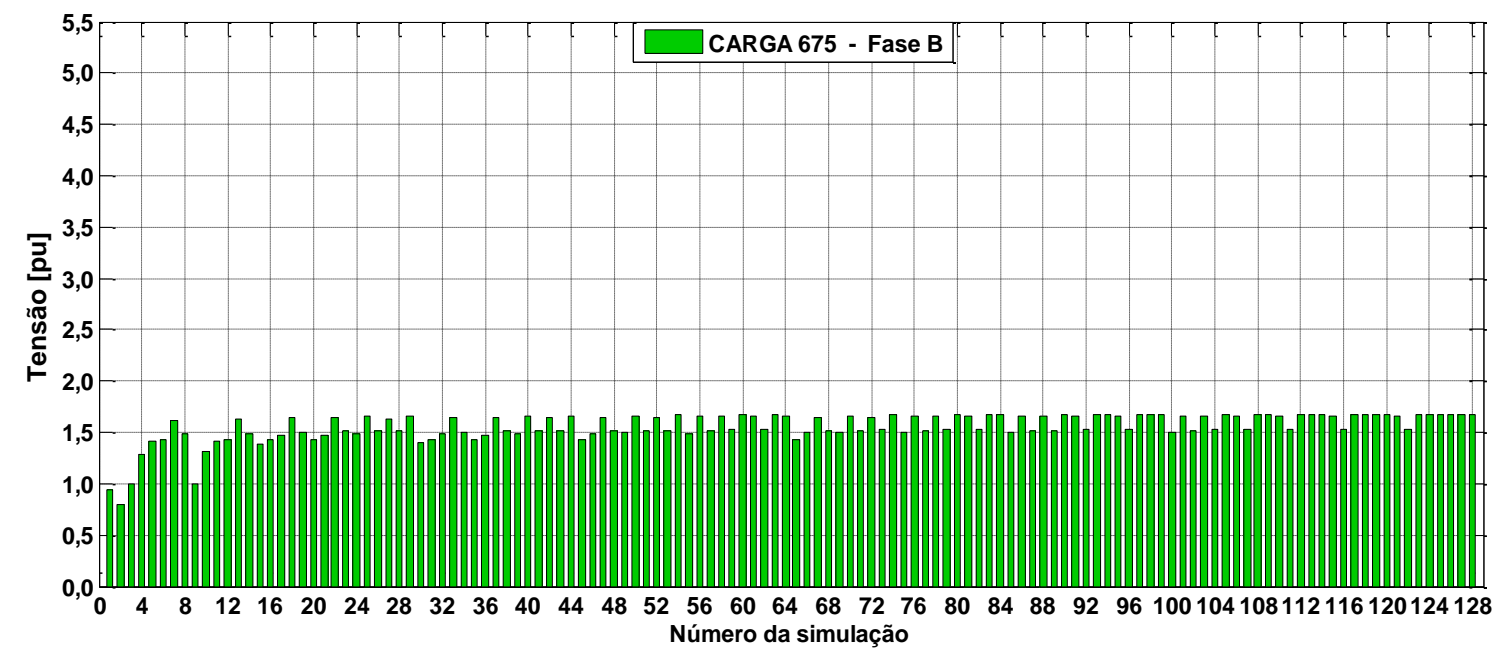

Figura 6.28: Tensão sobre a carga 675 para as 128 simulações do Grupo 2 (y=150 m).

Finalizando esta seção, por meio da Figura 6.29 vê-se que os para-raios que mais operam em ordem decrescente são: 9B, 8B, 7A, 11B, 4B, 5B, 6C, 3B, 2B e 10A, como pode ser contabilizado pela Figura 6.30. Comparando esta ordenação de atuação com a do Grupo 1 constata-se que os para-raios de número 7 aumentaram a quantidade de vez em que operaram enquanto os de número 4,5 e 1 diminuíram.

Examinado a Figura 6.29 e a Figura 6.30 nota-se que os para-raios de número 1 conectados ao nó 650 não atuaram em nenhuma das simulações, mesmo assim as tensões sobre o transformador da subestação não foram alteradas, como mencionado anteriormente. Ainda com relação a estas figuras, também se verifica uma queda acentuada do número de operação dos para-raios 4,5 e 11 em sua fase $\mathrm{A}$, e dos pararaios 2 e 3 na fase $\mathrm{C}$.

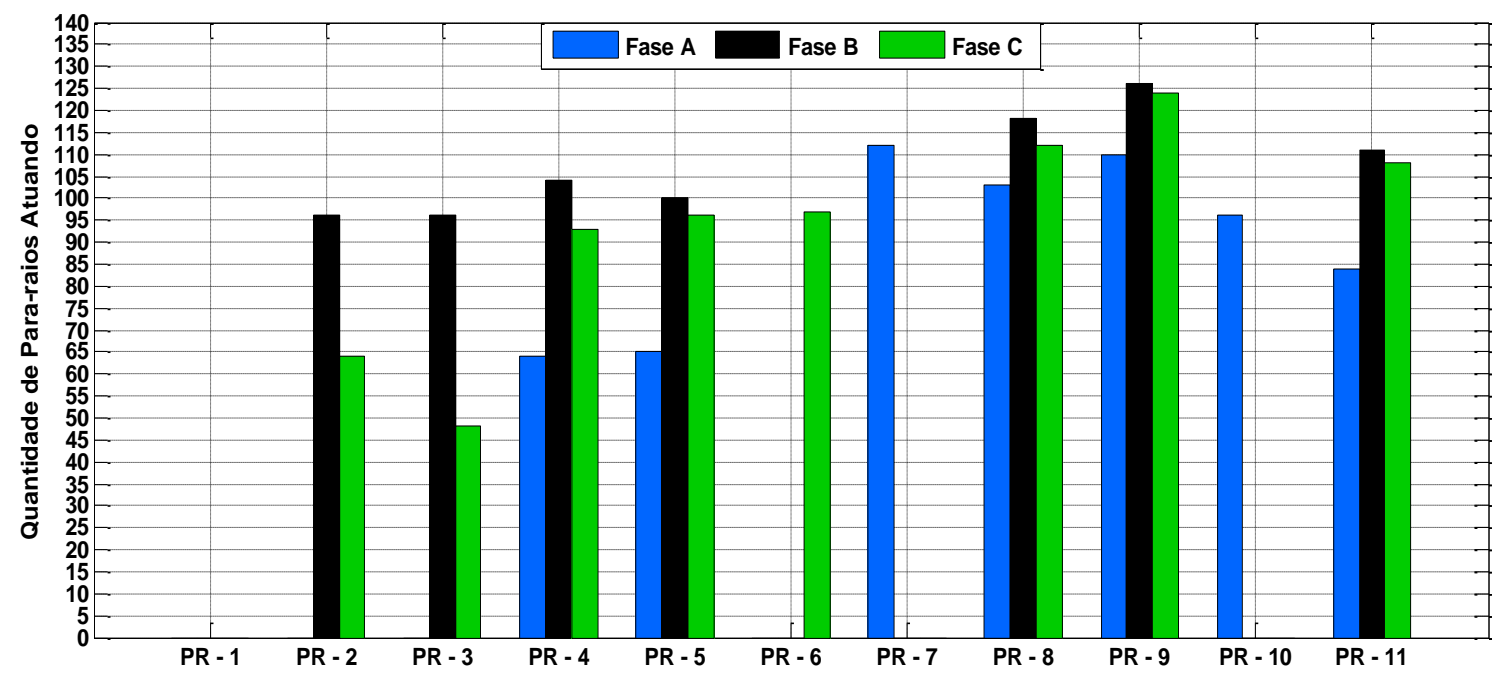

Figura 6.29: Quantificação do número de vezes em que os para-raios atuam nas 128 simulações do Grupo 2 (y=150 m). 


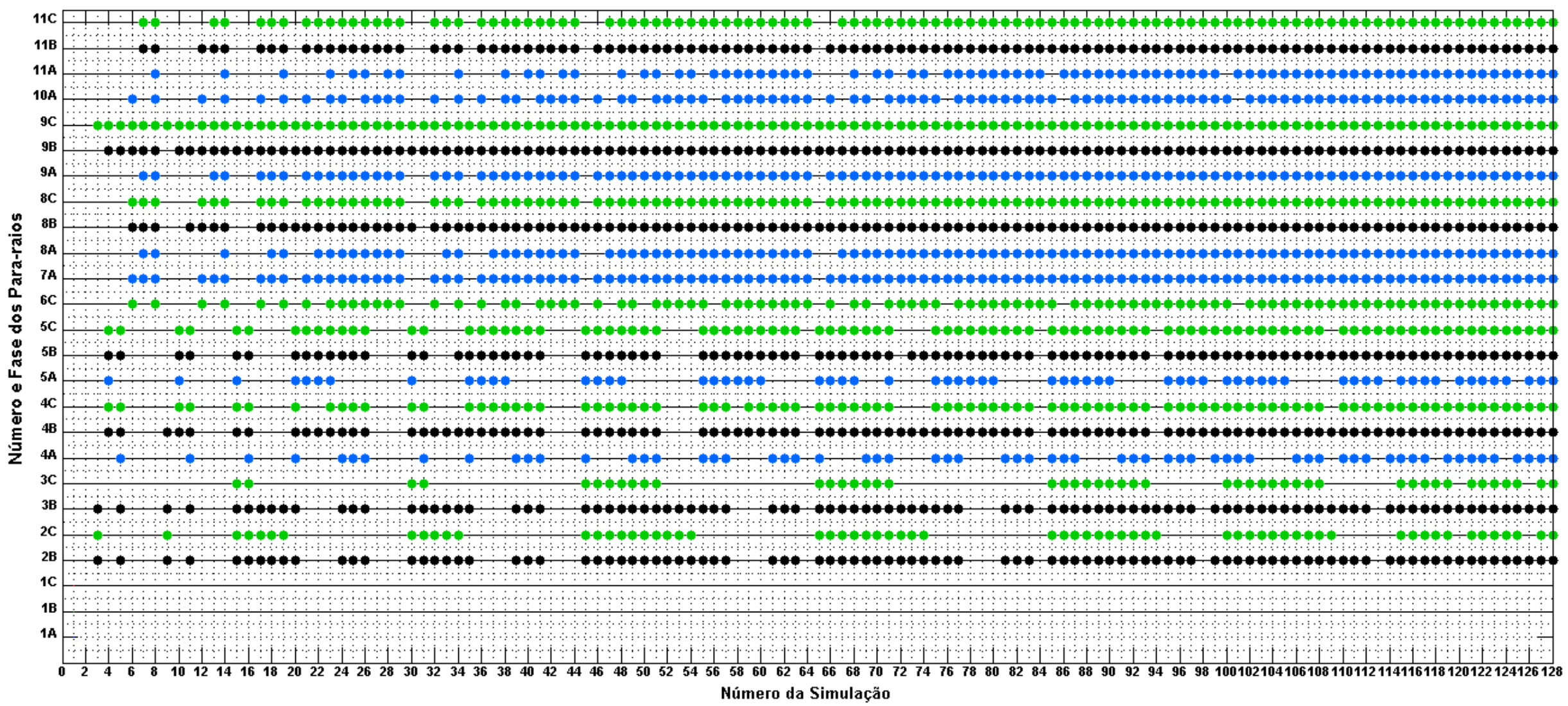

Figura 6.30: Indicação dos para-raios em atuação para cada uma das 128 simulações do Grupo 2 (y=150 m). 


\subsection{3 - Resultados e Análises das Simulações do Grupo - 3 e do Grupo - 4}

Devido à pequena diferença, da ordem de centésimos de pu, entre as tensões medidas sobre os transformadores e cargas para as simulações dos Grupos 3 e 4, a seguir serão mostradas as tensões sobre estes elementos apenas para o Grupo 3.

Esta diminuta desigualdade se deve a distância entre a linha e o ponto de incidência da descarga (y), pois quanto maior esta separação menor é o pico das tensões induzidas, e menor é a variação entre estas tensões para pontos de incidência próximos entre si, mas distantes da linha.

Dessa forma, como y $=250 \mathrm{~m}$ e $\mathrm{y}=350 \mathrm{~m}$ para os Grupos 3 e 4 , ou seja, como eles estão bastante afastados da linha, mas relativamente próximos entre si, seus picos de tensões induzidas alcançaram valores pouco distintos, como pode ser visto na Figura 6.2. Isto implicou em um comportamento semelhante das sobretensões sobre os transformadores e cargas frente a estas tensões induzidas, justificando a escolha de expor apenas os perfis de tensão para o Grupo 3.

Novamente, como nos casos anteriores, para estas simulações as maiores sobretensões se estabelecerão de acordo com a posição do elemento avaliado em relação ao ponto de ativação do SETI, e para as simulações nas quais estiver o maior número de SETIs ligados.

Não obstante, para as simulações do Grupo 3 os SETIs 1 e 4 estão estimando as tensões induzidas para duas possibilidades de incidência de descargas atmosféricas, e os SETIs 2, 3, 5, 6 e 7 para três, como se pode observar na Figura 6.31. Logo, as 128 simulações deste grupo estão representando, na verdade, $2^{2} \times 3^{5} \times 128$ (124.416) possibilidades de incidências de descargas atmosféricas nas imediações do alimentador teste.

Analogamente, para as simulações do Grupo 4 o SETI 4 estima as tensões induzidas para duas possibilidades de incidência de descargas, os SETIs 1, 2, 3, 5 e 7 para três possibilidades, e o SETI 6 para quarto, como se pode notar na Figura 6.32. Sendo assim, as 128 simulações deste grupo concebem, na realidade, $2^{1} \times 3^{5} \times 4^{1} \times 128$ (248.832) possibilidades de incidências de descargas atmosféricas. 


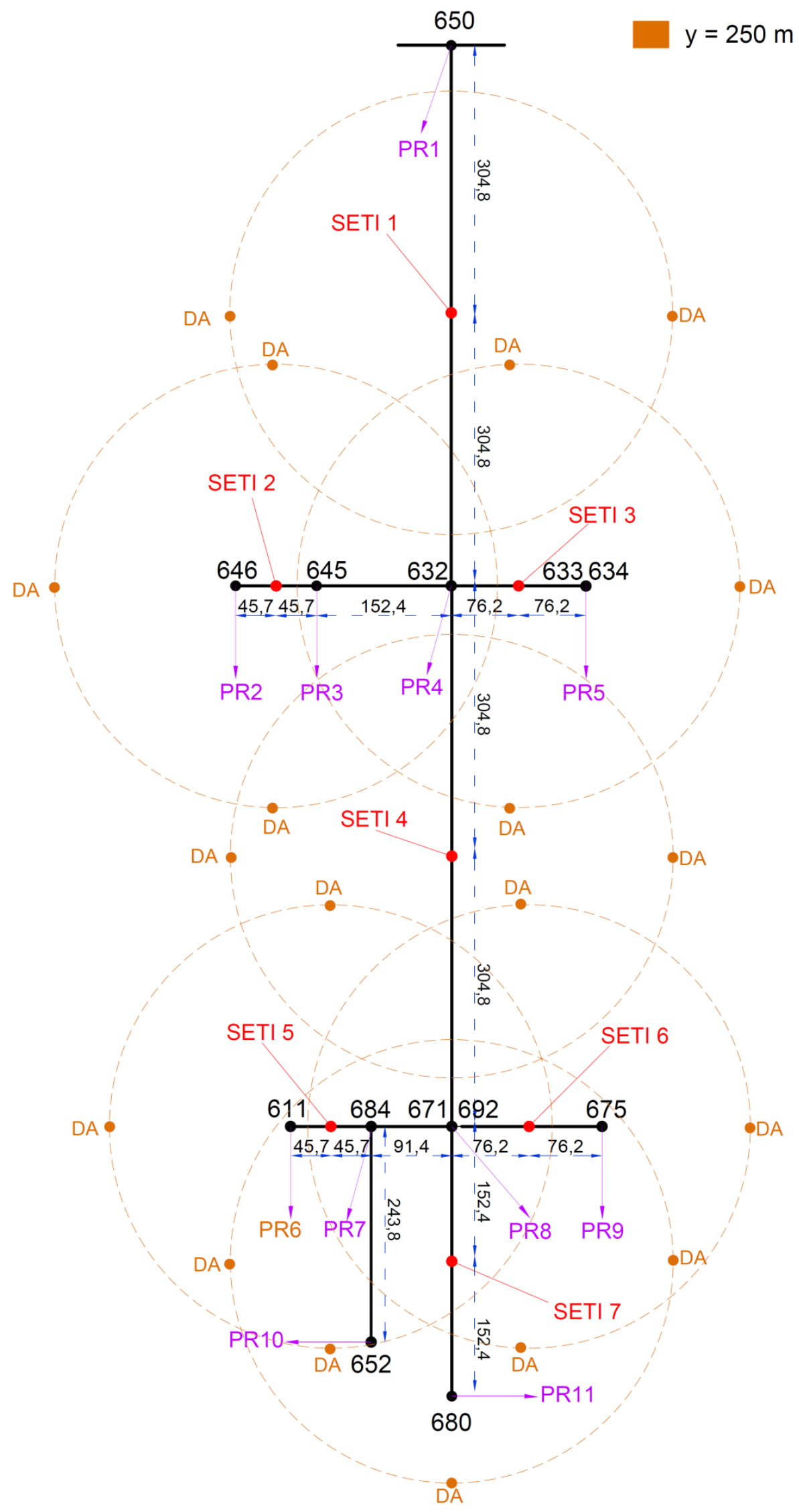

Figura 6.31: Correlação entre os pontos de localização dos subsistemas para estimação das tensões induzidas (SETIs) e os pontos de incidência das descargas atmosféricas (DA) em relação ao alimentador teste para $\mathrm{y}=\mathbf{2 5 0} \mathrm{m}$. 


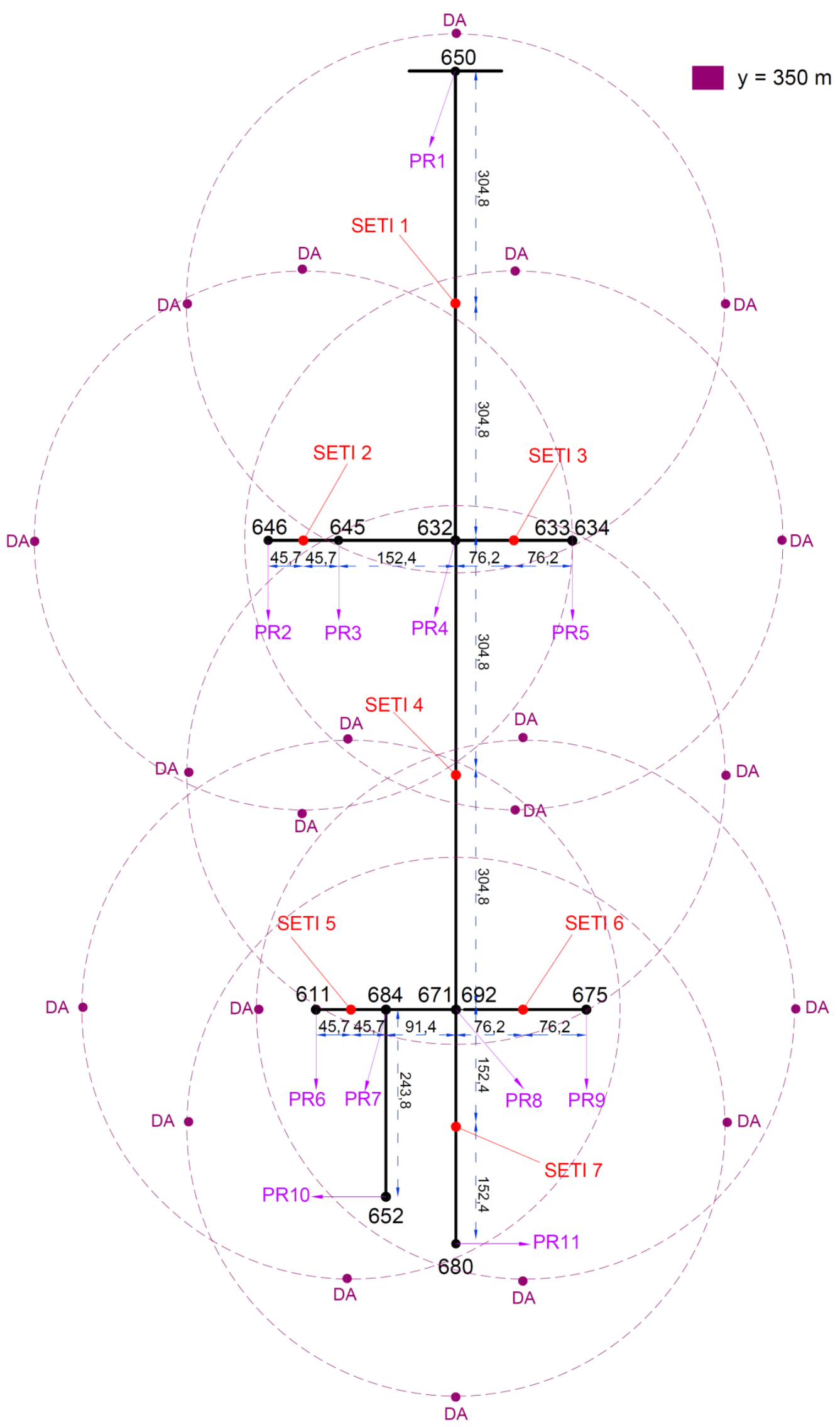

Figura 6.32: Correlação entre os pontos de localização dos subsistemas para estimação das tensões induzidas (SETIs) e os pontos de incidência das descargas atmosféricas (DA) em relação ao alimentador teste para $y=350 \mathrm{~m}$. 
Agora, analisando o perfil de tensão do transformador da subestação por meio da Figura 6.33, percebe-se que há uma variação ainda menor da sua tensão, ficando a mesma praticamente estável em 0,85 pu. Além disso, mais uma vez, isto ocorre mesmo com todos os para-raios alocados no nó 650 fora de operação, como pode ser visto na Figura 6.46.

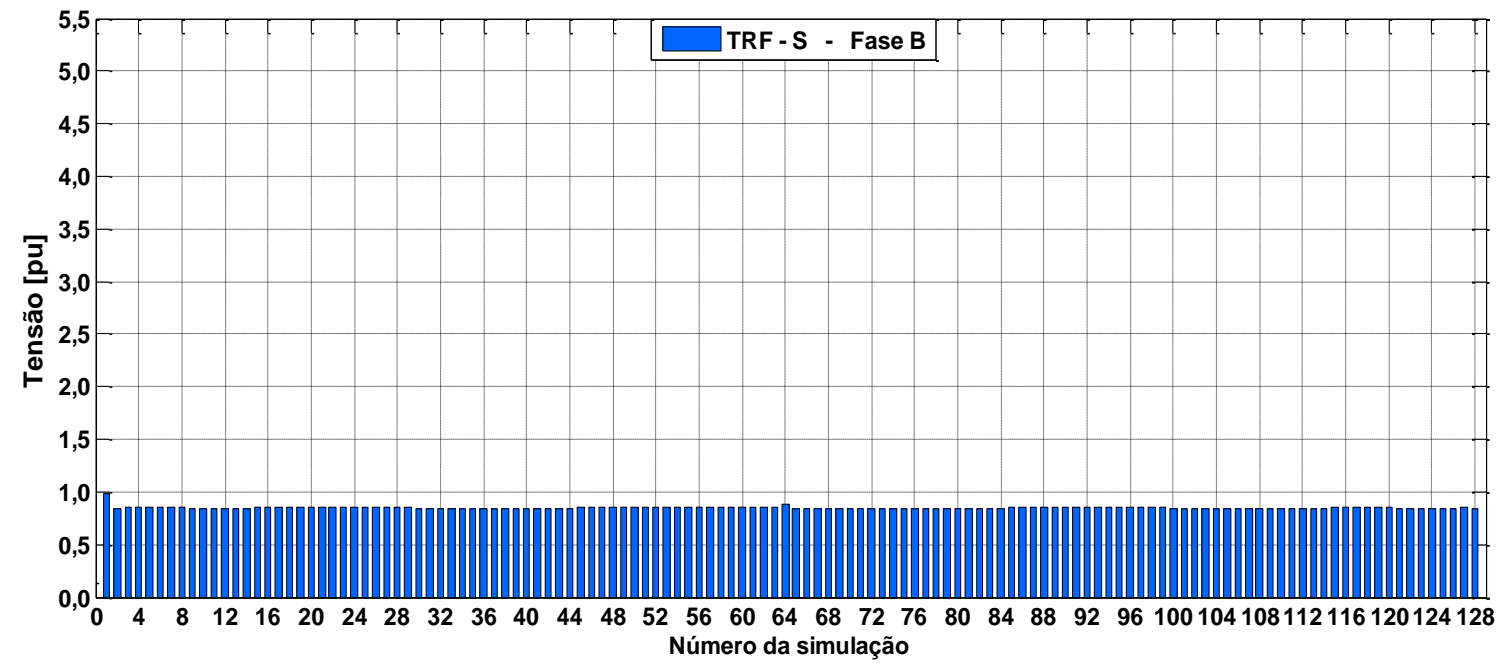

Figura 6.33: Tensão sobre o transformador da subestação para as 128 simulações do Grupo 3 $(\mathbf{y}=\mathbf{2 5 0} \mathrm{m})$.

Já para os demais elementos do alimentador averígua-se outra vez uma diminuição da tensão sobre os mesmos e uma tendência de estabilização dos seus respectivos perfis com o transcorrer das simulações. Com exceção da carga $\mathrm{C}-652$, a qual tem seu perfil de tensão consolidado próximo a 1,4 pu, o valor de pico da tensão dos demais componentes do sistema se estabiliza próximo a 1,6 pu.

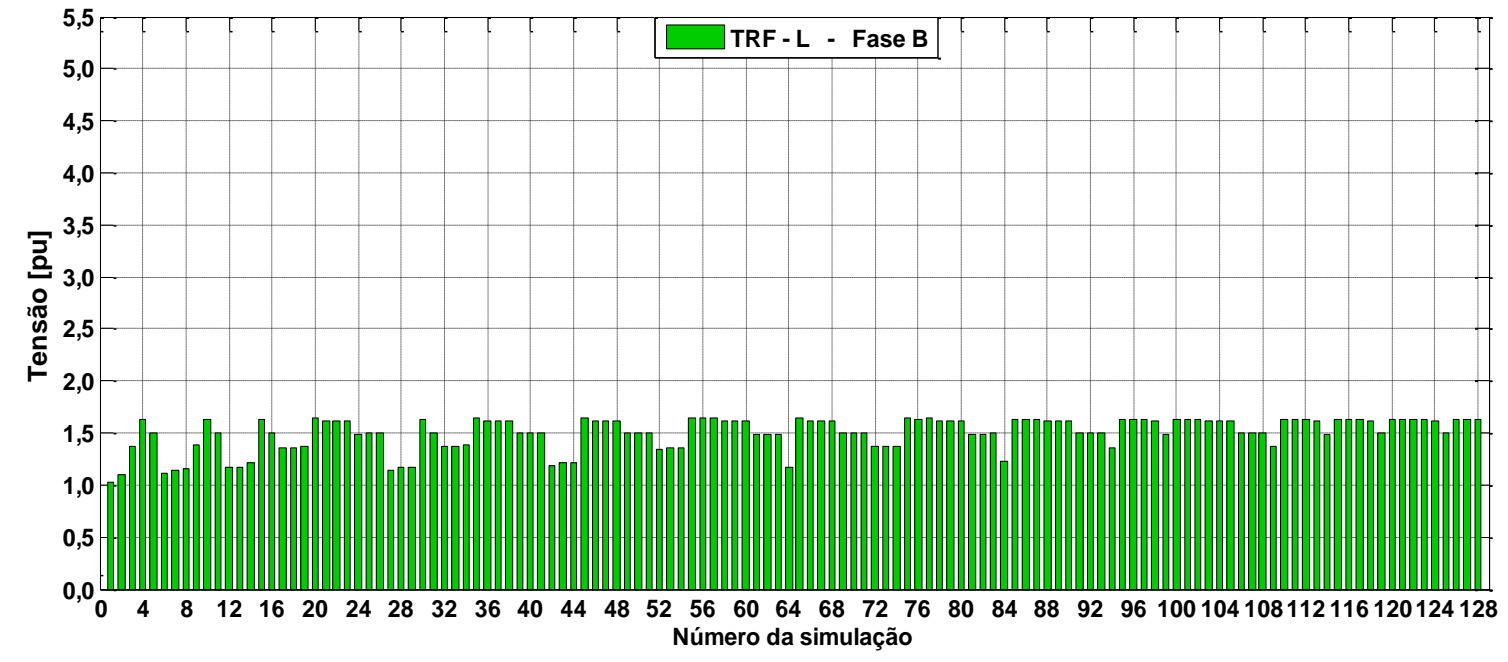

Figura 6.34: Tensão sobre o transformador da linha para as 128 simulações do Grupo 3 (y=250 m). 
Assim como realizado anteriormente, considerando as simulações de 2 a 8 para todas as cargas definem-se em ordem decrescente e de forma individual quais os SETIs que promovem as maiores tensões para as simulações dos Grupos 3 e 4 pelas séries abaixo.

- $\mathrm{C}-632 / 671: 4-3-2-7-6-5-1$;

- $\mathrm{C}-646: 2-4-3-7-6-5-1$;

- $\mathrm{C}-645: 2-4-3-7-6-5-1$;

- $\mathrm{C}-634: 3-4-2-1-7-6-5$.

- $\mathrm{C}-671: 7-6-5-4-3-2-1$;

- $\mathrm{C}-611: 5-7-6-4-3-2-1$;

- $\mathrm{C}-652: 7-5-6-4-3-2-1$;

- $\mathrm{C}-692: 7-6-5-4-3-2-1$;

- $\mathrm{C}-675: 6-7-5-4-3-2-1$.

Examinado estas séries e comparando com as sequências estabelecidas para os Grupos 1 e 2, observam-se algumas mudanças em suas ordenações, devido à combinação entre os menores picos das tensões induzidas e consequente atuação de um número menor de para-raios. Por meio da análise da Figura 6.44 até a Figura 6.47 esta afirmação é confirmada, conforme exposto pouco mais a frente neste capítulo.

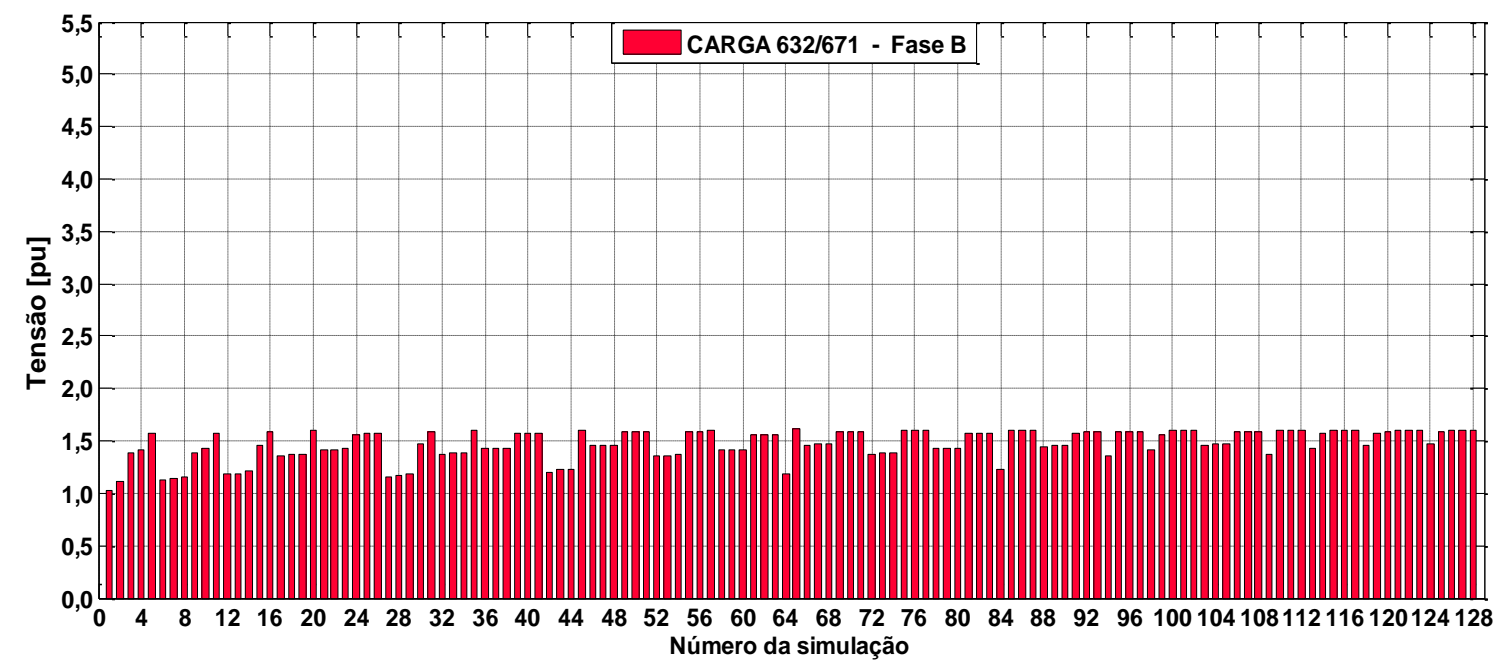

Figura 6.35: Tensão sobre a carga 632/671 para as 128 simulações do Grupo 3 (y=250 m). 


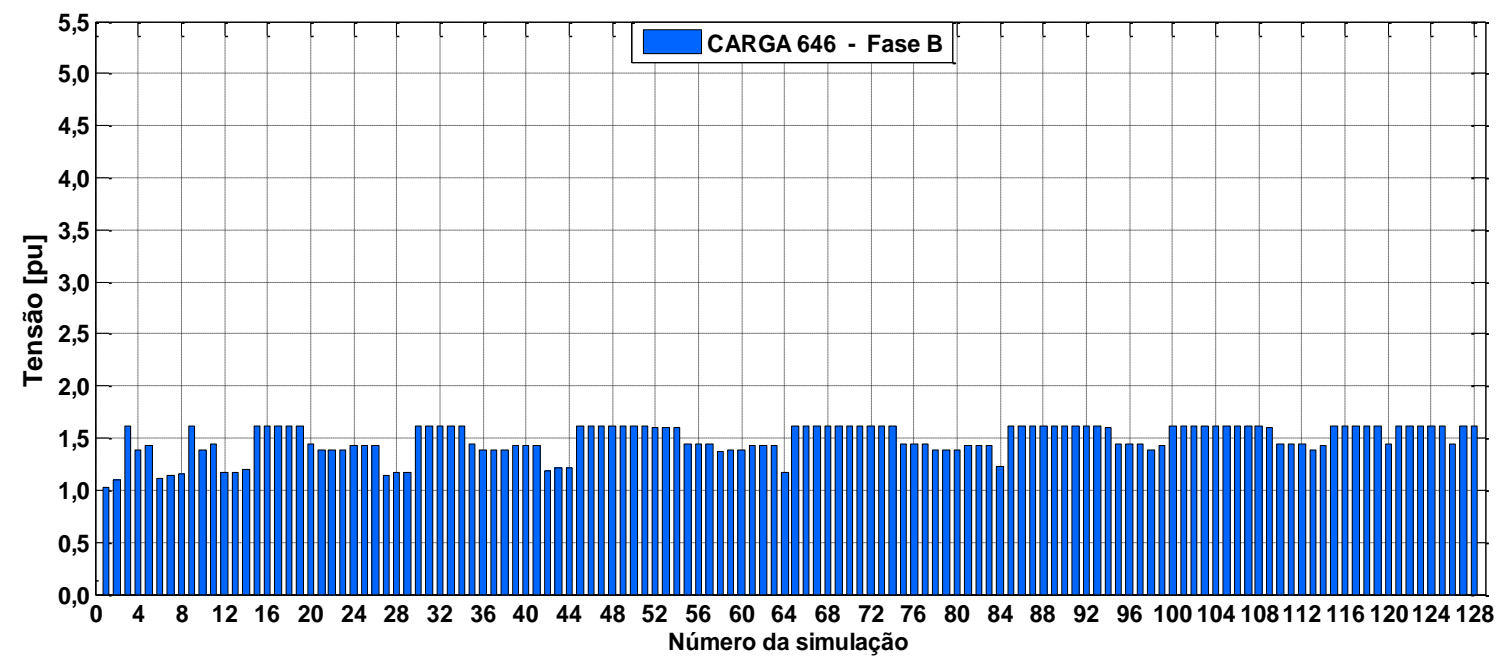

Figura 6.36: Tensão sobre a carga 646 para as 128 simulações do Grupo 3 (y=250 m).

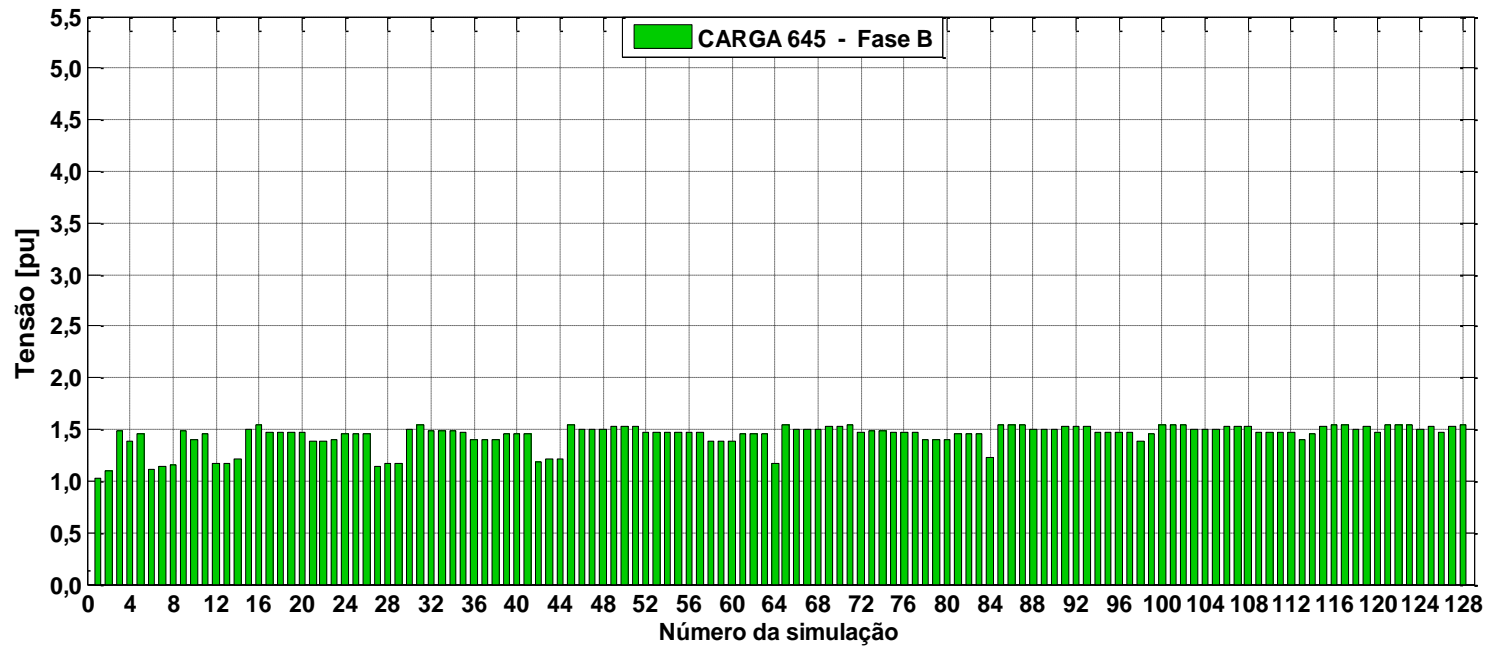

Figura 6.37: Tensão sobre a carga 645 para as 128 simulações do Grupo 3 (y=250 m).

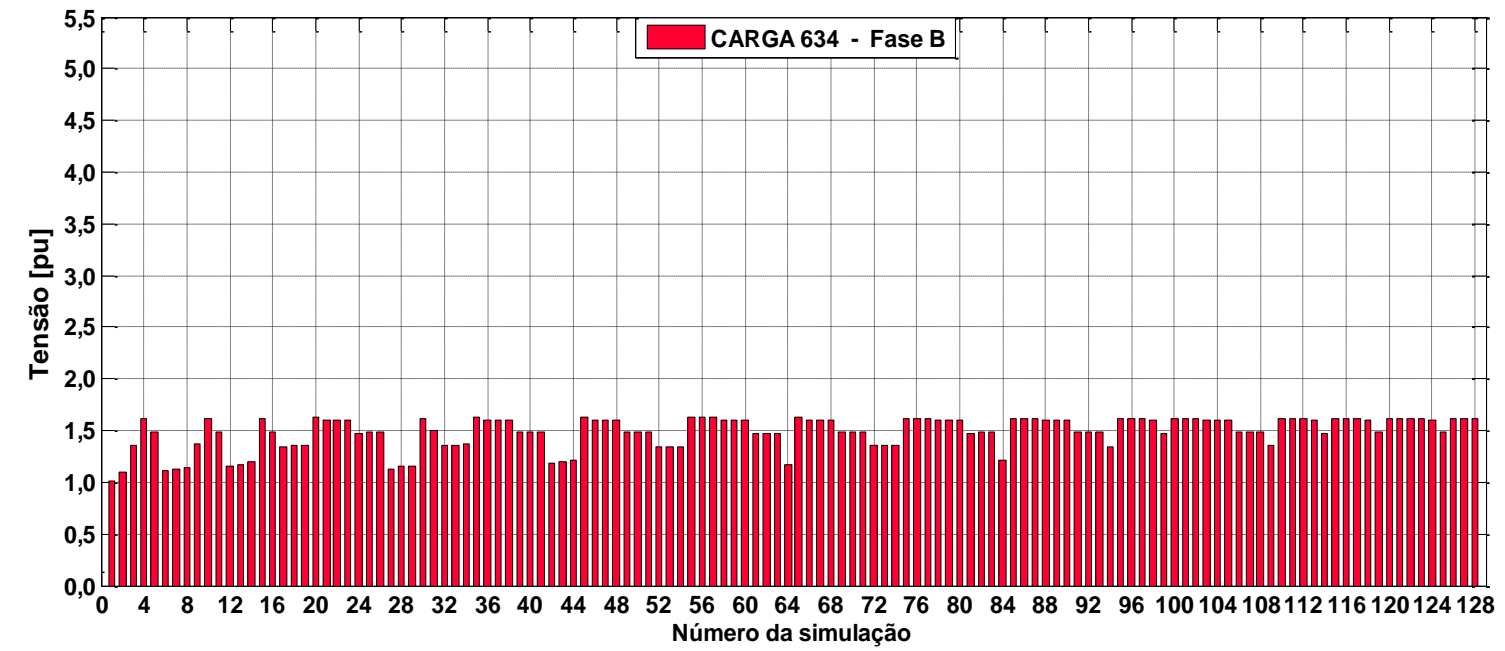

Figura 6.38: Tensão sobre a carga 634 para as 128 simulações do Grupo 3 (y=250 m). 


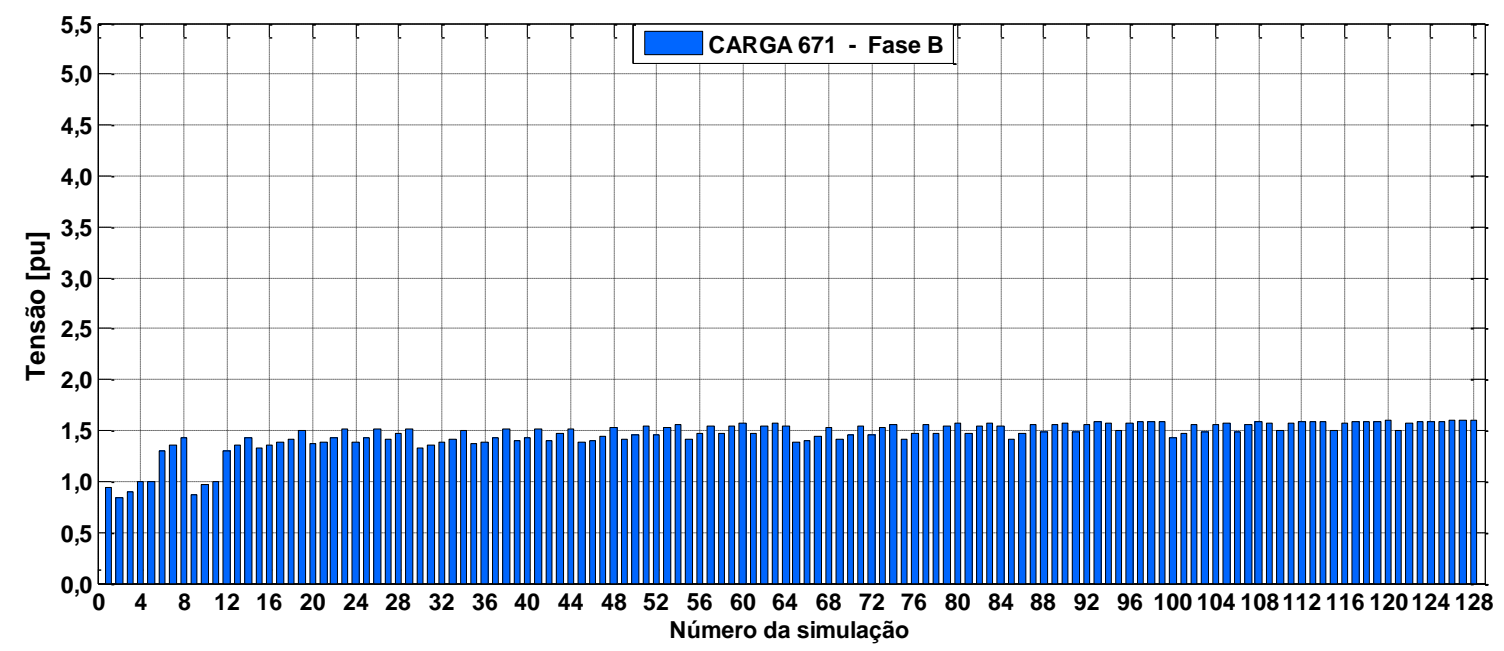

Figura 6.39: Tensão sobre a carga 671 para as 128 simulações do Grupo 3 (y=250 m).

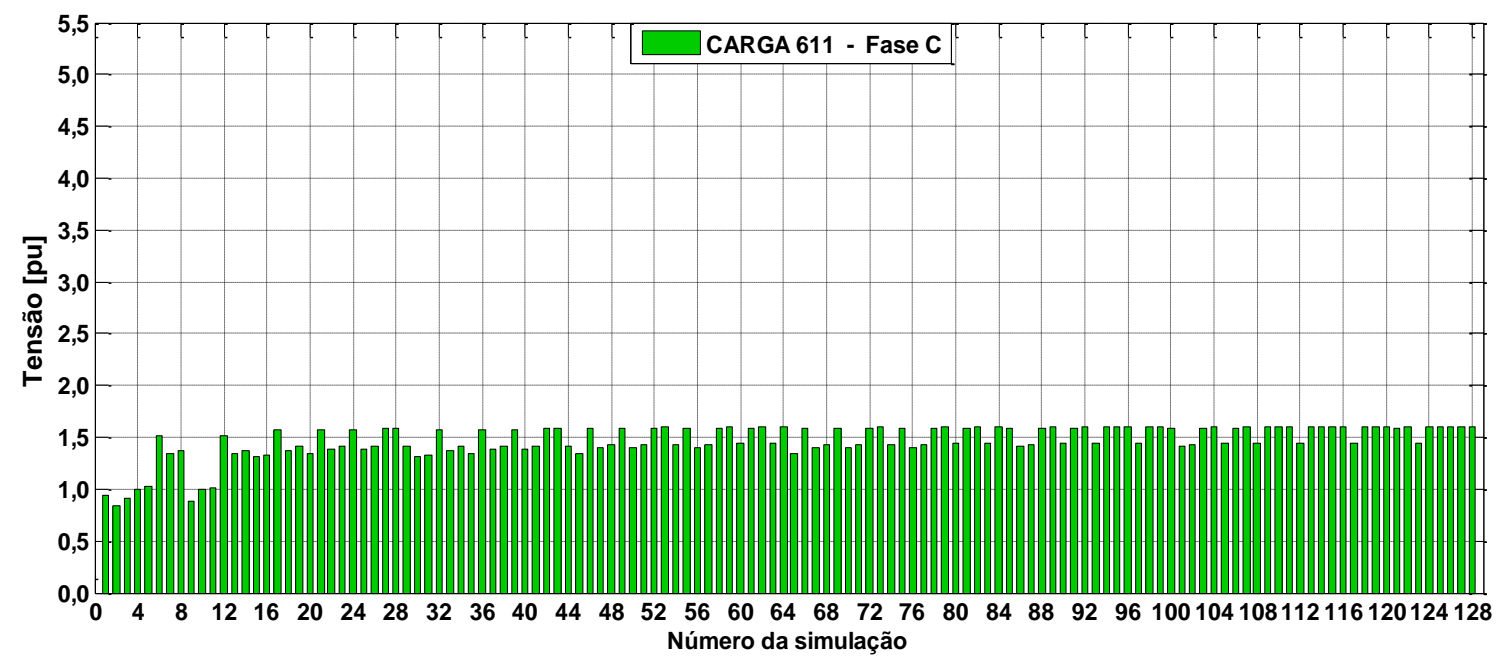

Figura 6.40: Tensão sobre a carga 611 para as 128 simulações do Grupo 3 (y=250 m).

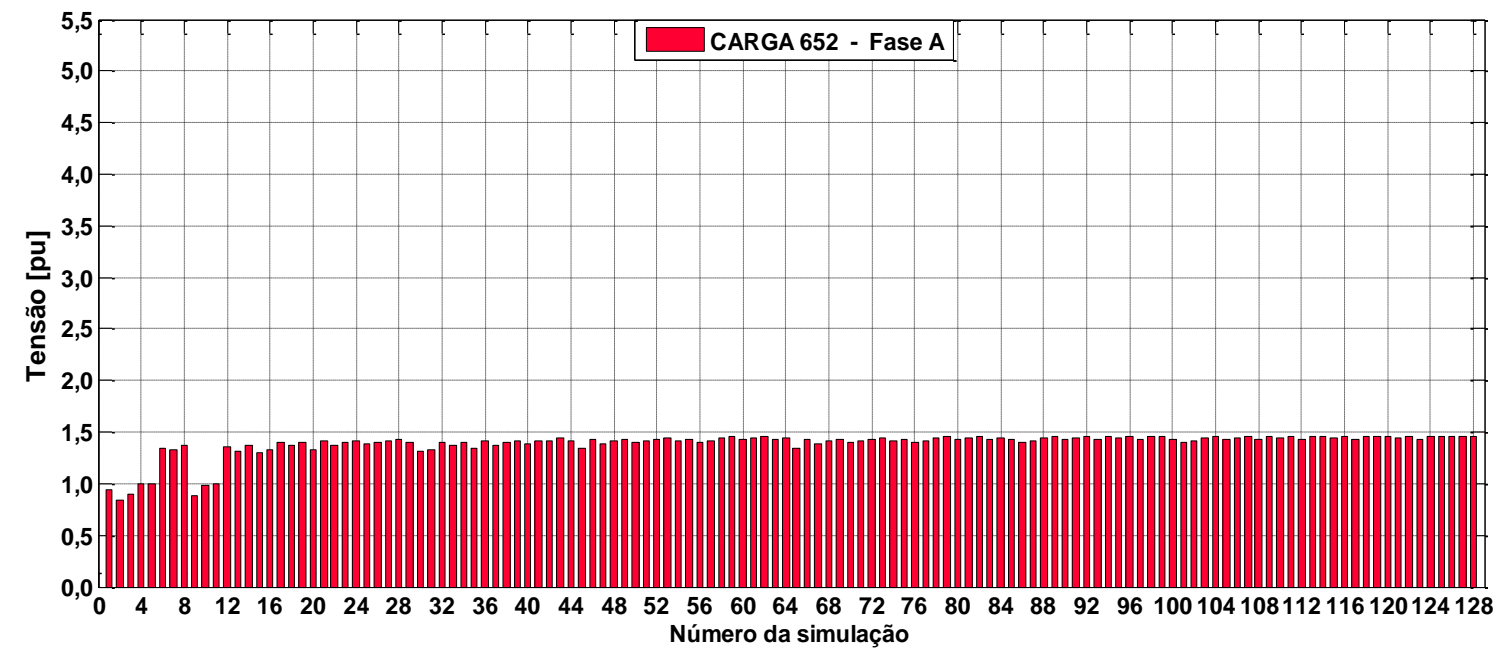

Figura 6.41: Tensão sobre a carga 652 para as 128 simulações do Grupo 3 (y=250 m). 


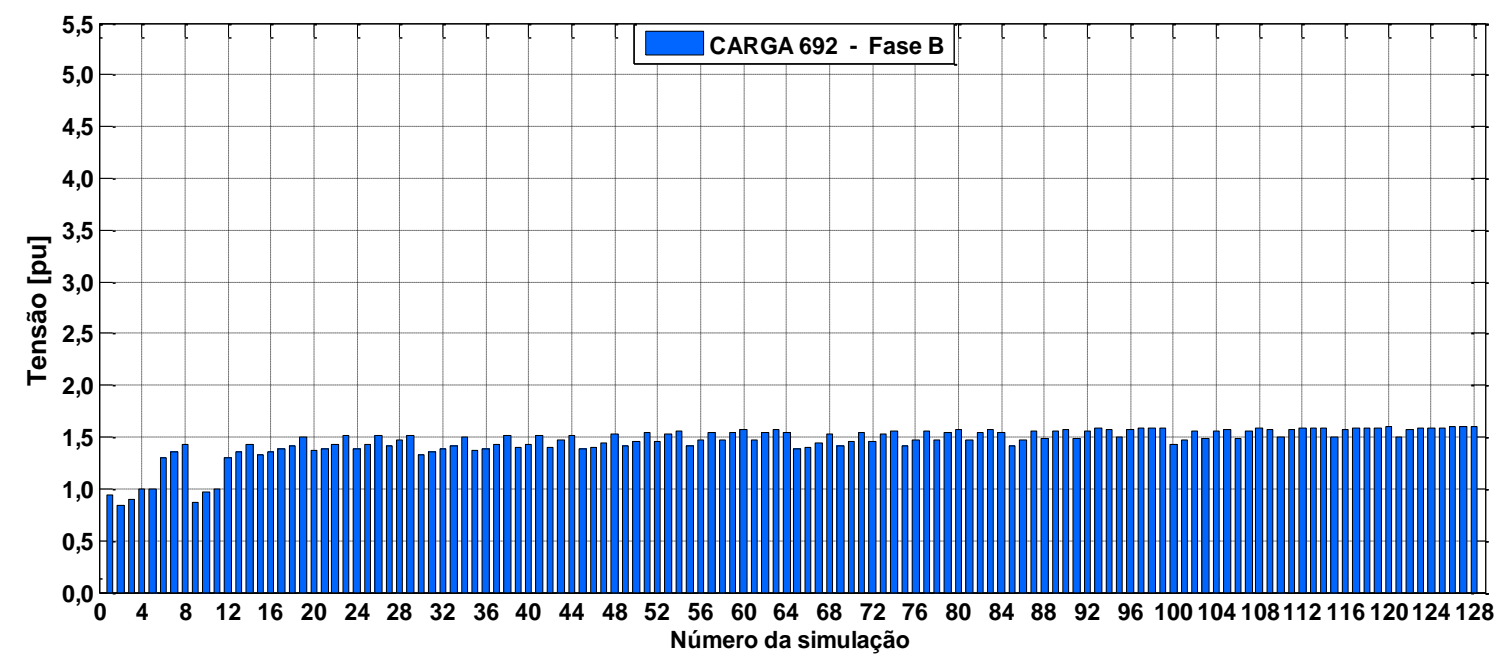

Figura 6.42: Tensão sobre a carga 692 para as 128 simulações do Grupo 3 (y=250 m).

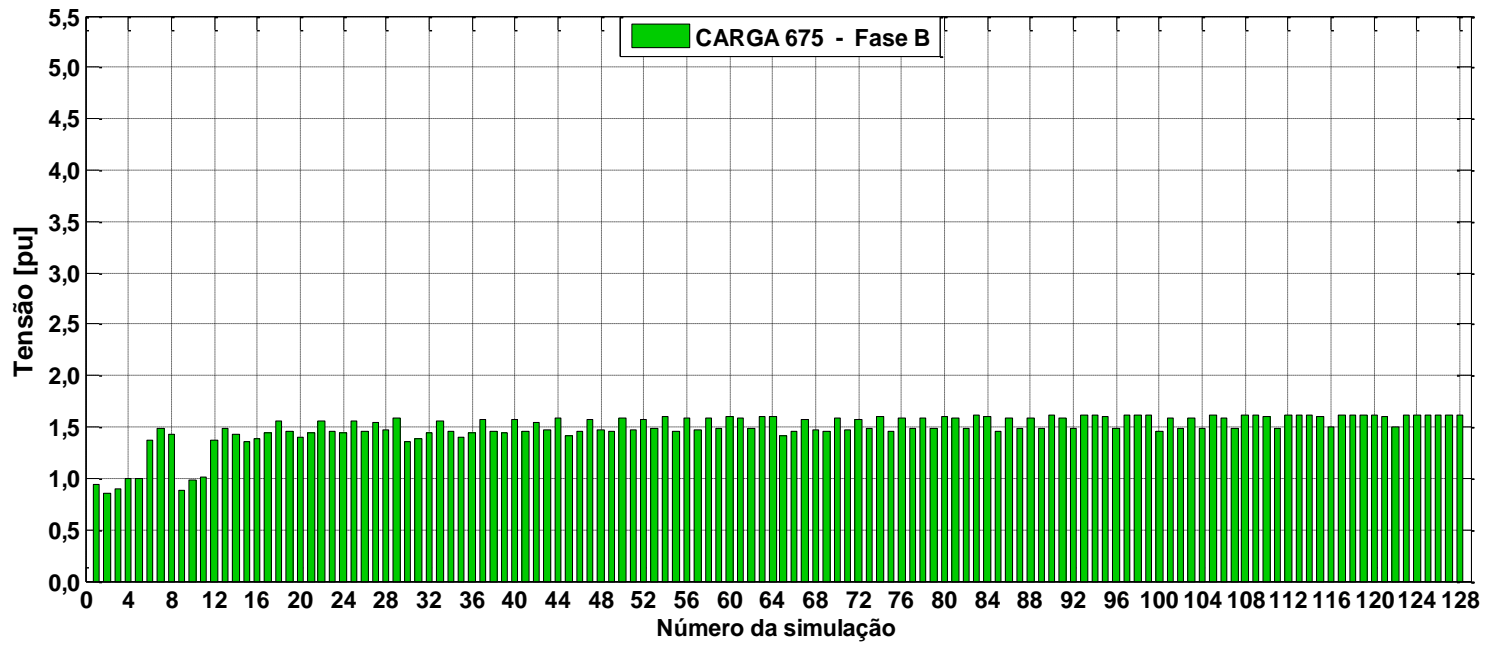

Figura 6.43: Tensão sobre a carga 675 para as 128 simulações do Grupo 3 (y=250 m).

Por fim, por meio da Figura 6.44 até a Figura 6.47 nota-se mais uma vez a diminuição da quantidade de para-raios atuantes em decorrência da queda dos picos das tensões induzidas para as simulações dos Grupos 3 e 4, respectivamente.

Analisando estas figuras ainda se vê que os para-raios de número 1 não mais atuaram, e para as simulações do Grupo 4 o para-raios 3 da fase $C$ também deixou de operar. Além disso, a redução acentuada da quantidade de vez de ativação dos pararaios da fase A de número 5, 8 e 11, bem como dos para-raios das fases $\mathrm{B}$ e $\mathrm{C}$ de número 2 demonstram que os mesmos não são tão necessários quanto os demais para a segura operação do alimentador frente às tensões induzidas estimadas.

Dessa forma, considerando a viabilidade técnico/econômica e a proteção proporcionada pela instalação dos para-raios neste alimentador, conclui-se que os para- 
raios indispensáveis para a operação continua de um sistema como o deste alimentador em ordem decrescente de importância são os seguintes por fase:

- Fase A: PR - 7, PR - 9 e PR - 4;

- Fase B: PR - 9, PR - 8, PR - 11, PR - 5, PR - 3 e PR - 4;

- Fase C: PR - 9, PR - 8, PR - 11, PR - 6, PR - 5 e PR - 4 .

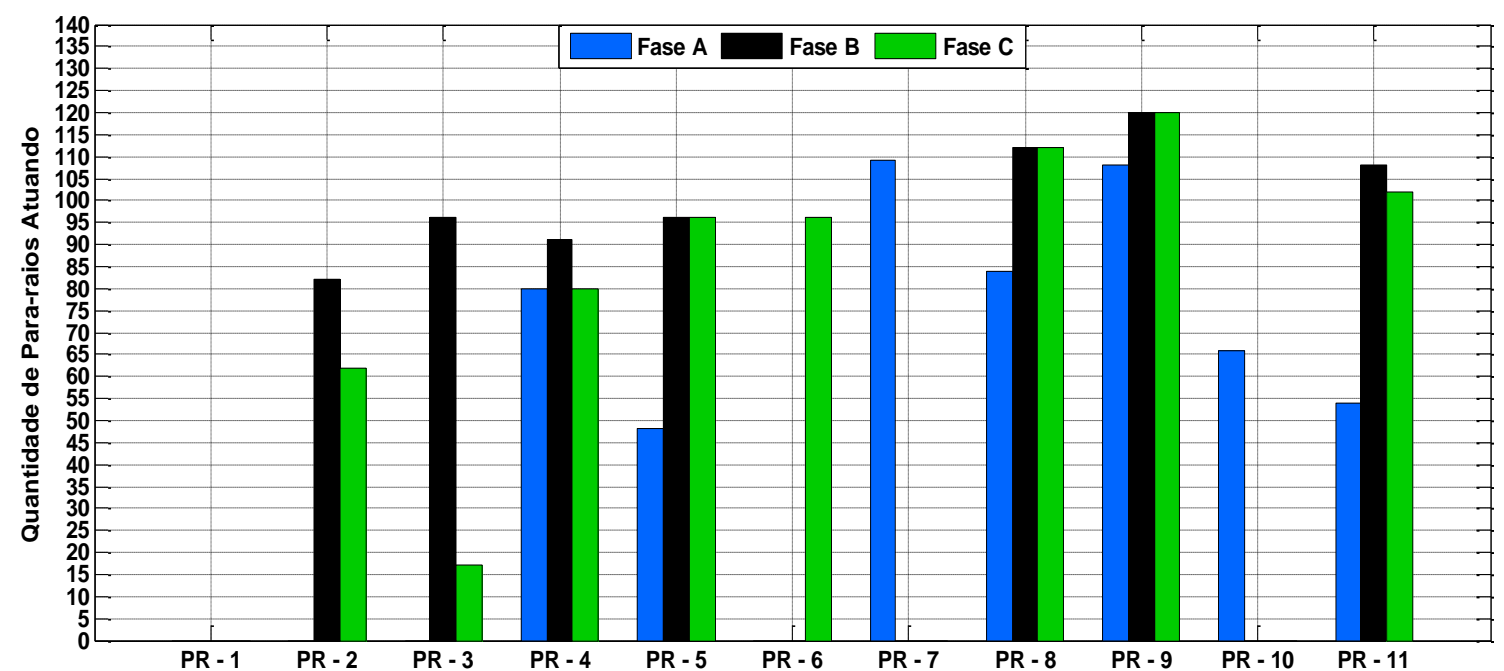

Figura 6.44: Quantificação do número de vezes em que os para-raios atuam nas 128 simulações do Grupo $3(y=250 \mathrm{~m})$.

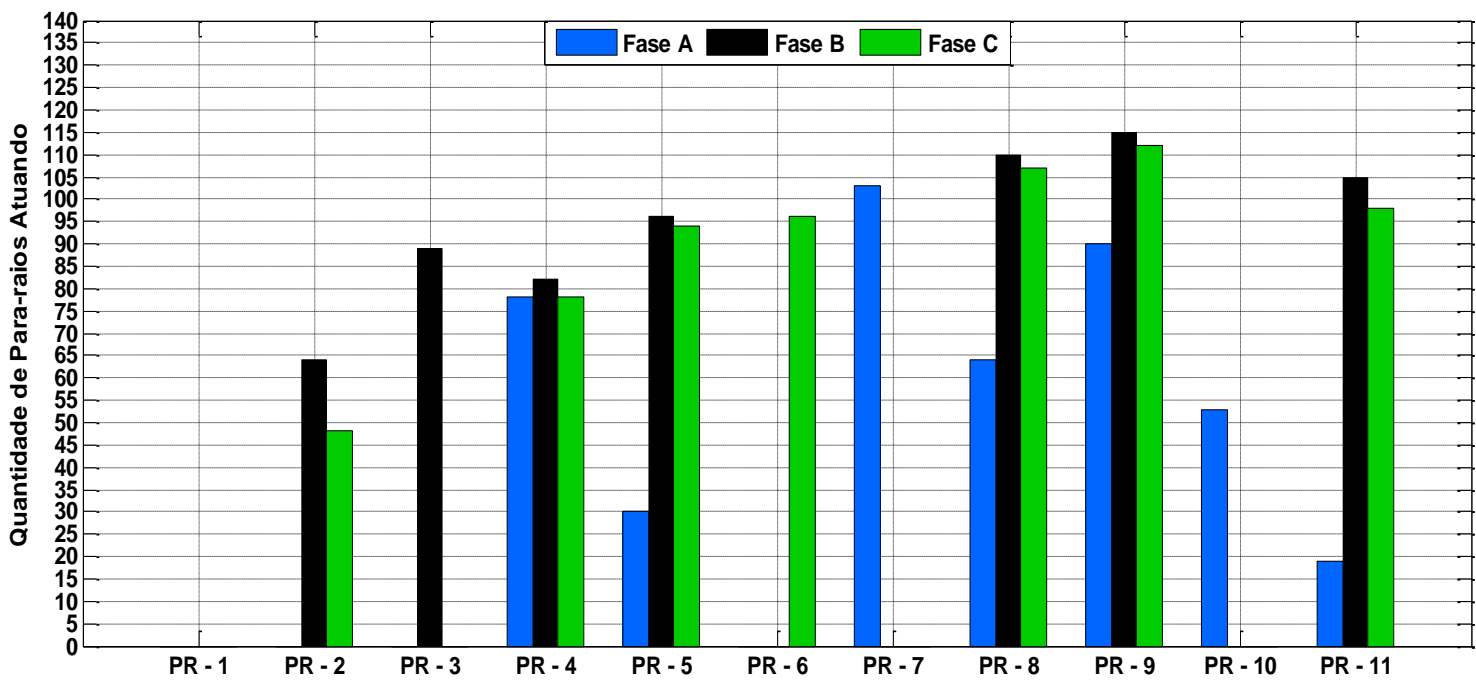

Figura 6.45: Quantificação do número de vezes em que os para-raios atuam nas 128 simulações do Grupo 4 (y=350 m). 


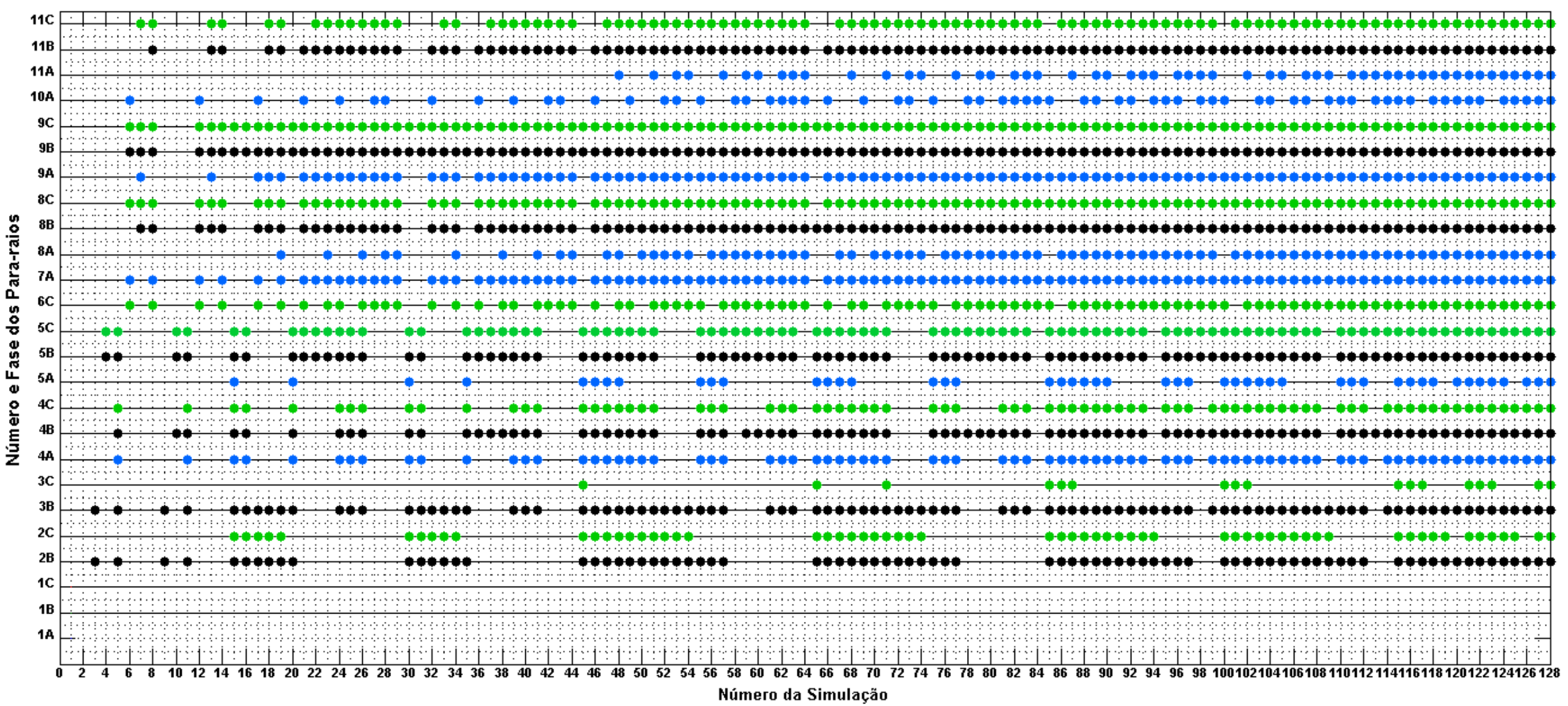

Figura 6.46: Indicação dos para-raios em atuação para cada uma das 128 simulações do Grupo 3 (y=250 m). 


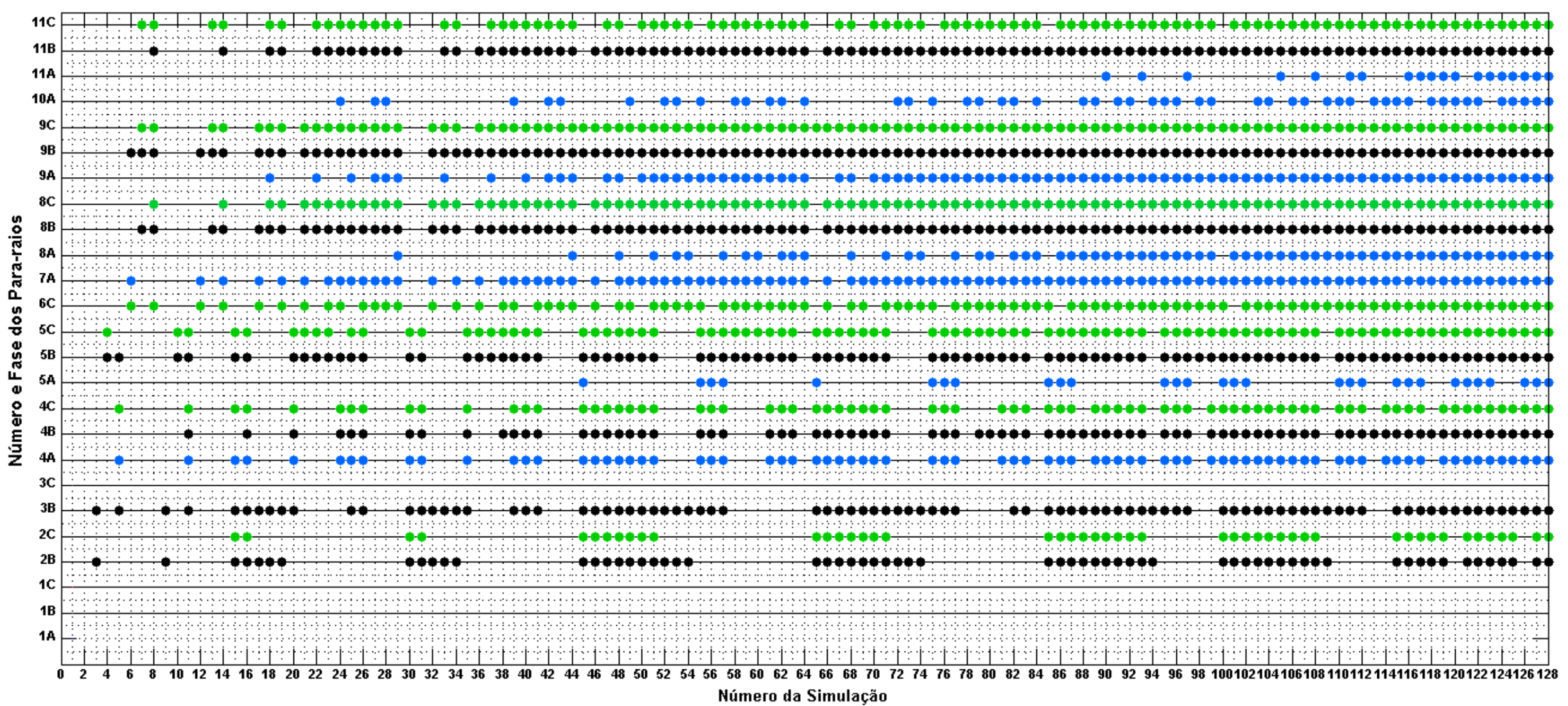

Figura 6.47: Indicação dos para-raios em atuação para cada uma das 128 simulações do Grupo 4 (y=350 m). 


\section{CAPÍTULO 7}

\section{CONCLUSÕES}

A partir do exposto nesta dissertação, conclui-se que os estudos bibliográficos e históricos realizados e os conceitos expostos nos capítulos 2 e 3 foram importantes para o desenvolvimento da mesma. Empregando os recursos destes capítulos foi possível a construção de uma base sólida sobre a teoria, o estabelecimento, e a modelagem dos fenômenos relacionados às descargas atmosféricas e as tensões por elas induzidas.

Por meio do conteúdo exposto no capítulo 3 compreende-se que para a presente pesquisa o Modelo de Rusck se mostra adequado para estimar computacionalmente as tensões induzidas por descargas indiretas em uma linha de distribuição. Isto se deve a sua simplicidade, facilidade de implementação, aproximações aceitáveis e por fornecer uma expressão analítica para o cálculo da tensão induzida, dentre outras características. Além disso, também se deve ressaltar que o mesmo foi escolhido devido a sua comprovada eficácia quando comparado aos demais modelos, confirmada em diversas aplicações de diferentes projetos de pesquisa (FONSECA, 1990), (BOAVENTURA, 1990), (PAULINO, 1994), (SILVA, 2001), (CARVALHO, 2004), (SILVA NETO, 2004) e (SEKIOKA, 2005).

Os trabalhos científicos do capítulo 4 também proporcionaram um embasamento consistente sobre o desenvolvimento dos para-raios, da sua implantação em linhas áreas, e a respeito do desempenho de linhas que utilizam os para-raios de $\mathrm{ZnO}$ como equipamento de proteção. Ainda infere-se que os para-raios de óxido de zinco possuem excelente desempenho quando empregados para proteção contra sobretensões devido a não linearidade dos seus varistores, e que estes são apropriados para se atingir os objetivos da pesquisa aqui desenvolvida.

Dessa forma, a partir do conteúdo apresentado e das modelagens e implementações do capítulo 5 pode-se concluir que o estudo aprofundado de uma metodologia para modelagem e simulação de tensões induzidas por descargas indiretas foi cumprido, e que o Modelo de Rusck foi implementado com êxito. 
Não obstante, por meio das simulações apresentadas no capítulo 6 foi possível avaliar o desempenho das cargas e transformadores do alimentador teste de distribuição frente às tensões induzidas por descargas incidindo próximo as suas estruturas. Com estas simulações ficou claro que as tensões induzidas decrescem com o aumento da distância entre a linha e o ponto de incidência das descargas. Também se observou que as tensões induzidas influenciam a tensão de todo o sistema, em maior ou menor grau, dependendo da posição em que ocorre a descarga, das características da rede, das particularidades dos elementos a ela conectados, e das ramificações do alimentador.

Por outro lado, analisando a atuação dos para-raios nas simulações do Grupo 1, averígua-se que o perfil de tensão das cargas e transformadores sofreu um brusco aumento em relação ao seu aspecto em regime permanente devido às tensões induzidas.

Por meio destas simulações também se verifica a eficiência da operação dos pararaios por meio da proteção exercida sobre a carga $C$ - 652, a qual é o único elemento protegido das tensões induzidas por dois para-raios consecutivos. Em posse desta informação, para proteção da carga C - 634, carga esta que é a mais afetada pela ação das tensões induzidas, sugere-se a instalação de para-raios em cada uma das fases da ligação entre esta carga e o transformador da linha. Ademais, é possível perceber que a eficiência dos para-raios é diretamente proporcional a proximidade destes com os elementos a serem protegidos.

Em seguida, examinando as simulações dos Grupos 2, 3 e 4 é possível notar, mais uma vez, a relação direta da distância entre os condutores do alimentador e o ponto de incidência da descarga sobre a amplitude das tensões induzidas, por meio da redução dos picos das mesmas com o aumento desta distância. Ainda com relação às simulações destes grupos observa-se a redução da quantidade de para-raios sob atuação conforme ocorre a diminuição dos picos de tensão induzida. Além disso, nota-se a estabilização dos perfis de tensão das cargas e transformadores de acordo com o crescimento do afastamento entre os condutores do alimentador e o ponto de incidência da descarga.

Ao avaliar a redução das sobretensões promovida pelos para-raios sobre o alimentador foi analisada também a viabilidade técnico/econômica da compra e instalação destes equipamentos para definição da melhor localização e quantidade destes elementos a serem instalado no sistema examinado. Isto é necessário, pois uma grande quantidade de para-raios resulta em um projeto de um sistema de proteção financeiramente inviável, contudo, um número reduzido destes dispositivos pode ocasionar a implantação de um sistema altamente vulnerável às sobretensões causadas por descargas diretas e indiretas. 
Neste contexto, os gráficos de indicação dos para-raios em atuação e de contabilização do número de atuações dos mesmos, mostrados em conjunto com os resultados das simulações, forneceram meios para se tomar a melhor decisão para instalação dos para-raios para proteção da linha de distribuição do alimentador teste.

Cabe ressaltar que as técnicas para estimação de tensões induzidas aplicadas nesta pesquisa, bem como os procedimentos para seleção e modelagem dos para-raios, podem ser aplicadas a outros sistemas elétricos desde que seja feita uma verificação criteriosa das características dos mesmos, adequando os para-raios para a rede avaliada. Além disso, a aplicação dos procedimentos desenvolvidos nesta pesquisa pode auxiliar na definição de estratégias de proteção para alimentadores reais, permitindo incrementar a eficiência dos processos envolvidos na especificação dos dispositivos de proteção de redes de distribuição.

\section{1 - Propostas de Continuidade}

A partir dos resultados obtidos para esta pesquisa podem ser definir novos objetivos a serem alcançados a fim de aperfeiçoar o estudo desenvolvido, por meio das seguintes frentes de pesquisa:

- Incorporação do efeito da resistividade do solo no cálculo das tensões induzidas;

- Desenvolvimento de um sistema inteligente para cálculo da tensão induzida em relação ao ponto mais próximo da linha;

- Integração de sistemas especialistas para seleção dos pontos mais adequados para instalação dos para-raios;

- Realização em laboratório da implementação dos casos estudados nesta pesquisa, mesmo que em modelos de escala reduzida para análises praticas dos desdobramentos das tensões induzidas sobre alimentadores de distribuição. 


\section{CAPÍTULO 8}

\section{REFERÊNCIAS BIBLIOGRÁFICAS}

ABB. High Voltage Surge Arresters Buyer's Guide. Edition 9.1, English, February, 2012.

AGRAWAL, A. K.; PRICE, H. J.; GURBAXANI, S. H. Transient Response of a Multiconductor Transmission Line Excited by a Nonuniform Electromagnetic Field. IEEE Transactions on Electromagnetic Compatibility, Vol. EMC-22, nº 2, p. 119-129, May, 1980.

ALMEIDA, D. R. Um Novo Modelo de Representação de Corrente de Retorno do Canal de Torre de Medição para Estudos de Contaminação de Ondas de Corrente de Descargas Atmosféricas. Dissertação de Mestrado submetida ao Programa de Pós-Graduação em Engenharia Elétrica, Universidade Federal de Minas Gerais, Belo Horizonte, 2002.

ALVES, L. C. Modelagem de Para-raios de ZnO para o Cálculo de Tensão Induzida por Descargas Atmosféricas em Redes de Distribuição. Dissertação de Mestrado submetida ao Programa de Pós-Graduação em Engenharia Elétrica, Universidade Federal Minas Gerais, Belo Horizonte, Agosto, 2010.

ANDERSON, J. G. Lightning Performance of Transmission Lines. Electric Power Research Institute, Transmission Line Reference Book, $345 \mathrm{kV}$ and Above, 2 Ed., Chapter 12, California, United States of America, 1982.

BABA, Y.; ISHII, M. Numerical Electromagnetic Field Analysis of Lightning Current in Tall Structures. IEEE Transactions on Power Delivery, Vol. 16, nº. 3, p. 324-328, April, 2001.

BABA, Y.; ISHII, M. Characteristics of Electromagnetic Return-Stroke Models. IEEE Transactions on Electromagnetic Compatibility, Vol. 45, nº 1, February, 2003. 
BARBOSA, C. F.; PAULINO, J. O. S. An approximate time domain formula for the calculation of the horizontal electric field from lightning. IEEE Transactions on Electromagnetic Compatibility, Vol. 49, nº 3, pp. 593-601, August, 2007.

BARBOSA, C. F.; PAUlinO, J. O. S.; MIRANDA, G. C.; BOAVENTURA, W. C.; NALLIN, F. E.; PERSON, S.; ZEDDAM A. Measured and modeled horizontal electric field from rocket-triggered lightning. IEEE Transactions on Electromagnetic Compatibility, Vol. 50, nº 4, pp. 913-920, November, 2008.

BARKER, P. P.; MANCAO, R. T.; KVALTINE, D. J.; PARRISH D. E. Characteristics of Lightning Surges Measured at Metal Oxide Distribution Arresters. IEEE Transactions on Power Delivery, Vol. 8, n 1, p. 301- 310, 1993.

BARKER, P. P.; SHORT, T. A.; EYBERT-BERARD, A. R.; BERLANDIS J. P. Induced Voltage Measurements on an Experimental Distribution Line During Nearby Rocket Triggered Lightning Flashes. IEEE Transactions on Power Delivery, Vol. 11, nº 2, p. 980995, 1996.

BBC Brasil, Noticias, Região Norte tem maior número de mortes por raios no Brasil, diz estudo inédito. Disponível no site do INPE em:

http://www.inpe.br/webelat/elatMidia/arquivos/20120224173728Imprimir\%20-

\%20BBC\%20Brasil.pdf. Acessado em 14/08/2012.

BERGER, K.; ANDERSON, R. B.; KRÖNINGER, H. Parameters of lightning flashes. Electra, nº 41, pp. 23-37, July, 1975.

BEWLEY, L. A. W. Traveling waves due to lightning. AIEE Transactions, ${ }^{\circ}$ 48, pp. 10501064, 1929.

BOAVENTURA, W. C. Estudos da Tensão Induzida em Linhas Aéreas por Descargas Atmosféricas Utilizando Técnicas de Modelo Reduzido. Dissertação de Mestrado submetida ao Programa de Pós-Graduação em Engenharia Elétrica, Universidade Federal de Minas Gerais, Belo Horizonte, 1990. 
BORGHETTI, A.; NUCCI, C. A.; PALONE, M. An Improved Procedure for the Assessment of Overhead Line Indirect Lightning Performance and Its Comparison with the IEEE Std. 1410 Method. IEEE Transactions on Power Delivery, Vol. 22, nº 1, January, 2007.

BRAGA, J. L. P. V. Desempenho de linhas de distribuição frente a descargas atmosféricas: estudo e implementação do Guia IEEE Std 1410. Dissertação de Mestrado submetida ao Programa de Pós-Graduação em Engenharia Elétrica, Universidade Federal de Minas Gerais, Belo Horizonte, 2009.

BUENO, H.; MINETA, C. T. N.; MONTEIRO, A. J.; ALVES, J. M.; MENDONÇA, P. H.; BACHEGA, R. J.; MARTINEZ, M. L. B. Lightning Performance Improved Method Applied to AES - Eletropaulo Utility $13,8 \mathrm{kV}$ Medium Voltage Distribution. Power Tech, IEEE Russian, 27-30 June, 2005.

BURKE, G. J.; POGGIO, A. J. Numerical electromagnetic code (NEC) - method of moments, Vol. 1 - Program Description Theory. Lawrence Livermore Laboratory, Livermore, California, 1977.

CARSON, J. R. Wave Propagation in Overhead Wires with Ground Return. Bell System Technical Journal, New York, Vol. 5, p. 539-554, 1926.

CARVAlHO, T. O. Desenvolvimento de Sistemas Para Estudo de Tensão Induzidas em Linhas de Média Tensão por Descargas Atmosféricas. Dissertação de Mestrado submetida ao Programa de Pós-Graduação em Engenharia Elétrica, Universidade de São Paulo, São Paulo, 2004.

CARVAlHO, A. M; ABREU, M. S; CAZETTA F., A; CARVAlHO, A. C; CHERCHIGLIA, L. C. L; DINIZ, J. H. Tecnologias para Análise e Melhoria do Desempenho de Instalações de Transmissão Frente a Descargas Atmosféricas. XV SNPTEE, Seminário Nacional de Produção e Transmissão de Energia Elétrica, Foz do Iguaçu, Brasil, Outubro, 1999.

CEPEL - ELETROBRAS, Curso sobre Para-raios de distribuição, Estação e Linhas de Transmissão. 53 p., 1977. 
CHOWDHURI, P.; GROSS, E. T. B. Voltage surges induced on overhead lines by lighting strokes. Proc. IEE, Vol. 114, nº12, pp. 1899-1907, December, 1967.

CIGRE Working Group 33.01 (Lightning), "Guide to Procedures for Estimating the Lightning Performance of Transmission Lines,” CIGRE Brochure 63, Paris, Oct. 1991.

CIGRÉ, Working Group 33.01 (Lightning) of Study Committee 33 (Overvoltages and Insulation Coordination). Guide to Procedures for Estimating the Lightning Performance of Transmission Lines. CIGRÉ Brochure 63, Paris, October, 1991.

CIRED/CIGRÉ, Working group 05. Protection of MV and LV networks against lightning: basic information. International Conference and Exhibition on Electricity Distribution, Proceedings CIRED 97, Conference Publication no 438, p. 2191-2196, Birmingham, 1997.

COLOMBO, E.; DE NIGRIS, M.; SIRONI, A. Failure Mode Tests for Distribution Type Metal-Oxide Surge Arresters with Polymeric Housing. IEEE Transactions on Power Delivery, Vol. 11, n 1, January, 1996.

CONTI A. R. Modelos para Definição de Ondas de Corrente e Tensão Representativas das Solicitações de Sistemas de Distribuição por Descargas Atmosféricas. Dissertação de Doutorado submetida ao Programa de Pós-Graduação em Engenharia Elétrica, Universidade Federal de Minas Gerais, Belo Horizonte, Agosto, 2006.

D’AJUZ, A.; RESENDE, F. M.; CARVALHO, F. M. S.; NUNES, I. G.; AMON FILHO, J.; DIAS, L. E. N.; PEREIRA, M. P.; KASTRUP FILHO, O.; MORAIS, S. A. Equipamentos elétricos - especificação e aplicação em subestação de alta tensão. Rio de Janeiro, Furnas, Universidade Federal Fluminense, 1985.

DE NIGRIS, M.; SIRONI, A.; BONFANTI, I.; GIORNELLI, F.; VALAGUSSA, C.; SHING, L. K.; Most Recent Developments in Surge Arresters Technology and Testing. POWERCON 98, International Conference on Power System Technology, Beijing, China, pp. 194-201, August, 1998. 
DURBAK, D. W. Surge arrester modeling. Power Engineering Society Winter Meeting, Columbus, OH, USA, Vol. 2, pp. 728-730, 2001.

ELAT, pagina inicial do site do Grupo de Eletricidade Atmosférica (ELAT), disponível em: http://www.inpe.br/webelat/homepage/, acessado em 09/07/2012.

EPRI. Transmission Line Lightning and Grounding Reference Book. Gray Book, Electric Power Research Institute (EPRI), Power Delivery \& Utilization, December, 2011.

ERIKSSON, A. J.; STRINGFELlOW, M. F.; MEAL, D. V. Lightning-Induced Overvoltages on Overhead Distribution Lines. IEEE Transactions on Power Apparatus and Systems, Vol. PAS-101, nº 4, p. 960-968, April, 1982.

FELIPE, M. A. Sobretensões em Redes de Distribuição Decorrentes da Incidência de Descargas Atmosféricas em Torres de Telecomunicações. Dissertação de Mestrado submetida ao Programa de Pós-Graduação em Engenharia Elétrica, Universidade Federal de Minas Gerais, Belo Horizonte, Dezembro, 2007.

FERNANDEZ, F.; DIAZ, R. Metal oxide surge arrester model for fast transient simulations. International Conference on Power System Transients, Paper 144, IPST 01, June, 2001.

FONSECA, A. F. L. Cálculo Analítico do Campo Eletromagnético e da Resposta Transitória de Uma Linha Unifilar Infinita Devido à Incidência de Uma Descarga Atmosférica Sobre Um Solo de Resistividade Nula. Dissertação de Mestrado submetida ao Programa de PósGraduação em Engenharia Elétrica, Universidade Federal de Minas Gerais, Belo Horizonte, 1990.

FRANCO, J. L. Estudo das Propriedades Elétricas dos Varistores de ZnO na Região de Baixas Tensões Aplicadas. Dissertação de Mestrado, Área de Processamento de Energia, Universidade Federal de Campina Grande, Paraíba, Junho, 1993.

FRANCO, J. L. Curso sobre Para-raios: Aplicação em redes de distribuição, subestações e linhas de transmissão. Franco Engenharia, São Paulo, p. 174, 2001. 
FRANCO, J. L. Treinamento técnico: Aplicação de para-raios em subestações. ELETROSUL, Florianópolis, SC, Brasil, Outubro, 2008.

FURTADO, J. G. M. Correlações entre Fenômenos de Grãos e de Contorno de Grãos e o Desempenho de Cerâmicas Varistoras. Dissertação de Mestrado submetida ao Programa de Pós-Graduação em Engenharia Metalúrgica e de Materiais, COPPE/UFRJ, Universidade Federal do Rio de Janeiro, Rio de Janeiro, Março, 2005.

GOLDE, R. H. Indirect lightning surges on overhead distribution lines. The Electrical Research Association, S/T 75, Leatherhead, 1954.

GREENWOOD, A. Electrical Transients in Power Systems. John Wiley \& Sons Inc., New York, 1992.

GROSS, C. A. Power System Analysis. New York, NY: John Wiley, 1986.

HALLIDAY, D.; RESNICK, R.; WALKER, J., Fundamentos de Física 1 -

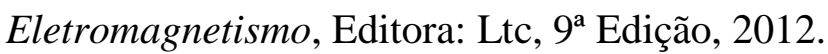

HARRINGTON, R. F. Field Computation by Moment Methods. New York: McMillan, 1968.

HINRICHSEN, V. Metal-oxide Surge Arrester, Fundamentals. 1 st Edition, Siemens AG, Berlin, Germany, 2001.

HINRICHSEN, V. Metal-oxide Surge Arrester in High-Voltage Power Systems, Fundamentals. 1 st Edition, Siemens AG, Berlin, Germany, 2012.

IEC 60099-4, Surge arresters - Part 4: Metal-oxide surge arresters without gaps for a.c. systems, Edition 2.2, 2009.

IEC 60099-5, Surge arresters - Part 5: Selection and application recommendations, Edition 1.1, 2000. 
IEEE, IEEE PES Distribution System Analysis Subcommittee's, Distribution Test Feeder Working Group, 13-bus Feeder. Disponível em: http://ewh.ieee.org/soc/pes/dsacom/testfeeders/index.html. Acessado em 27/05/2013.

IEEE, Power \& Energy Society. IEEE Guide for the Application of Metal-Oxide Surge Arresters for Alternating Current-Systems. Surge Protective Devices Committee, IEEE Standards Board, American National Standards Institute, New York, 2009.

IEEE, Working Group 3.4.11. Modeling of metal oxide surge arresters. IEEE Transactions on Power Delivery, Vol. 7, nº 1, pp. 302-309, January, 1992.

IEEE Working Group on Estimating Lightning Performance of Transmission lines, "IEEE guide for improving the lightning performance of transmission lines," Proposed IEEE P1243 draft, 1996.

IEEE, Working Group on the Lightning Performance of Distribution Lines. IEEE Guide for Improving the Lightning Performance of Electric Power Overhead Distribution Line. Transmission and Distribution Committee, IEEE Power Engineering Society, IEEE Std 1410, 1997.

IEEE, Working Group on the Lightning Performance of Distribution Lines. IEEE Guide for Improving the Lightning Performance of Electric Power Overhead Distribution Lines. IEEE Std 1410, 2004.

IEEE, Working Groups 3.4.10, 3.4.14, and 3.4.16. IEEE Guide for the Application of MetalOxide Surge Arresters for Alternating-Current Systems. Surge-Protective Devices Committee, IEEE Power Engineering Society, American National Standards Institute, IEEE Std C62.22-1991, 1991.

JANKOV, V. Estimation of the Maximal Voltage Induced on an Overhead Line Due to the Nearby Lightning. IEEE Transactions on Power Delivery, Vol. 12, nº 1, January, 1997.

KERSTING, W. H. Radial distribution test feeders, IEEE Power Engineering Society Winter Meeting, IEEE Conference Proceedings, Vol. 2, pp. 908-912, 2001 
KERSTING, W. H. Distribution System Modelling and Analysis. Boca Raton, FL: CRC, 2002. 314p.

KIM, I.; FUNABASHI, T.; SASAKI, H.; HAGIWARA, T.; KOBAYASHI, M. Study of ZnO arrester model for steep Front Wave. IEEE Transactions on Power Delivery, Vol. 11, $\mathrm{n}^{\mathrm{o}} 2$, pp. 834-841, April, 1996.

KINDERMANN, G. Descargas Atmosféricas. $1^{\mathrm{a}}$ Ed, Sagra-DC Luzzatto Editores, Porto Alegre, RS, 1992.

LAHTI, K.; KANNUS, K.; NOUSIAINEN, K. The Durability and Performance of polymer Housed Metal Oxide Surge Arrester. 16th International Conference and Exhibition on Electricity Distribution, CIRED, June, 2001.

LAT, M. V. A simplified method for surge protection of underground distribution systems with metal oxide arresters. IEEE Power Engineering Review, Vol. 2, n 4, pp. 1110-1116, Ontario Hydro, Toronto, Canada, October, 1987.

LAT, M. V.; KORTSCHINSKI, J. Application Guide for Surge Arrester and Field Research of Lightning Effects on Distribution Systems. Ontario Hydro Research Division, Canadian Electrical Association, International Conference and Exhibition on Electricity Distribution, CIRED, 1989.

MAMEDE, J. F. Manual de Equipamentos Elétricos. Ed. Livros Técnicos e Científicos, Vol.1, $3^{\text {a }}$ edição, Rio de Janeiro, 2005.

MARTINEZ J. A.; GONZALEZ-MOLINA F.; CHOWDHURI P. Calculation of Lightning Flashover Rates of Overhead Distribution Line, a Comparative Study. Power Engineering Society Summer Meeting, Vol. 4, p. 2577-1582, 2000.

MARTINEZ, J.A., GUSTAVSEN, B., DURBAK, D. Parameter Determination for Modeling System Transients - Part I: Overhead Lines. IEEE Transactions on Power Delivery, New York, Vol. 20, nº 3, p. 2038 - 2044, July, 2005. 
MATSUOKA, M. Nonohmic Properties of Zinc Oxide Ceramics. Japanese Journal of Applied Physics, Vol. 10, nº 6, pp. 736-746, June, 1971.

MATSUOKA, M. Progress in Research and Development of Zinc Oxide Varistors. Advances in Ceramics, Vol. 7, pp. 290-308, 1981.

MEISTER, A. Modelagem de Varistores de Óxido de Zinco para Estudos de Coordenação de Isolamento. Dissertação de Mestrado submetida ao Programa de Pós-Graduação em Engenharia Elétrica, Universidade de Brasília, Brasília, 2005.

MELCHIOR, R. D. Fault testing of gapless zinc oxide transmission line arresters under simulated field conditions. IEEE Transaction on Power Delivery, Vol. 10, n⿳亠丷厂 2 April 2003.

MICROTRAN, Power System Analysis Corporation, Transients Analysis Program Reference Manual, Vancouver, Canada, 1991.

MODRUSAN, M. Tests on High-Voltage Metal Oxide Surge Arresters with Impulse Currents. Fourth International Symposium on High Voltage Engineering, Athens, Greece, 1983.

MOTA, P. C. A. Um Estudo sobre Tensões Induzidas por Descargas Atmosféricas em Linhas de Transmissão. Dissertação de Mestrado submetida ao Programa de Pós-Graduação em Engenharia Elétrica, Universidade Federal de Uberlândia, Uberlândia, 2011.

MUNUKUTLA, K.; VITTAL, V.; HEYDT, G. T.; CHIPMAN, D.; KEEL, B. Practical Evaluation of Surge Arrester Placement for Transmission Line Lightning Protection. IEEE Transaction on Power Delivery, Vol. 25, n 3, July, 2010.

NACCARATO, K. P.; ALBRECHT, R. I.; PINTO Jr, O. Cloud-to-ground lightning density over Brazil based on high-resolution lightning imaging sensor (LIS) data. XIV International Conference on Atmospheric Electricity - ICAE, Rio de Janeiro, Brazil, 2011.

NBR 5419: Proteção de Estruturas Contra Descargas Atmosféricas, ABNT, Associação Brasileira de Normas Técnicas, Brasil, 2005. 
NOBLAT, B. M. Lightning and HV electrical installations. Cahier Technique Merlin Gerin $\mathrm{n}^{\circ} 168,1994$.

NUCCI C. A.; RACHIDI F. Lightning-Induced Overvoltages. IEEE Transmission and Distribution Conference, Panel Session Distribution Lightning Protection, New Orleans, April, 1999.

NUCCI, C. A.; DIENDORFER, G.; UMAN, M. A.; RACHIDI, F.; IANOZ, M.; MAZZETTI, C. Lightning Return Stroke Models With Specified Channel-Base Current: A Review and Comparison. Journal of Geophysical Research, Vol. 95, nº. D12, p. 2039520408, November, 1990.

OLIVEIRA, M. J. Avaliação do efeito geográfico-termal na capacidade de absorção de energia em para-raios de $\mathrm{ZnO}$. Dissertação de Mestrado submetida ao Programa de PósGraduação em Engenharia Metalúrgica e de Materiais, COPPE/UFRJ, Universidade Federal do Rio de Janeiro, Rio de Janeiro, Dezembro, 2004.

PAULINO, J. O. S. Uma contribuição ao estudo da proteção de redes elétricas contra tensões induzidas por descargas atmosféricas. Dissertação de Doutorado submetida ao Programa de Pós-Graduação em Engenharia Elétrica, Universidade Estadual de Campinas, Campinas, 1994.

PAUlinO, J. O. S.; BARBOSA, C. F.; LOPES, I. J. S.; BOAVENTURA, W. C. An approximate formula for the peak value of lightning-induced voltages in overhead lines. IEEE Transactions on Power Delivery, Vol. 25, n² 2, pp. 843-851, April, 2010.

PAUlinO, J. O. S.; BARBOSA, C. F.; LOPES, I. J. S.; BOAVENTURA, W. C. The Peak Value of Lightning-Induced Voltages in Overhead Lines Considering the Ground Resistivity and Typical Return Stroke Parameters. IEEE Transactions on Power Delivery, Vol. 26, $\mathrm{n}^{\circ} 2$, pp. 920-927 April, 2011.

PETERSON, H. A.; RUDGE Jr., W. J.; MONTEITH, A. C.; LUDWIG, L. R. Protection Tubes for Power System. Electrical Engineering (AIEE Transactions), Vol. 59, May, 1940. 
PIANTINI, A. Lightning Protection of Overhead Power Distribution Lines. 29th International Conference on Lightning Protection - ICLP, p. 1-29, Uppsala, Sweden, June, 2008.

PIANTINI, A.; JANISZEWSKI, J. M. Analysis of three different theories for computation of induced voltages on distribution lines due to nearby lightning. International Conference and Exhibition on Electricity Distribution, CIRED, p.127-132, Buenos Aires, Dec. 1996.

PIANTINI, A.; JANISZEWSKI, J. M. Induced voltages on distribution lines due to lightning discharges on nearby metallic structures. IEEE Transactions on Magnetics, Vol. 34, $\mathrm{n}^{\circ}$ 5, pp. 2799-2802, 1998.

PIANTINI, A.; JANISZEWSKI, J. M. The Extended Rusck Model for calculating lightning induced voltages on overhead lines. Proceedings of the 7th International Symposium on Lightning Protection (SIPDA), Curitiba, pp. 151-155, November, 2003.

PINCETI, P.; GIANNETTONI, M. A simplified model for zinc oxide surge arresters. IEEE Transactions on Power Delivery, Vol. 14, n² 2, April, 1999.

PINTO Jr, O., PINTO, I. R. A. Tempestades e relâmpagos no Brasil. São José dos Campos, Ed. Independente, 194 p., 2000.

PINTO Jr, O. Lightning in the Tropics: From a Source of Fire to a Monitoring System of Climatic Changes. Nova Science Publishers, New York, 2009.

POKHAREL, R.K.; ISHII, M.; BABA, Y. Numerical Electromagnetic Analysis of Lightning- Induced Voltage over Ground of Finite Conductivity. IEEE Transactions on Electromagnetic Compatibility, Vol. 45, nº . 4, November, 2003.

RACHIDI, F. Formulation of the Field-to-Transmission Line Coupling Equations in Terms of Magnetic Excitation Fields. IEEE Transactions on Electromagnetic Compatibility, Vol. 35, no 3, August, 1993. 
RAKOV, V. A. Characterization of Lightning Electromagnetic Fields and Their Modeling. Proceedings of the 14th International Symposium on Electromagnetic Compatibility, Zurique, Switzerland, p. 3-16, February, 2001.

RAKOV, V. A.; UMAN, M. A. Review and Evaluation of Lightning Return Stroke Models Including Some Aspects of their Application. IEEE Transaction on Electromagnetic Compatibility, Vol. 4, nº 4, 1998.

RINGLER, K. G.; KIRBY, P.; ERVEN, C. C.; LAT, M. V.; MALKIEWICZ, T. A. The Energy Absorption Capability and Time to Failure of Varistors Used in Station Class Metal Oxide Surge Arresters. IEEE Transaction on Power Delivery, Vol. 12, n 1, January, 1997.

RONDÓN, D. A.; SILVEIRA, F. H.; VISACRO, S. F. A Varying Surge Impedance Transmission Line Model for Simulation of Lightning Return Current in Time Domain. Proceedings of GROUND 2002 - International Conference on Grounding and Earthing, Rio de Janeiro, Brazil, November, 2002.

RUBINSTEIN, M. An approximate formula for the calculation of the horizontal electric field from lightning at close, intermediate and long range. IEEE Transactions on Electromagnetic Compatibility, Vol.38, nº 3, 1996.

RUSCK, S. Induced lightning overvoltages on power transmission lines with special reference to the overvoltage protection of low voltage networks. Ph.D. dissertation, Royal Institute of Technology, Stockholm, 1957.

RUSCK, S. Induced Lightning Overvoltages on Power Transmission Lines With Special Reference to the Overvoltage Protection of Low Voltage Networks. Transactions of the Royal Institute of Technology, Stockholm, Sweden, $\mathrm{n}^{\circ}$ 120, 1958.

SAKSHAUG, E. C. A Brief History of AC Surge Arresters. IEEE Power Engineering Review, Vol. 11, no 8, p. 11-13, August, 1991.

SALARI, J. C. F. Efeito das Descargas Atmosféricas no Desempenho de Linhas de Transmissão - Modelagens nos Domínios do Tempo e da Frequência. Dissertação de 
Doutorado submetida ao Programa de Pós-Graduação em Engenharia, Universidade Federal do Rio de Janeiro, Rio de Janeiro, 2006.

SANTOS, P. H. M. Análise de desempenho frente a impulsos atmosféricos induzidos em circuitos de media tensão. Dissertação de Mestrado submetida ao Programa de PósGraduação em Engenharia Elétrica, Universidade Federal de Itajubá, Itajubá, 2007.

SARAN, M. A. M. Sobretensões de Origem Atmosférica em Linhas de Media Tensão. Dissertação de Mestrado submetida ao Programa de Pós-Graduação em Engenharia Elétrica, Universidade Federal de Itajubá, Itajubá, Fevereiro, 2009.

SCHEI. A.; FRANCO, J. L. Experiência no Monitoramento de Para-raios de Óxido Metálico em Serviço. Anais do VIII ERLAC, Encuentro Regional Latinoamericano de la CIGRÉ, Ciudad del Este, Paraguay, 1999.

SEKIOKA, S. An Equivalent Circuit for Analysis of Lightning-Induced Voltages on Multiconductor System Using an Analytical Expression. Proceedings of IPST - International Conference on Power System Transients, Montreal, Canada, June, 2005.

SHORT, T. A.; AMMON, R. H. Monitoring results of the effectiveness of surge arrester spacings on distribution line protection. IEEE Transactions on Power Delivery, Vol. 14, $\mathrm{n}^{\circ} 3$, pp. 1142-1150, July, 1999.

SIEMENS, Guia de para-raios. Para-raios de média tensão tipo 3EK4 com invólucro de silicone, Disponível em: http://www.energy.siemens.com/br/pt/transmissao-deenergia/produtos-de-alta-tensao/descarregadores-de-sobretensao-limitadores/tensao-alta-emedia/, Acessado em 01/06/2013.

SILVA J. P. Cálculo de Tensão Induzida por Descarga Atmosférica: Implementação da Teoria de Rusck no EMTP. Dissertação de Doutorado submetida ao Programa de PósGraduação em Engenharia Elétrica, Universidade Federal de Minas Gerais, Belo Horizonte, Brasil, 2001. 
SILVA NETO, A. Tensões Induzidas Por Descargas Atmosféricas em Redes de Distribuição de Baixa Tensão. Dissertação de Mestrado submetida ao Programa de Pós-Graduação em Engenharia Elétrica, Universidade de São Paulo, São Paulo, 2004.

SILVA NETO, A.; PIANTINI, A. Sobretensões Induzidas por Descargas Atmosféricas em Redes Secundárias. VII Conferência Brasileira sobre Qualidade da Energia Elétrica, VII SBQEE, Vol. único, p. 1-6, 2007.

SILVEIRA, F. H. Aplicação de um Novo Modelo para Cálculo de Tensão Induzida por Descarga Atmosférica. Dissertação de Mestrado submetida ao Programa de Pós-Graduação em Engenharia Elétrica, Universidade Federal de Minas Gerais, Belo Horizonte, Julho, 2001.

SILVEIRA, F. H. Modelagem para Cálculo de Tensão Induzida por Descarga Atmosférica. Dissertação de Doutorado submetida ao Programa de Pós-Graduação em Engenharia Elétrica, Universidade Federal de Minas Gerais, Belo Horizonte, 2006.

SOARES Jr, A. Investigação do Comportamento dos Aterramentos Típicos de Linhas de Transmissão Frente a Descargas Atmosféricas. Dissertação de Mestrado submetida ao Programa de Pós-Graduação em Engenharia Elétrica, Universidade Federal de Minas Gerais, Belo Horizonte, 1996.

STEVENSON, W. D. Elementos de Análise de Sistemas de Potência, 2a edição, 1986.

TARASIEWICZ E. J.; RIMMER, F.; MORCHED, A. S. Transmission line arrester energy, cost, and risk of failure analysis for partially shielded transmission lines. IEEE Transaction on Power Delivery, Vol. 15, n 3, pp. 919-924, July, 2000.

TAYLOR, C. D.; SATTERWHITE, R. S.; HARRISON, C. W. The Response of a Terminated Two- Wire Transmission Line Excited by a Non-Uniform Electromagnetic Field. IEEE Transaction on Antennas and Propagations, Vol. AP-13, p. 987-989, 1965.

THANASAKSIRI T. Improving the Lightning Performance of Overhead Distribution Line. TENCON 2004, IEEE Region 10 Conference, Vol. 3, p. 369-372, 2004. 
The MathWorks, Inc., MATLAB ${ }^{\circledR}$ Getting Started Guide 2013a, Disponível em: http://www.mathworks.com/help/physmod/powersys/ref/surgearrester.html, acessado em 02/06/2013.

THOMAZELLA R. Implementação Computacional Para Avaliar os Níveis de Sobretensões Atmosféricas Induzidas em Linhas de Distribuição. Dissertação de Mestrado submetida ao Programa de Pós-Graduação em Engenharia Industrial, Universidade Estadual Paulista, Bauru, Dezembro, 2004.

TOMINAGA, S.; AZUMI, K.; SHIBUYA, Y.; IMATAKI, M.; FUJIWARA, Y.; NICHIDA, S. Protective performance of metal oxide surge arrester based on the dynamic V-I characteristics. IEEE Transactions on Power Apparatus and Systems, Vol. PAS-98, nº 6, November/December, 1979.

UMAN, M. A. Lightning. Ed. McGraw-Hill Book Company, 1984.

VISACRO, S. F. Descargas Atmosféricas: uma Abordagem de Engenharia. Editora Artiliber, São Paulo, SP, 2005.

VISACRO, S.; SOARES Jr., A. HEM: A Model for Simulation of Lightning Related Engineering Problems. IEEE Transactions on Power Delivery, Vol. 20, nº 2, 2005.

WAGNER, C. F.; MCCANN, G. D. Induced voltages on transmission lines. AIEE Transaction, no 61, pp. 916-930, 1942.

WAGNER, C. F.; MCCANN, G. D.; CLAYTON, J. M. Lightning Phenomena. Westinghouse Electric Corporation, Electrical Transmission and Distribution Reference Book, chapter 18, Fourth Edition, Pennsylvania, United States of America, 1950.

WAGNER, K. W. Elektromagnetische ausgleichvorgänge in freileitungen und kabeln. Per. 5, Leipzig, 1908. 
WATSON, N.R e ARRILlAGA, J. Power systems electromagnetic transients simulation. Published by the Institution of Engineering and Technology, London, United Kingdom, Institution of Electrical Engineers; 2003.

YOKOYAMA, S.; MIYAKE, K.; MITANI, H.; YAMAZAKI, N. Advanced Observations of Lightning Induced Voltage on Power Distribution Lines. IEEE Transactions on Power Delivery, Vol. 1, nº 2, p. 129-139, April, 1986.

YOKOYAMA, S.; YAMAMOTO, K.; KINOSHITA, H. Analogue simulation of lightning induced voltages and its application for analysis of overhead-ground-wire effects. IEEE Proceedings, Vol. 132, nº 4, July, 1985.

ZANETTA Jr, L. C. Transitórios Eletromagnéticos em Sistemas de Potência. Editora EDUSP, 2003. 